\title{
Uncertainty Analyses of Infiltration and Subsurface Flow and Transport for SDMP Sites
}

Manuscript Completed: September 1997

Date Published: September 1997

Prepared by

P. D. Meyer, M. L. Rockhold, G.W. Gee

Pacific Northwest National Laboratory

Richland, WA 99352

T.J. Nicholson, NRC Project Manager

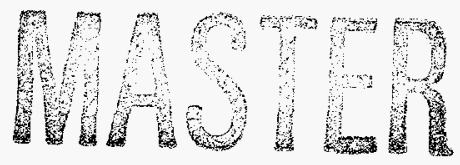

Prepared for

Division of Regulatory Applications

Office of Nuclear Regulatory Research U.S. Nuclear Regulatory Commission Washington, DC 20555-0001

NRC Job Code W6503

\section{DISCLAIMER}

This report was prepared as an account of work sponsored by an agency of the United States Government. Neither the United States Government nor any agency thereof, nor any of their employees, makes any warranty, express or implied, or assumes any legal liability or responsibility for the accuracy, completeness, or usefulness of any information, apparatus, product, or process disclosed, or represents that its use would not infringe privately owned rights. Reference herein to any specific commercial product, process, or service by trade name, trademark. manufacturer, or otherwise does not necessarily constitute or imply its endorsement, recommendation, or favoring by the United States Government or any agency thereof. The views and opinions of authors expressed herein do not necessarily state or reflect those of the United States Government or any agency thereof.

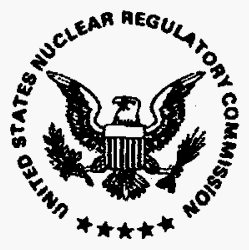




\section{DISCLAMMER}

Portions of this document may be illegible in electronic image products. Images are produced from the best available original document. 


\begin{abstract}
U.S. Nuclear Regulatory Commission staff have identified a number of sites requiring special attention in the decommissioning process because of elevated levels of radioactive contaminants. Traits common to many of these sites include limited data characterizing the subsurface, the presence of long-lived radionuclides necessitating a long-term analysis (1000 years or more), and potential exposure through multiple pathways. As a consequence of these traits, the uncertainty in predicted exposures can be significant. In addition, simplifications to the physical system and the transport mechanisms are often necessary to reduce the computational requirements of the analysis. Several multiple-pathway transport codes exist for estimating dose, two of which were used in this study. These two codes have built-in Monte Carlo simulation capabilities that were used for the uncertainty analysis.
\end{abstract}

Abstract

Several tools for improving uncertainty analyses of exposure estimates through the groundwater pathway have been developed and are discussed in this report.

Generic probability distributions for unsaturated and saturated zone soil hydraulic parameters are presented. These distributions can be used with available dose assessment codes to estimate exposure uncertainty in screening-level and preliminary analyses where site-specific data is limited. Tables of the distributions are contained in an appendix, categorized by soil texture. Parameters for the van Genuchten, Brooks-Corey, and Campbell water retention and hydraulic conductivity models are included.
The use of the generic probability distributions for soil hydraulic parameters is illustrated in a method for the estimation of net infiltration uncertainty. This method uses a relatively simple water budget calculation contained in an existing multiple pathway dose assessment code. On-site meteorological data were used. A distribution for the soil parameter required (plant available water capacity) was selected from the report appendix based solely on a description of the lysimeter soil texture. A comparison between the distribution of predicted annual net infiltration and the observed lysimeter drainage (mean and standard error) showed an agreeable match. For sites without local measurements of precipitation, temperature, etc., meteorological parameters can be estimated from National Climatic Data Center data.

The generic distributions are useful for modeling the uncertainty in soil hydraulic parameters when information about the soils at a site is limited to the soil texture. At many sites, however, there may be some site-specific soil hydraulic property data available. A method is presented to combine the generic distributions with site-specific water retention data using a Bayesian analysis. The resulting updated soil hydraulic parameter distributions can be used to obtain an updated estimate of the probability distribution of dose. The method is illustrated using a hypothetical decommissioning site. 


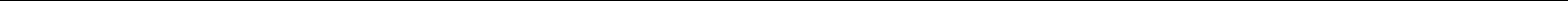




\section{Contents}

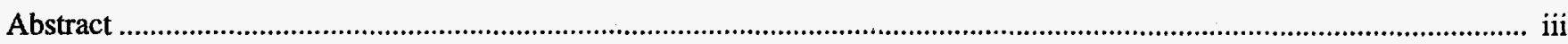

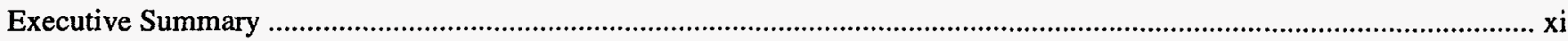

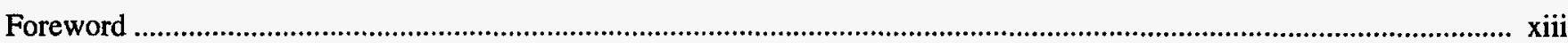

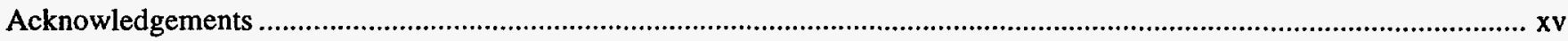

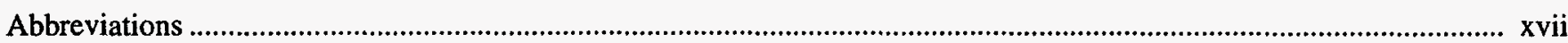

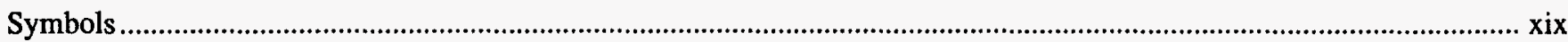

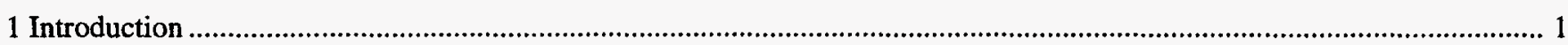

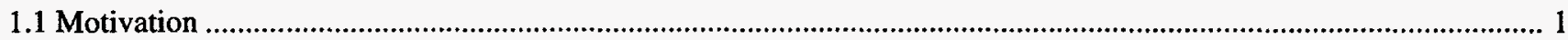

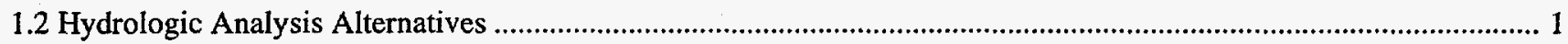

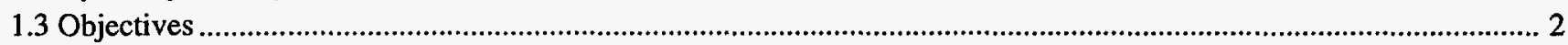

2 Recommended Distributions for Describing Uncertainty in Soil Hydraulic Parameters................................................... 3

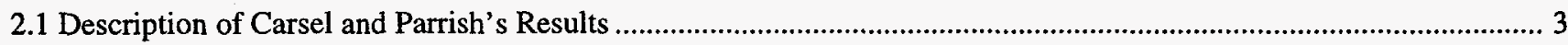

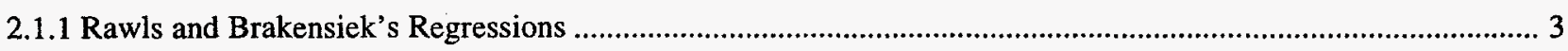

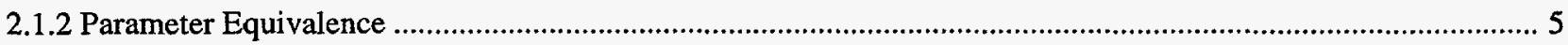

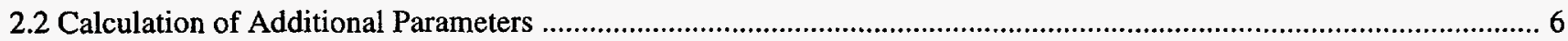

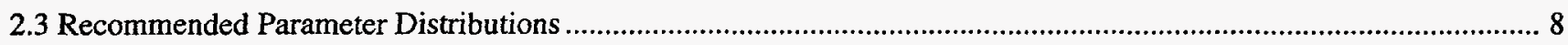

2.4 Comparison with Parameter Values from MEPAS and HELP ................................................................................ 10

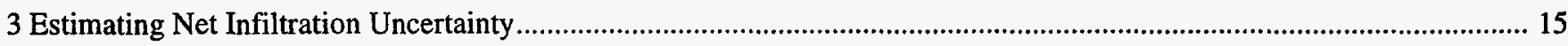

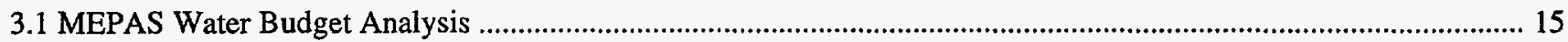

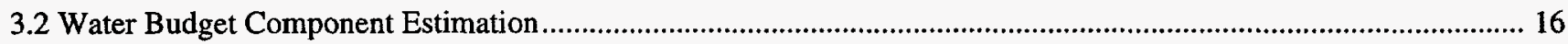

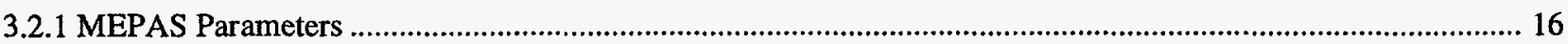

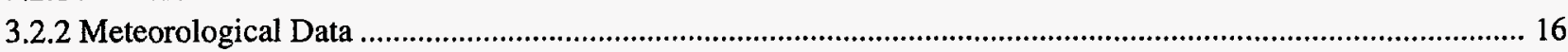

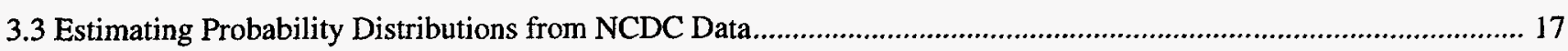

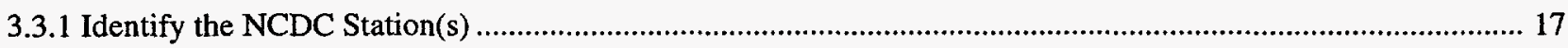

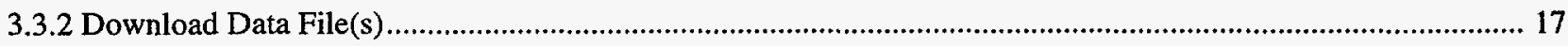

3.3.3 Calculate Monthly Averages and Statistics ............................................................................................... 18

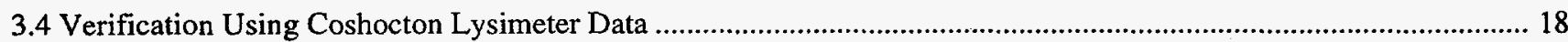

3.4.1 Description of Lysimeter Facility and Lysimeter Y 101D ............................................................................... 18

3.4.2 Water Balance and Meteorological Data .................................................................................................. 18

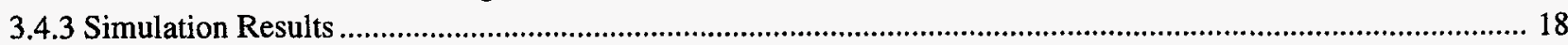

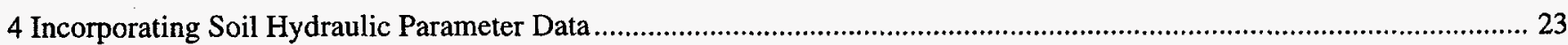

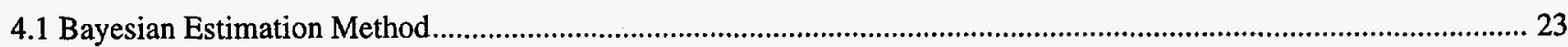

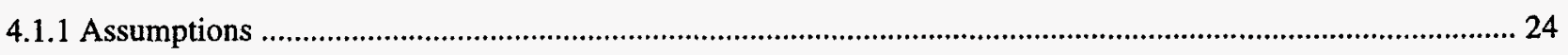

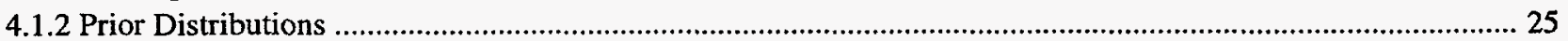


4.1.3 Updated Uncertainty Distributions using Bayesian Estimation ................................................................. 25

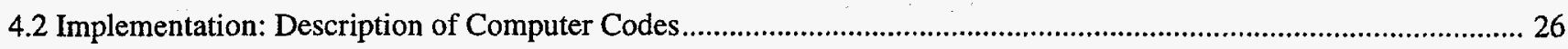

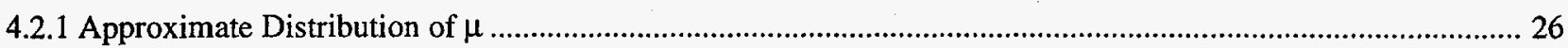

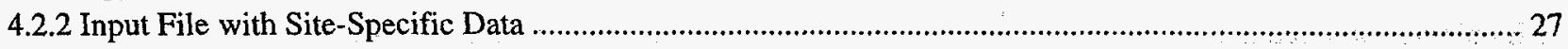

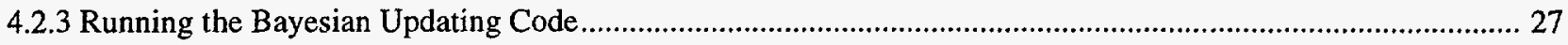

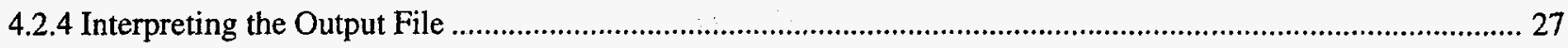

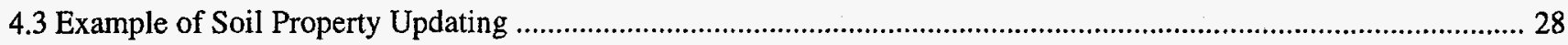

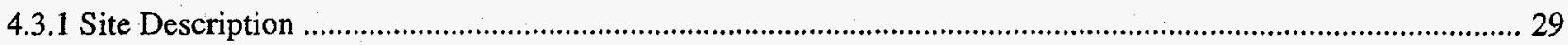

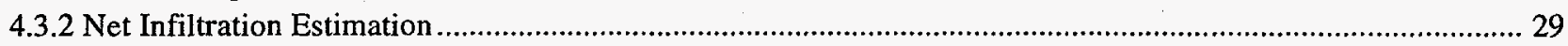

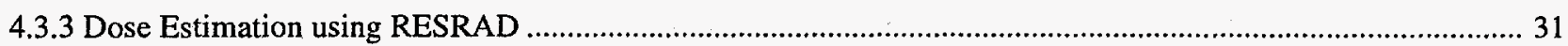

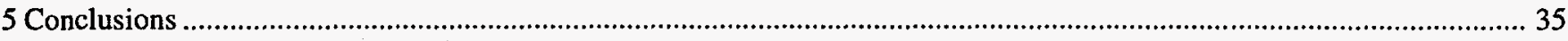

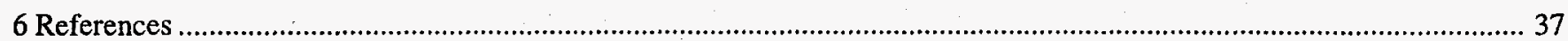

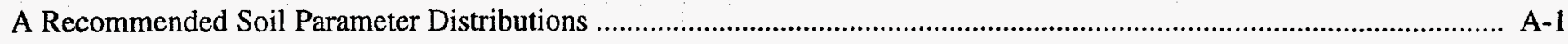

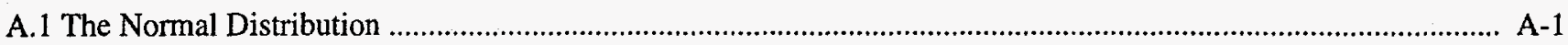

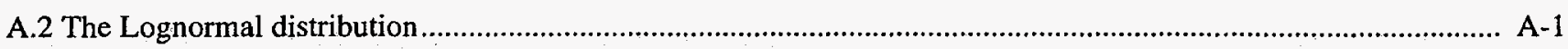

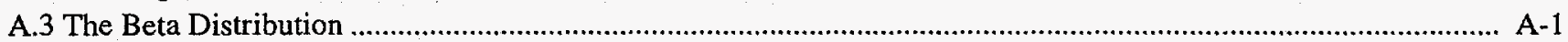

A.4 Recommended Probability Distributions for Soil Hydraulic Parameters by Soil Texture ...................................... A-2

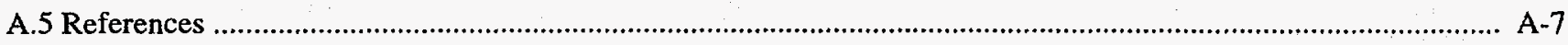

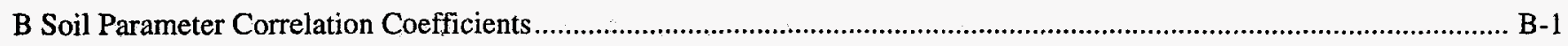

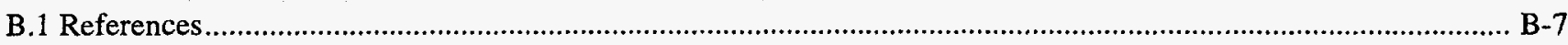

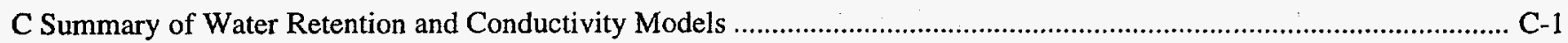

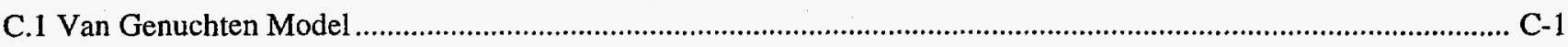

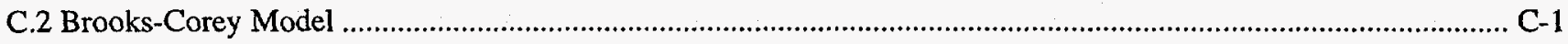

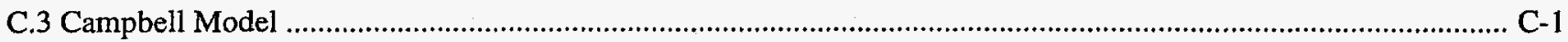

C.3.1 Calculation of Campbell's b Parameter ............................................................................................................. C-2

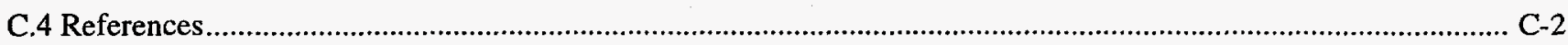

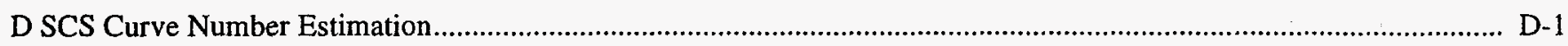

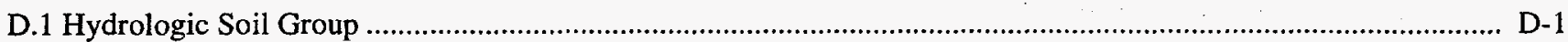

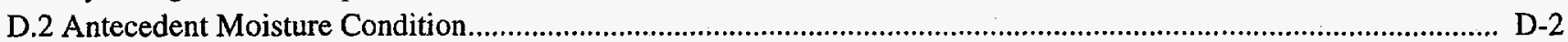

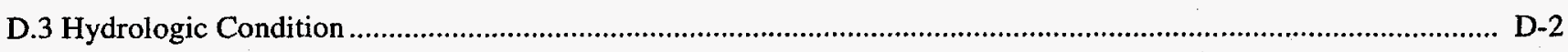

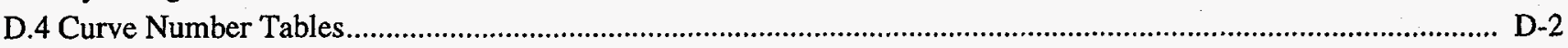

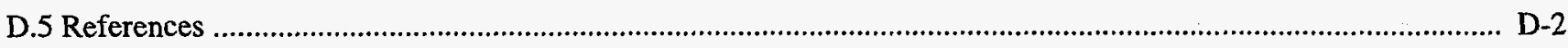

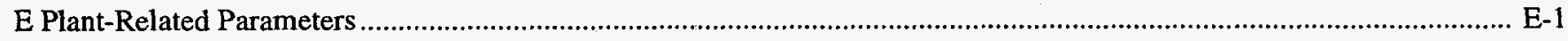

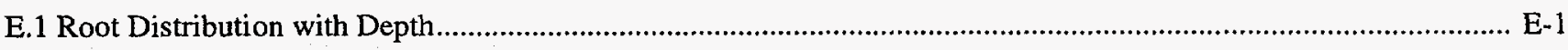

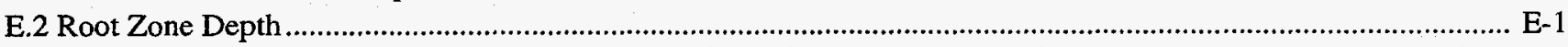

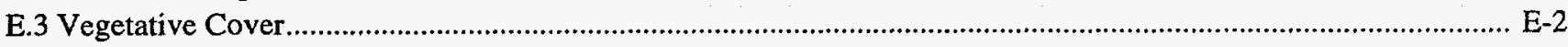


F An Improved Method for Vadose Zone Transport Analyses

\section{Figures}

2-1 USDA soil textural triangle.

2-2 Comparison between the van Genuchten and Brooks-Corey water retention (left) and hydraulic conductivity (right) models using the parameter equivalence, $h_{b}=\alpha^{-1}$ and $\lambda=n-1$

2-3 Calculation of field capacity and wilting point from hydraulic conductivity and water retention models for a typical loam soil

2-4 Drainable porosity, available water capacity, and unavailable water calculated using the average parameter values from the recommended distributions for porosity, field capacity, and wilting point.

2-5 Algorithm for selecting recommended distribution based on modified D-statistic

2-6 A comparison of fitted and empirical cdf's over a range of Kolmogorov-Smirnov D-statistic values for various soil parameters

2-7 Comparison of recommended soil hydraulic parameter distributions with values from the MEPAS and HELP documentation: $f_{c}, w_{p}$, and awc

2-8 Comparison of recommended soil hydraulic parameter distributions with values from the MEPAS and HELP documentation: $\theta_{\mathrm{s}}, \mathrm{K}_{\mathrm{s}}$, and $\mathrm{b}$.

2-9 Comparison of recommended soil hydraulic parameter distributions with values from Rawls et al. (1982) used in HELP to calculate field capacity and wilting point: $\theta_{r}, \lambda$, and $h_{b}$

2-10 Drainable porosity, available water capacity, and unavailable water calculated using the average parameter values from the recommended distributions for porosity, field capacity, and wilting point.

3-1 Observed monthly water balance for Coshocton lysimeter Y101D: data from 1945 to 1994

3-2 Empirical cdf's of predicted drainage compared to the observed average and standard error for Coshocton lysimeter Y101D.

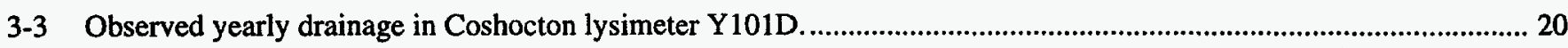

4-1 Flowchart illustrating application of the Bayesian updating procedure .......................................................................2 23

4-2 Left axis: relationship between $\tau$ and (Equation 23); Right axis: the maximum error in the cdf between a student- $t$ distribution and a normal distribution with the same mean and variance. ...........................................................................25

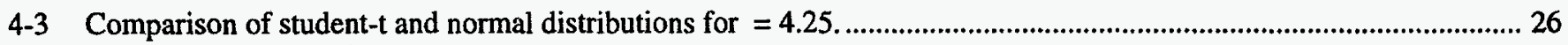

4-4 Example input file containing site-specific data for the Bayesian updating code........................................................ 27

4-5 Example output file from the Bayesian updating code .................................................................................................... 28

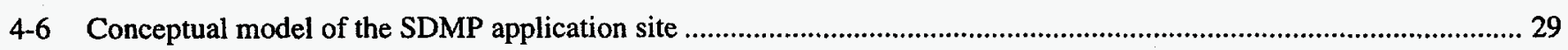

4-7 Example updating for a silty clay loam soil using the site-specific data of Figure 4-4 …........................................ 31

4-8 Prior and updated annual net infiltration distributions for the example problem ......................................................31 31

4-9 Prior and updated estimates of total dose predicted by RESRAD for the example site for times between 1000 and 10,000 years. 


\section{Contents}

E-1 Cumulative root fraction as a function of soil depth with the model parameter $\beta$ listed for each of the biomes considered. Results taken from Jackson et al. (1996). E-1

E-2 Cumulative root fraction as a function of plant group E-2

E-3 Maximum rooting depth as a function of biome and plant group E-3

F-1 Volumetric water content as a function of depth for the analytical solution and the unit gradient approximation

\section{Tables}

1-1 Characteristics of hydrologic analysis alternatives.

2-1 Approximate number of soil samples used by Carsel and Parrish (1988) for each textural class 3

4-1 Initial concentrations and distribution coefficients in the contaminated, unsaturated, and saturated zones ...................30

4-2 Average monthly climatic parameter values for the example site (from NCDC daily data) ...................................... 30

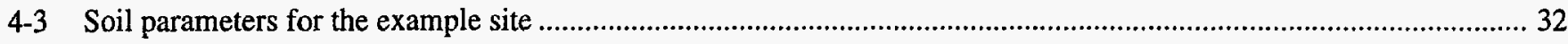

4-4 Prior and updated mean, standard deviation, and median of the net infiltration ( $\mathrm{cm} / \mathrm{yr}$ ) and dose estimates (mrem/yr) calculated for the example site.

A-1 Recommended distributions for Sand

A-2 Recommended distributions for Loamy Sand. A-2

A-3 Recommended distributions for Sandy Loam. A-3

A-4 Recommended distributions for Sandy Clay Loam A-3

A-5 Recommended distributions for Loam A-4

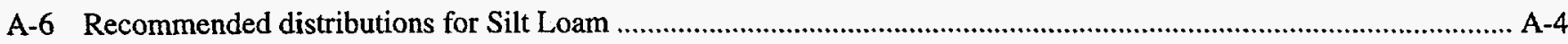

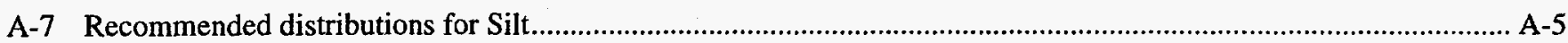

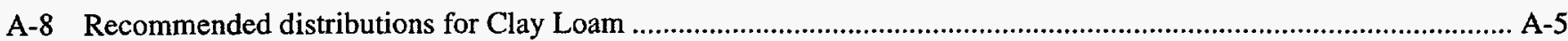

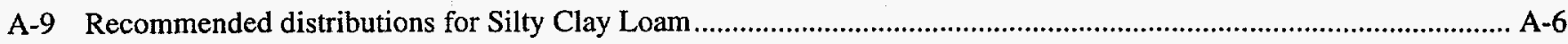

A-10 Recommended distributions for Sandy Clay .............................................................................................................. A-6

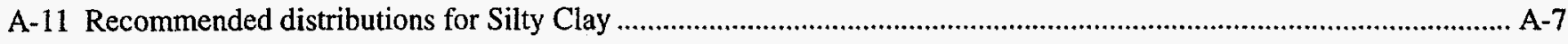

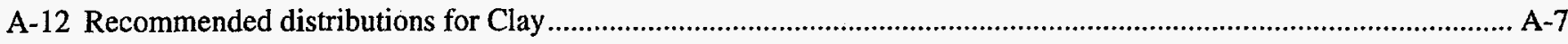

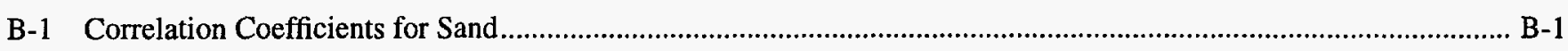

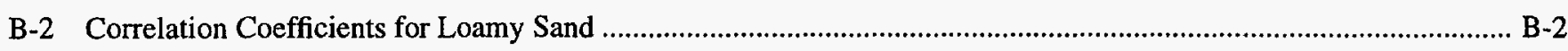

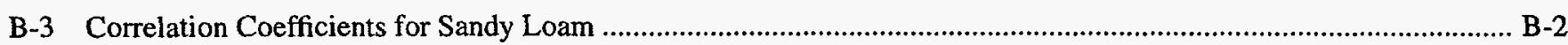

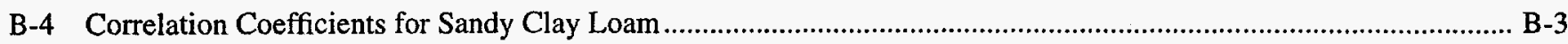

B-5 Correlation Coefficients for Loam .............................................................................................................. B-3

B-6 Correlation Coefficients for Silt Loam ................................................................................................................... B-4

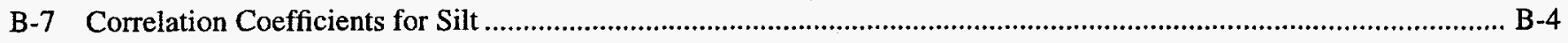

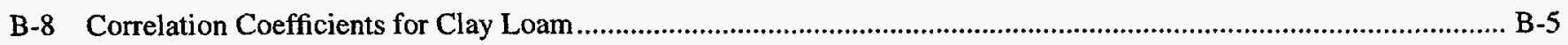

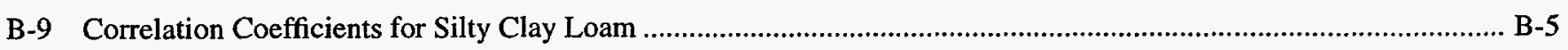

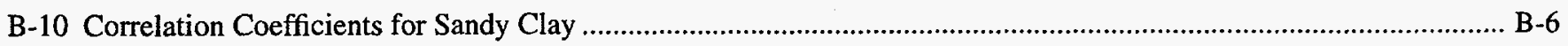


B-11 Correlation Coefficients for Silty Clay... B-6

B-12 Correlation Coefficients for Clay . B-7

D-1 SCS runoff curve numbers for average antecedent moisture condition (AMC II) D-1

D-2 Adjusted curve numbers for dry (AMC I) and wet (AMC III) antecedent moisture condition D-2

E-1 Average Root Depth by Plant Group from Foxx et al. (1984) E-2

F-1 Hydraulic Parameters used for Analytical Solution Technique Example F-1 



\section{Executive Summary}

U.S. Nuclear Regulatory Commission staff have identified a number of sites requiring special attention in the decommissioning process because of elevated levels of radioactive contaminants. Decisions regarding the safety of these SDMP sites are likely to be made in an atmosphere of significant uncertainty, arising from a number of conditions:

- The presence of long-lived radionuclides requiring exposure predictions many years into the future $(1000$ years or more),

- Potential exposure through multiple pathways,

- Limited data characterizing the hydrologic performance of the subsurface, and

- Simplifications to the physical system and the transport mechanisms to reduce the computational requirements of the exposure analysis.

Several multiple-pathway transport codes exist for estimating dose. Because site-specific data on the soil hydraulic parameters used in these codes are often not available, NRC staff must make assumptions regarding the parameter values to use in estimating dose impacts from SDMP sites. This report was prepared to assist NRC staff in selecting appropriate soil hydraulic parameter values and in assessing the uncertainty in these parameters. The report illustrates how these parameter distributions can be used to estimate uncertainties in net infiltration and dose using the built-in Monte Carlo simulation capabilities of available multiple-pathway transport codes.

Several tools for improving uncertainty analyses of exposure estimates through the groundwater pathway are discussed in this report. Generic probability distributions for unsaturated and saturated zone soil hydraulic parameters are presented. These distributions can be used with available dose assessment codes to estimate exposure uncertainty in screening-level and preliminary analyses where site-specific data is limited. Tables of the generic distributions are presented in Appendices A and B, categorized by soil texture. Distributions are presented for the following parameters: saturated and residual water content, saturated hydraulic conductivity, the van Genuchten water retention parameters $\alpha$ and $n$, effective porosity, field capacity, wilting point, available water capacity, the Brooks-Corey water retention parameters $h_{b}$ and $\lambda$, and Campbell's unsaturated hydraulic conductivity parameter $b$.

The generic distributions for soil hydraulic parameters are compared to the default or recommended parameter values from other sources. The most significant differences exist in the exponent parameter of the water retention models (i.e., the parameter related to the pore-size distribution). These differences could result from the use of different soil databases, regression equations, and analytical procedures in fitting parameter values to water retention data. The actual error in the regressions on which the generic distributions were based is unknown, but is likely to be 30 to $40 \%$ or more. The generic distributions are thus likely to underestimate the actual parameter uncertainty.

The use of the generic soil hydraulic parameter distributions is illustrated in the estimation of uncertainty in net infiltration at a lysimeter facility. The method used to calculate net infiltration was a relatively simple water budget calculation contained in an existing multiple pathway dose assessment code. On-site meteorological data from the lysimeter facility was used. For this example, the uncertain parameters were the average monthly precipitation and temperature, and the plant available water capacity. Distributions for the meteorological parameter uncertainty were based on the measured, site-specific data. The available water capacity uncertainty was modeled using the generic distribution from Appendix A. The soil texture selected was based solely on a description of the lysimeter soil. A comparison between the distribution of predicted annual net infiltration and the observed lysimeter drainage (mean and standard error) showed an agreeable match. The measured long-term average drainage rate from the lysimeter fell between the 90th and 95th percentiles of the predicted distribution.For sites without local measurements of precipitation, temperature, etc., meteorological parameters can be estimated from National Climatic Data Center data. The means to obtain this data for a particular site is described, as is a computer code to summarize the monthly statistics of the data.

The generic distributions are useful for modeling the uncertainty in soil hydraulic parameters when information about the soils at a site is limited to the soil texture. At many sites, however, there may be some site-specific soil hydraulic property data available. At those sites where water retention measurements exist, a Bayesian updating method presented in this report can be used to combine the generic distributions and the site-specific data. The resulting updated soil hydraulic parameter distributions can be used to obtain an updated estimate of the probability distribution of dose. A computer code written to implement the Bayesian updating method is described.

The method for updating soil hydraulic parameter distributions using site-specific data was illustrated for an example SDMP site. Monthly average precipitation and air temperature as well as the plant available water capacity were modeled as uncertain parameters. The available water capacity was updated using five site-specific measurements of the van Genuchten water retention parameters. The effect of updating with the site-specific data was to reduce the estimate of the mean annual net infiltration by $17 \%$. The standard deviation, representing uncertainty in the net infiltration estimate, was reduced by $31 \%$. Similar effects were seen in the estimates of dose (means and standard deviations were lower when using the updated net infiltration distribution). For example, at 1000 years the probability that the total dose was greater than $25 \mathrm{mrem} / \mathrm{yr}$ was 
about $40 \%$ before updating, but was reduced to about $15 \%$ when the site-specific data was incorporated in the analysis.

The updating example illustrates that the impact on dose estimates of site-specific water retention data can be significant. The relative impact of various parameters on the predictions of dose should therefore be considered when performing site characterization. One way to do this is to calculate partial correlation coefficients from a Monte Carlo simulation using generic distributions of parameters. Parameters with the largest partial correlation coefficients are the ones for which site-specific data is likely to be most valuable. Calculation of partial correlation coefficients is carried out by some available multiple-pathway exposure assessment codes.

Several limitations of the methods used in this report have been identified. As mentioned above, the actual error in the regressions on which the soil hydraulic parameter distributions are based is unknown, but probably significant. The result is that the generic distributions are likely to underestimate the true parameter uncertainty. In addition, the Bayesian updating method assumes that the site-specific data have no uncertainty associated with them. The effectiveness of the data in reducing the variance of the updated distributions is thus exaggerated. Most data measurements are somewhat uncertain and including this additional uncertainty in the Bayesian updating method would provide a more realistic estimate of the updated parameter uncertainty. The conclusion to be drawn from these limitations is that the parameter uncertainties derived using the methods presented in this report represent a lower bound. Actual uncertainty may be greater.
The exposure assessment codes used in this report to predict net infiltration and dose do not consider the small-scale temporal and spatial variabilities that exist in many real life processes. Such variability may play an important role in contaminant transport. For example, recharge generally occurs over short periods of time in response to events such as heavy rainfall and spring snowmelt. In addition, spatially variable soils may have locally concentrated recharge. Ignoring these variabilities may lead to nonconservative dose predictions in some cases. There is no clear methodology, however, for determining when the consideration of temporal and/or spatial variability is crucial. Such a determination will depend on site conditions as well as the decision to be made. For example, variability is likely to be more important at sites with a thin unsaturated zone and significant seasonal fluctuations in the water table and when remediation alternatives are being assessed.

To conclude, at many SDMP sites, the water pathway will be a major contributor to total dose. Net water infiltration is therefore one of the most important parameters of the contaminant transport analysis. Using the methods described in this report will provide quantitative estimates of the uncertainty in net infiltration and the uncertainty in dose arising from the hydrologic uncertainties. Such estimates improve the transport analysis and, with site-specific data, can help to reduce the uncertainties at a given SDMP site. The analysis presented here may be applicable to estimating uncertainties in other parameters, such as contaminant distribution coefficients and atmospheric or surface water transport parameters. 


\section{Foreword}

This technical report, NUREG/CR-6565, was prepared by Pacific Northwest National Laboratory ${ }^{1}$ (PNNL) to document results from research conducted for the Waste Management Branch, Office of Nuclear Regulatory Research, U.S. Nuclear Regulatory Commission (JOB CODE W6503). The research project and this report build on earlier work that developed methodologies for estimating infiltration and unsaturated flow at low-level radioactive waste disposal sites (i.e., NUREG/CR's 5523 and 6346). The research reported here responds to NRC licensing needs for assessing uncertainties in hydrologic analyses, whether simple or complex, as input to dose/risk assessments at Site Decommissioning Management Plan (SDMP) sites. The report presents information on hydraulic parameter distributions and analytical tools useful in determining uncertainties related to infiltration and subsurface flow and transport calculations at SDMP sites.

This report, NUREG/CR-6565, presents a strategy for estimating uncertainties in dose estimates using a range of soil hydraulic parameter information. Parameter information may range from simple estimates of soil texture to detailed site-specific field data of water retention. The report demonstrates how generic probability distributions for soil hydraulic parameters and site-specific data can be used to generate and update probability distributions of dose estimates. This strategy is illustrated through examples using the generic parameter distributions and analytical methods provided in the report and appendices. The report concludes with an analysis of a hypothetical SDMP site using realistic field data coupled to assumed source-term release data and potential exposure multiple pathways. The report has been peer-reviewed by outside experts.

NUREG/CR-6565 is not a substitute for NRC regulations, and compliance is not required. The approaches and/or methods described in this NUREG/CR are provided for information only. Publication of this report does not necessarily constitute NRC approval or agreement with the information contained herein. Use of product or trade names is for identification purposes only and does not constitute endorsement by the NRC or PNNL.
1. Pacific Northwest National Laboratory is operated for the U.S. Dept. of Energy by Battelle Memorial Institute under Contract DE-AC06-76RLO 1830. 



\section{Acknowledgements}

The authors gratefully acknowledge the financial assistance of the Office of Nuclear Regulatory Research of the U.S. Nuclear Regulatory Commission. Tom Nicholson of the NRC is the Technical Monitor for the project, Groundwater Flow and Transport Analyses, and has provided invaluable guidance and support. A number of other NRC staff members have also reviewed the report and provided valuable commentary, among them Mark Thaggard, Boby Abu-Eid, Chris Daily, and Ralph Cady.
Marcel Schaap of the U.S. Salinity Laboratory and Michael Young of The University of Arizona provided valuable reviews of this report. Their comments and time are greatly appreciated.

We would like to thank Jim Bonta and Vickie Dreher of the USDA-ARS at Coshocton, Ohio for providing the lysimeter and meteorological data used in evaluating the net infiltration uncertainty calculation. 



\section{Abbreviations}

ARS

C

cdf

CL

DOE

D-statistic

EPA

FSOD

ftp

HELP

L

LS

MEPAS

MMSOILS

NCDC

NRC

pdf

RESRAD

$S$

SC

SCL

SCS

SDMP

$\mathrm{Si}$

$\mathrm{SiC}$

$\mathrm{SiCL}$

SiL

SL

USDA

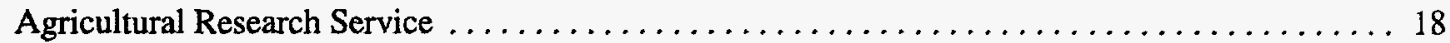

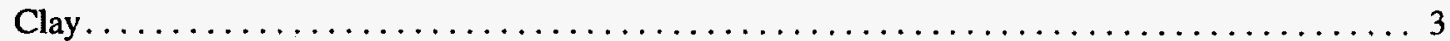

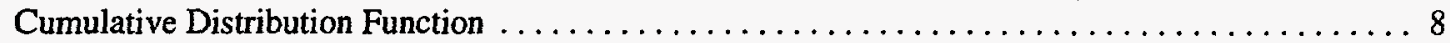

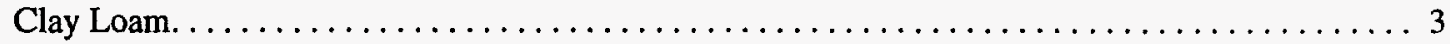

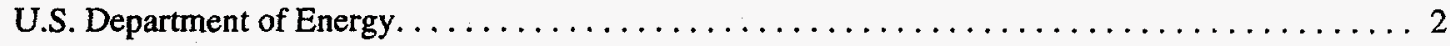

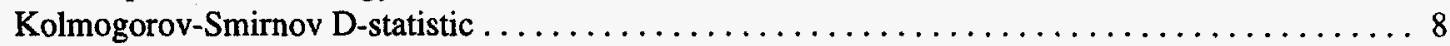

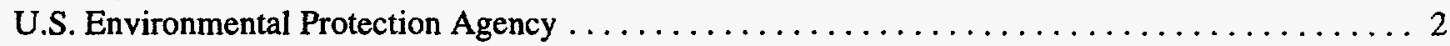

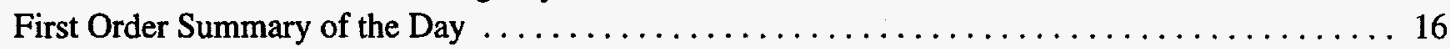

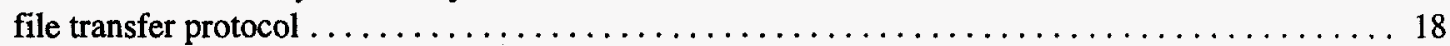

Hydrologic Evaluation of Landfill Performance Model . . . . . . . . . . . . . . . . . . 10

Loam . . . . . . . . . . . . . . . . . . . . . . . . . . . . . . . . . . . . 3

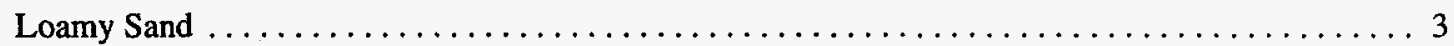

Multimedia Environmental Pollutant Assessment System Model ................... 2

Multimedia Contaminant Fate, Transport, and Exposure Model $\ldots \ldots \ldots \ldots \ldots \ldots \ldots \ldots \ldots, 2$

National Climatic Data Center ....................................... 16

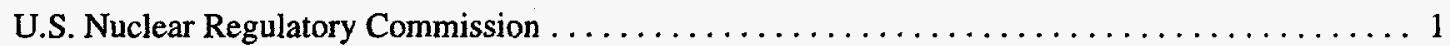

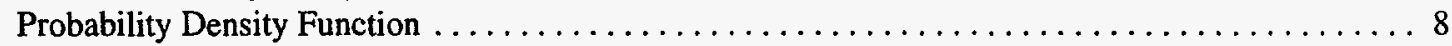

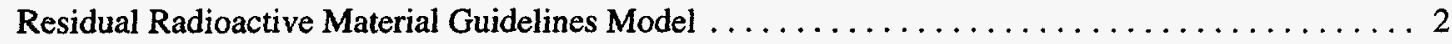

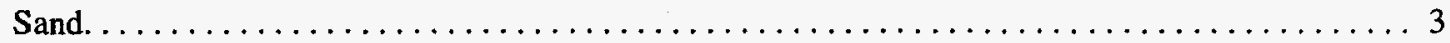

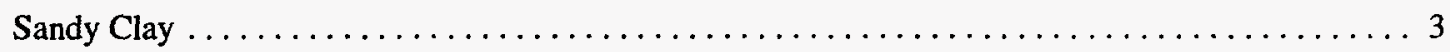

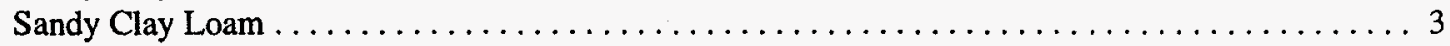

U.S. Soil Conservation Service. . . . . . . . . . . . . . . . . . . . . . . . 15

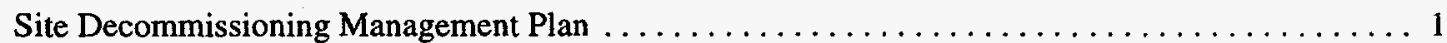

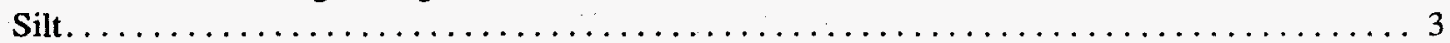

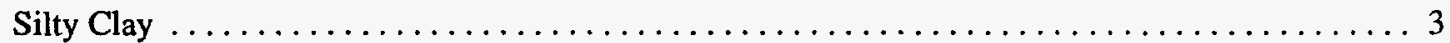

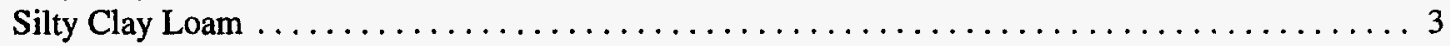

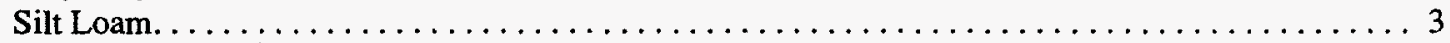

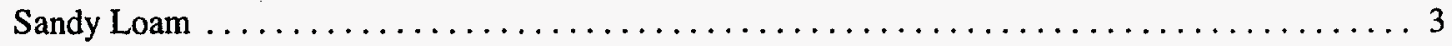

United States Department of Agriculture $\ldots \ldots \ldots \ldots \ldots \ldots \ldots \ldots \ldots \ldots \ldots \ldots \ldots \ldots \ldots \ldots \ldots \ldots \ldots$ 



\section{Symbols}

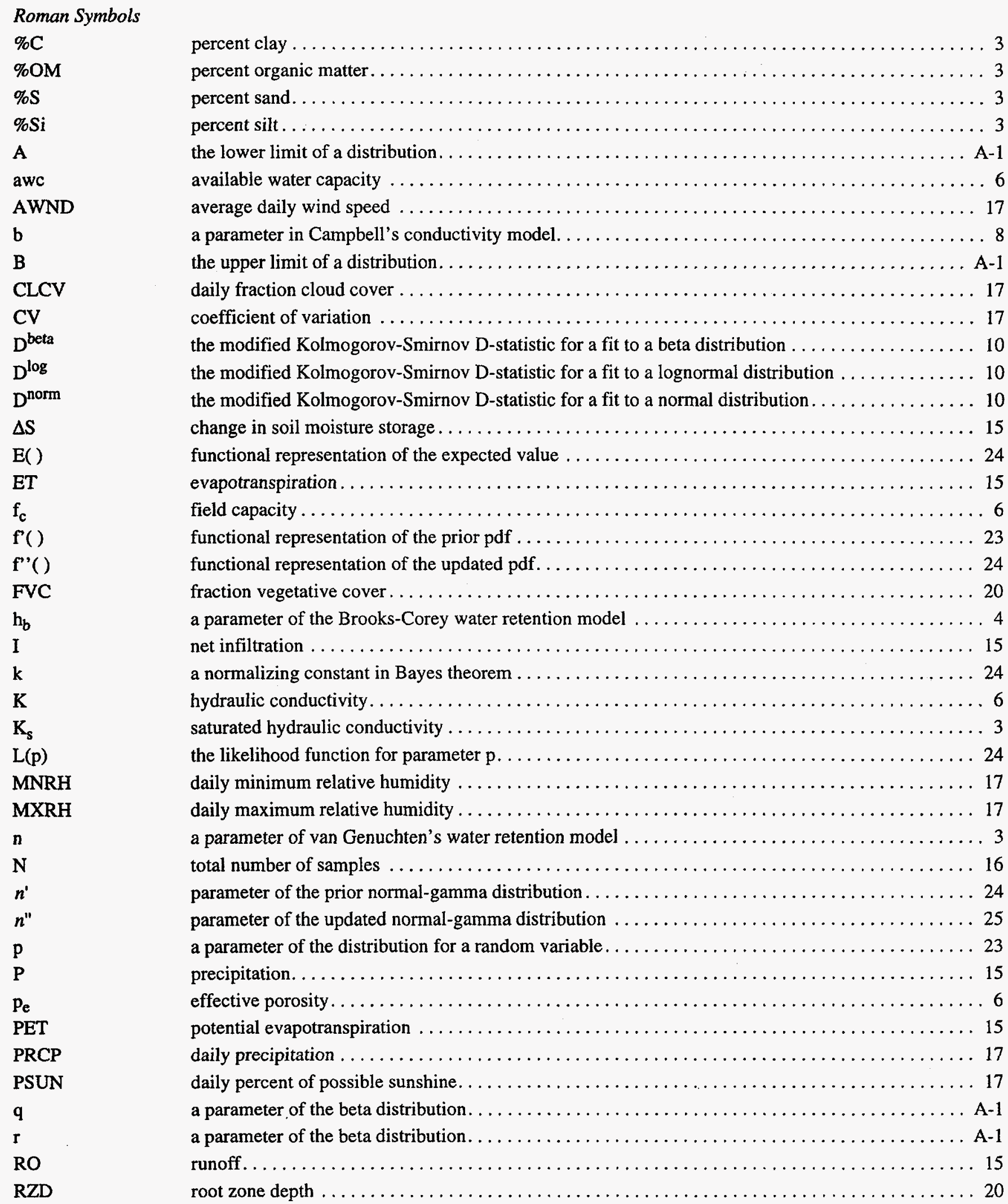




\section{Greek Symbols}

$\alpha$

$\beta($,

$\gamma$

$\Gamma()$

$\lambda$

$\mu$

$\mu_{\mathrm{CP}}$

$\theta$

$\theta_{\mathrm{r}}$

$\theta_{s}$

$\rho_{b}$

$\hat{\rho}$

$\sigma$

$\sigma_{C P}^{2}$

$\tau$

$\zeta$

a sample standard deviation

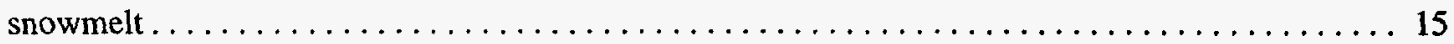

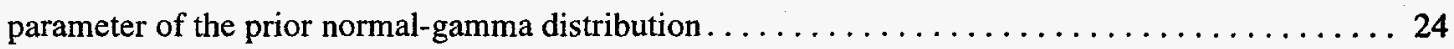

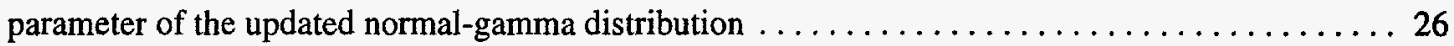

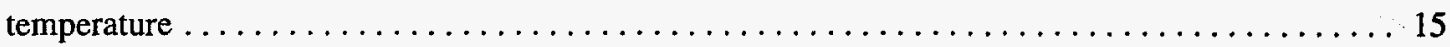

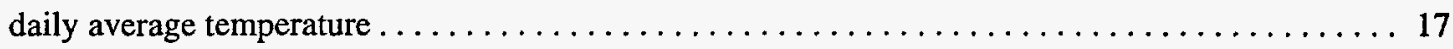

daily maximum temperature $\ldots \ldots \ldots \ldots \ldots \ldots \ldots \ldots \ldots \ldots \ldots \ldots \ldots \ldots \ldots \ldots \ldots \ldots$

daily minimum temperature $\ldots \ldots \ldots \ldots \ldots \ldots \ldots \ldots \ldots \ldots \ldots \ldots \ldots \ldots \ldots \ldots \ldots$

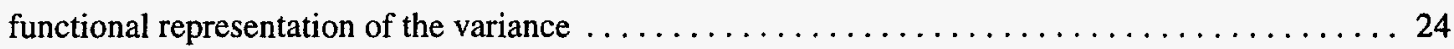

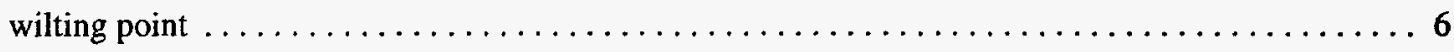

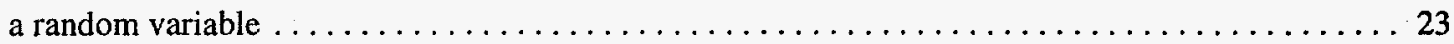

a sample mean . . . . . . . . . . . . . . . . . . . . . . . . . . . . 16

parameter of the prior normal-gamma distribution $\ldots \ldots \ldots \ldots \ldots \ldots \ldots \ldots \ldots \ldots \ldots \ldots$

parameter of the updated normal-gamma distribution $\ldots \ldots \ldots \ldots \ldots \ldots \ldots \ldots \ldots \ldots$

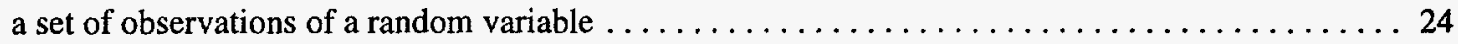

a parameter of van Genuchten's water retention model $\ldots \ldots \ldots \ldots \ldots \ldots \ldots \ldots \ldots \ldots \ldots \ldots$

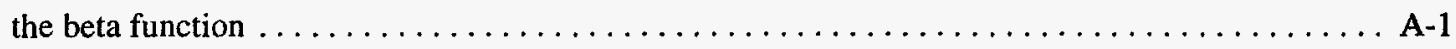

a parameter of the lognormal distribution $\ldots \ldots \ldots \ldots \ldots \ldots \ldots \ldots \ldots \ldots \ldots \ldots \ldots \ldots \ldots$

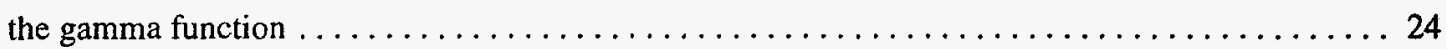

a parameter of the Brooks-Corey water retention model $\ldots \ldots \ldots \ldots \ldots \ldots \ldots \ldots \ldots \ldots \ldots \ldots$

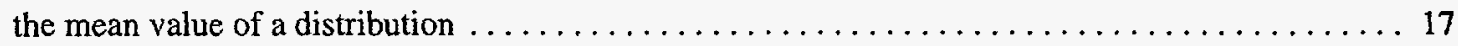

the mean value of a transformed parameter from Carsel and Parrish (1988) . . . . . . . . . 24

volumetric water content. . . . . . . . . . . . . . . . . . . . . . . . 6

residual volumetric water content $\ldots \ldots \ldots \ldots \ldots \ldots \ldots \ldots \ldots \ldots \ldots \ldots \ldots \ldots \ldots \ldots$

saturated volumetric water content $\ldots \ldots \ldots \ldots \ldots \ldots \ldots \ldots \ldots \ldots \ldots \ldots \ldots \ldots \ldots$

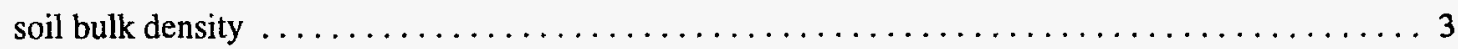

sample correlation coefficient $\ldots \ldots \ldots \ldots \ldots \ldots \ldots \ldots \ldots \ldots \ldots \ldots \ldots \ldots \ldots \ldots \ldots$

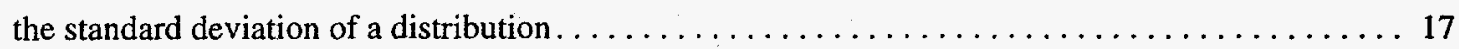

the variance of a transformed parameter from Carsel and Parrish (1988) . . . . . . . . . . 24

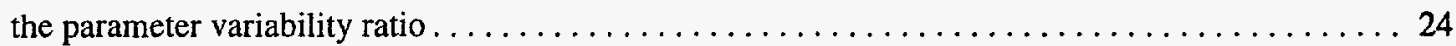

a parameter of the lognormal distribution $\ldots \ldots \ldots \ldots \ldots \ldots \ldots \ldots \ldots \ldots \ldots \ldots \ldots \ldots \ldots$ 


\section{Introduction}

\subsection{Motivation}

The Nuclear Regulatory Commission (NRC) has responsibility for licensing and regulating commercial nuclear facilities. This includes the subsequent decommissioning of these facilities (i.e., the process of removing facilities safely from service and reducing residual radioactivity to levels that permit the release of property in accord with NRC requirements). Effective site characterization is required in the decommissioning process and guidance for such characterization has been provided in recent NRC publications (U.S. NRC, 1993, 1994).

The essential steps in site characterization include 1) determination of the type and extent of radiological contamination; 2) determination of the environmental conditions that affect transport of radionuclides to the accessible environment; and 3) assessment of the fate and transport of the radiological contaminants. These steps require documentation of the inventory of residual radioactivity, evaluation of the geologic and hydrologic environment and subsequent application of computer simulation codes to estimate existing and future radiological exposures (dose) within and adjacent to sites being decommissioned.

Exposure to radiological contaminants can occur through a number of pathways, any number of which may be significant at a particular site. This report, however, addresses transport through the subsurface only (unsaturated and saturated zones). In the recent development of a hydrologic evaluation methodology for commercial low-level waste (LLW) sites (Meyer et al., 1996), it was made clear that determination of net infiltration and the estimation of flow in the subsurface are critical to accurately predicting the performance of disposal facilities. Model simplifications such as temporal and spatial averaging can significantly influence net infiltration estimates. In addition, estimates of the performance of engineered features such as surface covers can be quite sensitive to the analytical methods used.
Because of the identified importance of net infiltration in LLW disposal, this study was undertaken to improve the analysis of infiltration and unsaturated flow and transport at Site Decommissioning Management Plan (SDMP) sites (U.S. NRC, 1993). Like a LLW facility, exposure via the groundwater pathway to contaminants left in place is a concern at many of the SDMP sites.

Although this report addresses exposure via the groundwater pathway only, the ideas and methods discussed are general enough that they could be applied to other pathways. This would require a similar level of analysis (see Section 1.2) and a similar amount of generic information concerning the transport parameters for the pathway.

\subsection{Hydrologic Analysis Alternatives}

The range of alternatives available for the hydrologic analysis component of estimating dose is shown in Table 1-1. The appropriate complexity of the analysis depends on a number of factors, including the decision to be made, the availability of site characterization data, and the quality of that data. For many decommissioning sites, where the potential for exposure is small and the decision is whether or not a more complex analysis is required, a fairly simple analysis such as the NUREG/CR-5512 methodology (Kennedy and Strenge, 1992) is appropriate. (The NUREG/CR-5512 methodology is used in the computer code DandD.) At SDMP sites, where the potential for exposure is greater and the decision is based on a prediction of dose, an intermediate or complex analysis is appropriate.

Increasing the complexity of the analysis can potentially lead to a more accurate prediction. As discussed at length by Focht (1994), however, the data and the analysis method should be commensurate. The use of a more complex analysis will not necessarily result in a more accurate prediction when the quality of data is poor. Similarly, increasing the

TABLE 1-1. Characteristics of hydrologic analysis alternatives

\begin{tabular}{|c|c|c|}
\hline Least Complex & Intermediate & Most Complex \\
\hline $\begin{array}{l}\text { Bucket-type models with little or no } \\
\text { reference to underlying mechanisms; } \\
\text { Conservatism likely to be built in. }\end{array}$ & $\begin{array}{l}\text { Simplified analytical or empirical } \\
\text { models with some reference to under- } \\
\text { lying mechanisms; may or may not } \\
\text { attempt to be conservative. }\end{array}$ & $\begin{array}{l}\text { Mechanistic models based on first } \\
\text { principles, often requiring numerical } \\
\text { solutions; no conservatism built in. }\end{array}$ \\
\hline $\begin{array}{l}\text { One-dimensional, homogeneous, and } \\
\text { steady-state. }\end{array}$ & $\begin{array}{l}\text { Usually one-dimensional and homoge- } \\
\text { neous; incorporates some transient } \\
\text { effects. }\end{array}$ & $\begin{array}{l}\text { Multi-dimensional, heterogeneous, } \\
\text { and transient. }\end{array}$ \\
\hline $\begin{array}{l}\text { Limited ability to incorporate site-spe- } \\
\text { cific data; likely to use default parame- } \\
\text { ter values. }\end{array}$ & $\begin{array}{l}\text { Can incorporate site-specific data, usu- } \\
\text { ally with some averaging; may use } \\
\text { default parameter values. }\end{array}$ & $\begin{array}{l}\text { Can incorporate site-specific data } \\
\text { with or without averaging; unlikely to } \\
\text { use default parameter values. }\end{array}$ \\
\hline e.g., DandD, RESRAD water budget & e.g., MEPAS water budget & e.g., Meyer et al.(1996) \\
\hline
\end{tabular}


quantity and precision of the data may provide no benefit when the analysis is relatively simple.

At SDMP sites, the relatively high potential for exposure argues for a more complex analysis. An intermediate level of analysis is likely to be appropriate, however, because data characterizing the hydrologic transport of radiological contaminants are limited at the majority of SDMP sites. A complex analysis will be most appropriate at sites where remediation of contamination is required. As observed by Bugai et al. (1997), overly simplified and conservative analyses may lead to ineffective remedial efforts.

There are a number of codes in the intermediate category that can be used for assessment of radiological dose. The Department of Energy (DOE) and the Environmental Protection Agency (EPA) recently evaluated three such codes [RESRAD (Yu et al., 1993a,b), MMSOILS (U.S. EPA, 1992), and MEPAS (Whelan et al., 1987; Buck et al., 1995)] in a "benchmarking" exercise (Cheng et al. 1995) in which the codes were all analyzed at comparative endpoints (e.g., contaminant concentrations vs. time at a receptor, cancer risk to maximally exposed individual, etc.) for both the air and water pathways. The methods presented in this report were developed to be used with codes such as these. In fact, RESRAD and MEPAS are used to illustrate the application of the methods. The methods presented, however, may have wider application to both simpler and more complex codes.

As illustrated in Table 1-1, intermediate-level codes are typically simple representations of reality, assuming steadystate and homogeneous conditions, for example. In addition, they are often applied using very limited amounts of sitespecific data. Because of these conditions, the exposure estimates produced may be highly uncertain, and it may be difficult to verify that a code is providing conservative results (e.g., that there are no reasonable combinations of parame- ter values that result in a significantly greater estimate of dose). These issues can be partially addressed by improving the methods used in the codes. For example, Appendix $F$ describes a computationally efficient solution to steady-state flow in layered soils that does not require the unit gradient assumption. Even with improved computational methods, however, an intermediate-level code will still produce uncertain results. A formal uncertainty analysis can help quantify this uncertainty, focusing attention on the most important parameters and thus improving the decisions made. This study develops tools for the analysis of hydrologic uncertainties at SDMP sites. These tools are intended to be applied with existing dose assessment codes.

\subsection{Objectives}

The general goal of this work was to provide the NRC with an improved, analysis capability that would enhance the credibility and defensibility of SDMP site reviews. Toward this goal, the specific objectives of this study were

(1) to provide probability distributions of soil hydraulic parameters that can be used in uncertainty analyses with available dose assessment codes,

(2) to develop a methodology, consistent with the dose assessment codes, that will provide reasonable estimates of the uncertainty in net infiltration at SDMP sites, and

(3) to develop a methodology that allows site-specific data on soil hydraulic properties to be systematically incorporated in uncertainty analyses.

These three objectives are addressed in the following three chapters. 


\section{Recommended Distributions for Describing Uncertainty in Soil Hydraulic Parameters}

This chapter describes the procedure used to derive probability distributions of common soil hydraulic parameters. Particular distributions are recommended as a function of USDA soil textural classification. Correlations between parameters are considered. These distributions can be used to represent parameter uncertainty when the information about a soil is limited to its textural class.

\subsection{Description of Carsel and Parrish's Results}

Carsel and Parrish (1988) presented joint probability distributions for the parameters of the van Genuchten (1980) water retention and unsaturated hydraulic conductivity models (see Section C.1). These parameters are:

- Saturated volumetric water content, $\theta_{\mathrm{s}}$

- Residual volumetric water content, $\theta_{\mathrm{r}}$

- Saturated hydraulic conductivity, $K_{s}$

- van Genuchten's parameter, $\alpha$

- van Genuchten's parameter, $n$

Carsel and Parrish based their analysis on data from soil samples collected by the Natural Resources Conservation Service (formerly Soil Conservation Service), representing soils from 42 U.S. states. Soil measurements used were bulk density, percent sand $(0.05-2 \mathrm{~mm})$, and percent clay $(<0.002 \mathrm{~mm})$. Bulk density was used to infer $\theta_{\mathrm{s}}$. Percent sand and clay, along with $\theta_{s}$, were used with the regressions of Rawls and Brakensiek (1985) to estimate the remaining parameters.

Carsel and Parrish's soil database included 15,737 samples from twelve USDA soil textural classifications. Not all samples were used to derive the probability distributions. The approximate number of samples used in each class (which varied for each parameter) and the textural abbreviations used in the remainder of this report are given in Table 2-1. The USDA soil textural triangle is shown in Figure 2-1 for reference.

Within each textural class, Carsel and Parrish took the data for each parameter and determined the transformation that would best make the data fit a normal distribution. The transformations they considered were:

$$
\begin{aligned}
& \mathrm{Y}=\mathrm{X} \text { \{no transformation; NO in Carsel and Parrish }\} \\
& \mathrm{Y}=\ln (\mathrm{X})\{\mathrm{LN} \text { in Carsel and Parrish } \\
& \mathrm{Y}=\ln [(\mathrm{X}-\mathrm{A}) /(\mathrm{B}-\mathrm{X})] \text { SB in Carsel and Parrish }\} \\
& \left.\mathrm{Y}=\sinh ^{-1}[(\mathrm{X}-\mathrm{A}) /(\mathrm{B}-\mathrm{A})] \text { \{SU in Carsel and Parrish }\right\}
\end{aligned}
$$

Here $X$ represents the untransformed data for a particular parameter and textural class. A and B are the lower and upper limits of variation of the parameter within the textural class. The limits of variation were based on the observed data and on theoretical considerations (Carsel and Parrish,
Table 2-1. Approximate number of soil samples used by Carsel and Parrish (1988) for each textural class

\begin{tabular}{ccc}
\hline USDA Textural Classification & Abbrev. & Number \\
\hline Sand & $\mathrm{S}$ & 246 \\
Loamy Sand & $\mathrm{LS}$ & 315 \\
Sandy Loam & $\mathrm{SL}$ & 1183 \\
Sandy Clay Loam & $\mathrm{SCL}$ & 214 \\
Loam & $\mathrm{L}$ & 735 \\
Silt Loam & $\mathrm{SiL}$ & 1093 \\
Silt & $\mathrm{Si}$ & 82 \\
Clay Loam & $\mathrm{CL}$ & 364 \\
Silty Clay Loam & $\mathrm{SiCL}$ & 641 \\
Sandy Clay & $\mathrm{SC}$ & 46 \\
Silty Clay & $\mathrm{SiC}$ & 374 \\
Clay & $\mathrm{C}$ & 400 \\
\hline
\end{tabular}

1988). In a small number of cases, Carsel and Parrish fit a truncated normal distribution to the transformed data.

The sample mean and variance of the transformed data were used as estimates of the parameters of the best-fit normal distribution. Sample covariances and correlations were calculated on the transformed data. Carsel and Parrish's results are presented in Tables 6 and 7 of their paper. (Note, in their Table 6, the mean of $K_{s}$ for sandy loam (SL) should be -2.49.) The goodness of fit for Carsel and Parrish's transformed data was presented graphically in their paper by plotting the empirical cdf's of their transformed data over the best-fit (normal) cdf's. In general the fits were very good with the poorest fits occurring for the fine soil textures and those parameters with the fewest data ( $\mathrm{Si}, \mathrm{SC}, \mathrm{SiC}$, and $\mathrm{C}$ ).

\subsubsection{Rawls and Brakensiek's Regressions}

Rawls and Brakensiek's regression equations (Rawls and Brakensiek, 1985), used by Carsel and Parrish to estimate the water retention and unsaturated hydraulic conductivity parameters, are based on earlier work (Rawls et al., 1982; Rawls et al., 1983) in which regressions were derived for estimating water content at particular tension values from percent sand, silt, and clay, organic matter, and bulk density data.

$$
\begin{gathered}
\text { Regressions of Rawls et al., 1982, } 1983 \\
\theta=c_{0}+c_{1} \% S+c_{2} \% S i+c_{3} \% C+c_{4} \% \mathrm{OM}+c_{5} \rho_{b}
\end{gathered}
$$

where $\% \mathrm{~S}, \% \mathrm{Si}, \% \mathrm{C}$, and $\% \mathrm{OM}$ are percent sand, silt, clay, and organic matter, respectively, and $\rho_{b}$ is soil bulk density. 


\section{Recommended Distributions for Describing Uncertainty in Soil Hydraulic Parameters}

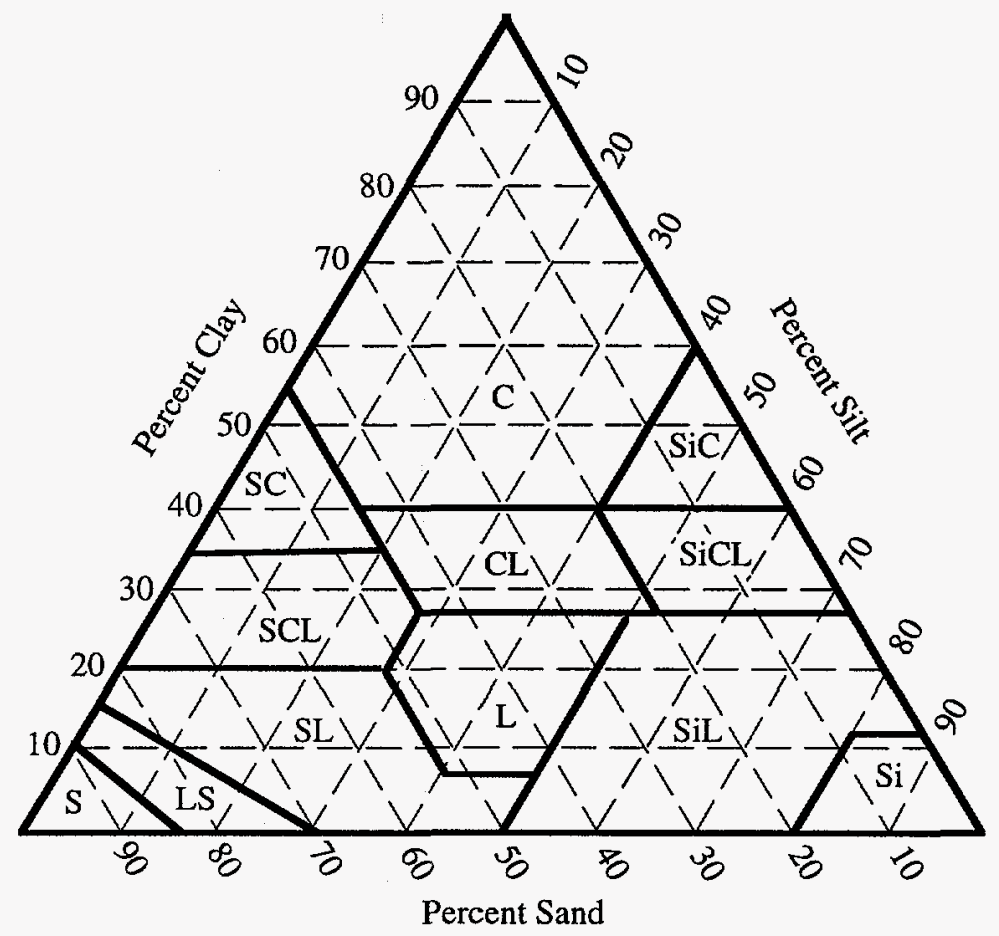

Figure 2-1. USDA soil textural triangle. Soil classification is determined by the percent (by weight) of the sand, silt and clay fractions. Clay $<0.002 \mathrm{~mm}, 0.002<$ Silt $<0.05 \mathrm{~mm}, 0.05<$ Sand $<2.0 \mathrm{~mm}$ diameter.

The $c_{i}$ are regression coefficients and are a function of tension.

Kern (1995) evaluated the accuracy of the regression model of Rawls et al. (1982) for tensions of 102, 340, and 15,300 $\mathrm{cm}\left(0.1,0.33\right.$, and 15 bars at $\left.4^{\circ} \mathrm{C}\right)$. He found that the model overestimated the measured water content at both high and low water contents, but had a small bias overall. In addition, he found that the standard deviation of the relative error in the predicted water content was between 30 and $40 \%$. Assuming that the errors were normally distributed, this suggests that the predicted water content was within 30 to $40 \%$ of the measured water content approximately $68 \%$ of the time.

Rawls et al. (1983) reported $R^{2}$ values from 0.66 to 0.78 for the regression equations they used to obtain water content at specific tension values. This indicates that 22 to $34 \%$ of the observed variability in their fitted data is not explained by their regression model(s). Rawls et al. (1983) used their regression equations to obtain water content at nine tension values (from 200 to $15,000 \mathrm{~cm}$ ) for combinations of percent sand, percent clay, and porosity (inferred from bulk density). For each combination, they fit the water retention model of Brooks and Corey (1964; see Section C.2) to the nine points. Saturated hydraulic conductivity was calculated as a function of the Brooks-Corey model parameters.
Rawls and Brakensiek (1985) used the parameter values generated by Rawls et al. (1983) to produce regression equations for the Brooks-Corey parameters as a function of percent sand, percent clay, and saturated water content (or porosity). Their regression equations had the following form.

\section{Regressions of Rawls and Brakensiek (1985)}

$$
\begin{aligned}
\theta_{\mathrm{r}} \ln \left(K_{s}\right), \ln \left(h_{b}\right), \ln (\lambda) & =\mathrm{c}_{0}+\mathrm{c}_{1} \% \mathrm{~S}+\mathrm{c}_{2} \% \mathrm{C}+\mathrm{c}_{3} \theta_{\mathrm{s}}+ \\
& c_{11} \% \mathrm{~S}^{2}+\mathrm{c}_{22} \% \mathrm{C}^{2}+\mathrm{c}_{33} \theta_{\mathrm{s}}{ }^{2}+ \\
& \mathrm{c}_{12} \% \mathrm{~S} \% \mathrm{C}+\mathrm{c}_{13} \mathrm{~S} \theta_{\mathrm{s}}+\mathrm{c}_{23} \% \mathrm{C} \theta_{\mathrm{s}}+ \\
& \mathrm{c}_{112} \% \mathrm{~S}^{2} \mathrm{C}+\mathrm{c}_{223} \% \mathrm{C}^{2} \theta_{\mathrm{s}}+\mathrm{c}_{113} \mathrm{~s}^{2} \theta_{\mathrm{s}}+ \\
& \mathrm{c}_{122} \% S \mathrm{C}^{2}+\mathrm{c}_{233} \% \mathrm{C} \theta_{\mathrm{s}}{ }^{2}+\mathrm{c}_{1133} \mathrm{~S}^{2} \theta_{\mathrm{s}}{ }^{2} \\
& +\mathrm{c}_{2233} \% \mathrm{C}^{2} \theta_{\mathrm{s}}{ }^{2}
\end{aligned}
$$

where $\theta_{r}$ is the residual water content and $h_{b}$ and $\lambda$ are the Brooks-Corey air-entry pressure and pore size distribution parameters. The $c_{i}$ are a function of the parameter being estimated.

Rawls and Brakensiek (1985) do not give any indication of the error in their regressions. It seems reasonable to assume that the error is at least the 30 to $40 \%$ described by Kern (1995). Some additional error may have been introduced in 
fitting the Brooks-Corey model (Rawls et al., 1983) and in deriving the final regressions (Rawls and Brakensiek, 1985).

The regression equations of Rawls and Brakensiek (1985) are reproduced in Figure 1 of Carsel and Parrish (1988) with several errors in the coefficients. For $\theta_{\mathrm{r}}$ the correct coefficients, as given in Rawls and Brakensiek (1985), are:

$$
\begin{aligned}
& c_{1}=0.00087269 \\
& c_{22}=-0.00015395 \\
& c_{223}=0.00030703 \\
& c_{2233}=-0.00018233
\end{aligned}
$$

For $\ln \left(\alpha^{-1}\right)$, the correct coefficient is:

$$
c_{113}=-0.00072472
$$

\subsubsection{Parameter Equivalence}

The regression equations of Rawls and Brakensiek (1985) were derived for the Brooks-Corey parameters, whereas Carsel and Parrish (1988) write these regressions in terms of the van Genuchten parameters. Carsel and Parrish used the following equivalence between the Brooks-Corey and van Genuchten parameters:

$$
h_{b}=\alpha^{-1} \text { and } \lambda=n-1 \text {. }
$$

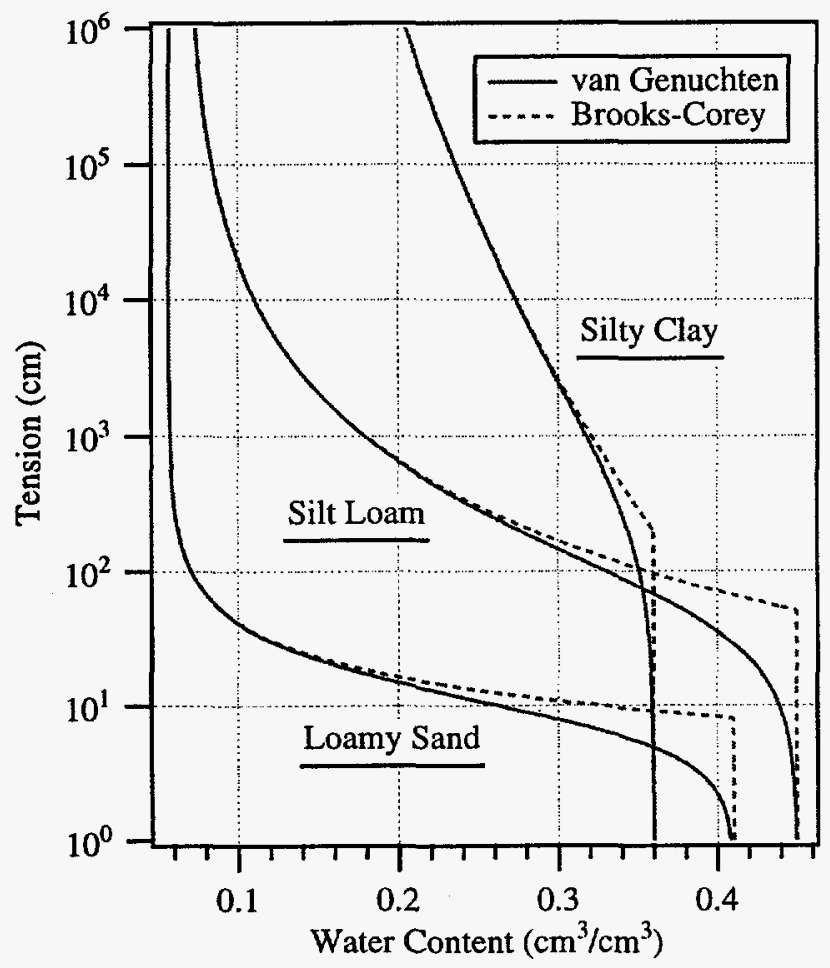

The resulting water retention and hydraulic conductivity relationships for the two models are shown in Figure 2-2 for several representative soils. As shown in this figure and as discussed by van Genuchten (1980), the equivalence used by Carsel and Parrish (1988) produces minor differences between the two models under dry conditions. Under wet conditions, however, differences can be significant, particularly in the hydraulic conducitvity models for fine-textured soils (right side of Figure 2-2). As shown by Morel-Seytoux et al. (1996), this can lead to differences in predicted infiltration. Although alternative equivalences exist (Lenhard et al., 1989; Morel-Seytoux et al., 1996), none has been shown to be superior under all conditions. The primary error introduced by the equivalence used in Carsel and Parrish (1988) is the generation of $n$ values that are systematically too small. Some error in the generated field capacity values is also expected.

Carsel and Parrish assumed that saturated water content was equivalent to the porosity. For soils that are generally unsaturated, entrapped air will limit the saturated water content to a value less than the porosity. Thus the results of Carsel and Parrish (1988) will tend to overestimate $\theta_{\mathrm{s}}$ for field soils in the unsaturated zone. As a consequence, field capacity and wilting point values will also tend to be overestimated. The actual error is difficult to estimate, however, since some

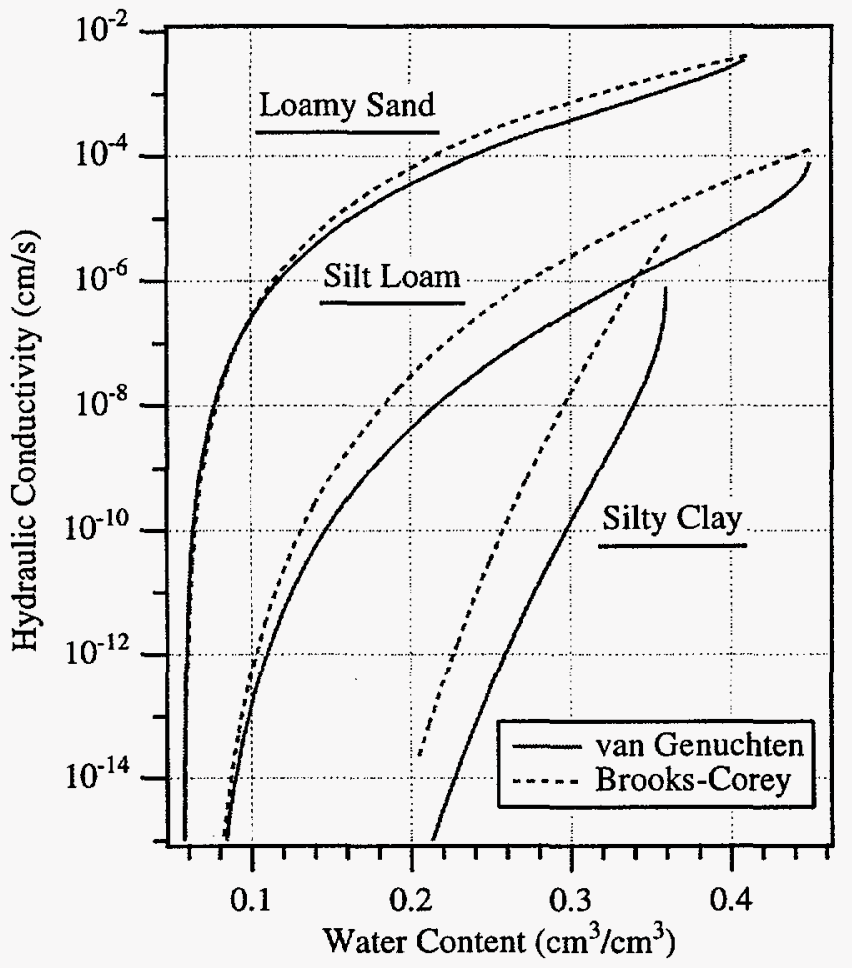

Figure 2-2. Comparison between the van Genuchten and Brooks-Corey water retention (left) and hydraulic conductivity (right) models using the parameter equivalence, $h_{b}=\alpha^{-1}$ and $\lambda=n-1$ 


\section{Recommended Distributions for Describing Uncertainty in Soil Hydraulic Parameters}

additional error was introduced in assuming a value for the particle density, which is required to calculate porosity from bulk density measurements.

\subsection{Calculation of Additional Parameters}

Because soil hydraulic parameters other than those listed in Section 2.1 are often required by simulation models, a number of additional parameters were calculated. These parameters and the methods by which they were calculated are discussed here.

- Effective porosity, $p_{e}=\theta_{\mathrm{s}}-\theta_{\mathrm{r}}$

- Field capacity, $f_{c}=\theta\left(K=10^{-8} \mathrm{~cm} / \mathrm{s}\right)$

Field capacity is generally interpreted as the water content at which drainage from a field soil becomes negligible (see the discussion by Hillel, 1980). Field capacity is often calculated as the water content at a specified tension, usually taken to be $340 \mathrm{~cm} \mathrm{(1/3}$ bar). Hillel (1980) argues, however, that the field capacity should be based on the drainage rate considered negligible (which is a function of the intended application). Field capacity was calculated here as the water content at which the unsaturated hydraulic conductivity equals $10^{-8} \mathrm{~cm} / \mathrm{s}$ using the van Genuchten model $\left(10^{-8} \mathrm{~cm} / \mathrm{s} \cong 3 \mathrm{~mm} / \mathrm{yr}\right)$. The value of $10^{-8}$

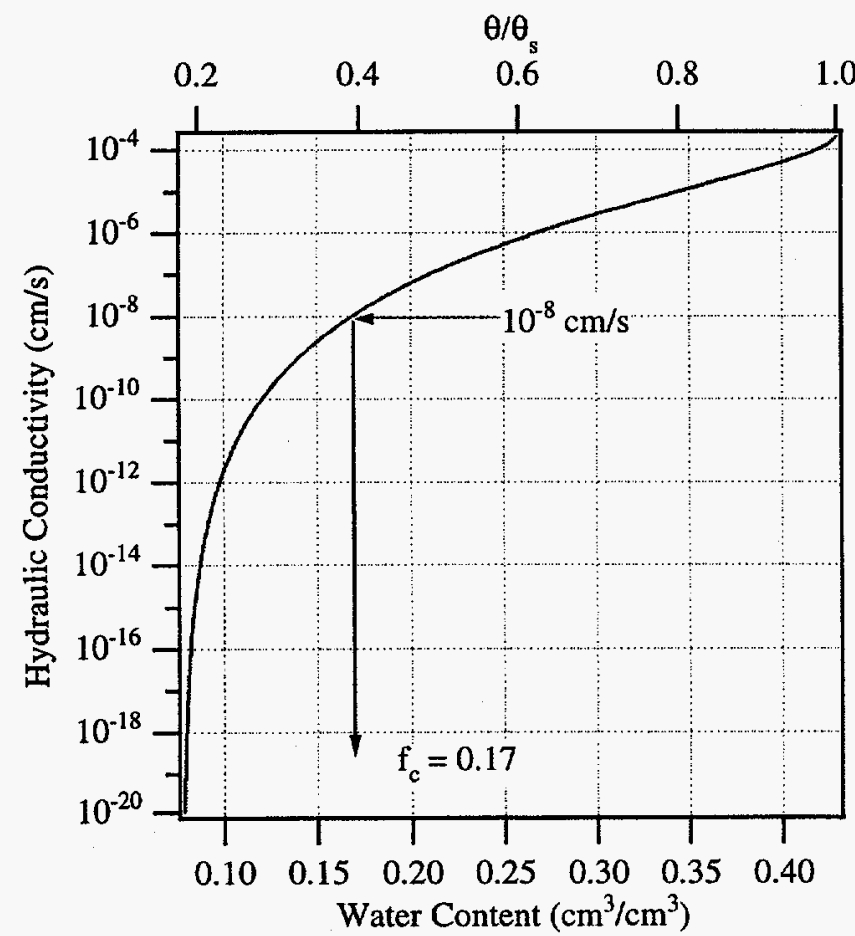

$\mathrm{cm} / \mathrm{s}$ was chosen because it represents a water flux at which contaminant transport is likely to be insignificant. The field capacity calculation is illustrated in Figure 2-3 (left side). Van Genuchten's equation for hydraulic conductivity as a function of water content (van Genuchten, 1980) was inverted numerically.

A comparison between the field capacity calculation used here and the typical calculation (water content at $1 / 3$ bar) is shown in Figure 2-4. Values shown are for the average parameter values obtained using the procedure described in Section 2.3. Figure 2-4 also compares the available water capacity resulting from the two field capacity calculations. Using the water content at a hydraulic conductivity of $10^{-8} \mathrm{~cm} / \mathrm{s}$ results in somewhat larger field capacity values and a more realistic available water capacity for very coarse textured soils.

- Wilting point, $w_{p}=\theta(h=15,300 \mathrm{~cm})$

Wilting point is the minimum water content (or maximum tension) at which plants can extract water from the soil. Wilting point was calculated as the water content at a tension of $15,300 \mathrm{~cm}$ ( 15 bars). This calculation is also illustrated in Figure 2-3 (right side).

- Available water capacity, $a w c=f_{c}-w_{p}$

Available water capacity represents the amount of water available for plant uptake (see Figure 2-4).

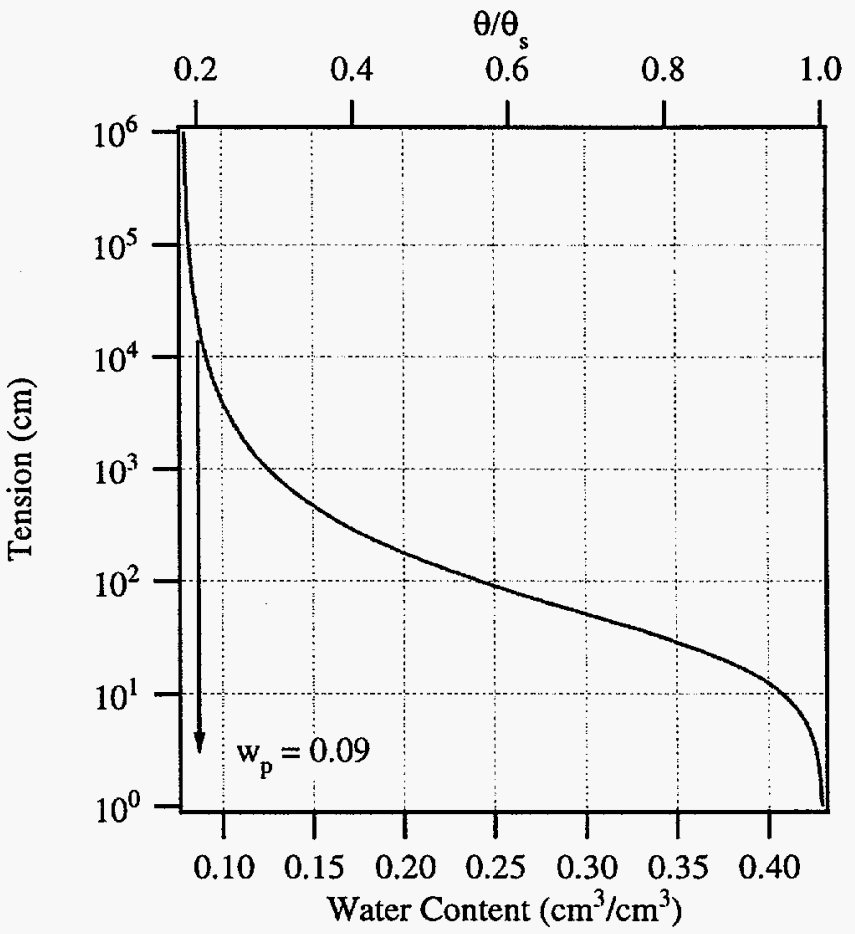

Figure 2-3. Calculation of field capacity and wilting point from hydraulic conductivity and water retention models for a typical loam soil 

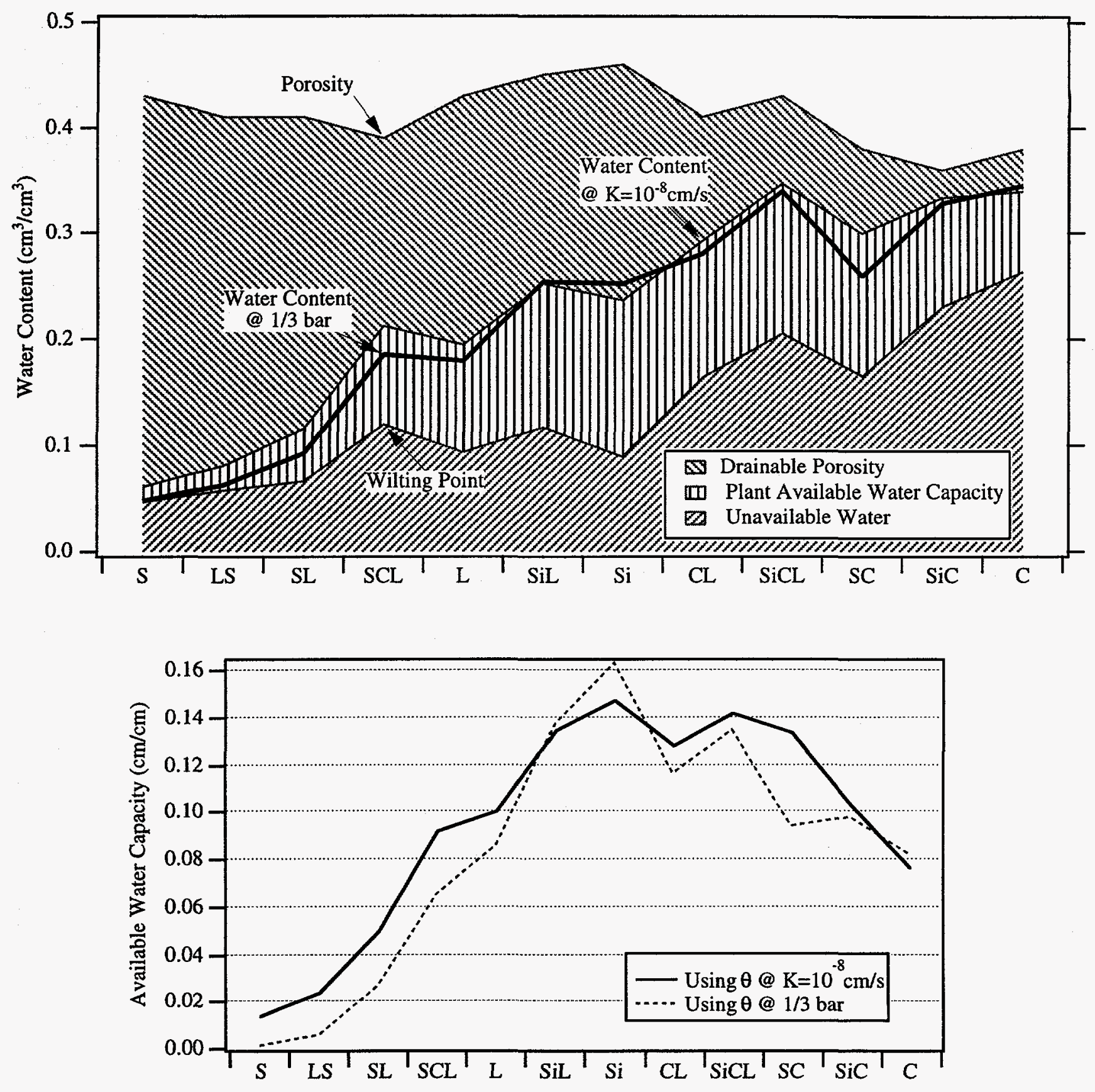

Figure 2-4. Drainable porosity, available water capacity, and unavailable water calculated using the average parameter values from the recommended distributions for porosity, field capacity, and wilting point. Top graph compares the calculation of field capacity as the water content at a hydraulic conductivity of $10^{-8} \mathrm{~cm} / \mathrm{s}$ and as the water content at a tension of $1 / 3$ bar. Bottom graph shows the resulting available water capacities. 


\section{Recommended Distributions for Describing Uncertainty in Soil Hydraulic Parameters}

- Brooks-Corey air-entry parameter, $h_{b}=\alpha^{-1}$

As mentioned previously, alternative equivalences between $h_{b}$ and $\alpha$ have been proposed (Lenhard et al., 1989; Morel-Seytoux et al., 1996). In the range of $200-15,300 \mathrm{~cm}$ of tension, however, the equivalence used here provides a more consistent fit between the two water retention models over the wide range of soil types considered.

- Brooks-Corey pore size distribution parameter, $\lambda=n-1$

- The exponent in Campbell's unsaturated conductivity model (Campbell, 1974; see Section C.3), $b$

The parameter $b$, which is used in MEPAS and RES-

RAD, was calculated by equating Campbell's expression for relative conductivity with Brooks and Corey's at a water content equivalent to an effective saturation of 0.5 , i.e., $S_{e}=\left(\theta-\theta_{r}\right) /\left(\theta_{s}-\theta_{r}\right)=0.5$. This leads to the following expression.

$$
b=0.5\left\{\frac{\ln (0.5)(3+2 / \lambda)}{\ln \left[0.5\left(1+\theta_{r} / \theta_{s}\right)\right]}-3\right\}
$$

See Section C. 4 for details.

\subsection{Recommended Parameter Distributions}

Probability distributions of the soil hydraulic parameters listed in Sections 2.1 and 2.2 were obtained by the following procedure.

(1) Generate realizations of the parameters using Latin hypercube sampling and the distributions from Carsel and Parrish (1988).

(2) Calculate the Kolmogorov-Smirnov D-statistic for a fit of each simulated parameter distribution to normal, lognormal, and beta distributions.

(3) Select the recommended distribution based on the Dstatistic values.

500 realizations of $\theta_{\Gamma} K_{s}, \alpha$, and $n$ for each soil texture class were generated using the Latin hypercube sampling code of Iman and Shortencarier (1984) and the distributions given in Carsel and Parrish (1988, Tables 6 and 7). The Latin hypercube sampling was carried out on the transformed (normally distributed) parameters. In addition, 500 realizations of $\theta_{s}$ were generated using the mean and standard deviation given in Carsel and Parrish (1988, Table 2) and assuming a normal distribution for $\theta_{\mathrm{s}}$ in each USDA classification. For each realization of these generated parameters, the additional parameters listed in Section 2.2 were also calculated.

These generated parameter realizations could serve as input to a simulation model if the model allowed empirical distributions as input. Standard operation of MEPAS and RESRAD requires, however, that a closed-form distribution of each uncertain parameter be entered as input (e.g., normal distribution with mean and variance given). In addition, the SB and SU distributions used by Carsel and Parrish (1988) are not allowed in MEPAS or RESRAD. For these reasons, closed-form distributions (normal, lognormal, and beta) were evaluated for their fit to the empirical parameter distributions resulting from the Latin hypercube sampling.

Each empirical parameter distribution was evaluated for its goodness of fit to normal, lognormal, and beta distributions using the Kolmogorov-Smirnov D-statistic (D-statistic). The D-statistic represents the largest absolute difference between an empirical cumulative distribution function (cdf) and a hypothesized (fitted) cdf. In this case, the Latin hypercube sampling results provided the empirical cdf. Probability density functions (pdf) and parameters for the three hypothesized distributions (normal, lognormal, and beta) are presented in Appendix A. Parameters of the normal and beta distributions were estimated from the Latin hypercube sampling results using the method of moments; the lognormal distribution parameters were estimated using maximum likelihood.

The D-statistic was calculated using the computer code described in Davis and Stephens (1989). A modified form of the D-statistic is calculated in this code using the results of Stephens (1974). (With the modified form of the statistic, the critical test value for a given significance level is independent of the number of samples.)

In most cases, the distribution type with the smallest D-statistic value was selected as the recommended distribution. A bias against the use of the beta distribution was implemented, however, because it was felt that, in most cases, the minimum and maximum limits of this distribution were somewhat arbitrary. If the beta distribution had the lowest

$$
\begin{aligned}
& \text { IF } \min \left(D^{\text {norm }}, D^{\log }, D^{\text {beta }}\right)=D^{\text {norm }}, \text { select Normal } \\
& \text { IF } \min \left(D^{\text {norm }}, D^{\log }, D^{\text {beta }}\right)=D^{\text {log }}, \text { select Lognormal } \\
& \text { IF } \min \left(D^{\text {norm }}, D^{\log }, D^{\text {beta }}\right)=D^{\text {beta }} \text { THEN } \\
& \text { IF } \min \left(D^{\text {norm }}, D^{\log }\right)<0.56 \text { THEN } \\
& \text { IF min }\left(D^{\text {norm }}, D^{\log }\right)=D^{\text {norm }}, \text { select Normal } \\
& \text { ELSE select Lognormal } \\
& \text { ELSEIF min }\left(D^{\text {norm }}, D^{\log }\right) / D^{\text {beta }}-1 \leq 0.2 \text { THEN } \\
& \text { IF min }\left(D^{\text {norm }}, D^{\text {log }}\right)=D^{\text {norm }}, \text { select Normal } \\
& \text { ELSE select Lognormal }
\end{aligned}
$$

ELSE select Beta

\section{ENDIF}

Figure 2-5. Algorithm for selecting recommended distribution based on modified D-statistic 

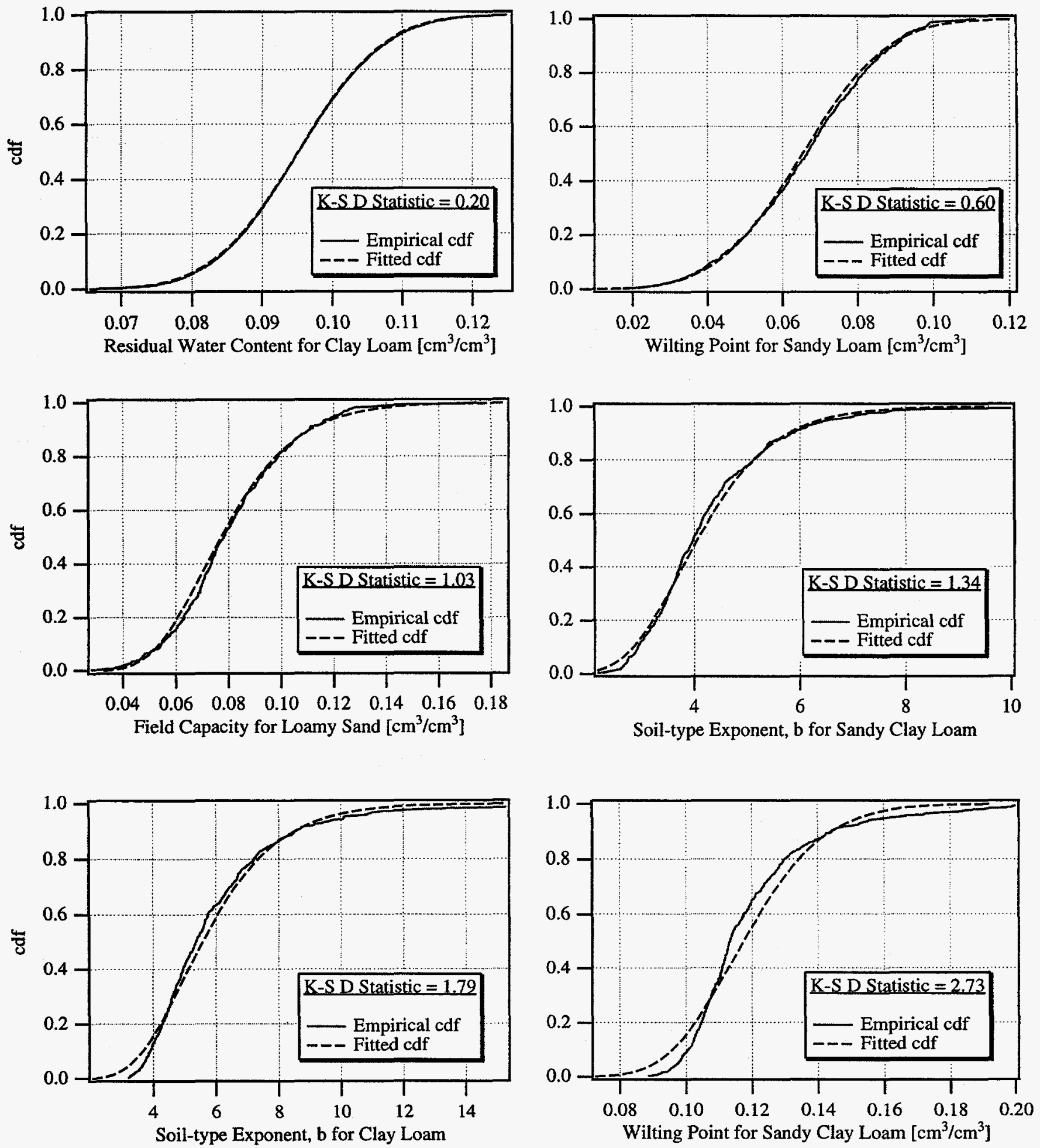

Figure 2-6. A comparison of fitted and empirical cdf's over a range of Kolmogorov-Smirnov D-statistic values for various soil parameters (using 500 realizations) 
D-statistic value, a normal or lognormal distribution was nevertheless recommended when the modified D-statistic for one of these distributions had a value less than 0.56 . A beta distribution was also rejected if the modified D-statistic for the normal or lognormal distribution was no more than $20 \%$ larger than the statistic for the beta distribution. (These cut-off values were based on visual observations of the parameter distributions contained in Appendix G.

Figure 2-6 compares fitted and empirical cdf's over a range of D-statistic values for various soil parameters.) The algorithm used to select a recommended distribution is listed in Figure 2-5. $D^{\text {norm }}, D^{\log }$, and $D^{\text {beta }}$ are the modified D-statistics for the normal, lognormal, and beta distributions, respectively.

The recommended probability distributions for each soil hydraulic parameter are given in Appendix A. The sample correlations between parameters were calculated from the Latin hypercube sampling results and are presented in Appendix B. The tables in these appendices are organized by USDA soil classification. These results can be used directly in MEPAS and RESRAD (as well as other models) when there are few site-specific data and an estimate of soil hydraulic parameter uncertainty is needed. (Note, however, that the version of RESRAD used in this report - v. 5.6.1 does not allow the use of the beta function, even though RESRAD uses Iman and Shortencarier's Latin hypercube sampling program, which includes the beta function as an option.)

Appendix G contains empirical pdf's and cdf's for the 500 Latin hypercube realizations of each soil hydraulic parameter. The recommended distributions are overlain on the empirical distributions to allow a visual appraisal of the goodness of fit.

\subsection{Comparison with Parameter Values from MEPAS and HELP}

A number of the soil hydraulic parameter distributions in Appendix A were compared to parameter values recom- mended in the documentation of the computer models HELP (Schroeder et al., 1994) and MEPAS (Buck et al., 1995). These comparisons are presented in Figures 2-7 to 2-9. The Appendix A distributions are represented by their average value and the 5 and 95 percentiles. The HELP values are based on the results of Rawls et al. (1982). The MEPAS values are based on a variety of sources.

For the most part, the values from MEPAS and HELP fall within the distribution percentiles shown, with several exceptions. The available water capacity distributions for the coarse textured soils (bottom of Figure 2-7) are lower than the MEPAS and HELP values. In addition, the distributions for $b$ (middle of Figure 2-8) are significantly smaller than the MEPAS-recommended values for many of the coarser soil textures. (The MEPAS values were taken from Clapp and Hornberger, 1978.)

Figure 2-9 illustrates a considerable discrepancy between the average Brooks-Corey parameter values obtained by Rawls et al. (1982) and the distributions based on the results of Carsel and Parrish (1988). The differences could be attributed to the use of different soil databases, the use of different regression equations, and the process used by Rawls et al. (1982) to fit the Brooks-Corey water retention function.

Figure 2-10 compares the average results from the recommended distributions for porosity, field capacity, and wilting point to the default values from the HELP model. The primary difference in terms of water use is in the available water capacity for the coarse textured soils (sand, loamy sand, and sandy loam). The HELP parameter values result in a significantly greater available water capacity than the average recommended values. This is due primarily to differences in the average Brooks-Corey parameters (see Figure 2-8) and differences in the method of calculating field capacity. 

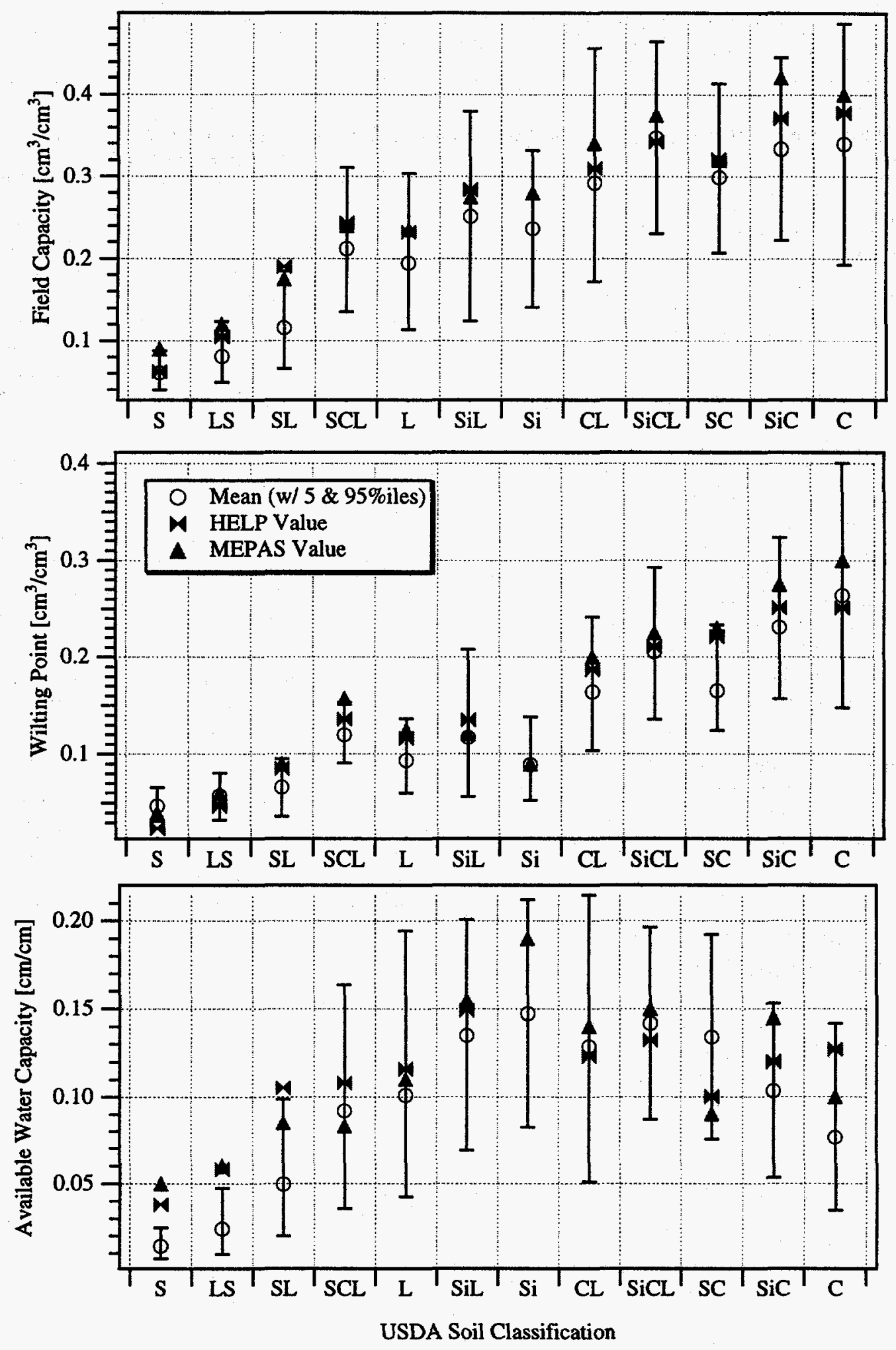

Figure 2-7. Comparison of recommended soil hydraulic parameter distributions with values from the MEPAS and HELP documentation: $f_{c}$, $w_{p}$, and awc 

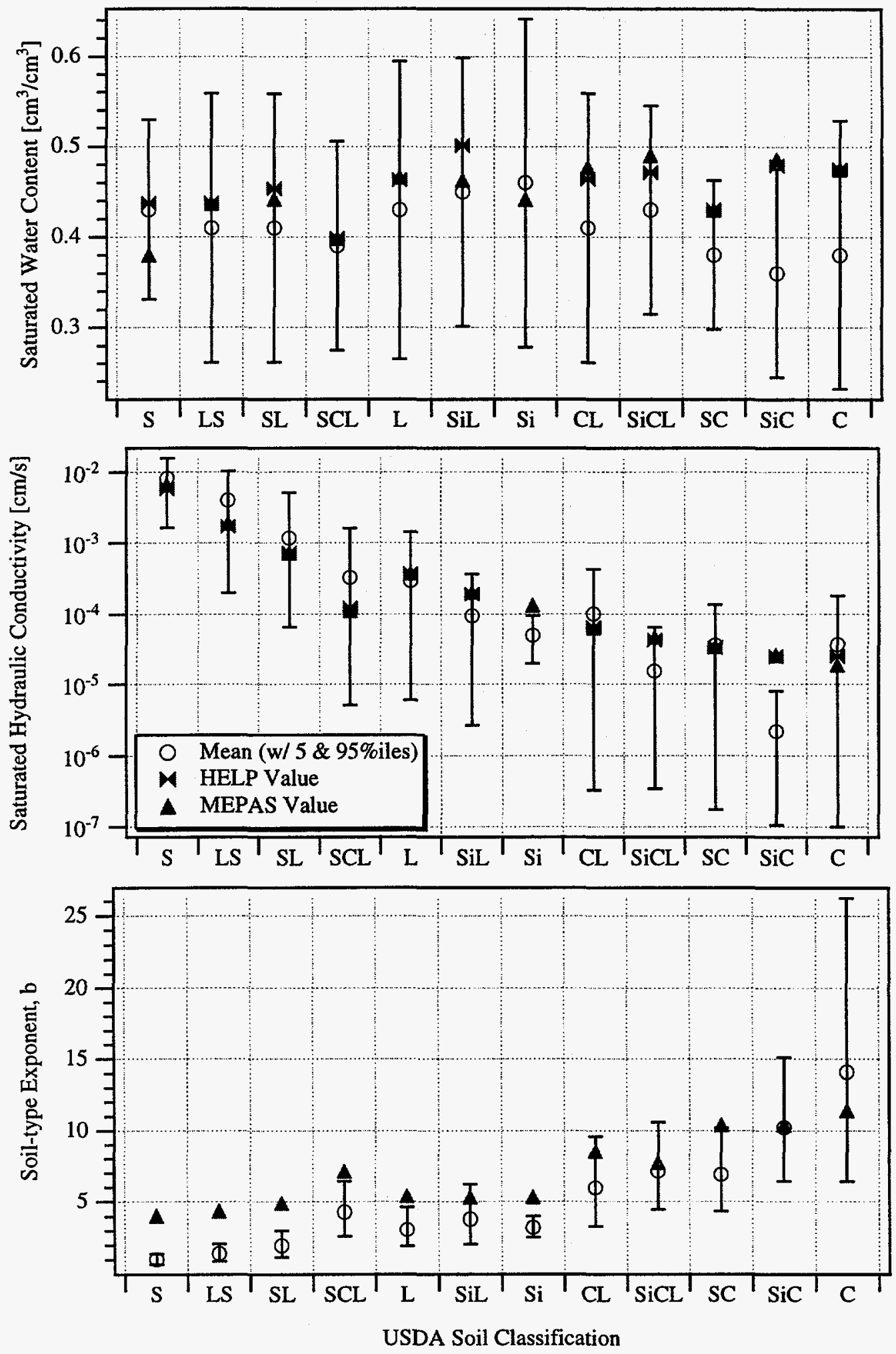

Figure 2-8. Comparison of recommended soil hydraulic parameter distributions with values from the MEPAS and HELP documentation: $\theta_{s}, K_{s}$, and b 

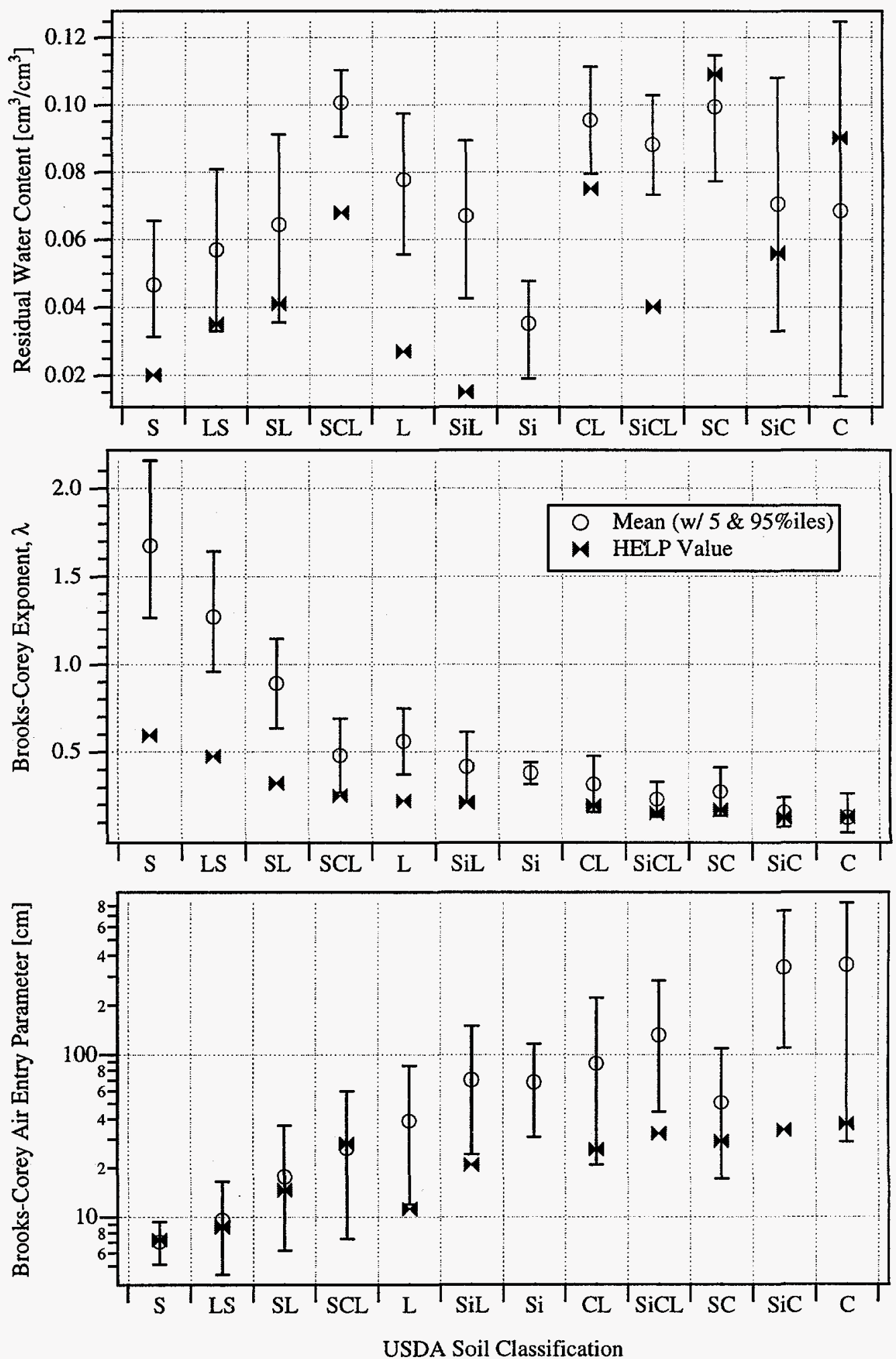

Figure 2-9. Comparison of recommended soil hydraulic parameter distributions with values from Rawls et al. (1982) used in HELP to calculate field capacity and wilting point: $\theta_{r} \lambda$, and $h_{b}$ 


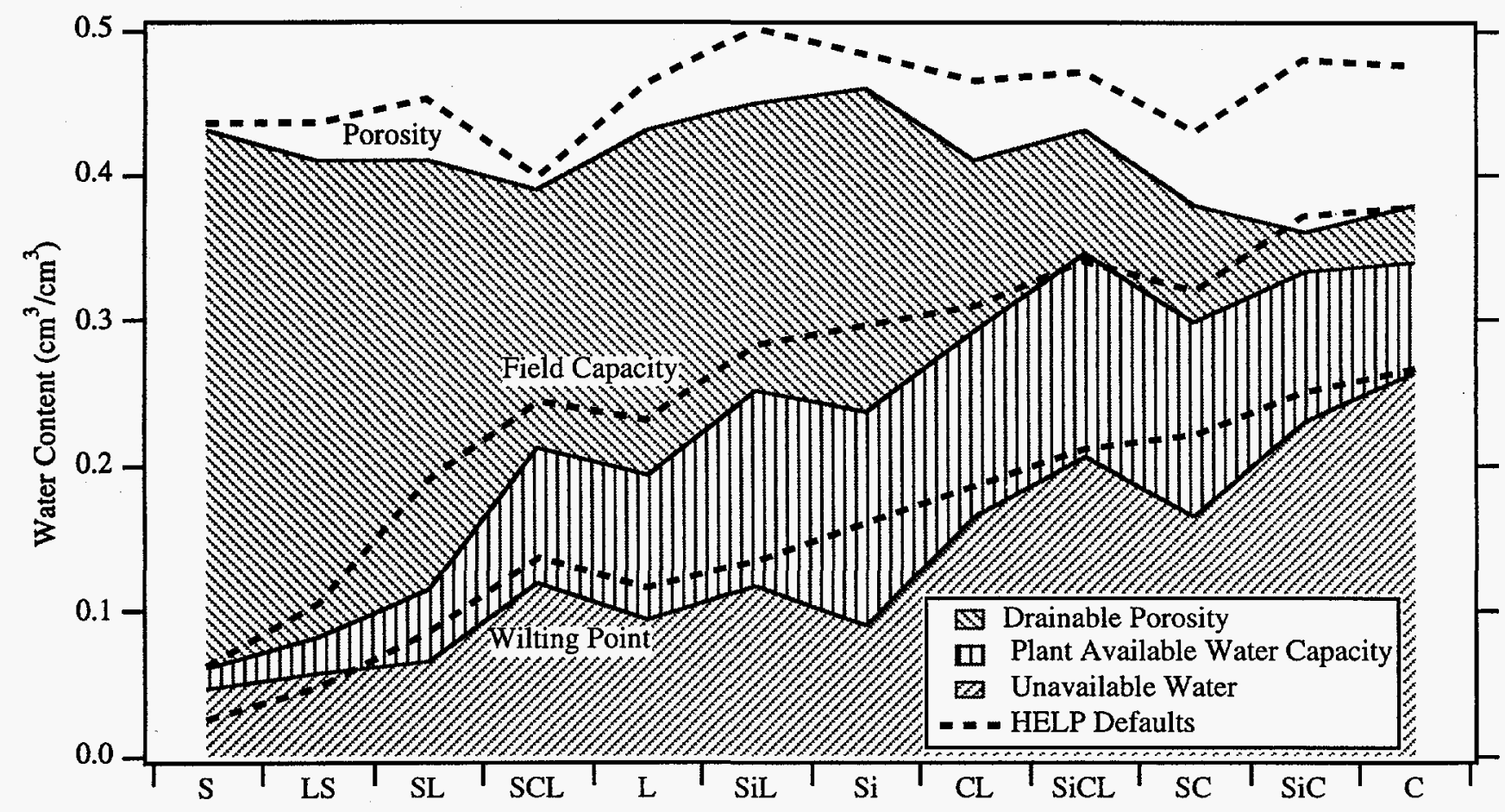

Figure 2-10. Drainable porosity, available water capacity, and unavailable water calculated using the average parameter values from the recommended distributions for porosity, field capacity, and wilting point. Default HELP values are shown for comparison. 


\section{Estimating Net Infiltration Uncertainty}

A variety of methods exist for estimating net infiltration. Water budget analysis, lysimetry, tracers, and simulation are some of the more common methods used. At SDMP sites, however, lysimetry is not likely to be practical because of the cost and time required. Environmental tracer analysis, using chloride or chlorine-36 for example, may not be applicable at sites that have been disturbed in the recent past or that will be disturbed during closure. Simulation typically requires extensive site characterization and, for numerical simulation, considerable computational effort.

A water budget analysis is the most appropriate method to estimate net infiltration and its uncertainty at SDMP sites, primarily as a consequence of the limited data at these sites. A water budget analysis is carried out by estimating precipitation (including snow), runoff, evapotranspiration, and change in soil moisture storage and then calculating net infiltration as

$$
I=P \cdot R O \cdot E T-\Delta S
$$

where

$$
\begin{array}{ll}
I & =\text { net infiltration } \\
P & =\text { precipitation } \\
R O & =\text { runoff } \\
E T & =\text { evapotranspiration } \\
\Delta S & =\text { change in soil moisture storage }
\end{array}
$$

The accuracy of a water budget analysis depends on the accuracy of the component estimates. Likewise, the uncertainty in the net infiltration estimate is a function of the uncertainty in each of the components. With careful determination of the individual water balance components, the error in the net infiltration estimate can be $20 \%$ or less at humid sites. Because the difference between precipitation and evapotranspiration is much smaller in arid climates, the relative error in net infiltration estimates may be significantly larger at arid sites. When the estimates of the water budget components rely on generic information instead of site specific data, the errors are potentially greater still.

This chapter describes the particular water budget analysis used in this report. In addition, sources of information for estimating the water budget components and their uncertainties at SDMP sites are discussed.

\subsection{MEPAS Water Budget Analysis}

The water budget analysis used here is part of the MEPAS code (Buck et al., 1995; Whelan et al., 1987). MEPAS was chosen because it is applicable to the estimation of dose from radioactive contaminants at SDMP sites and because it includes most of the important environmental transport processes while remaining computationally tractable. Note that although MEPAS v. 3.1 was used, it was modified to include each realization of the calculated net infiltration in its Monte Carlo output. Displaying an empirical cdf (such as shown in Section 3.4) and approximating the net infiltration uncertainty with a closed-form probability distribution (which is done in Chapter 4) require this output. If MEPAS is used for the transport analysis, however, this output is not necessarily required.

MEPAS calculates a steady-state net infiltration rate using average monthly estimates of the water budget components. Net infiltration for each month is calculated as:

$$
\begin{array}{ll}
I_{i}=P_{i}+S M_{i}-R O_{i}-\Delta S_{i}-E T_{i} & T_{i}>0{ }^{\circ} \mathrm{C} \\
I_{i}=0 & T_{i} \leq 0^{\circ} \mathrm{C}
\end{array}
$$

where

$$
\begin{array}{ll}
S M & =\text { snowmelt } \\
T & =\text { temperature }
\end{array}
$$

and the subscript $i$ indicates that average monthly values are used in the water budget $(1 \leq i \leq 12)$.

The water budget components are calculated as follows. MEPAS accumulates precipitation as snowfall stored on the ground for those months with $T_{i} \leq 0^{\circ} \mathrm{C}$. The stored snow is allowed to melt and infiltrate or run off beginning with the first month in which $T_{i}>0{ }^{\circ} \mathrm{C}$. Runoff is calculated using the U.S. Soil Conservation Service (SCS) method (U.S. Soil Conservation Service, 1985; see Whelan et al., 1987 for the MEPAS implementation). Monthly potential evapotranspiration $\left(P E T_{i}\right)$ is calculated as the minimum of three methods: modified Blaney-Criddle, Penman, and modified Penman with correction factor (see Whelan et al., 1987 for the MEPAS implementation). $P E T_{i}$ and the soil moisture retention tables of Thornthwaite and Mather (1957) are used to calculate the change in soil moisture storage. Actual evapotranspiration is calculated as

$$
E T_{i}=\min \left\{P E T_{i}, P_{i}+S M_{i}-R O_{i}-\Delta S_{i}\right\}
$$

The monthly average net infiltration is then calculated using Equations 3 and 4.

The steady-state net infiltration is calculated as the average yearly value

$$
I=\sum_{i=1}^{12} I_{i}
$$

This is the water flux (e.g., $\mathrm{cm} / \mathrm{yr}$ ) used by MEPAS in its source term and unsaturated zone transport calculations.

In reality, recharge generally occurs over short periods of time in response to short-term events such as heavy rainfall and spring snowmelt. For many sites, ignoring the temporal variability of recharge is not likely to lead to nonconservative dose predictions. However, for sites where preferential flow processes are important, or sites with a thin unsaturated zone and significant seasonal fluctuations in the water table, 
ignoring temporal variability in recharge may result in a nonconservative analysis.

\subsection{Water Budget Component Estimation}

At many SDMP sites there will be very limited site-specific data with which to estimate the water budget components. This section discusses the parameters required in the MEPAS water budget calculation, and regional or generic information that can be used to estimate these parameters and their uncertainty.

\subsubsection{MEPAS Parameters}

MEPAS requires the input of a limited set of parameters in order to estimate the water budget components. Each parameter may be either a constant (no uncertainty) or a random variable. Random variables are entered as a distribution type with the associated characteristics (e.g., mean and variance). For each month of the year, the average value of each of the following parameters is required by MEPAS.

- Precipitation (in.)

- Temperature $\left({ }^{\circ} \mathrm{F}\right)$

- Wind speed (mph)

- Maximum and minimum relative humidity (\%)

- Cloud cover (tenths)

- SCS curve number

- Number of days with at least $0.25 \mathrm{~mm}(0.01 \mathrm{in}$.) of precipitation

Temperature, wind speed, relative humidity, and cloud cover are used to estimate snowmelt and potential evapotranspiration. Runoff is estimated using the SCS curve number and the number of days with precipitation. In addition, calculation of the change in soil moisture storage requires

- Top-soil water capacity (in.) = available water capacity (in./in.) $\times$ root zone depth (in.) $x$ fraction vegetative cover

The SCS curve number can be estimated using the information in Appendix D, taken from Soil Conservation Survey reports. Uncertainty in the SCS curve number can be addressed by modeling it as a random variable if there is information to support a probability distribution. If a distribution cannot be supported, uncertainty in the SCS curve number can be addressed by systematically varying its value within its likely range.

Top-soil water capacity should be estimated using the recommended distributions for available water capacity derived in Chapter 2 (and listed in Appendix A). Estimates for the plant-related parameters can be obtained using the information in Appendix $E$. Uncertainty in the root zone depth and fraction vegetative cover can be addressed by systematically varying the value of their product. Note that as long as this product is a constant, the distribution of the top-soil water capacity will have the same form as the distribution of the available water capacity. In addition, the mean and standard deviation of the top-soil water capacity will be equal to the mean and standard deviation of the available water capacity multiplied by the product of the root zone depth and the vegetative cover fraction.

The remaining parameters are all related to meteorological conditions and are discussed in the following section.

\subsubsection{Meteorological Data}

It is unlikely that long-term meteorological records will be available at any SDMP sites. The National Climatic Data Center (NCDC), however, has databases of long-term meteorological data from a large number of monitoring stations across the U.S. These data are likely to be the best source of meteorological data for use in SDMP water budget analyses. These meteorological data can be used in MEPAS to estimate precipitation, snowmelt, and potential evapotranspiration.

Daily summary data can be obtained from the NCDC First Order Summary of the Day (FSOD) database. The station with the required data that is closest to the SDMP site under study should be used. In many cases, it may be appropriate to use data from more than one station. For example, the station closest to the SDMP site may have a record of precipitation and temperature only. Data from a more distant station could be used to estimate potential evapotranspiration. Data can be downloaded electronically from the NCDC via anonymous ftp (see Section 3.3.2 for details). Record lengths for meteorological parameters typically vary from 10 to 40 years or more. Precipitation and temperature records are the longest.

For this study, each month of FSOD data was averaged to provide $N$ years of monthly data. The sample mean $(\bar{x})$ and variance $\left(s^{2}\right)$ for each of the twelve months of the year were calculated (for each meteorological parameter) as:

$$
\bar{x}=\frac{1}{N} \sum_{j=1}^{N} x_{j} \text { and } s^{2}=\frac{1}{N-1} \sum_{j=1}^{N}\left(x_{j}-\bar{x}\right)^{2}
$$

where

$$
\begin{array}{ll}
x_{j} & =\text { average data value for a given month in year } j \\
N & =\text { total number of years of data }
\end{array}
$$

The sample mean provides an estimate of the average meteorological parameter value for each month. This value can be used in MEPAS for those parameters that are deterministically modeled. For parameters included in an uncertainty analysis, however, a probability distribution describing their 
likely variability is required. A distribution can be arrived at by recognizing that the sample mean is itself a random variable that depends on the particular set of samples used in its estimation. If the samples are random and if the sample size is large enough so that the central limit theorem applies, then it can be assumed that the sample mean is normally distributed (Ang and Tang, 1975) with a mean value of $\mu$ and a standard deviation of $\sigma / \sqrt{N}$, where $\mu$ and $\sigma$ are the true mean and standard deviation of the sampled parameter. If the number of samples is relatively large $(>20)$ then the sample mean and standard deviation, $\bar{x}$ and $s$, are relatively good approximations of $\mu$ and $\sigma$ (Ang and Tang, 1975). Thus, for each month, the uncertain meteorological parameters were assumed to be normally distributed with a mean of $\bar{x}$ and a standard deviation of $s / \sqrt{N}$. (Note, $s / \sqrt{N}$ is often referred to as the standard error.)

At most SDMP sites it is likely that precipitation will have the highest degree of variability among the meteorological parameters, as measured by the coefficient of variation $(C V)$,

$$
C V=\frac{s}{\bar{x}}
$$

In addition, precipitation has the most direct influence on net infiltration. For these reasons, precipitation is likely to contribute the most to uncertainty in net infiltration and should be modeled as a random variable.

The remaining meteorological parameters are likely to have much smaller coefficients of variation. Temperature, however, may have an important impact on net infiltration uncertainty, because of the dependence of snowmelt on temperature. MEPAS accumulates precipitation as snowfall for those months with an average temperature less than $0^{\circ} \mathrm{C}$ and then melts that snow beginning in the first month with a temperature above $0^{\circ} \mathrm{C}$. Precipitation that accumulates as snow is thus likely to contribute to net infiltration during the first month with a temperature above freezing. Since evapotranspiration in the spring is at a relatively low level, the amount of snowmelt can contribute significantly to the annual net infiltration. It may thus be important to model temperature as an uncertain parameter.

If the other meteorological parameters happen to have a large coefficient of variation or are believed to be important in some other way, they can also be modeled as uncertain parameters. However, cross-correlation between parameters may be important and should be included if significant. In addition, serial correlation from month to month and from year to year (for a given month) should be checked. If significant correlations exist, the assumption of normality in the parameter distributions may be invalid.

\subsection{Estimating Probability Distributions from NCDC Data}

There are three steps involved in estimating probability distributions for the (monthly) meteorological parameters listed in Section 3.2.

(1) Identify the appropriate station(s) from which to obtain data.

(2) Download the data using anonymous ftp.

(3) Run a computer code (available from the first author) to average data on a monthly basis and calculate statistics.

The statistics from the monthly data are the basis of the probability distributions, as described in Section 3.2.2.

\subsubsection{Identify the NCDC Station(s)}

The first step in obtaining NCDC data is to identify the appropriate station. Available stations have been grouped by state in the files accompanying the computer code discussed in Section 3.3.3. Each state file lists the stations in alphabetical order by name. For each station, a unique station id number is listed as well as the length of the station record and the parameters (meteorological data elements) measured at the station. (This information is available from the NCDC.) Note that the parameters are listed by a code letter and that the length of the record may vary by parameter. The NCDC parameters required to estimate the net infiltration using the method described in Sections 3.1 and 3.2 are

A - TMAX, Daily maximum temperature

B - TMIN, Daily minimum temperature

C - PRCP, Daily precipitation

F - $M X R H$, Maximum relative humidity

$\mathrm{G}-M N R H$, Minimum relative humidity

$\mathrm{J}$ - PSUN, Daily percent of possible sunshine.

$\mathrm{P}$ - AWND, Average daily wind speed

Daily average temperature (TAVE) is calculated as

$$
T A V E=(T M A X+T M I N) / 2
$$

Cloud cover ( $C L C V)$ is calculated from the daily percent of possible sunshine using a relationship from MEPAS,

$$
C L C V=0.1\left[\sqrt{\frac{100.762-P S U N}{0.0084}}-9.52\right]
$$

where PSUN has units of percent and $C L C V$ has units of tenths.

\subsubsection{Download Data File(s)}

NCDC FSOD data are available on-line via anonymous ftp. The complete data record for each station is contained in an 
ascii file identified by the unique station id number. After obtaining the station id number (see Section 3.3.1), ftp to

ftp ftp.ncdc.noaa.gov
login: anonymous
password: your e-mail address
cd /pub/data/fsod
get fsod_ascii.stid\#

where stid\# is the appropriate five-digit station id number. Additional data files can be downloaded by executing multiple 'get' commands. (Note, these data files may be $1.7 \mathrm{Mb}$ or larger.)

\subsubsection{Calculate Monthly Averages and Statistics}

A Fortran computer code was written to read the daily data from the NCDC FSOD data files and compute average parameter values for each month of the data record. This code (fsodread.f with executable, fsod.exe) is available from the first author. When run, the code will prompt for the name of the NCDC FSOD data file and then read through the entire file. For those parameters required to calculate net infiltration, the daily data values are averaged over each month (precipitation and the number of days with precipitation are monthly totals). Statistics for the monthly values of each parameter are calculated and printed to file 'stats.out'. These statistics (e.g., mean and standard error) can be entered into a code such as MEPAS to describe the error in the meteorological parameters.

The actual monthly data values for each parameter are printed to a set of files with the filenames given by the fourcharacter NCDC data element types (see Section 3.3.1). For example, precipitation can be found in the file 'prcp'. Average temperature, cloud cover, and the number of days with precipitation can be found in the files 'tave', 'clcv', and 'prdy', respectively. These files can be read into a statistical analysis package to examine correlations in the data. Each row represents monthly data for a year. The twelve columns contain data for January through December. Missing data are given in these files by -999 .

\subsection{Verification Using Coshocton Lysimeter Data}

The net infiltration calculation described above was verified by comparing model simulation results with long-term field water balance data collected from a lysimeter located near Coshocton, Ohio. A lysimeter facility at this site is part of the Midwest Area, North Appalachian Experimental Watershed, operated by the Agricultural Research Service of the U.S. Department of Agriculture (USDA-ARS). Brief descriptions of the lysimeter facility and water balance data from one of the lysimeters are given below.

\subsubsection{Description of Lysimeter Facility and Lysimeter Y101D}

A number of monolith lysimeters were constructed in southeastern Ohio near Coshocton during the period from 193740 to study the water balance of agricultural crop land (Harrold and Dreibelbis, 1958). The lysimeters were constructed in situ around undisturbed $6.22 \mathrm{ft}$-wide, by $14-\mathrm{ft}-$ long, by 8 ft-deep soil monoliths. Several lysimeters at Coshocton were equipped with self-recording weighing mechanisms, and represent the first lysimeters of this type in the history of lysimeter investigations (Harrold and Dreibelbis, 1958). These lysimeters are still in operation. To the best of our knowledge, the data sets from these lysimeters represent the longest continuous records of complete daily water balance data available anywhere.

Data from lysimeter Y101D were used for model verification. The upper 8 inches of the soil monolith in this lysimeter is classified as silt loam. This silt loam grades into loam with sandstone fragments at deeper depths, and eventually into decomposed sandstone at the base of the monolith. The surface of the lysimeter has a $23 \%$ slope and has been vegetated primarily with natural grasses and legumes (brome grass and alfalfa) (Harrold and Dreibelbis, 1958).

\subsubsection{Water Balance and Meteorological Data}

A 50-year record of daily water balance and meteorological data were obtained from the USDA-ARS at Coshocton for lysimeter Y101D, for the years 1945-94. These daily data were analyzed to determine monthly averages and parameter distributions for input to the water balance model. The monthly water balance components for the lysimeter are depicted in Figure 3-1. The error bars shown in Figure 3-1 represent the 5th and 95th percentiles of the distributions for each month. Note that the majority of the drainage occurs during the winter and spring. On average, soil water storage decreases when evapotranspiration is high (April - September) and increases when evapotranspiration is low (October - March).

\subsubsection{Simulation Results}

Monte Carlo simulation of the water balance (using MEPAS) was carried out for lysimeter Y 101D at Coshocton. Five hundred realizations were generated, with the available water capacity, monthly average precipitation, and temperature all treated as random variables. Based on the description of the lysimeter, a silt loam soil type was specified for the model simulations. The available water capacity was modeled as a normally distributed random variable 

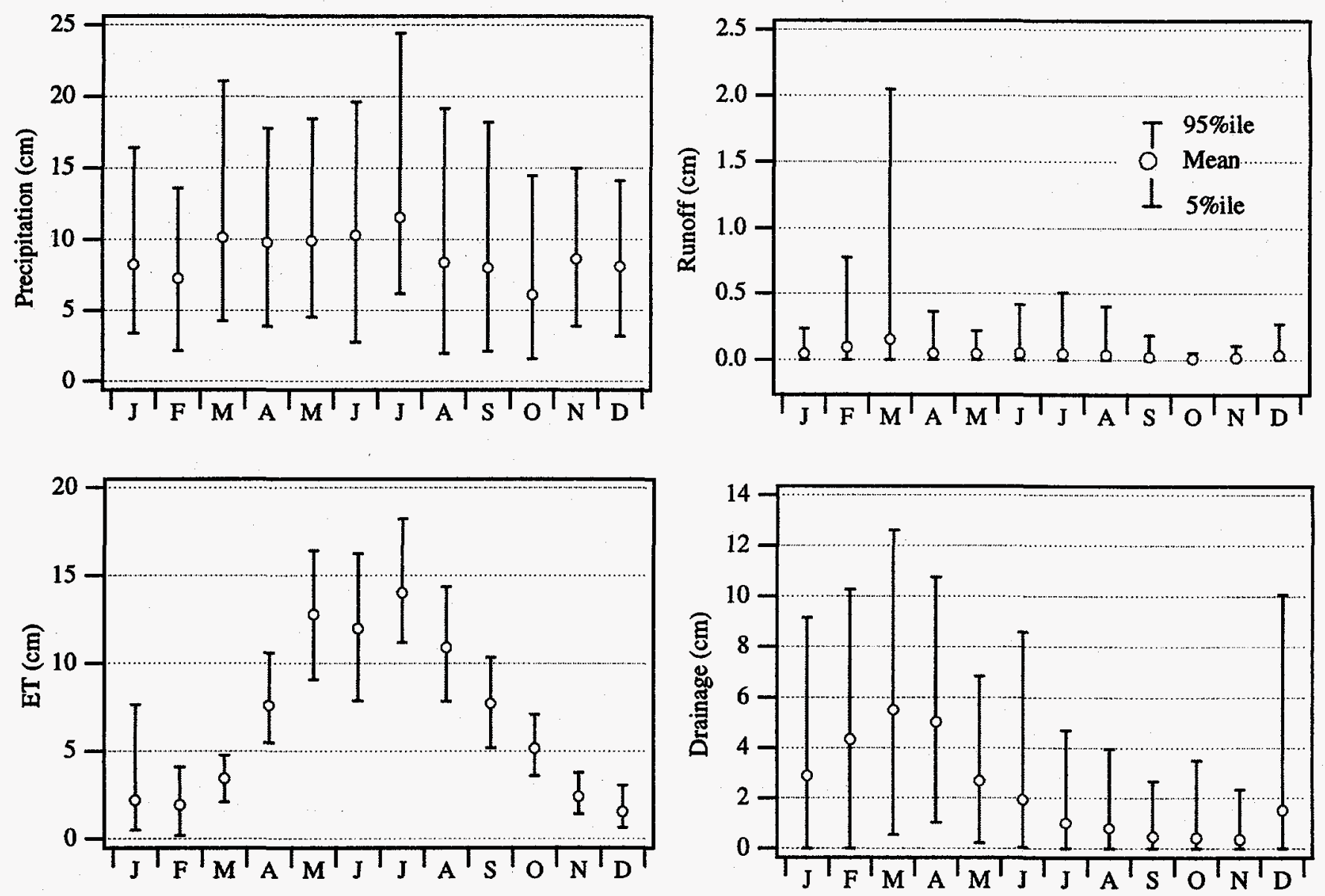

Figure 3-1. Observed monthly water balance for Coshocton lysimeter Y101D: data from 1945 to 1994

with a mean of $0.135 \mathrm{~cm} / \mathrm{cm}$ and a standard deviation of $0.04 \mathrm{~cm} / \mathrm{cm}$, using the recommended distribution from Appendix A, Table A-6. An SCS curve number of 30 was assumed in all cases, to represent a well drained soil.

Three sets of Monte Carlo simulations were conducted, each with 500 realizations. In the initial Monte Carlo simulation, a rooting depth of $100 \mathrm{~cm}$ was assumed, with a vegetative cover fraction of 1,0. This resulted in a predicted mean net infiltration rate of $23.3 \mathrm{~cm} / \mathrm{yr}$, with a minimum value of $16.7 \mathrm{~cm} / \mathrm{yr}$ and a maximum of $30.9 \mathrm{~cm} / \mathrm{yr}$. Empirical cdf's of the simulation results are shown in Figure 3-2. The simulation results compare well with the measured long-term average drainage rate from the lysimeter of 26.9 $\mathrm{cm} / \mathrm{yr}$, which falls between the 90 th and 95 th percentiles of the predicted distribution. The standard error of the measured drainage is approximately $2.0 \mathrm{~cm} / \mathrm{yr}$ for the 50 -year record.

The results in the initial simulation were obtained without model calibration. Site-specific meteorological data were used, but the remainder of the model input parameters were chosen based solely on a physical description of the lysimeter. Two additional Monte Carlo simulations were performed to examine the sensitivity of the results to the assumed root zone depth and vegetative cover fraction, and to provide reasonable bounds on the net infiltration distribution.

A simulation was conducted that maximized evapotranspiration using a root zone depth of $2.0 \mathrm{~m}$ (considering the presence of alfalfa on the lysimeter) and a fraction vegetative cover of 1.0. The resulting net infiltration distribution ranged from 14 to $27 \mathrm{~cm} / \mathrm{yr}$, with a median value of approximately $19.5 \mathrm{~cm} / \mathrm{yr}$. A simulation that minimized evapotranspiration was also conducted, using a root zone depth of $0.5 \mathrm{~m}$, and a fraction vegetative cover of 0.25 . This simulation resulted in a net infiltration distribution that ranged from 27 to $36 \mathrm{~cm} / \mathrm{yr}$, with a median value of approximately $31 \mathrm{~cm} / \mathrm{yr}$. The cdf's for these additional simulations are also shown in Figure 3-2.

As noted in Section 3.2.1, root zone depth and fraction vegetative cover enter the net infiltration calculation as a prod- 


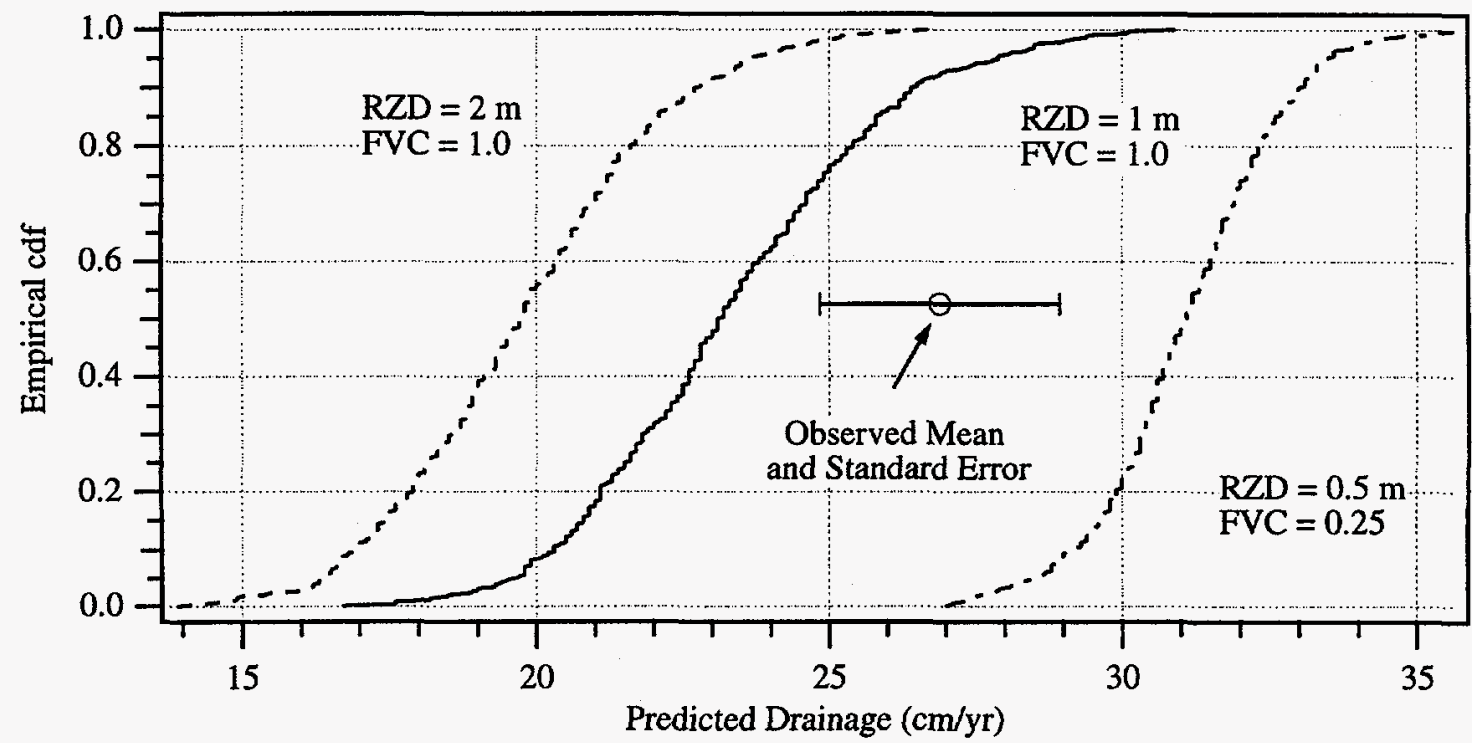

Figure 3-2. Empirical cdf's of predicted drainage compared to the observed average and standard error for Coshocton lysimeter Y101D. $R Z$ D = root zone depth, FVC = fraction vegetative cover

uct. Since the available water capacity distribution is the same for all three cases displayed in Figure 3-2, the bounding cases represent an increase by a factor of two $(\mathrm{RZD} * \mathrm{FVC}=2.0)$ and a decrease by a factor of eight (RZD*FVC $=0.125$ ) over the basecase top-soil water capacity.

The distributions shown in Figure 3-2 represent estimates of the uncertainty in the long-term average drainage from the lysimeter using limited information about the soil hydraulic properties and plant water use. It should be noted, however, that the uncertainty in the long-term average drainage is significantly smaller than the year-to-year variability in the drainage. Figure 3-3 is a plot of the yearly drainage in lysimeter Y101D. The drainage is highly variable and ranges from zero to more than $60 \mathrm{~cm} /$ year. This is in contrast to the cdfs of Figure 3-2, which have a maximum range of about $14 \mathrm{~cm}$.

These data and model comparisons indicate that the MEPAS water balance model is capable of predicting average annual net infiltration rates that are similar to those observed from a lysimeter located in a humid environment. Using typical root zone or vegetative cover parameters, the average annual drainage is predicted within $20 \%$ of the measured value. It may be of interest to note that the MEPAS water balance model uses a book-keeping method of Thornthwaite and Mather (1957) for computing soil water depletion patterns. Thornthwaite and Mather (1957) used water balance

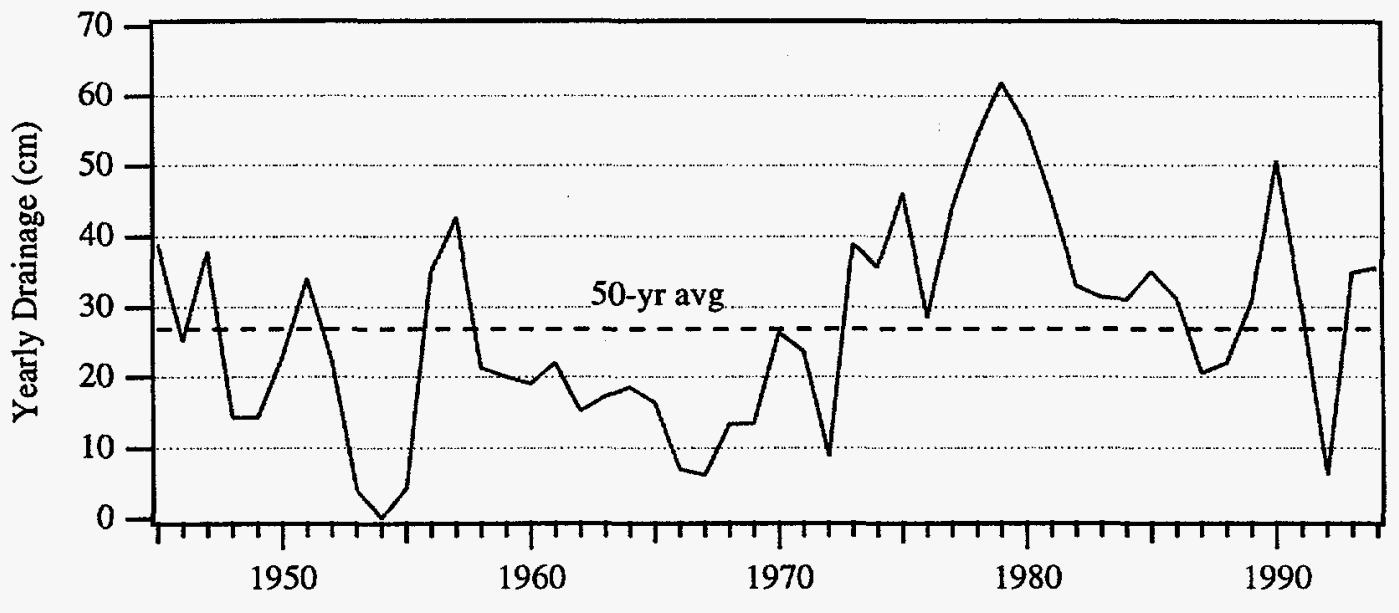

Figure 3-3. Observed yearly drainage in Coshocton lysimeter Y101D. 


\section{Estimating Net Infiltration Uncertainty}

data from humid sites including some early data from the Coshocton lysimeters in developing their method.

The ability of the MEPAS code to match the long-term record from Coshocton provides some confidence that time dependence of preferential flow is not a serious concern for the grass covered Coshocton site. However, Figure 3-3 illustrates the large variability in drainage that is ignored when using a long-term average value. This variability may play an important role in contaminant transport. 



\section{Incorporating Soil Hydraulic Parameter Data}

The distributions described in Chapter 2 and listed in Appendix A are useful for modeling the uncertainty in soil hydraulic parameters when information about the soils at a site is limited to the USDA soil textural classification. These distributions can be used with a code such as RESRAD or MEPAS to provide an estimate of the prior (unconditional) dose distribution. This estimate is called 'prior' because it is made prior to obtaining site-specific soil hydraulic property data (it is not conditioned on data). When soil hydraulic property data become available, we would like to update the distributions of Appendix A with the site-specific data. The updated soil hydraulic parameter distributions would then be used to obtain an updated (conditional) dose distribution (i.e., a dose estimate conditioned on the data).

A flowchart illustrating this process is shown in Figure 4-1. As shown, when site-specific data are not available, the prior dose distributions are used. If data are available, they are combined with the distributions from Appendix $A$ in the updating procedure. In this case, updated dose distributions are used in the evaluation of a site. Section 4.1 describes the Bayesian estimation method used in the updating procedure. Section 4.2 describes a computer code that implements this procedure and Section 4.3 provides an example that illustrates its application at a hypothetical SDMP site.

\subsection{Bayesian Estimation Method}

Consider a random variable, $\mathrm{X}$, that represents a spatially variable soil property at a particular site. The probability distribution of $\mathrm{X}$ is characterized by one or more parameters, $p$ (e.g., $p=\mu$, the mean value when $\mathrm{X}$ follows a normal distribution). In the Bayesian approach, the parameter, $p$, is treated as a random variable. The following three steps define the Bayesian approach to parameter estimation.

(1) Specify the prior distribution of $p$, denoted $f^{\prime}(p)$. The prior distribution may be based on informed judgement, data from another site, or previous measurements of $X$.
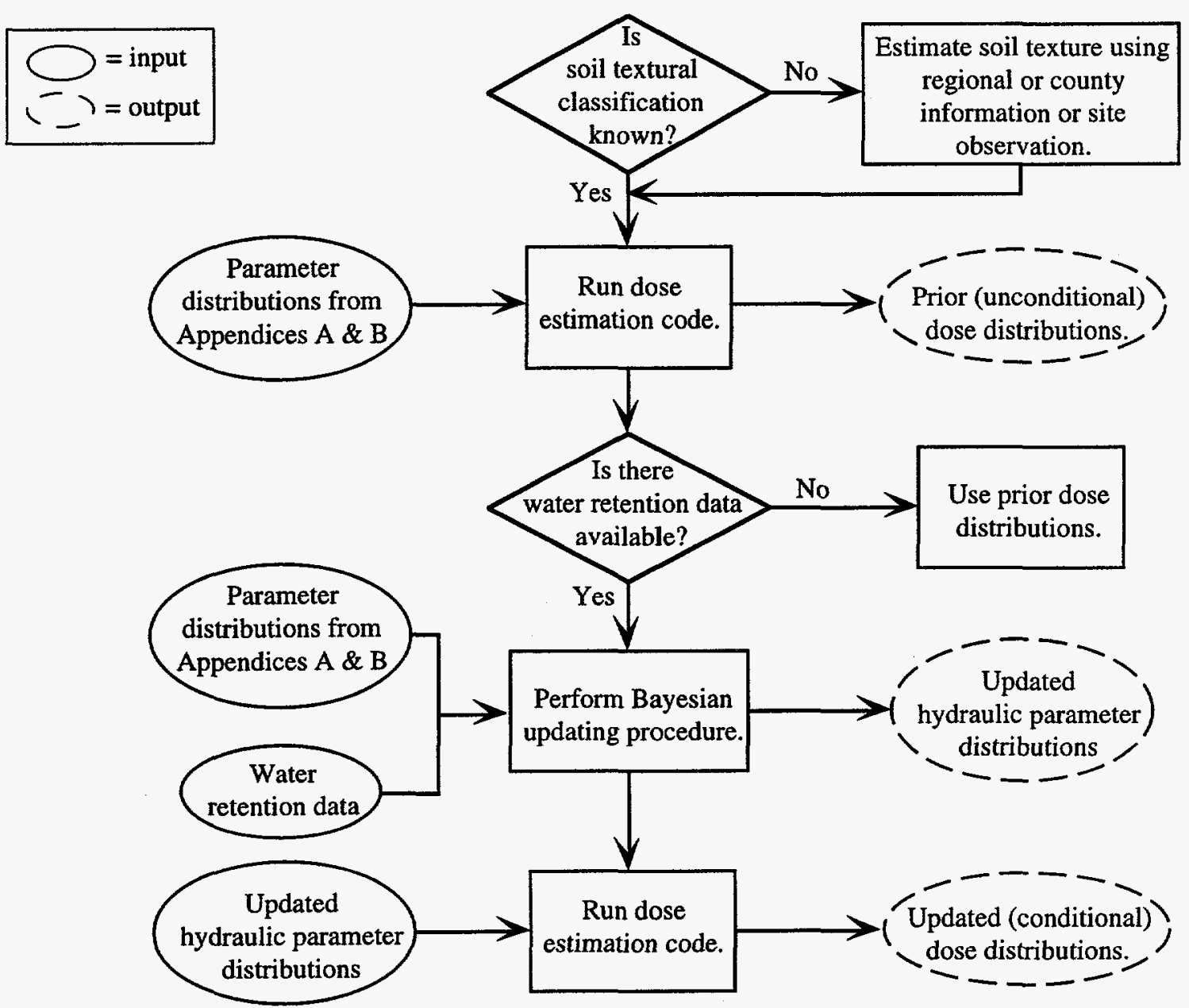

Figure 4-1. Flowchart illustrating application of the Bayesian updating procedure; solid ellipses are inputs, dashed ellipses are outputs 
(2) Obtain $N$ site-specific observations of $\mathrm{X}$, denoted $\underline{x}=\left\{x_{1}, x_{2}, \ldots, x_{N}\right\}$.

(3) Apply Bayes' theorem to obtain the updated (sometimes called posterior) distribution of $p$, denoted $f^{\prime \prime}(p)$. Bayes theorem can be written as

$$
f^{\prime \prime}(p)=k L(p) f^{\prime}(p)
$$

where $L(p)$ (the likelihood function) specifies the probability of observing $x$ given a particular value of $p$, and $k$ is a normalizing constant,

$$
k=\left[\int_{-\infty}^{\infty} L(p) f^{\prime}(p) d p\right]^{-1} .
$$

Bayes theorem (Equation 11) combines observational data (via the likelihood function) with prior information and judgement (via the prior distribution).

For arbitrary distributions of $\mathrm{X}$ and the prior of $p$, the updated distribution is difficult to calculate. When the distributions of $\mathrm{X}$ and $p$ are so-called conjugate distributions, however, the prior and updated distribution have the same form; it is only the value of the parameter(s) of the updated distribution that change. This fact is used below.

The particular Bayesian estimation method used to update soil hydraulic parameters is described in the remainder of this section. Assumptions about the distributional forms of $\mathrm{X}$ and the prior are given. The choice of parameter values for the prior distribution is discussed and the resulting updated parameter values are presented.

\subsubsection{Assumptions}

The Bayesian estimation method presented here requires several assumptions.

Assumption 1. At the scale of measurement, the soil hydraulic parameters $\theta_{s}, \theta_{r}, K_{s}, \alpha$, and $n$ are normally distributed (spatially) at a given site when transformed as given in Carsel and Parrish (1988). That is, given the limited information available at a site, it is reasonable to assume that the soil hydraulic parameters follow the distributions determined by Carsel and Parrish (1988).

For example, if $\mathrm{K}_{\mathrm{s}}$ is measured for a silt loam soil at a site, then $X=\ln \left(K_{s}\right)$ is assumed to be distributed spatially with the following density function.

$$
f(x)=\frac{1}{\sqrt{2 \pi} \sigma} \exp \left[-\frac{1}{2}\left(\frac{x-\mu}{\sigma}\right)^{2}\right]
$$

Assumption 2. Soil properties are modeled (e.g., in RESRAD and MEPAS) as spatially homogeneous. At a given site, an estimate of the average value of each soil hydraulic parameter is therefore required. The average (transformed) value is given by $\mu$ in Equation 12 .
Adopting the Bayesian perspective, the unknown parameters of Equation 12, $\mu$ and $\sigma$, are treated as random (i.e., uncertain) variables.

Assumption 3. The joint distribution of $\mu$ and $\sigma$ is assumed to be the normal-gamma distribution, with a density function given by (Ang and Tang, 1975)

$$
\begin{aligned}
& f(\mu, \sigma)=\left\{\frac{\sqrt{N^{\prime}}}{\sqrt{2 \pi} \sigma} \exp \left[-\frac{1}{2}\left(\frac{\mu-\bar{x}^{\prime}}{\sigma / \sqrt{N^{\prime}}}\right)^{2}\right]\right\} \\
& \cdot\left\{\frac{\left[\left(N^{\prime}-1\right) / 2\right]^{(N+1) / 2}}{\Gamma\left[\left(N^{\prime}+1\right) / 2\right]}\left(\frac{s^{\prime 2}}{\sigma^{2}}\right)^{(N-1) / 2} \exp \left(-\frac{N^{\prime}-1}{2} \frac{s^{\prime 2}}{\sigma^{2}}\right)\right\}
\end{aligned}
$$

where $\bar{x}^{\prime}, \vec{s}^{\prime}$, and $N^{\prime}$ are parameters of the distribution and $\Gamma$ is the gamma function. This assumption is made for analytical convenience. Given limited site-specific data, however, there is no compelling reason to choose another distributional form. Using the normal-gamma distribution, site-specific data may increase or decrease either the mean or the variance of $\mu$.

Since the normal-gamma distribution is the conjugate pair of the normal distribution (the distribution of the underlying random variable, $X$ ), incorporating new measurements of $X$ will not alter the form of Equation 13. The parameters of the distribution, $\vec{x}^{\prime}, \vec{s}^{\prime}$, and $N^{\prime}$, will change, however.

Given no information about the soil properties at a site other than the USDA soil textural classification(s), the following two assumptions are used to determine the prior parameters of Equation 13.

Assumption 4 . The mean and variance of $\mu$ are given by the results of Carsel and Parrish (1988). That is,

$$
\begin{gathered}
\mathrm{E}(\mu)=\mu_{C P} \\
\operatorname{Var}(\mu)=\sigma_{C P}^{2}
\end{gathered}
$$

where $\mathrm{E}()$ and $\operatorname{Var}()$ indicate the expected value and variance, respectively. $\mu_{C P}$ and $\sigma_{C P}^{2}$ are the mean and variance from Carsel and Parrish (1988; Table 6) for a given soil hydraulic parameter and soil texture (after transformation to a normal distribution).

Assumption 5. The expected value of $\sigma$ can be expressed as a multiple of the standard deviation of $\mu$ as defined in Equation 15. That is,

$$
\mathrm{E}(\sigma) / \sigma_{C P}=\tau \quad \tau>0 .
$$

Recall that $\sigma^{2}$ is the spatial variance of a soil hydraulic parameter at a particular site (after transformation to a normal distribution). $\tau$ is a measure of the heterogeneity of the site relative to the data set of Carsel and Parrish (1988), who determined variances for each soil textural classification 
from samples taken at a large number of sites. Selecting a value of $\tau<1$ reflects a belief that the soil at the site is more homogeneous than Carsel and Parrish's data. Selecting a value of $\tau>1$ reflects a belief that the soil at the site is relatively heterogeneous. A value of $\tau>1$ might reflect a belief that the soil at a site does not uniformly fall within a single soil textural classification. (In the implementation described in Section 4.2, the maximum value of $\tau$ allowed is 3.0.)

\subsubsection{Prior Distributions}

The mean and variance of $\mu$ and $\sigma$ (from Equation 13) are given by the following expressions (Ang and Tang, 1975).

$$
\begin{gathered}
\mathrm{E}(\mu)=\bar{x}^{\prime} \\
\operatorname{Var}(\mu)=\frac{s^{\prime}}{N^{\prime}}\left(\frac{N^{\prime}-1}{N^{\prime}-3}\right) \\
\mathrm{E}(\sigma)=s^{\prime} \sqrt{\frac{N^{\prime}-1}{2}} \frac{\Gamma\left[\left(N^{\prime}-2\right) / 2\right]}{\Gamma\left[\left(N^{\prime}-1\right) / 2\right]} \\
\operatorname{Var}(\sigma)=s^{\prime 2}\left(\frac{N^{\prime}-1}{N^{\prime}-3}\right)-E^{2}(\sigma)
\end{gathered}
$$

These relationships (Equations 17-20) and the assumptions of Section 4.1.1 are used to define the parameters of the prior distribution, $\bar{x}^{\prime}, s^{\prime}$, and $N^{\prime}$. Equations 14 and 17 lead to

$$
\bar{x}^{\prime}=\mu_{C P}
$$

Equations 15 and 18 result in

$$
s^{\prime}=\sigma_{C P} \sqrt{\frac{N^{\prime}\left(N^{\prime}-3\right)}{N^{\prime}-1}}
$$

Combining Equations 16, 19, and 22 produces an expression that can be numerically evaluated for $N^{\prime}$, given a value of $\tau$.

$$
\tau=\frac{\Gamma\left[\left(N^{\prime}-2\right) / 2\right]}{\Gamma\left[\left(N^{\prime}-1\right) / 2\right]} \sqrt{\frac{N^{\prime}\left(N^{\prime}-3\right)}{2}}
$$

The relationship between $\tau$ and $N^{\prime}$ is shown in Figure 4-2 (left axis).

After obtaining $N^{\prime}$, Equation 22 is evaluated to obtain $s^{\prime}$. With the prior parameters defined, site-specific data can then be used to obtain updated parameters and the updated distribution of $\mu$.

\subsubsection{Updated Uncertainty Distributions using Bayesian Estimation}

After obtaining $N$ observations of the soil hydraulic parameter $\mathrm{X}, \underline{x}=\left\{x_{1}, x_{2}, \ldots, x_{N}\right\}$, the following statistics are calculated.

$$
\begin{gathered}
\bar{x}=\frac{1}{N} \sum_{i=1}^{N} x_{i} \\
s^{2}=\frac{1}{N-1} \sum_{i=1}^{N}\left(x_{i}-\bar{x}\right)^{2}
\end{gathered}
$$

The parameters of the normal-gamma distribution are updated as follows (Ang and Tang, 1975)

$$
N^{\prime \prime}=N^{\prime}+N
$$

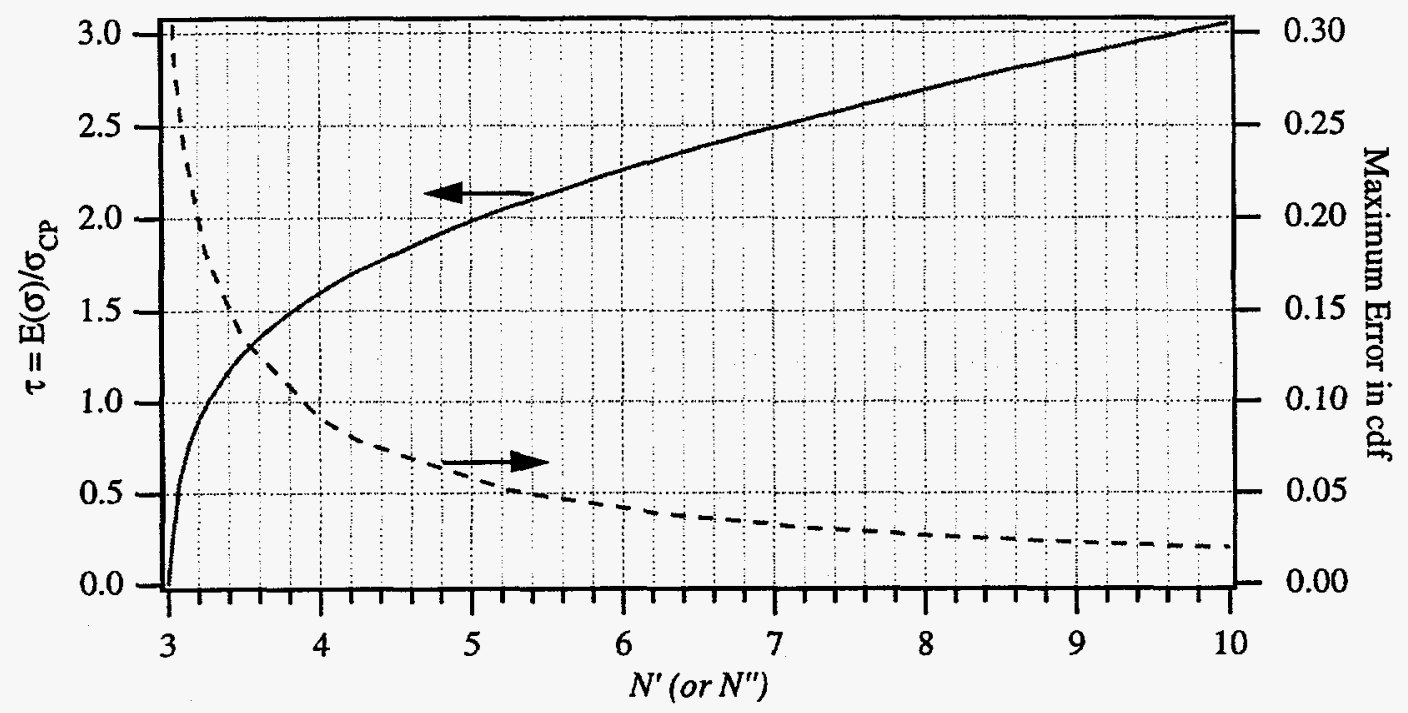

Figure 4-2. Left axis: relationship between $\tau$ and $N^{\prime}$ (Equation 23); Right axis: the maximum error in the cdf between a student-t distribution and normal distribution with the same mean and variance. 


$$
\begin{gathered}
\bar{x}^{\prime \prime}=\frac{N^{\prime} \bar{x}^{\prime}+N \bar{x}}{N^{\prime \prime}} \\
s^{\prime \prime 2}=\frac{\left[\left(N^{\prime}-1\right) s^{\prime 2}+N^{\prime} \bar{x}^{\prime 2}\right]+\left[(N-1) s^{2}+N \bar{x}^{2}\right]-N^{\prime \prime} \bar{x}^{\prime \prime}}{N^{\prime \prime}-1}
\end{gathered}
$$

These updated parameters can be used in Equations 17 and 18 to calculate the updated mean and variance of $\mu$.

\subsection{Implementation: Description of Computer Codes}

A Fortran computer code has been written to implement the Bayesian updating procedure described above for site specific measurements of soil hydraulic properties. This code (soilpr.f with executable, soilpr.exe) is available from the first author. The marginal distribution of $\mu$, based on the updated parameters of Section 4.1.3, is used in a Latin hypercube sampling code (Iman and Shortencarier, 1984) to generate a number of realizations of the transformed soil hydraulic parameter represented by $\mu$. These realizations are inverse transformed (using the results of Carsel and Parrish, $1988)$ to obtain the original soil hydraulic parameter $\left(\theta_{\mathrm{s}}, \theta_{\mathrm{r}}\right.$, $\mathrm{K}_{\mathrm{s}}, \alpha$, or $\mathrm{n}$ ). The Kolmogorov-Smirnov D-statistic is calculated for fits of the untransformed parameter to normal, lognormal, and beta distributions (as described in Section 2.3) and the best fitting distribution is used in a Monte Carlo simulation (e.g., using MEPAS or RESRAD). Multiple soil hydraulic parameters can be concurrently updated. Distributions of additional soil hydraulic parameters can be calculated as described in Section 2.2. Note that the parameter correlations as specified by Carsel and Parrish (1988) are assumed to remain unchanged for the updated parameters.

Four steps are required to implement the Bayesian updating procedure.

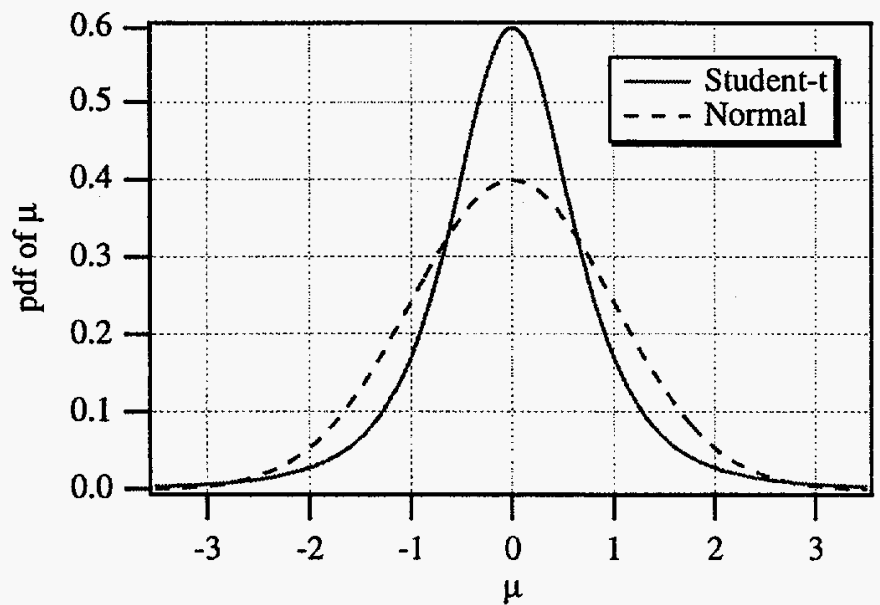

(1) Approximate the marginal distribution of $\mu$.

(2) Prepare an input file containing the site specific measurements of soil hydraulic properties.

(3) Run the code with appropriate interactive input.

(4) Correctly interpret the output.

These steps are discussed in the following sections.

\subsubsection{Approximate Distribution of $\mu$}

The marginal distribution of $\mu$, determined by integrating Equation 13 over all values of $\sigma$, is a student-t distribution (Raiffa and Schlaifer, 1961; DeGroot, 1970). The Latin hypercube sampling code being used (Iman and Shortencarier, 1984) does not allow the student-t distribution, however. For this reason, the student-t distribution for $\mu$ is approximated by a normal distribution with the same mean and variance.

The student-t distribution is a symmetric distribution like the normal distribution, but has more weight in the extremes of its tails for a given variance (compared to the normal distribution). As $N^{\prime}$ increases, the difference between a student-t and a normal distribution with the same mean and variance decreases.

Figure 4-3 is a comparison between a student- $t$ and a normal distribution, each with a mean of zero and a variance of one. $N^{\prime}=4.25$ in this case. A measure of the difference between the student- $t$ and the normal distribution is the maximum difference in the cdfs of the two distributions, as shown in the right half of Figure 4-3. This measure is a function of $N^{\prime}$, but does not depend on the mean and variance. The relationship is illustrated in Figure 4-2 (right axis). The maximum error in the cdf decreases rapidly as $N^{\prime}$ increases from 3.0 and is less than five percent for $N^{\prime}$ greater than 5.4. Note that if a value of $\tau=1$ is chosen, then $N^{\prime}=3.25$.

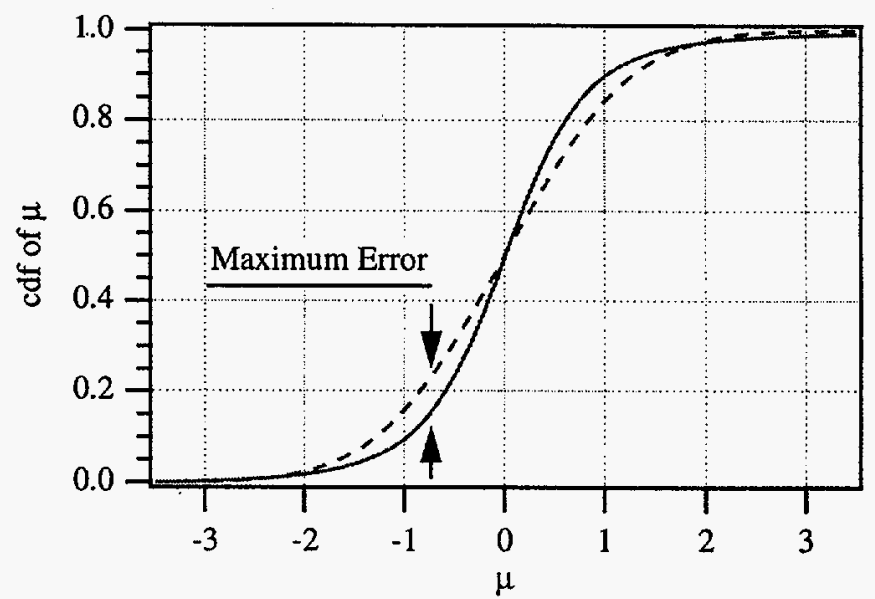

Figure 4-3. Comparison of student-t and normal distributions for $N^{\prime \prime}=4.25$. 
With just two site-specific samples, $N^{\prime \prime}$ will be 5.25 (see Equation 26) resulting in a fairly small error in the normal approximation to a student- $t$ distribution.

\subsubsection{Input File with Site-Specific Data}

Site-specific data are input to the code as an ascii (text) file. Figure 4-4 shows an example input file. Because the updating is based on the parameter distributions presented by Carsel and Parrish, the parameters that can be entered are $\alpha$, $K_{s}, n, \theta_{r}$ and $\theta_{s}$. The parameters must be listed in the file in that order. The units of $\alpha$ must be $1 / \mathrm{cm}$; those of $\mathrm{K}_{\mathrm{s}}$ must be $\mathrm{cm} / \mathrm{s}$. Water contents are volumetric. As shown in Figure 44 , the number of site-specific data values for each parameter is listed on a separate line followed by the actual data values, which may be listed on a single line or multiple lines (all input is free format). If there are no data for a parameter, that must be indicated by entering a zero for the number of data values. Note that there may be a different number of data values for each parameter. The maximum allowable number of samples for each parameter is controlled by a variable (max_samp) in the code (file 'bayesupd.f'). The current maximum number of samples is 30 .

The Bayesian updating procedure currently assumes that the site-specific data are error-free. As such, the data may have a greater effect on reducing uncertainty than is warranted. A future version of the code will account for data uncertainty in the Bayesian updating process.

\subsubsection{Running the Bayesian Updating Code}

The code to generate a Latin hypercube sample of soil hydraulic properties that incorporates site-specific data using the Bayesian updating method described above will prompt for a number of inputs.

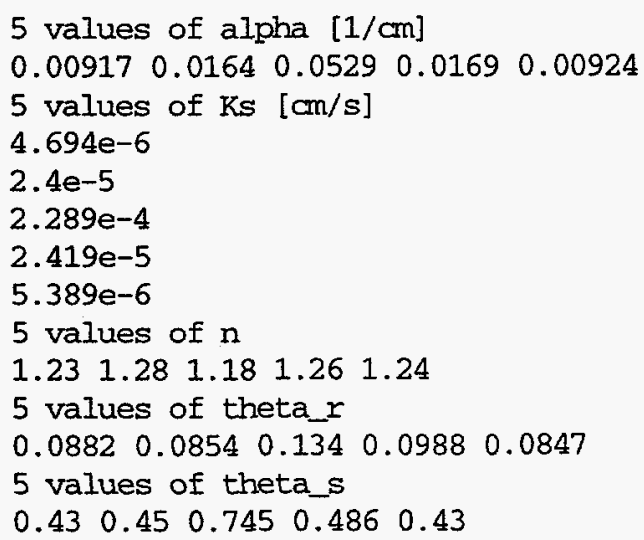

Figure 4-4. Example input file containing site-specific data for the Bayesian updating code
- The USDA soil textural classification of the soil under consideration.

- The number of realizations to generate in the Latin hypercube sample. The greater the number of realizations, the smoother the results, but the greater the computational effort required. The current maximum number of realizations allowed is 1000 . This limit can be modified by changing the parameter 'nmax' in files 'soilpr.f' and 'lhs.f'.

- An integer random seed for the Latin hypercube sampling code.

- The name of the input file containing the site-specific parameter values.

- The variability ratio, $\tau$, for each parameter. The significance of this ratio was discussed in Section 4.1.1. Variability ratios can be set individually for each parameter $\left(\theta_{s}, \theta_{r}, K_{s}, \alpha\right.$, or $\left.n\right)$. The default value of $\tau$ is 1.0 .

The following options are also provided.

- Bypass the Bayesian updating with site-specific data. This will generate parameters based solely on the statistics of Carsel and Parrish (1988). The recommended distributions discussed in Chapter 2 were developed using this option.

- The generated realizations of all parameters (including the additional parameters listed in Section 2.2) can be written to the output file 'soil_lhs.out'. Depending on the number of realizations used, the output file can be quite large if this option is chosen.

\subsubsection{Interpreting the Output File}

The output file from the Bayesian updating code is named 'soil_lhs.out' and contains descriptive information from the Latin hypercube sampling, statistical quantities for the generated soil hydraulic parameters, and the actual generated realizations for all parameters (optional). An example output file is shown in Figure 4-5. This output file was produced by using the input file of Figure 4-4 for a silty clay loam soil.

Line 1 of the output file identifies that the Bayesian updating procedure was used and specifies the file from which the data were obtained. The variability ratio $(\tau)$ used for each parameter is also listed. In this case, the default ratios were used. The prior and updated moments of the (transformed) parameters are then listed. The prior moments are from Carsel and Parrish (1988, Table 6). If the option to bypass the Bayesian updating is chosen (see Section 4.2.3) the information to this point is not present. Immediately below the prior and updated moments, the number of Latin hypercube realizations generated, the soil type being modeled, and the random seed used in the Latin hypercube sampling code are identified. The next nine lines identify the soil hydraulic parameters as they appear in the table at the bottom of 
Incorporating Soil Hydraulic Parameter Data

\begin{tabular}{|c|c|c|c|c|c|c|c|c|c|}
\hline \multicolumn{10}{|c|}{$\begin{array}{l}\text { *** Updating parameters from data in file site_data.in } \\
\text { Default variability ratios (tau }=1 \text { ) used } \\
\text { Prior and updated moments of TRANSFORMED parameters }\end{array}$} \\
\hline \multicolumn{2}{|c|}{$\begin{array}{l}\text { Parameter } \\
\text { ha }[1 / \mathrm{cm}] \\
{[\mathrm{cm} / \mathrm{hr}]} \\
\\
t a \_r \\
\text { ta_s }\end{array}$} & $\begin{array}{r}\text { Prior Mean } \\
-2.7500 \mathrm{E}+00 \\
-5.3100 \mathrm{E}+00 \\
1.2300 \mathrm{E}+00 \\
8.8000 \mathrm{E}-02 \\
4.3000 \mathrm{E}-01\end{array}$ & $\begin{array}{r}\text { Prior StdDev } \\
6.0498 \mathrm{E}-01 \\
1.6200 \mathrm{E}+00 \\
6.1003 \mathrm{E}-02 \\
8.9968 \mathrm{E}-03 \\
7.0000 \mathrm{E}-02\end{array}$ & \multicolumn{2}{|c|}{$\begin{array}{r}\text { Updated Mean } \\
-2.3236 \mathrm{E}+00 \\
-4.4019 \mathrm{E}+00 \\
1.2348 \mathrm{E}+00 \\
9.4180 \mathrm{E}-02 \\
4.7728 \mathrm{E}-01\end{array}$} & \multicolumn{2}{|c|}{$\begin{array}{c}\text { Updated StdDev } \\
3.1440 \mathrm{E}-01 \\
6.4171 \mathrm{E}-01 \\
1.4436 \mathrm{E}-02 \\
6.7849 \mathrm{E}-03 \\
4.5090 \mathrm{E}-02\end{array}$} & & \\
\hline \multicolumn{8}{|c|}{$\begin{array}{l}500 \text { LHS samples of SicL soil type using random seed } \\
\text { alpha [1/cm] \& } n \text { : van Genuchten parameters } \\
\text { Ks [cm/s] : saturated hydraulic conductivity } \\
\text { theta_r \& theta_s : residual and saturated volumetric water content } \\
\text { air_entry : Brooks-Corey air entry (bubbling) pressure [cm] } \\
\text { lambda : Brooks-Corey exponent parameter } \\
\text { eff_por : effective porosity = (theta_s - theta_r) } \\
\text { b : Campbell-model exponent parameter } \\
\text { fld_cap \& wilt_pt : field capacity and wilting point } \\
\text { av_wat_cap : available water capacity = (fld_cap - wilt_pt) }\end{array}$} & & \\
\hline Parameter & $\mathrm{N}$ & Minimm & Maximum & Mean & Sta.Dev. & Median & D-normal & D-Innormal & \\
\hline theta_s & 500 & 0.347 & 0.617 & 0.477 & 0.045 & 0.477 & 0.055 & & \\
\hline theta_r & 500 & 0.073 & 0.114 & 0.094 & 0.007 & 0.094 & 0.049 & 0.373 & 0.414 \\
\hline eff_por & 500 & 0.258 & 0.522 & 0.383 & 0.046 & 0.384 & 0.384 & 0.882 & 0.742 \\
\hline fld_cap & 500 & 0.264 & 0.494 & 0.364 & 0.037 & 0.365 & 0.568 & 0.796 & 0.812 \\
\hline wilt_pt & 500 & 0.157 & 0.283 & 0.205 & 0.018 & 0.204 & 0.700 & 0.560 & 0.909 \\
\hline av_wat_cap & 500 & 0.107 & 0.217 & 0.159 & 0.020 & 0.159 & 0.511 & 0.980 & 0.752 \\
\hline alpha & 500 & 0.006 & 0.031 & 0.014 & 0.004 & 0.013 & 1.184 & 0.167 & 0.591 \\
\hline & 500 & 1.190 & 1.279 & 1.235 & 0.014 & 1.235 & 0.058 & 0.093 & 0.377 \\
\hline air_entry & 500 & 32.437 & 178.440 & 78.163 & 22.909 & 74.750 & 1.423 & 0.167 & 0.742 \\
\hline lambda & 500 & 0.190 & 0.279 & 0.235 & 0.014 & 0.235 & 0.047 & 0.316 & 0.389 \\
\hline $\mathrm{b}$ & 500 & 5.252 & 7.737 & 6.329 & 0.389 & 6.300 & 0.907 & 0.634 & 0.927 \\
\hline Ks & 500 & $1.71 \mathrm{E}-06$ & $7.95 \mathrm{E}-05$ & $1.43 \mathrm{E}-05$ & $9.76 \mathrm{E}-06$ & $1.18 \mathrm{E}-05$ & 2.751 & 0.089 & 1.662 \\
\hline
\end{tabular}

Figure 4-5. Example output file from the Bayesian updating code. See Section 4.2.4 for a discussion.

Figure 4-5. The table lists the following values for the untransformed soil hydraulic parameters: parameter name, number of realizations, minimum and maximum of the generated values, mean, standard deviation, and mean. In addition, the modified Kolmogorov-Smirnov D-statistics are listed for fitted distribution types of normal, lognormal, and beta.

A number of additional statistical parameters are written to the output file, but are not included in Figure 4-5. These are the parameters of the lognormal $(\gamma$-gamma, $\zeta$-zeta) and beta $(q, r, A, B)$ distributions determined from the generated values. These parameters are defined and discussed in Appendix A.

The complete set of soil hydraulic parameter realizations is written to the bottom of the output file if this option is chosen.

The modified K-S D-statistics were calculated and can be interpreted as described in Section 2.3. They provide a comparative measure of the goodness-of-fit (see Figure 2-6); the smaller the D-statistic, the better the fit. In the example of Figure 4-5, the normal distribution provides the best fit to the updated empirical distribution of $\theta_{s}$ values (D-statistic of 0.055 ), while the $K_{s}$ values are best fit with a lognormal distribution (D-statistic of 0.089). The minimum D-statistic for each parameter is indicated with italics. In choosing the distribution by which to model the updated soil hydraulic parameters, the algorithm of Figure 2-5 (or some modification thereof) may be used. If a lognormal or beta distribution is chosen, the parameters of the distribution $(\gamma$ and $\zeta$ or $q, r, A$, and $B$ ) can be read from the output file. Note that the relative values of the modified D-statistics may change as $N$ increases. This may affect which distribution type is chosen.

\subsection{Example of Soil Property Updating}

To illustrate the use of the soil hydraulic parameter updating methodology, an example application is presented in this section. The example is a realistic representation of an 
SDMP site, but the conceptual model and data used are hypothetical.

\subsubsection{Site Description}

The example site is located in a relatively humid region of the eastern U.S. with average annual precipitation approximately $96 \mathrm{~cm}$. The site has minor topographic relief. Surface soils are generally silty clay loams. Unconsolidated alluvial and lacustrine deposits varying from approximately 8 to $22 \mathrm{~m}$ thick overlie shale bedrock. The unconsolidated deposits are generally characterized as silts and clays with interbedded silty sands. Depth to the water table varies over the year from 0 to $3 \mathrm{~m}$ below ground surface. The primary radioactive contaminants at the site are thorium and uranium, which became incorporated in the waste slag from ore processing. A mixture of slag and soil is stored in a pile on the site.

Based on the site characterization, a conceptual model of groundwater transport and drinking water exposure was developed. The conceptual model of the site includes the above-grade waste pile, a $2.13 \mathrm{~m}$ thick unsaturated zone, and a $12.2 \mathrm{~m}$ thick saturated zone. Particle size distribution data from a number of on-site samples were used to classify the unsaturated zone as a silty clay loam and the saturated zone as a sandy loam. Since this example application used RESRAD to calculate contaminant transport, an on-site receptor at the edge of the waste pile was assumed. The well screen for this receptor extended $3 \mathrm{~m}$ below the water table. Figure 4-6 is a diagram of the groundwater conceptual model.
Initial concentrations of radionuclides were estimated from samples of the various materials comprising the waste pile. Distribution coefficients for the contaminants within the waste pile and within the sediments were also estimated. Distribution coefficients and initial concentrations are listed in Table 4-1 for those radionuclides with half-lives greater than six months. Bulk density of the contaminated zone (primarily slag) was estimated as $2.65 \mathrm{~g} / \mathrm{cm}^{3}$.

\subsubsection{Net Infiltration Estimation}

The method described in Chapter 3 was used to determine a distribution for the net infiltration at the example site. Climatic data from a nearby location were downloaded from the NCDC First-Order Summary of the Day database. Monthly average values for the parameters required in the MEPAS water budget calculation were calculated and are presented in Table 4-2. Standard errors for precipitation and average temperature are given in Table 4-2. These two parameters were modeled as normally distributed random variables, with the standard deviation equal to the standard error for each month.

The available water capacity was also modeled as a random variable. The prior distribution for this parameter was chosen from Appendix A, Table A-9, representing the silty clay loam surface soils. This distribution (Normal, $\mu=0.142 \mathrm{~cm}$ /

1. NRC Licensing Staff, November 1995, personal communication. Values in Table 4-1 and the bulk density value are for the hypothetical example and may not be representative of actual sites.

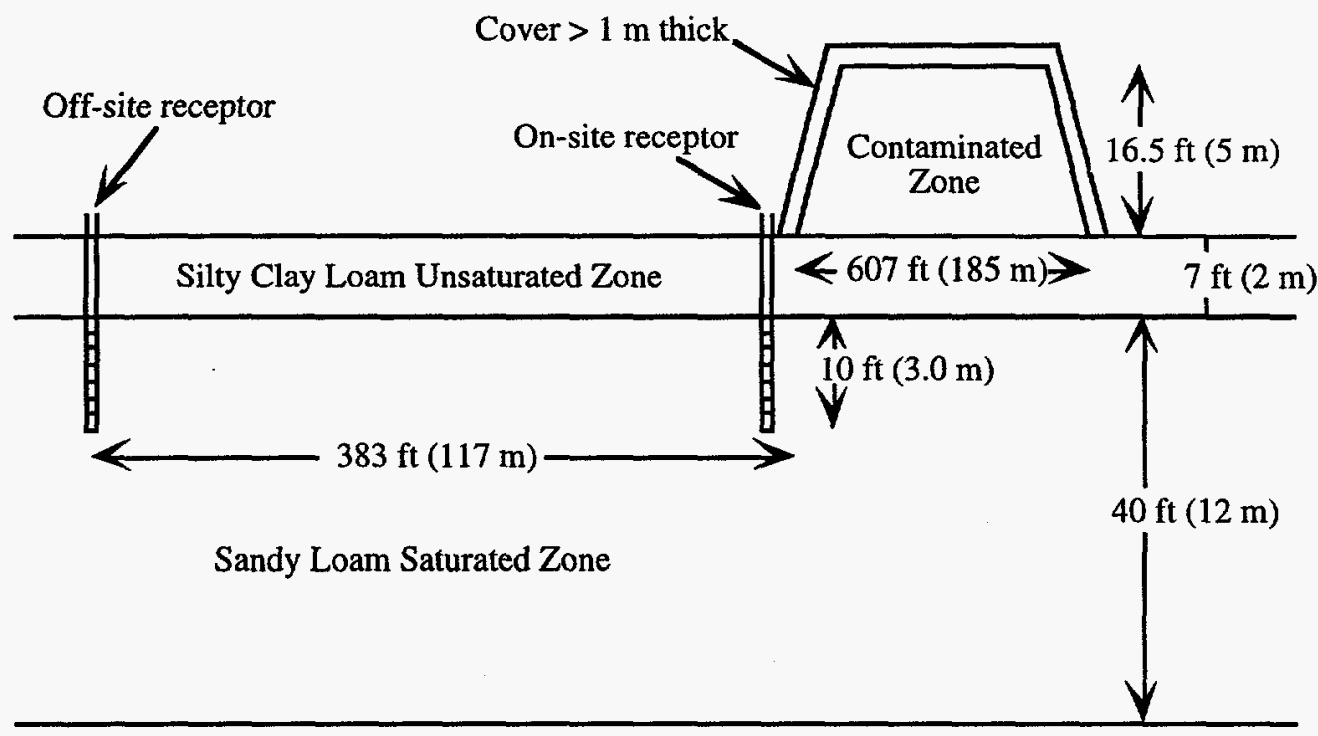

Figure 4-6. Conceptual model of the SDMP application site. Total area of the contaminated zone is $33330 \mathrm{~m}^{2}$. Note, drawing is not to scale. 
Table 4-1. Initial concentrations and distribution coefficients in the contaminated, unsaturated, and saturated zones

\begin{tabular}{|c|c|c|c|c|}
\hline & $\begin{array}{c}\text { Initial } \\
\text { Conc. } \\
{[p \mathrm{Ci} / \mathrm{g}]}\end{array}$ & $\begin{array}{c}\text { Cont. } \\
\text { Zone K }_{\mathbf{d}} \\
{\left[\mathrm{cm}^{3} / \mathrm{g}\right]}\end{array}$ & $\begin{array}{c}\text { Unsat. } \\
\text { Zone K } \\
{\left[\mathrm{cm}^{3} / \mathrm{g}\right]}\end{array}$ & $\begin{array}{c}\text { Sat. } \\
\text { Zone K }_{\mathrm{d}} \\
{\left[\mathrm{cm}^{3} / \mathrm{g}\right]}\end{array}$ \\
\hline Ac- 227 & 5.48 & 4191 & 538 & 228 \\
\hline $\mathrm{Pa}-231$ & 10.30 & 4553 & 50 & 0 \\
\hline $\mathrm{Pb}-210^{\circ}$ & 90.40 & 1045 & 1830 & 234 \\
\hline $\mathrm{Ra}-226$ & 6.39 & 180 & 100 & 24 \\
\hline $\mathrm{Ra}-228$ & 2.08 & 180 & 100 & 24 \\
\hline Th-228 & 2.02 & 66760 & 500 & 100 \\
\hline Th-230 & 285.00 & 66760 & 500 & 100 \\
\hline Th-232 & 3.74 & 66760 & 500 & 100 \\
\hline U-234 & 4.20 & 23810 & 50 & 0 \\
\hline U-235 & 0.92 & 23810 & 50 & 0 \\
\hline U-238 & 4.04 & 23810 & 50 & 0 \\
\hline
\end{tabular}

$\mathrm{cm}, \sigma=0.0333 \mathrm{~cm} / \mathrm{cm}$ ) was updated using the computer code described in Section 4.2 and the site-specific hydraulic parameter data shown in Figure 4-4. The updated distribution was Normal, $\mu=0.159 \mathrm{~cm} / \mathrm{cm}, \sigma=0.0202 \mathrm{~cm} / \mathrm{cm}$ (see Figure 4-5). Prior and updated distributions for $\alpha$ (for which there are site-specific data) and for $a w c$ (for which there are no direct data) are shown in Figure 4-7. The influence of the data is clear.
The site-specific data for this example were derived from particle size distribution data collected at the example site. Soil hydraulic parameters were calculated from the particle size data using the regressions of Rawls and Brakensiek (1985). Parameter values derived in this manner are obviously not free of error. Parameter estimates will generally contain error even when they are derived from water retention measurements. Since the current methodology assumes that the data are error-free, the effectiveness of the data in reducing the variance of the updated distributions is exaggerated.

A distribution of net infiltration was determined by Monte Carlo simulation using 500 realizations of monthly precipitation, average temperature, and top-soil water capacity. For prior and updated simulations, a root zone depth of $100 \mathrm{~cm}$ and a vegetative cover fraction of 1.0 were assumed. (Recall that top-soil water capacity is the product of these two parameters and the available water capacity.) The resulting distributions of net infiltration are shown in Figure 4-8. The empirical pdf's represent the results of the Monte Carlo simulations. The fitted pdf's are the analytical distributions used in the calculation of dose. The prior fitted distribution is Normal, $\mu=7.08 \mathrm{~cm} / \mathrm{yr}, \sigma=2.65 \mathrm{~cm} / \mathrm{yr}$. The updated fitted distribution is Normal, $\mu=5.87 \mathrm{~cm} / \mathrm{yr}, \sigma=1.82 \mathrm{~cm} / \mathrm{yr}$.

As shown in Figure 4-8, updating the available water content with site specific hydraulic parameter data has a noticeable effect on the net infiltration rate. The estimate of the mean annual net infiltration is reduced by $17 \%$. The standard deviation, representing uncertainty in the net infiltration estimate, is reduced by $31 \%$.

Table 4-2. Average monthly climatic parameter values for the example site (from NCDC daily data)

\begin{tabular}{ccccccccccccc}
\hline & Jan & Feb & Mar & Apr & May & Jun & Jul & Aug & Sep & Oct & Nov & Dec \\
\hline Precipitation [in.] & 2.81 & 2.28 & 3.12 & 3.38 & 3.81 & 3.93 & 4.59 & 3.26 & 2.71 & 2.06 & 3.06 & 2.73 \\
Standard Error & 0.26 & 0.17 & 0.23 & 0.20 & 0.23 & 0.29 & 0.32 & 0.25 & 0.21 & 0.17 & 0.26 & 0.18 \\
$\quad$ Average & 27.87 & 30.77 & 40.39 & 51.42 & 61.58 & 70.39 & 74.33 & 72.54 & 65.68 & 54.16 & 42.76 & 32.34 \\
$\begin{array}{c}\text { Temperature [F] } \\
\text { Standard Error }\end{array}$ & 0.84 & 0.70 & 0.58 & 0.42 & 0.51 & 0.36 & 0.29 & 0.34 & 0.38 & 0.47 & 0.45 & 0.74 \\
$\begin{array}{c}\text { Average Wind } \\
\text { Speed [mph] }\end{array}$ & 8.52 & 8.15 & 8.41 & 7.97 & 6.80 & 5.99 & 5.50 & 5.16 & 5.64 & 6.17 & 7.99 & 7.93 \\
$\begin{array}{c}\text { Cloud Cover } \\
\text { [tenths] }\end{array}$ & 7.94 & 7.42 & 7.34 & 6.87 & 6.51 & 6.20 & 6.26 & 6.34 & 6.30 & 6.60 & 7.94 & 8.25 \\
$\begin{array}{c}\text { Number of Rainy } \\
\quad \text { Days }\end{array}$ & 13.44 & 11.35 & 13.73 & 13.15 & 12.33 & 10.73 & 10.85 & 9.43 & 8.49 & 8.98 & 11.62 & 12.96 \\
$\begin{array}{c}\text { Max. Relative } \\
\text { Humidity [\%] }\end{array}$ & 85.31 & 87.78 & 86.87 & 84.55 & 90.16 & 91.30 & 92.58 & 93.23 & 89.21 & 90.95 & 88.87 & 89.02 \\
$\begin{array}{c}\text { Min. Relative } \\
\text { Humidity [\%] }\end{array}$ & 58.07 & 55.85 & 48.58 & 42.71 & 44.15 & 46.35 & 47.98 & 46.94 & 44.52 & 46.58 & 52.90 & 60.26 \\
\hline
\end{tabular}



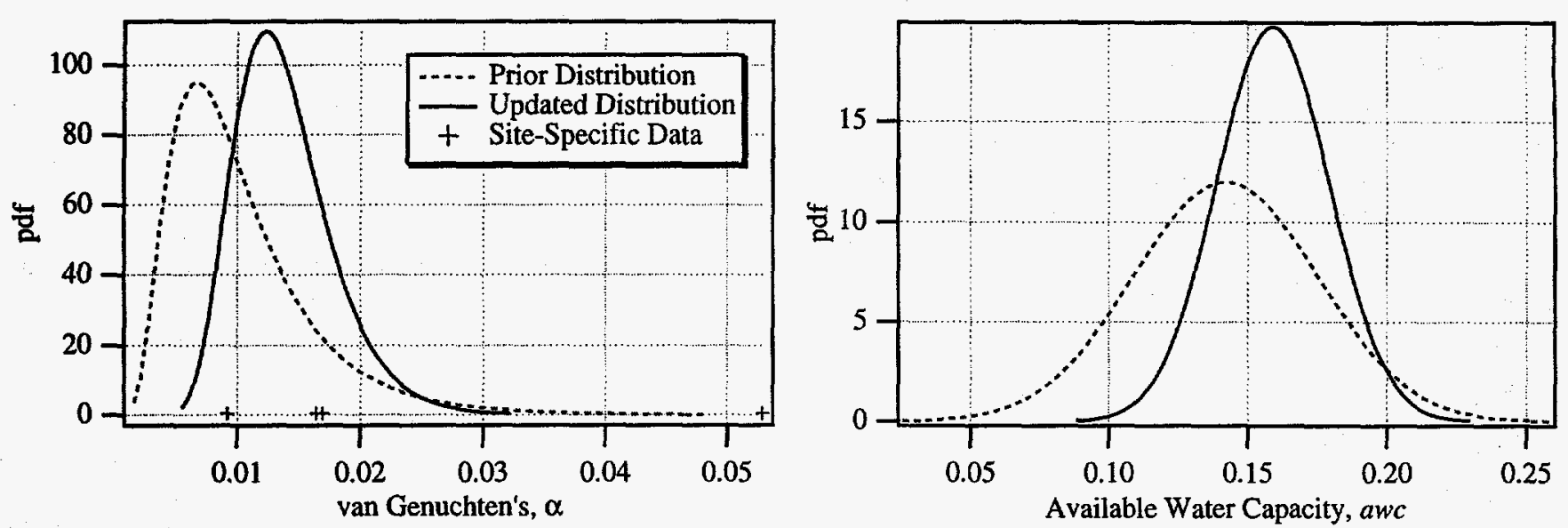

Figure 4-7. Example updating for a silty clay loam soil using the site-specific data of Figure 4-4. Prior distributions are from Table A-9. Note, there are five data points for $\alpha$; two of the symbols overlap.

The normal distributions chosen to represent the net infiltration (see Figure 4-8) have a small probability of being less than zero, an unrealistic scenario. The net infiltration values generated for the RESRAD Monte Carlo simulations were checked to make sure they were all positive. For the updated distribution, this was the case. For the prior distribution, however, the smallest value generated was negative. The sign of this value was changed (although it remained the smallest value generated) for the RESRAD simulation.

A beta distribution, with a minimum value of zero, may be a more appropriate model for the net infiltration. This distri- bution is not allowed in the version of RESRAD used, however (v. 5.61), even though the Latin hypercube sampling code used in RESRAD does allow the beta distribution.

\subsubsection{Dose Estimation using RESRAD}

The effect on the estimate of dose from updating the net infiltration distribution was determined for the example site using RESRAD. For the RESRAD simulations, the only parameter treated as a random variable was the precipitation. The distributions used for precipitation were the prior and updated net infiltration distributions from Section 4.3.2.

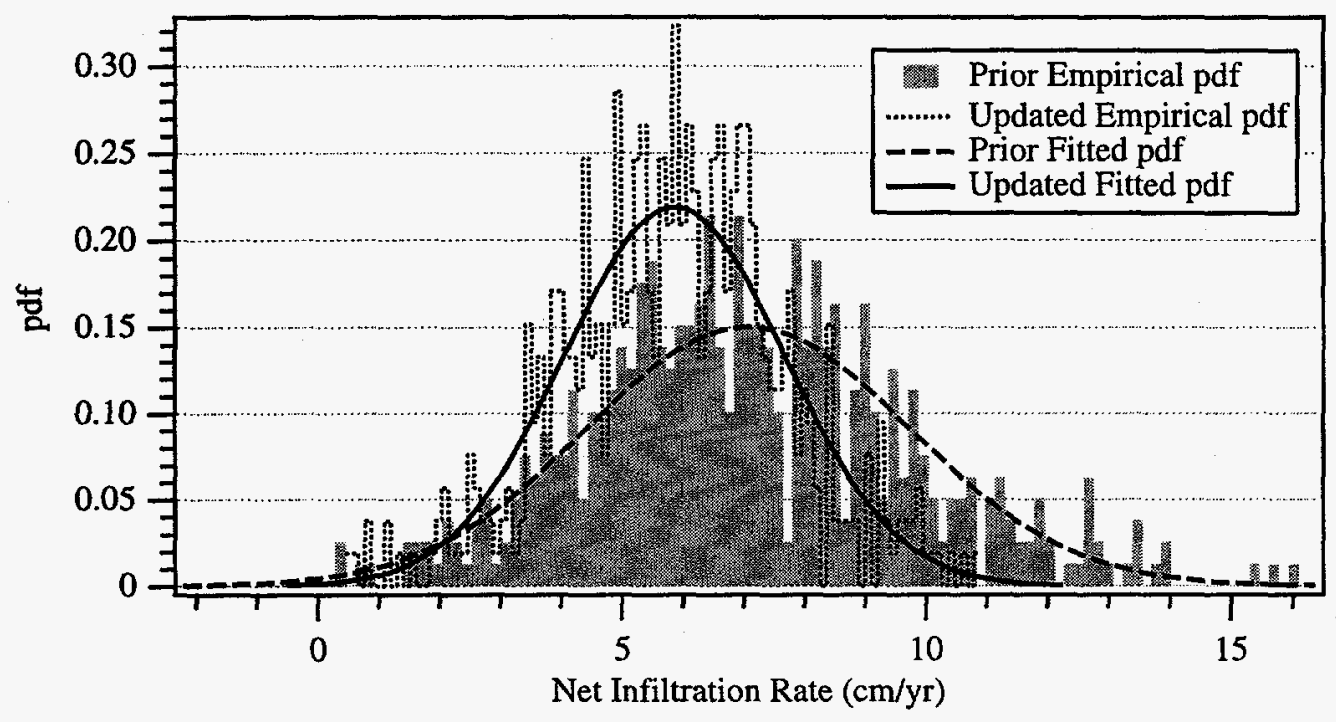

Figure 4-8. Prior and updated annual net infiltration distributions for the example problem. Empirical pdfs result from using the MEPAS water budget method. Fitted pdfs have the same mean and standard deviation as the empirical results. 
The runoff and evapotranspiration coefficients in RESRAD were set to zero so that the precipitation equaled the flux through the waste and the unsaturated zone.

The soil parameter values used in the RESRAD simulations are listed in Table 4-3. These values are representative of a silty clay loam unsaturated zone and a sandy loam saturated zone. The hydraulic gradient in the saturated zone was 0.007 . Although the soil hydraulic parameters of the unsaturated and saturated zones were modeled as known constants in this example, they could easily be modeled as random variables to incorporate their uncertainties in the estimates of dose. The updating procedure described in this chapter applies equally as well to these parameters.

Figure 4-9 contains plots of total dose from all radionuclides through the drinking water pathway for particular points in time, as calculated by RESRAD. Total dose for any given year represents the average dose received during that year. The effect on dose of updating the net infiltration distribution is clear. The smaller mean and standard deviation of the updated net infiltration result in similar changes
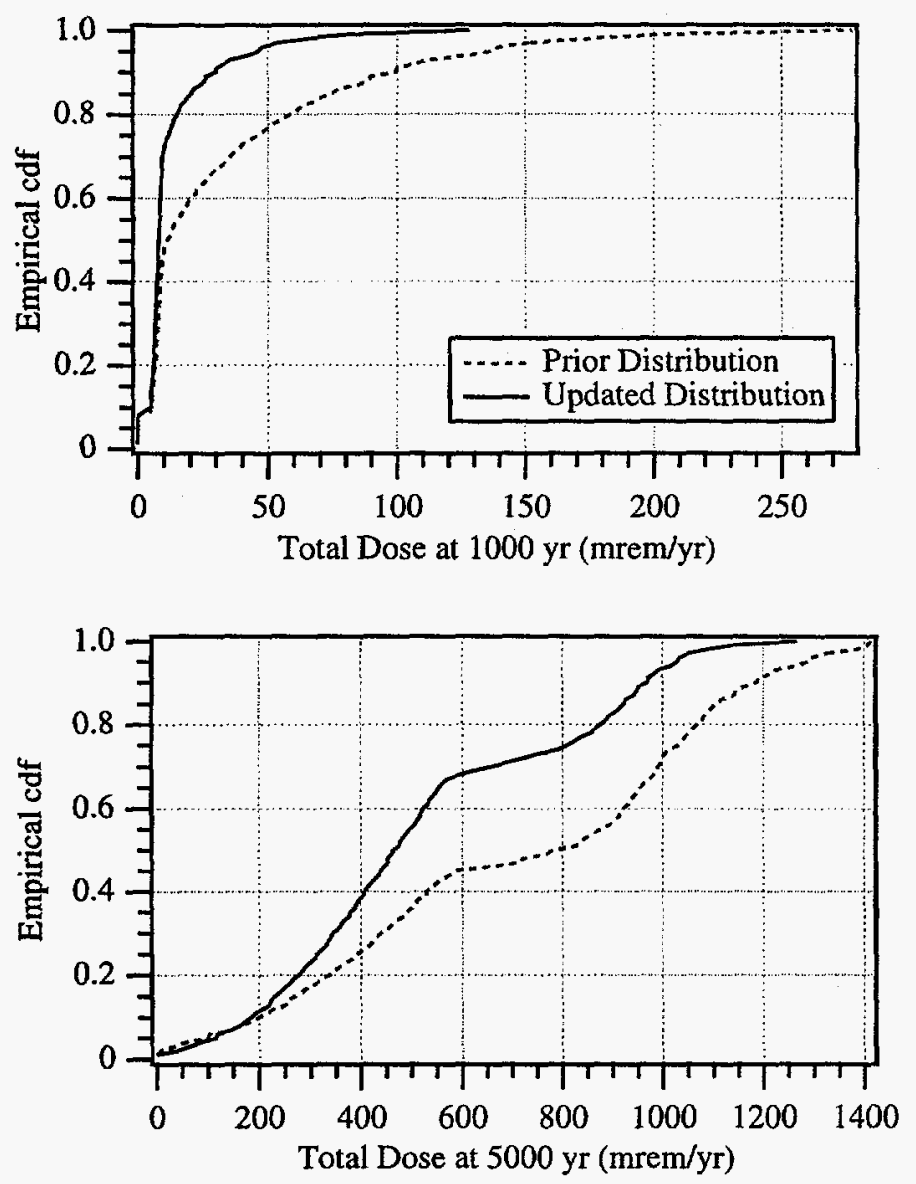

Table 4-3. Soil parameters for the example site

\begin{tabular}{cccc}
\hline & $\begin{array}{c}\text { Contaminated } \\
\text { Zone }\end{array}$ & $\begin{array}{c}\text { Unsaturated } \\
\text { Zone }\end{array}$ & $\begin{array}{c}\text { Saturated } \\
\text { Zone }\end{array}$ \\
\hline$\rho_{b}{ }^{\mathrm{a}}$ & $2.65 \mathrm{~g} / \mathrm{cm}^{3}$ & 1.35 & 1.48 \\
$\theta_{s}$ & 0.397 & 0.49 & 0.442 \\
$p_{e}$ & 0.21 & 0.115 & 0.267 \\
$f_{c}$ & $\mathrm{n} / \mathrm{a}$ & 0.375 & $\mathrm{n} / \mathrm{a}$ \\
$K_{s}$ & $0.304 \mathrm{~cm} / \mathrm{s}$ & $1.7 \times 10^{-4}$ & $3.45 \times 10^{-3}$ \\
$b$ & 3.0 & 7.75 & 4.9 \\
\hline
\end{tabular}

a. bulk density

to the dose estimates. For example, at 1000 years the probability that the total dose is greater than $25 \mathrm{mrem} / \mathrm{yr}$ is about $40 \%$ for the prior distribution, but is reduced to about $15 \%$ when the site-specific data are incorporated in the analysis. The mean, standard deviation, median, and coefficient of variation of the dose distributions are listed in Table 4-4.
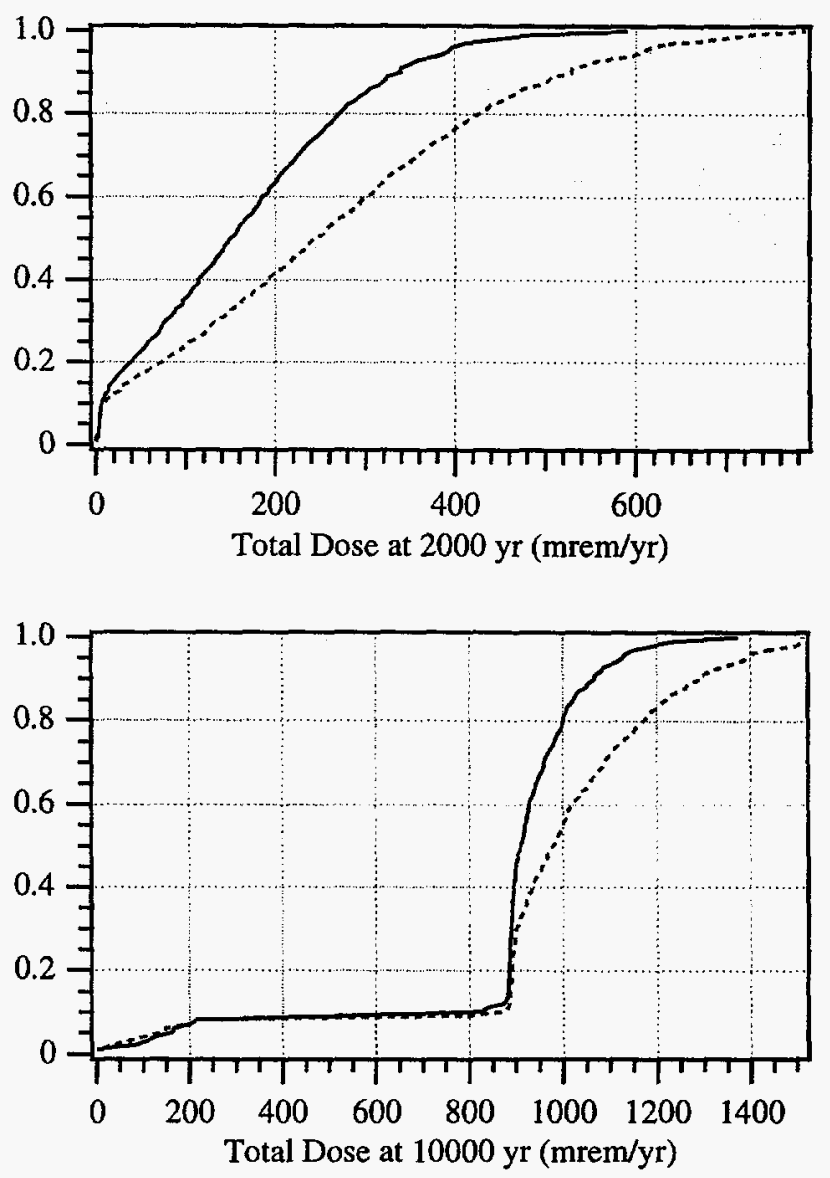

Figure 4-9. Prior and updated estimates of total dose predicted by RESRAD for the example site for times between 1000 and 10,000 years. Net infiltration is the only uncertain parameter. 
Table 4-4. Prior and updated mean, standard deviation, and median of the net infiltration $(\mathrm{cm} / \mathrm{yr})$ and dose estimates (mrem/yr) calculated for the example site

\begin{tabular}{ccccccccc}
\hline & \multicolumn{2}{c}{ Mean } & \multicolumn{2}{c}{ Standard Deviation } & \multicolumn{2}{c}{ Median } & \multicolumn{2}{c}{ CV } \\
\cline { 2 - 8 } & Prior & Updated & Prior & Updated & Prior & Updated & Prior & Updated \\
\hline Net Infiltration & 7.08 & 5.87 & 2.65 & 1.82 & 6.9 & 5.9 & 0.37 & 0.31 \\
Dose at 1000 yr. & 35 & 13 & 49 & 18 & 12 & 8 & 1.40 & 1.38 \\
Dose at 2000 yr. & 265 & 167 & 191 & 127 & 248 & 153 & 0.72 & 0.76 \\
Dose at 5000 yr. & 720 & 534 & 382 & 296 & 806 & 469 & 0.53 & 0.55 \\
Dose at 10,000 yr. & 975 & 884 & 302 & 244 & 982 & 912 & 0.31 & 0.28 \\
\hline
\end{tabular}

As illustrated in Figure 4-9, the impact of site-specific data can be significant. Data should therefore be collected for those parameters that will have the greatest impact on uncertainty. Morgan and Henrion (1990) discuss various measures of uncertainty importance, including partial correlation coefficients and rank-order correlations. These measure the strength of relationships between the uncertain inputs parameters and the output of a Monte Carlo simulation. RESRAD calculates partial correlation coefficients automatically. A Monte Carlo simulation using prior distributions of parameters will identify those parameters with the largest partial correlation coefficients. These are the parameters for which site-specific data are likely to be most valuable. 



\section{Conclusions}

Decisions regarding the safety of SDMP sites are likely to be made in an atmosphere of significant uncertainty. The uncertainty arises from a number of conditions.

- The presence of long-lived radionuclides requires predicting exposures many years into the future.

- Potential exposure exists through multiple pathways.

- There are limited data characterizing the hydrologic performance of the subsurface.

- Simplifications to the physical system and the transport mechanisms are often necessary to reduce the computational requirements of the analysis when making predictions about future exposures.

Because site-specific data on soil hydraulic parameters are often not available, NRC staff must make assumptions regarding the parameter values to use in estimating dose impacts from SDMP sites. This report was prepared to assist NRC staff in selecting appropriate soil hydraulic parameter values and in assessing the uncertainty in these parameters. The report illustrates how these parameter distributions can be used to estimate uncertainties in net infiltration and dose.

Several tools for improving uncertainty analyses of exposure estimates through the groundwater pathway at SDMP sites have been presented. The uncertainty analysis tools discussed in this report address parameter uncertainty only and are particularly applicable to analyses that use Monte Carlo simulation. Other sources of uncertainty, such as alternative conceptual models and model error are not well addressed with a Monte Carlo analysis. These uncertainties are better addressed by evaluating a small number of carefully chosen alternatives.

The generic probability distributions presented in Appendices A and B represent the uncertainty in unsaturated and saturated zone soil hydraulic parameters when given no information other than soil texture. These distributions can be used as input to the built-in Monte Carlo simulation capabilities of available dose assessment codes (e.g., RESRAD and MEPAS) to provide estimates of exposure uncertainty. The use of these generic distributions is appropriate in screening-level and preliminary analyses where site-specific data are limited and an estimate of soil hydraulic parameter uncertainty is needed. The generic distributions are categorized by soil texture with parameters for the van Genuchten, Brooks-Corey, and Campbell water retention and hydraulic conductivity models included.

The generic distributions compare reasonably well to the default or recommended parameter values from other sources. The most significant differences exist in the exponent parameter of the water retention models (i.e., the parameter related to the pore-size distribution). These differences could result from the use of different soil databases, regression equations, and analytical procedures in fitting parameter values to water retention data. The actual error in the regressions on which the generic distributions were based is unknown, but is likely to be 30 to $40 \%$ or more. The generic distributions are thus likely to underestimate the parameter uncertainty.

The generic distributions for the available water capacity of coarse textured soils (sand, loamy sand, and sandy loam) are somewhat lower than the default values used in the HELP code. This is due in part to differences in the method of calculating field capacity. This report defined field capacity as the water content at which the hydraulic conductivity equals $10^{-8} \mathrm{~cm} / \mathrm{s}$. This method results in a value of field capacity more consistent with its application than the traditional definition (water content at $1 / 3$ or $1 / 10$ bar). In addition, the derived field capacity is consistent across soil textures.

At those sites where water retention measurements exist, the Bayesian updating method presented in Chapter 4 can be used to combine the generic distributions and the site-specific data. The resulting updated soil hydraulic parameter distributions can be used to obtain an updated estimate of the probability distribution of dose. The updating method was illustrated using an example SDMP site. Site precipitation, air temperature, and plant available water capacity were modeled as random variables. The available water capacity was updated using five measurements of the van Genuchten water retention parameters.

A distribution of net infiltration was determined using Monte Carlo simulation and a simple water budget model. The effect of updating with the site-specific data was to reduce the estimate of the mean annual net infiltration by $17 \%$. The standard deviation, representing uncertainty in the net infiltration estimate, was reduced by $31 \%$. Similar effects were seen in the estimates of dose (means and standard deviations were lower when using the updated net infiltration distribution). For example, at 1000 years the probability that the total dose was greater than $25 \mathrm{mrem} / \mathrm{yr}$ was about $40 \%$ before updating, but was reduced to about $15 \%$ when the site-specific data were incorporated in the analysis.

The updating example illustrated that the impact on dose estimates of site-specific water retention data can be significant. The relative impact of various parameters on the predictions of dose should therefore be considered when performing site characterization. One way to do this is to calculate partial correlation coefficients from a Monte Carlo simulation using prior distributions of parameters. Parameters with the largest partial correlation coefficients are the ones for which site-specific data are likely to be most valuable.

The updating method presented assumes that the site-specific data have no uncertainty associated with them. The effectiveness of the data in reducing the variance of the updated distributions is thus exaggerated. Most data measurements are somewhat uncertain and including this addi- 


\section{Conclusions}

tional uncertainty in the Bayesian updating method would provide a more realistic estimate of the updated parameter uncertainty.

The water budget method used to calculate the probability distribution of net infiltration in the updating example was evaluated using a long-term ( $50 \mathrm{yr}$ ) record of drainage from a lysimeter. Precipitation and air temperature were modeled as random variables using data collected on site. A distribution for the available water capacity was selected from Appendix A based solely on a description of the lysimeter soils. No water retention data were used. A comparison between the distribution of predicted annual net infiltration and the observed lysimeter drainage (mean and standard error) showed an agreeable match. The measured long-term average drainage rate from the lysimeter fell between the 90th and 95th percentiles of the predicted distribution.

The simple water budget model used was able to provide a reasonable estimate of the uncertainty in the long-term average drainage from the lysimeter. As noted, however, the standard error of the mean annual drainage from the lysimeter was significantly smaller than the year-to-year variability in the drainage. The intermediate-level codes used in this report to predict net infiltration and dose do not consider the small-scale temporal and spatial variabilities that exist in many real life processes. Such variability may play an important role in contaminant transport. For example, recharge generally occurs over short periods of time in response to events such as heavy rainfall and spring snowmelt. In addition, spatially variable soils may have locally concentrated recharge. Ignoring these variabilities may lead to nonconservative dose predictions in some cases. There is no clear methodology, however, for determining when the consideration of temporal and/or spatial variability is crucial. Such a determination will depend on site conditions as well as the decision to be made. For example, variability is likely to be more important at sites with a thin unsaturated zone and significant seasonal fluctuations in the water table and when remediation alternatives are being assessed.

At many SDMP sites, the water pathway will be a major contributor to total dose. Net water infiltration is therefore one of the most important parameters of the contaminant transport analysis. Using the methods described in this report will provide quantitative estimates of the uncertainty in net infiltration and the uncertainty in dose arising from the hydrologic uncertainties. Such estimates improve the transport analysis and, with site-specific data, can help to reduce the uncertainties at a given SDMP site. The analysis presented here may be applicable to estimating uncertainties in other parameters, such as contaminant distribution coefficients and atmospheric or surface water transport parameters. Such an analysis would require a database on these other parameters similar to that used by Carsel and Parrish. 


\section{References}

Ang, A. H-S. and W. H. Tang, Probability Concepts in Engineering Planning and Design, Volume 1, Basic Principles, John Wiley \& Sons, New York, 409 pp., 1975.

Buck, J. W., G. Whelan, J. G. Droppo Jr, D. L. Strenge, K.J. Castleton, J. P. McDonald, C. Sato, G. P. Streile, "Multimedia Environmental Pollutant Assessment System (MEPAS) Application Guidance," PNL-10395, Pacific Northwest National Laboratory, Richland, WA, 1995.

Bugai, D. A., R. D. Waters, S. P. Dzhepo, and A. S. Skalsk'ij, "The cooling pond of the Chernobyl nuclear power plant: A groundwater remediation case history," Water Resources Research, 33(4):677-688, 1997.

Brooks, R. H. and A. T. Corey, "Hydraulic Properties of Porous Media," Hydrology Paper No. 3, Colorado State University, Fort Collins, CO, March, 1964.

Campbell, G. S., "A simple method for determining unsaturated conductivity from moisture retention data," Soil Sci., 117:311-314, 1974.

Carsel, R. F., and R. S. Parrish, "Developing joint probability distributions of soil water retention characteristics," Water Resources Research, 24(5):755-770, 1988.

Cheng, J.-J., J. G. Droppo, E. R. Faillace, E. K. Gnanapragasam, R. Johns, G. Laniak, C. Lew, W. Mills, L. Owens, D. L. Strenge, J. F. Sutherland, C. C. Travis, G. Whelan, C. Yu, "Benchmarking Analysis of Three Multimedia Models: RESRAD, MMSOILS, and MEPAS" DOE/ORO-2033, U.S. Department of Energy, Washington, DC, 1995.

Clapp, R. B. and G. M. Hornberger, "Empirical Equations for Some Soil Hydraulic Properties," Water Resources Research, 14(4):601-604, 1978.

Davis, C. S. and M. A. Stephens, "Algorithm AS 248: Empirical distribution function goodness-of-fit tests," Applied Statistics, 38(3):535-582, 1989.

DeGroot, M. H., Optimal Statistical Decisions, McGrawHill Inc., New York, 489 pp., 1970.

Focht, Jr., J. A., "Lessons learned from missed predictions," ASCE J. Geotechnical Engineering, 120(10): 1653-1683, 1994.

Harrold, L. L. and F. R. Dreibelbis, "Evaluation of Agricultural Hydrology by Monolith Lysimeters, 1944-55," Technical Bulletin No. 1179, U.S. Dept. of Agriculture,

Agricultural Research Service, in cooperation with the Ohio Agricultural Experiment Station, Washington, D.C., 1958.

Hillel, D., Applications of Soil Physics, Academic Press, San Diego, CA, 385 pp., 1980.

Iman, R. L. and M. J. Shortencarier, "A FORTRAN 77 Program and User's Guide for the Generation of Latin Hypercube and Random Samples for Use with Computer
Models," NUREG/CR-3624, SAND83-2365, U.S. Nuclear Regulatory Commission, Washington, D.C., 1984

Kennedy, J.D., and D.L. Strenge, "Residual Radioactive Contamination from Decommissioning: Technical Basis for Translating Contamination Levels to Annual Total Effective Dose Equivalent," NUREG/CR-5512, PNL-7994. U.S. Nuclear Regulatory Commission, Washington, D.C., 1992.

Kern, J. S., "Evaluation of soil water retention models based on basic soil physical properties," Soil Sci. Soc. Am. J., 59:1134-1141, 1995.

Lenhard, R. J., J. C. Parker, and S. Mishra, "On the correspondence between Brooks-Corey and van Genuchten models," ASCE J. Irrigation and Drainage Engineering, 115(4):744-751, 1989.

Meyer, P. D., M. L. Rockhold, W. E. Nichols, and G. W. Gee, "Hydrologic Evaluation Methodology for Estimating Water Movement Through the Unsaturated Zone at Commercial Low-Level Radioactive Waste Disposal Sites" NUREG/CR-6346, U. S. Nuclear Regulatory Commission, Washington, DC, 1996.

Morel-Seytoux, H. J., P. D. Meyer, M. Nachabe, J. Touma, $M$. T. van Genuchten, and R. J. Lenhard, "Parameter equivalence for the Brooks-Corey and van Genuchten soil characteristics: preserving the effective capillary drive," 32(5):1251-1258, 1996.

Morgan, M. G. and M. Henrion, Uncertainty: A Guide to Dealing with Uncertainty in Quantitative Risk and Policy Analysis, Cambridge University Press, New York, 332 pp., 1990.

Raiffa, H. and R. Schlaifer, Applied Statistical Decision Theory, Division of Research, Harvard Business School, Boston, MA, 356 pp., 1961.

Rawls, W. J., D. L. Brakensiek, and K. E. Saxton, "Estimation of soil water properties," Trans. ASAE, 25(5):13161328, 1982.

Rawls, W. J., D. L. Brakensiek, and B. Soni, "Agricultural management effect on soil water processes, Part 1: Soil water retention and Green and Ampt infiltration parameters," Trans. ASAE, 26(6):1747-1752, 1983.

Rawls, W. J. and D. L. Brakensiek, "Prediction of soil water properties for hydrologic modeling," in Proceedings, Watershed Management in the Eighties, pp. 293-299, American Society of Civil Engineers, New York, 1985.

Scherer, T. F., B. Seelig, and D. Franzen, "Soil, Water, and Plant Characteristics Important to Irrigation," North Dakota State University Extension Service, EB-66 (found at http:// ndsuext.nodak.edu/extpubs/ageng/irrigate/eb66w.htm), 1996. 


\section{References}

Schroeder, P. R., T. S. Dozier, P. A Zappi, B. M. McEnroe, J. W. Sjostrom, and R. L. Peyton, "The Hydrologic Evaluation of Landfill Performance (HELP) Model, Engineering Documentation for Version 3," EPA/600/R-94/168b, U.S. Environmental Protection Agency, Cincinnati, OH, 1994.

Stephens, M. A., "EDF statistics for goodness of fit and some comparisons," J. Amer. Stat. Assoc., 69(347):730-737, 1974.

Thornthwaite, C. W. and J. R. Mather, "Instruction and Tables for Computing Potential Evapotranspiration and the Water Balance," Publications in Climatology, Vol. X, No. 3, Drexel Institute of Technology, Laboratory of Climatology, Centerton, NJ, 1957.

U.S. EPA, "MMSOILS: Multimedia Contaminant Fate, Transport, and Exposure Model. Documentation and User's Manual," Office of Research and Development, Washington, DC, 1992.

U.S. NRC, "Site Decommissioning Management Plan," NUREG-1444, U. S. Nuclear Regulatory Commission, Washington, DC, 1993.

U.S. NRC, "Branch Technical Position on Site Characterization for Decommissioning," U. S. Nuclear Regulatory Commission, Washington, DC, 1994.
U.S. Soil Conservation Service, National Engineering Handbook, Section 4, Hydrology, U.S. Department of Agriculture, Washington, DC, 1985.

van Genuchten, M. Th., "A closed-form equation for predicting the hydraulic conductivity of unsaturated soils," Soil Sci. Soc. Am. J., 44:892-898, 1980.

Whelan, G., D. L. Strenge, J. G. Droppo, Jr., B. L. Steelman, and J. W. Buck, "The Remedial Action Priority System (RAPS): Mathematical Formulations," DOE/RL/87-09 (also PNL-6200), Pacific Northwest Laboratory, Richland, WA, 1987.

Yu, C., A. J. Zielen, J.-J. Cheng, Y. C. Yuan, L. G. Jones, D. J. LePoire, Y.Y Wang, C. O. Loureiro, E. Gnanapragasam, E. Faillace, A. Wallo III, W. A. Williams, and H. Peterson, "Manual for Implementing Residual Radioactive Material Guidelines Using RESRAD, Version 5.0," ANL/EAD/LD-2, Argonne National Laboratory, Argonne, IL, 1993a.

Yu, C., C. Loureiro, J.-J. Cheng, L. G. Jones, Y. Y. Wang, Y. P. Chia, and E. Faillace, "Data Collection Handbook to Support Modeling the Impacts of Radioactive Material in Soil," ANL/EAIS-8, Argonne National Laboratory, Argonne, IL, 1993b. 


\section{Appendix A： Recommended Soil Parameter Distributions}

Probability distributions of three types (normal, lognormal, and beta) were used to approximate the soil hydraulic parameter distributions generated from the Carsel and Parrish (1988) statistics. This appendix provides a summary of these distributions and presents tables of recommended distributions for selected soil hydraulic parameters. The information provided in Sections A.1 - A.3 can be found in many good probability or statistics textbooks (e.g., Ang and Tang, 1975).

\section{A.1 The Normal Distribution}

The normal distribution has a density function given by

$$
f(x)=\frac{1}{\sqrt{2 \pi} \sigma^{\prime}} \exp \left[\frac{1}{2}\left(\frac{x-\mu^{\prime}}{\sigma^{\prime}}\right)^{2}\right]
$$

where $x$ is the soil parameter being modeled and $\mu^{\prime}$ and $\sigma^{\prime}$ are the parameters of the distribution. The mean, $\mu$, and the variance, $\sigma^{2}$, are related to the parameters of the normal distribution as follows.

$$
\begin{aligned}
\mu & =\mu^{\prime} \\
\sigma^{2} & =\sigma^{2}
\end{aligned}
$$

Although the normal distribution is unbounded, soil parameters modeled by a normal distribution often have physical limits. These limits can be enforced by specifying that the soil parameter values fall between given quantiles of the normal distribution. In the tables below, the lower $(A)$ and upper $(B)$ limits of each normal distribution are the 0.001 and 0.999 quantiles calculated as follows.

$$
A=\mu^{\prime}-3.09 \sigma^{\prime} \quad B=\mu^{\prime}+3.09 \sigma^{\prime}
$$

\section{A.2 The Lognormal distribution}

The lognormal distribution has a density function given by

$$
f(x)=\frac{1}{\sqrt{2 \pi} \zeta x} \exp \left[\frac{1}{2}\left(\frac{\ln (x)-\gamma}{\zeta}\right)^{2}\right]
$$

where $\gamma$ and $\zeta$ are the parameters of the distribution. The mean and variance of the lognormal distribution are related to the parameters as follows.

$$
\begin{gathered}
\mu=\exp \left(\gamma+\frac{1}{2} \zeta^{2}\right) \\
\sigma^{2}=\mu^{2}\left[\exp \left(\zeta^{2}\right)-1\right]
\end{gathered}
$$

These relationships can also be inverted.

$$
\gamma=\ln \mu-\frac{1}{2} \zeta^{2}
$$

$$
\zeta=\sqrt{\ln \left(\frac{\sigma^{2}}{\mu^{2}}+1\right)}
$$

The lognormal distribution is thus completely specified by either its parameters or its mean and variance.

The lognormal distribution is bounded below by zero, but has no upper bound. In the tables below, the lower and upper bound for the lognormal distributions are the 0.001 and 0.999 quantiles calculated as follows.

$$
A=\exp (\gamma-3.09 \zeta) \quad B=\exp (\gamma+3.09 \zeta)
$$

\section{A.3 The Beta Distribution}

The beta distribution has a density function given by

$$
f(x)=\frac{1}{\beta(q, r)} \frac{(x-A)^{q-1}(B-x)^{r-1}}{(B-A)^{q+r-1}}
$$

where $q$ and $r$ are parameters controlling the shape of the distribution and $A$ and $B$ are the lower and upper limits of the distribution. $\beta(q, r)$ is the beta function, calculated through its relationship to the gamma function.

$$
\beta(q, r)=\frac{\Gamma(q) \Gamma(r)}{\Gamma(q+r)}
$$

where $\Gamma()$ indicates the gamma function.

The mean and variance of the beta distribution are related to the parameters as follows.

$$
\begin{gathered}
\mu=A+\frac{q}{q+r}(B-A) \\
\sigma^{2}=\frac{q r}{(q+r)^{2}(q+r+1)}(B-A)^{2}
\end{gathered}
$$

With some algebraic manipulation, these relationships can be inverted to provide the shape parameters as a function of the mean, variance, and limits.

$$
\begin{gathered}
\eta=\left(\frac{(B-\mu)(\mu-A)}{\sigma^{2}}-1\right)\left(\frac{\mu-A}{B-A}\right) \\
r=q\left(\frac{B-\mu}{\mu-A}\right)
\end{gathered}
$$

The beta distribution can thus be completed specified by its lower and upper limits and either its mean and variance or its shape parameters.

In the tables below, the lower and upper limits for the beta distributions are the actual limits, $A$ and $B$. 


\section{A.4 Recommended Probability Distributions for Soil Hydraulic Parameters by Soil Texture}

Tables A-1 to A-12 contain the recommended distributions for the selected soil hydraulic parameters. Each table represents a particular USDA soil textural classification.

Observed correlations between parameters are given in Appendix B.

Table A-1. Recommended distributions for Sand

\begin{tabular}{|c|c|c|c|c|c|}
\hline Parameter & Distribution $^{1}$ & Mean & Std. Deviation & Lower Limit ${ }^{2}$ & Upper Limit ${ }^{2}$ \\
\hline$\theta_{s}$ & Normal & 0.430 & 0.0600 & 0.245 & 0.615 \\
\hline$\theta$ & $\operatorname{LN}(3.09,0.224) *$ & 0.0466 & 0.0106 & 0.0228 & 0.0907 \\
\hline$p_{e}$ & Normal & 0.383 & 0.0610 & 0.195 & 0.572 \\
\hline f. & $\operatorname{IN}(-2.83 .0 .241)$ & 0.0607 & 0.0150 & 0.0280 & 0.124 \\
\hline$w_{p}$ & $\mathrm{LN}(-3.09,0.224)$ & 0.0466 & 0.0106 & 0.0227 & 0.0907 \\
\hline anve & $\operatorname{lN}(-4.34,0.387)$ & 0.0141 & $6.12 \mathrm{E}_{03}$ & $395 \mathrm{E} 03$ & 0.0431 \\
\hline$\alpha\left[\mathrm{cm}^{-1}\right]$ & Normal & 0.147 & 0.0255 & 0.0687 & 0.226 \\
\hline$n$ & LN(0.978000998) & 2.67 & 0267 & 1.95 & 3.62 \\
\hline$h_{b}$ & LN $(1.93,0.183)$ & 7.02 & 1.38 & 3.92 & 12.1 \\
\hline$\lambda$ & INos $502,0.161)$ & 1.67 & 0.267 & 1.00 & 2.72 \\
\hline$b$ & $\mathrm{LN}(-0.0253,0.216)$ & 0.998 & 0.226 & 0.501 & 1.90 \\
\hline R $[\mathrm{cm} / \mathrm{s}]$ & $\operatorname{Beta}(1.398,1.842)$ & $822 \mathrm{E}-03$ & $4.39 \mathrm{E}-03$ & $350 \mathrm{E}-04$ & 0.0186 \\
\hline
\end{tabular}

Table A-2. Recommended distributions for Loamy Sand

\begin{tabular}{|c|c|c|c|c|c|}
\hline Parameter & Distribution 1 & Mean & Std. Deviation & Lower Limit ${ }^{2}$ & Upper Limit $^{2}$ \\
\hline$\theta_{s}$ & Normal & 0.410 & 0.0900 & 0.132 & 0.688 \\
\hline 酐 & Normal & 0.0569 & 0.0145 & 0.0121 & 0.102 \\
\hline$p_{e}$ & Normal & 0.353 & 0.0913 & 0.0711 & 0.635 \\
\hline$f_{c}$ & $\mathrm{LN}(2,55,0.281)$ & 0.0809 & 00224 & 0.0327 & 0.186 \\
\hline$w_{p}$ & Normal & 0.0570 & 0.0146 & 0.0119 & 0.102 \\
\hline awe & LN( $(3.85 .0499)$ & 0.0239 & 0.0125 & $4.65 \mathrm{E}-03$ & 0.0966 \\
\hline$\alpha\left[\mathrm{cm}^{-1}\right]$ & Normal* & 0.125 & 0.0404 & 2.03E-04 & 0.250 \\
\hline$n$ & LN(0.81600910) & 227 & 0269 & 1.71 & 300 \\
\hline$h_{b}$ & $\mathrm{LN}(2.15,0.401)$ & 9.58 & 8.59 & 2.48 & 29.5 \\
\hline X & $1 N(0.2260 .164)$ & 127 & 0.209 & 0.756 & 2.08 \\
\hline$b$ & $\mathrm{LN}(0.305,0.258)$ & 1.40 & 0.397 & 0.610 & 3.01 \\
\hline R. [cm/s] & Betr $(0.7992,1.910)$ & $3.99 \mathrm{E}-03$ & $317 \mathrm{E} \cdot 3$ & $300 \mathrm{E}-05$ & 0.0134 \\
\hline
\end{tabular}


Table A-3. Recommended distributions for Sandy Loam

\begin{tabular}{|c|c|c|c|c|c|}
\hline Parameter & Distribution $^{1}$ & Mean & Std. Deviation & Lower Limit $^{2}$ & Upper Limit ${ }^{2}$ \\
\hline$\theta_{\mathrm{s}}$ & Normal & 0.410 & 0.0899 & 0.132 & 0.688 \\
\hline$\theta$ & $\operatorname{Beta}(2,885,2,304)$ & 0.0644 & 00169 & 0.0173 & 0.102 \\
\hline$p_{e}$ & Normal & 0.346 & 0.0915 & 0.0629 & 0.628 \\
\hline$f_{c}$ & $1 \mathrm{NN}(-2,21,0.314)$ & 0116 & 0.0369 & 00417 & 0.291 \\
\hline$w_{p}$ & Normal & 0.0659 & 0.0179 & 0.0106 & 0.121 \\
\hline arve & $\mathrm{LN}(3,12,0.489)$ & 00498 & 0.0256 & $9.75 \mathrm{P} .03$ & 0.200 \\
\hline$\alpha\left[\mathrm{cm}^{-1}\right]$ & Beta(1.816,3.412) & 0.0757 & 0.0368 & 8.72E-03 & 0.202 \\
\hline$n$ & $1 N(0.6340 .0818)^{t}$ & 1.89 & 0.155 & 1.46 & 2.43 \\
\hline$h_{b}$ & $\mathrm{LN}(2.71,0.538)$ & 17.7 & 12.0 & 2.85 & 79.4 \\
\hline$\lambda$ & Normal & 0.892 & 0.155 & 0.412 & 137 \\
\hline$b$ & $\mathrm{LN}(0.632,0.282)$ & 1.96 & 0.597 & 0.786 & 4.50 \\
\hline R, $[\mathrm{col} / \mathrm{s}]$ & $1 \mathrm{~N}(7,46,1.33)$ & $1.17 \mathrm{E} 03$ & $137 \mathrm{E} .03$ & $962 \mathrm{E} \cdot 06$ & 00347 \\
\hline
\end{tabular}

Table A-4. Recommended distributions for Sandy Clay Loam

\begin{tabular}{|c|c|c|c|c|c|}
\hline Parameter & Distribution $^{1}$ & Mean & Std. Deviation & Lower Limit ${ }^{2}$ & Upper Limit ${ }^{2}$ \\
\hline$\overline{\theta_{s}}$ & Normal & 0.390 & 0.0700 & 0.174 & 0.606 \\
\hline$\theta_{1}$ & $\operatorname{Beta}(2.2022 .010)$ & 0.101 & $6.09 \mathrm{e}-03$ & 0.0860 & 0.114 \\
\hline$p_{e}$ & Normal & 0.289 & 0.0703 & 0.0723 & 0.507 \\
\hline$f_{c}$ & $1 N(-159.0 .254)$ & 0.212 & 0.0568 & 0.0933 & 0.449 \\
\hline$w_{p}$ & LN(-2.14,0.158) & 0.120 & 0.0214 & 0.0724 & 0.193 \\
\hline awe & Beta $(1890,3.817)$ & 0,0920 & 0.0393 & 0.0204 & 0.237 \\
\hline$\alpha\left[\mathrm{cm}^{-1}\right]$ & $\mathrm{LN}(-3.04,0.639)$ & 0.0572 & 0.0337 & $6.62 \mathrm{E}-03$ & 0.343 \\
\hline$n$ & $\operatorname{LN}(0.388,0.0858) *$ & 148 & 0.127 & 1.13 & 1.92 \\
\hline$h_{b}$ & $\mathrm{LN}(3.04,0.639)$ & 26.2 & 21.3 & 2.92 & 151. \\
\hline 2 & Normal & 0.479 & 0.127 & 0.0865 & 0.872 \\
\hline$b$ & $\operatorname{LN}(1.41,0.275)$ & 4.27 & 1.39 & 1.75 & 9.57 \\
\hline R. $[\mathrm{cm} / \mathrm{s}]$ & $1 \mathrm{NN}(-9.30,175)$ & $3.23 \mathrm{E}-04$ & $5.98 \mathrm{E}-04$ & $4.12 \mathrm{E}-07$ & 0.0202 \\
\hline
\end{tabular}


Recommended Soil Parameter Distributions

Table A-5. Recommended distributions for Loam

\begin{tabular}{|c|c|c|c|c|c|}
\hline Parameter & Distribution $^{1}$ & Mean & Std. Deviation & Lower Limit ${ }^{2}$ & Upper Limit ${ }^{2}$ \\
\hline$\theta_{s}$ & Normal & 0.430 & 0.0998 & 0.122 & 0.738 \\
\hline 6. & $\operatorname{Bet}(3.639,2.652)$ & 0.0776 & 0.0127 & 0.0374 & 0.107 \\
\hline$p_{e}$ & Normal & 0.352 & 0.101 & 0.0414 & 0.663 \\
\hline$f_{c}$ & $1 / N(1,68.0 .300)$ & 0.194 & 0.6609 & 0.0735 & 0.468 \\
\hline$w_{p}$ & $\mathrm{LN}(-2.40,0.250)$ & 0.0935 & 0.0246 & 0.0418 & 0.196 \\
\hline owe & $1 / N(-2,400.462)$ & 0.101 & 0.0454 & 0.0218 & 0.380 \\
\hline$\alpha\left[\mathrm{cm}^{-1}\right]$ & $\operatorname{Beta}(1.576,3.625)$ & 0.0367 & 0.0202 & $3.51 \mathrm{E}-03$ & 0.113 \\
\hline$n$ & $1 \mathrm{~N}(0.442,0.0730)$ & 1.56 & 0.14 & 1.24 & 1.95 \\
\hline$h_{b}$ & $\operatorname{LN}(3.470,0.598)$ & 38.9 & 29.3 & 5.05 & 203. \\
\hline 2 & Normal & 0.560 & 0.114 & 0.209 & 0.911 \\
\hline$b$ & $\mathrm{LN}(1.08,0.271)$ & 3.07 & 0.900 & 1.28 & 6.82 \\
\hline 1. $[\mathrm{cm} / \mathrm{s}]$ & $\operatorname{LN}(-9.26,1,66)$ & $2.92 \mathrm{E}-04$ & $4.911-04$ & $5.51 \mathrm{E}-07$ & 0.0159 \\
\hline
\end{tabular}

Table A-6. Recommended distributions for Silt Loam

\begin{tabular}{|c|c|c|c|c|c|}
\hline Parameter & Distribution $^{1}$ & Mean & Std. Deviation & Lower Limit ${ }^{2}$ & Upper Limit $^{2}$ \\
\hline$\theta_{s}$ & Normal & 0.45 & 0.0800 & 0.203 & 0.697 \\
\hline$\theta_{1}$ & $\operatorname{Beta}(3.349,2,566)$ & 0.0670 & 0.0142 & 0.0243 & 0.0998 \\
\hline$p_{e}$ & Normal & 0.383 & 0.0813 & 0.132 & 0.634 \\
\hline$f$. & Nornal & 0.252 & 0.0776 & 0.0119 & 0.491 \\
\hline$w_{p}$ & $\mathrm{LN}(-2.22,0.397)$ & 0.117 & 0.0471 & 0.0318 & 0.368 \\
\hline awe & Normal & 0.135 & 0.0402 & 0.0107 & 0.259 \\
\hline$\alpha\left[\mathrm{cm}^{-1}\right]$ & LN $(-4.10,0.554)^{*}$ & 0.0193 & 0.0115 & $2.99 \mathrm{E}-03$ & 0.0919 \\
\hline$n$ & LN $(0.343,0.0851)$ & 1.41 & 0,120 & 1.08 & 183 \\
\hline$h_{b}$ & $\mathrm{LN}(4.10,0.554)$ & 70.3 & 41.9 & 10.9 & 335. \\
\hline$\lambda$ & Normal & 0.414 & 0.120 & 0.0417 & 0.786 \\
\hline$b$ & $\mathrm{LN}(1.28,0.334)$ & 3.80 & 1.42 & 1.28 & 10.1 \\
\hline$r_{3}[\mathrm{~cm} / \mathrm{s}]$ & $\mathrm{IN}(-10.4,1.49)$ & $9.33 \mathrm{E}-05$ & $2.24 \mathrm{E}-04$ & $3.12 \mathrm{E} \cdot 07$ & 3. $11 \mathrm{E} \cdot 03$ \\
\hline
\end{tabular}


Table A-7. Recommended distributions for Silt

\begin{tabular}{|c|c|c|c|c|c|}
\hline Parameter & Distribution $^{1}$ & Mean & Std. Deviation & Lower Limit ${ }^{2}$ & Upper Limit ${ }^{2}$ \\
\hline$\overline{\theta_{s}}$ & Normal & 0.456 & 0.110 & 0.1206 & 0.799 \\
\hline 6 & Beta $(17,7,1.072)$ & 0.0352 & $8.97 \mathrm{e} 03$ & 0.0131 & 0.0490 \\
\hline$p_{e}$ & Normal & 0.425 & 0.110 & 0.0839 & 0.766 \\
\hline$f$ & Nomal & 0.236 & 0.0578 & 00575 & 0.415 \\
\hline$w_{p}$ & $\operatorname{LN}(-2.46,0.295)$ & 0.0890 & 0.0268 & 0.0342 & 0.212 \\
\hline$a+c$ & Normal & 0.147 & 00395 & 0.0252 & 0269 \\
\hline$\alpha\left[\mathrm{cm}^{-1}\right]$ & Normal* & 0.0178 & $5.73 \mathrm{E}-03$ & $3.91 \mathrm{E}-05$ & 0.0355 \\
\hline$n$ & Normalt & 1.38 & 0.0369 & 1.27 & 1.49 \\
\hline$h_{b}$ & $\operatorname{LN}(4.10,0.403)$ & 68.1 & 74.8 & 17.3 & 209. \\
\hline$\lambda$ & Normal & 0.380 & 0.6369 & 0.266 & 0.494 \\
\hline$b$ & LN(1.16,0.140) & 3.21 & 0.465 & 2.06 & 4.89 \\
\hline f. $[\mathrm{cm} / \mathrm{s}$ & $1 \mathrm{~N}(10.0,0.475)$. & 4.891805 & $2.76 \mathrm{E} .05$ & $9.95 \mathrm{E}-06$ & $1.871 \mathrm{e} 04$ \\
\hline
\end{tabular}

Table A-8. Recommended distributions for Clay Loam

\begin{tabular}{|c|c|c|c|c|c|}
\hline Parameter & Distribution 1 & Mean & Std. Deviation & Lower Limit ${ }^{2}$ & Upper Limit ${ }^{2}$ \\
\hline$\theta_{\mathrm{s}}$ & Normal & 0.410 & 0.0900 & 0.132 & 0.688 \\
\hline 6 & Nomal & 0.0954 & $968 \mathrm{E}-03$ & 00655 & 0.125 \\
\hline$p_{e}$ & Normal & 0.315 & 0.0905 & 0.0349 & 0.594 \\
\hline$f=$ & $1 \mathrm{NN}(-1.27 .0 .297)$ & 0,292 & 0.0862 & 0.112 & 0.700 \\
\hline$w_{p}$ & $\mathrm{LN}(-1.84,0.257)$ & 0.164 & 0.0468 & 0.0714 & 0.350 \\
\hline awe & Beta $(2986.4318)$ & 0,128 & 0.0497 & $9.34 \mathrm{E} 03$ & 0.301 \\
\hline$\alpha\left[\mathrm{cm}^{-1}\right]$ & $\operatorname{LN}(-4.22,0.719)^{*}$ & 0.0190 & 0.0153 & $1.59 \mathrm{E}-03$ & 0.136 \\
\hline m & Normal & 1,32 & 0.0973 & 1.02 & 1.62 \\
\hline$h_{b}$ & $\mathrm{LN}(4.22,0.719)$ & 88.0 & 71.3 & 7.37 & 628. \\
\hline$\lambda$ & Nomil & 0.318 & 0.0973 & 00170 & 0.618 \\
\hline$b$ & LN $(1.73,0.323)$ & 5.97 & 2.37 & 2.08 & 15.3 \\
\hline R. $[\mathrm{cm} / \mathrm{s}]$ & $4 \mathrm{~N}(11,3,2,17)$ & $998 \mathrm{E} 05$ & $2.51 \mathrm{E} .04$ & $1,42 \mathrm{E} 08$ & $976 \mathrm{E}=03$ \\
\hline
\end{tabular}


Recommended Soil Parameter Distributions

Table A-9. Recommended distributions for Silty Clay Loam

\begin{tabular}{|c|c|c|c|c|c|}
\hline Parameter & Distribution $^{1}$ & Mean & Std. Deviation & Lower Limit ${ }^{2}$ & Upper Limit ${ }^{2}$ \\
\hline$\theta_{s}$ & Normal & 0.430 & 0.0699 & 0.214 & 0.646 \\
\hline$\theta$ & Nornal & 0.0880 & $900 \mathrm{E} 03$ & 0.0602 & 0.116 \\
\hline$p_{e}$ & Normal & 0.342 & 0.0705 & 0.124 & 0.560 \\
\hline$f_{c}$ & Normal & 0.347 & 0.0710 & 0127 & 0.566 \\
\hline$w_{p}$ & LN $(-1.61,0.233)$ & 0.205 & 0.0508 & 0.0970 & 0.410 \\
\hline arc & Nornal & 0.142 & 0.0333 & 0.0387 & 6245 \\
\hline$\alpha\left[\mathrm{cm}^{-1}\right]$ & $\mathrm{LN}(-4.72,0.563)$ & 0.0104 & $6.08 \mathrm{E}-03$ & $1.57 \mathrm{E}-03$ & 0.0508 \\
\hline$n$ & Nomal & 1.23 & 0.0610 & 1.04 & 1.42 \\
\hline$h_{b}$ & $\operatorname{LN}(4.72,0.563)$ & 132. & 81.4 & 19.7 & 638. \\
\hline$\lambda$ & Nomal & 0.230 & 0.0610 & 0.0416 & 0.418 \\
\hline$b$ & $\mathrm{LN}(1.96,0.265)$ & 7.13 & 2.34 & 3.02 & 15.5 \\
\hline$K_{s}[\mathrm{~cm} / \mathrm{s}]$ & $12 N(12,3,1.59)$ & $154 \mathrm{E} 05$ & $3.38 \mathrm{E}-05$ & $3.4, E 08$ & $6.49 \mathrm{E}-04$ \\
\hline
\end{tabular}

Table A-10. Recommended distributions for Sandy Clay

\begin{tabular}{|c|c|c|c|c|c|}
\hline Parameter & Distribution $^{1}$ & Mean & Std. Deviation & Lower Limit ${ }^{2}$ & Upper Limit ${ }^{2}$ \\
\hline$\theta_{s}$ & Normal & 0.380 & 0.0500 & 0.226 & 0.534 \\
\hline$\theta_{t}$ & Beta $(4000,1.487)$ & 0.0993 & 0.0116 & 0.0508 & 0.117 \\
\hline$p_{e}$ & Normal & 0.281 & 0.0513 & 0.122 & 0.439 \\
\hline$f$ & LN $(1230210)$ & 0.299 & 0.0623 & 0.153 & 0.559 \\
\hline$w_{p}$ & $\operatorname{Beta}(1.142,4.640)$ & 0.165 & 0.0344 & 0.121 & 0.346 \\
\hline ans & Nornal & 0.134 & 0.0356 & 00238 & 0.244 \\
\hline$\alpha\left[\mathrm{cm}^{-1}\right]$ & LN $(-3.77,0.562)^{*}$ & 0.0270 & 0.0164 & $4.06 \mathrm{E}-03$ & 0.131 \\
\hline$n$ & LN $(0.241,00653)^{*}$ & 128 & 0.0834 & 104 & 1.56 \\
\hline$h_{b}$ & $\operatorname{LN}(3.77,0.562)$ & 50.7 & 30.5 & 7.64 & 246. \\
\hline$\lambda$ & Normal & 0.275 & 0.0834 & 0.0177 & 0.533 \\
\hline$b$ & $\operatorname{LN}(1.89,0.260)$ & 6.90 & 2.27 & 2.97 & 14.8 \\
\hline $\mathrm{R}_{S}[\mathrm{~cm} / \mathrm{s}]$ & $\operatorname{LN}(12,2,2.02)^{*}$ & $3.5512-05$ & $1.48 \mathrm{E}-04$ & $9.59 \mathrm{R} 09$ & $250 \mathrm{E}-03$ \\
\hline
\end{tabular}


Table A-11. Recommended distributions for Silty Clay

\begin{tabular}{|c|c|c|c|c|c|}
\hline Parameter & Distribution ${ }^{1}$ & Mean & Std. Deviation & Lower Limit ${ }^{2}$ & Upper Limit $^{2}$ \\
\hline$\theta_{\mathrm{s}}$ & Normal & 0.360 & 0.0698 & 0.144 & 0.576 \\
\hline$\theta_{3}$ & Normalt & 0.0706 & 0.0228 & $1.47 \mathrm{E} .64$ & 0.141 \\
\hline$p_{e}$ & Normal & 0.289 & 0.0735 & 0.0623 & 0.517 \\
\hline$f_{C}$ & Normal & 0.334 & 0.0678 & 0.124 & 0.543 \\
\hline$w_{p}$ & $\mathrm{LN}(-1.49,0.220)$ & 0.230 & 0.0512 & 0.114 & 0.444 \\
\hline are & Normal & 0.103 & 0.0303 & $9.63 \mathrm{E}-03$ & 0.197 \\
\hline$\alpha\left[\mathrm{cm}^{-1}\right]$ & LN $(-5.66,0.584)^{*}$ & 4.13E-03 & $2.60 \mathrm{E}-03$ & $5.73 \mathrm{E}-04$ & 0.0211 \\
\hline$n$ & LN(0.145,0.0430) & 1.16 & 0.0499 & 1.01 & 132 \\
\hline$h_{b}$ & $\operatorname{LN}(5.66,0.584)$ & 340. & 216. & 47.3 & 1743. \\
\hline$\lambda$ & $\operatorname{Beta}(2.591,3.268)$ & 0.157 & 0.0499 & 0.0404 & 0.304 \\
\hline$b$ & $\operatorname{LN}(2.29,0.259)$ & 10.2 & 2.96 & 4.43 & 22.0 \\
\hline R. [chis] & $12 N(-13,9,1.31)^{*}$ & $2: 191806$ & $4.08 \mathrm{E}-06$ & 1.6416 .08 & $5.37 \mathrm{E}-05$ \\
\hline
\end{tabular}

Table A-12. Recommended distributions for Clay

\begin{tabular}{|c|c|c|c|c|c|}
\hline Parameter & Distribution $^{1}$ & Mean & Std. Deviation & Lower Limit $^{2}$ & Upper Limit ${ }^{2}$ \\
\hline$\theta_{\mathrm{s}}$ & Normal & 0.380 & 0.0900 & 0.102 & 0.658 \\
\hline 6. & Betar $1.501,1.580)$ & 0.0685 & 0.0344 & $8.36 \mathrm{E}-04$ & 0.140 \\
\hline$p_{e}$ & Normal & 0.311 & 0.0963 & 0.0138 & 0.609 \\
\hline$f_{c}$ & Normal & 0.340 & 0.0893 & 0.0638 & 0.615 \\
\hline$w_{p}$ & $\operatorname{Beta}(2.751,4.921)$ & 0.263 & 0.0770 & 0.0939 & 0.567 \\
\hline awe & $\mathrm{LN}(-2.66,0.429)$ & 0.0761 & 0.0299 & 0.0186 & 0.263 \\
\hline$\alpha\left[\mathrm{cm}^{-1}\right]$ & $\mathrm{LN}(-5.54,0.893)$ & $6.18 \mathrm{E}-03$ & $7.59 \mathrm{E}-03$ & $2.50 \mathrm{E}-04$ & 0.0621 \\
\hline$n$ & Beta(0.8857.2.400) & 1.13 & 0.0697 & 1.04 & 1.36 \\
\hline$h_{b}$ & $\operatorname{Beta}(0.8002,1.546)$ & 353. & 257. & 14.1 & 1007 \\
\hline$\lambda$ & Beta $(0.8854,2,399)$ & 0.127 & 0.0697 & 0.0397 & 0.365 \\
\hline$b$ & $\operatorname{Beta}(1.751,11.61)$ & 14.1 & 6.24 & 4.93 & 75.0 \\
\hline$R^{2}[\mathrm{~cm} / \mathrm{s}]$ & $1 N(12,36,2,269)$ & 3.65005 & $108 \mathrm{EO} 04$ & $3.87 \mathrm{E}-09$ & $4.76 \mathrm{E} 103$ \\
\hline
\end{tabular}

1. $\mathrm{LN}()=$, Lognormal $(\gamma, \zeta)$; see Section A.2. Beta $()=,B e t a(q, r)$; see Section A.3.

2. Lower Limit and Upper Limit are 0.001 and 0.999 quantiles for Normal and Lognormal distributions.

* Indicates that the recommended distribution is the same type as used by Carsel and Parrish (1988). This applies to the parameters $\theta_{\Gamma} \alpha, n$, and $K_{s}$ only.

\section{A.5 References}

Ang, A. H-S. and W. H. Tang, Probability Concepts in Engineering Planning and Design, Volume 1, Basic Principles, John Wiley \& Sons, New York, 409 pp., 1975.
Carsel, R. F., and R. S. Parrish, "Developing joint probability distributions of soil water retention characteristics," Water Resources Research, 24(5):755-770, 1988. 


\section{Appendix B: Soil Parameter Correlation Coefficients}

The correlation coefficient is a measure of the strength of a linear relationship between two random variables (i.e., soil parameters), $X$ and $Y$. Sample correlation coefficients were calculated as follows [e.g., Ang and Tang (1975)].

$$
\hat{\rho}=\frac{1}{N-1} \frac{\sum_{i=1}^{N} x_{i} y_{i}-N \bar{x} \bar{y}}{s_{x} s_{y}}
$$

where

$\hat{\rho} \quad=$ sample correlation coefficient

$x_{i}, y_{i}=$ sample values for parameters $X$ and $Y$

$\bar{x}, \bar{y}=$ sample mean values calculated as

$$
\vec{x}=\frac{1}{N} \sum_{i=1}^{N} x_{i}
$$

$s_{x} s_{y}=$ sample standard deviations calculated as

$$
s_{x}^{2}=\frac{1}{N-1} \sum_{i=1}^{N}\left(x_{i}-\bar{x}\right)^{2}
$$

$N \quad=$ the number of sample values

Correlations between parameters were induced by applying the correlations between $\theta_{\mathrm{r}} \alpha, n$, and $K_{s}$ given in Carsel and Parrish (1988). The rank correlation method of Iman and Conover (1982) as embodied in the Latin hypercube sampling code of Iman and Shortencarier (1984) was used. Note that the correlations given in the tables below do not necessarily appear to be the same as those of Carsel and Parrish (1988) since their correlations were calculated after the parameters were transformed to normal distributions. The correlations given below were calculated on the untrans-

\begin{tabular}{|c|c|c|c|c|c|c|c|c|c|c|c|c|}
\hline & $\theta_{s}$ & $\theta_{\mathbf{r}}$ & $\mathbf{p}_{\mathbf{e}}$ & $\mathbf{f}_{\mathrm{c}}$ & $\mathbf{w}_{\mathbf{p}}$ & awc & $\alpha$ & $\mathbf{n}$ & $\mathbf{h}_{\mathbf{b}}$ & $\lambda$ & b & $\mathbf{K}_{\boldsymbol{s}}$ \\
\hline$\theta_{s}$ & 1 & -0.01 & 0.99 & 0.15 & -0.01 & 0.38 & 0.00 & 0.00 & -0.02 & 0.00 & -0.29 & 0.00 \\
\hline$\theta_{1}$ & & 1 & -0.18 & 0.94 & 1 & 0.59 & 0.12 & -0.84 & -0.12 & -0.84 & 0.91 & -0.50 \\
\hline $\mathbf{p e}$ & & & 1 & -0.02 & -0.18 & 0.27 & -0.02 & 0.15 & 0.01 & 0.15 & -0.44 & 0.08 \\
\hline 1 & & & & 1 & 0.94 & 0.82 & -0.11 & .091 & 0.11 & -0.91 & 0.89 & 0.67 \\
\hline $\mathbf{w}_{\mathbf{p}}$ & & & & & 1 & 0.59 & 0.12 & -0.84 & -0.12 & -0.84 & 0.91 & -0.50 \\
\hline awc & & & & & & 1 & -0.49 & -0.79 & 0.49 & .0 .79 & 0.59 & 0.78 \\
\hline$\alpha$ & & & & & & & 1 & 0.29 & -0.97 & 0.29 & -0.09 & 0.73 \\
\hline$n$ & & & & & & & & 1 & -0.28 & 1 & -0.88 & 0.84 \\
\hline $\mathbf{h}_{\mathbf{b}}$ & & & & & & & & & 1 & -0.28 & 0.09 & -0.68 \\
\hline$\lambda$ & & & & & & & & & & 1 & 0.88 & 0.84 \\
\hline b & & & & & & & & & & & 1 & -0.65 \\
\hline$R_{s}$ & & & & & & & & & & & & 1 \\
\hline
\end{tabular}
formed parameters.

Table B-1. Correlation coefficients for Sand 
Soil Parameter Correlation Coefficients

Table B-2. Correlation coefficients for Loamy Sand

\begin{tabular}{|c|c|c|c|c|c|c|c|c|c|c|c|c|}
\hline & $\theta_{\mathbf{s}}$ & $\theta_{\mathbf{r}}$ & $\mathbf{p e}_{\mathbf{e}}$ & $\mathbf{f}_{\mathrm{c}}$ & $\mathbf{w}_{\mathbf{p}}$ & awc & $\alpha$ & $\mathbf{n}$ & $h_{b}$ & $\lambda$ & b & $\mathbf{K}_{\mathbf{s}}$ \\
\hline$\theta_{s}$ & 1 & -0.01 & 0.99 & 0.27 & 0.00 & 0.49 & 0.00 & 0.01 & -0.03 & 0.01 & -0.50 & 0.01 \\
\hline $6_{r}$ & & 1. & 0.16 & 0.85 & 1 & 0.34 & -0.29 & -0.58 & 0.16 & 0.58 & 0.71 & 0.34 \\
\hline $\mathbf{p}_{\mathbf{e}}$ & & & 1 & 0.13 & -0.16 & 0.42 & 0.05 & 0.10 & -0.05 & 0.10 & -0.60 & 0.07 \\
\hline$f_{c}$ & & & & 1 & 0.85 & 0.79 & -0.53 & 0.76 & 033 & -0.76 & 0.57 & 0.58 \\
\hline $\mathbf{w}_{\mathbf{p}}$ & & & & & 1 & 0.35 & -0.30 & -0.58 & 0.17 & -0.58 & 0.72 & -0.35 \\
\hline ance & & & & & & 1 & -0.60 & -0.68 & 0.39 & -0.68 & 0.19 & -0.63 \\
\hline$\alpha$ & & & & & & & 1 & 0.38 & -0.57 & 0.38 & -0.29 & 0.88 \\
\hline$n$ & & & & & & & & 1 & $=0.22$ & 1. & 0.64 & 0.65 \\
\hline $\mathbf{h}_{\mathbf{b}}$ & & & & & & & & & 1 & -0.22 & 0.17 & -0.38 \\
\hline$\lambda$ & & & & & & & & & & 1. & 0.64 & 0.65 \\
\hline b & & & & & & & & & & & 1 & -0.41 \\
\hline K & & & & & & & & & & & & 1 \\
\hline
\end{tabular}

Table B-3. Correlation coefficients for Sandy Loam

\begin{tabular}{|c|c|c|c|c|c|c|c|c|c|c|c|c|}
\hline & $\theta_{s}$ & $\theta_{\mathbf{r}}$ & $\mathbf{P e}_{\mathbf{e}}$ & $\mathbf{f}_{c}$ & $w_{p}$ & awc & $\alpha$ & $\mathbf{n}$ & $\mathbf{h}_{\mathrm{b}}$ & $\lambda$ & b & $\mathbf{K}_{\mathbf{s}}$ \\
\hline$\theta_{\mathrm{s}}$ & 1 & 0.00 & 0.98 & 0.38 & 0.03 & 0.54 & 0.01 & 0.00 & 0.01 & 0.00 & -0.44 & 0.01 \\
\hline$\theta$ & & 1 & 0.19 & 0.72 & 1. & 0.34 & 0.14 & 0.79 & 0.17 & -0.79 & 0.77 & -0.22 \\
\hline $\mathbf{P e}$ & & & 1 & 0.24 & -0.16 & 0.46 & -0.02 & 0.15 & 0.04 & 0.15 & -0.57 & 0.05 \\
\hline$f_{c}$ & & & & 1. & 0.78 & 0.90 & -0.35 & 0.85 & 0.35 & -0.85 & 0.51 & -0.51 \\
\hline $\mathbf{w}_{\mathbf{p}}$ & & & & & 1 & 0.42 & 0.08 & -0.82 & -0.10 & -0.82 & 0.77 & -0.25 \\
\hline arc & & & & & & 1 & -0.56 & -0.65 & 0.57 & 0.65 & 0.20 & 0.56 \\
\hline$\alpha$ & & & & & & & 1 & 0.36 & -0.77 & 0.36 & -0.11 & 0.82 \\
\hline in. & & & & & & & 8 & 1 & -0.28 & 1 & 0.78 & 0.60 \\
\hline $\mathbf{h}_{\mathbf{b}}$ & & & & & & & & & 1 & -0.28 & 0.05 & -0.51 \\
\hline 1 & & & & & & & & & & 1 & 0.78 & 0.60 \\
\hline b & & & & & & & & & & & 1 & -0.33 \\
\hline 18. & & & & & & & & & & & & 1 \\
\hline
\end{tabular}


Soil Parameter Correlation Coefficients

Table B-4. Correlation coefficients for Sandy Clay Loam

\begin{tabular}{|c|c|c|c|c|c|c|c|c|c|c|c|c|}
\hline & $\theta_{\mathrm{s}}$ & $\theta_{\mathbf{r}}$ & $\mathbf{P e}_{\mathbf{e}}$ & $\mathbf{f}_{\mathbf{c}}$ & $\mathbf{w}_{\mathbf{p}}$ & awc & $\alpha$ & $\mathbf{n}$ & $\mathbf{h}_{\mathrm{b}}$ & $\lambda$ & b & $\mathbf{K}_{\mathbf{s}}$ \\
\hline$\theta_{\mathrm{s}}$ & 1 & 0.00 & 1 & 0.48 & 0.21 & 0.58 & -0.01 & 0.00 & -0.02 & 0.00 & -0.43 & -0.01 \\
\hline$\theta$ & & 1 & 0.09 & -0.02 & 0.23 & -0.16 & 0.77 & 0.11 & 0.36 & 0.11 & 0.21 & 0.16 \\
\hline $\mathbf{P e}$ & & & 1 & 0.48 & 0.19 & 0.59 & -0.04 & 0.01 & 0.01 & 0.01 & -0.45 & -0.03 \\
\hline r. & & & & 1 & 0.88 & 0997 & 0.67 & .0 .81 & 0.66 & -0.8 .1 & 0.42 & 0.50 \\
\hline $\mathbf{w}_{\mathbf{p}}$ & & & & & 1 & 0.73 & -0.51 & -0.81 & 0.68 & -0.81 & 0.65 & -0.33 \\
\hline 018 & & & & & & 1 & -0.69 & 0.73 & 0.58 & 0.73 & 0.24 & 6.54 \\
\hline$\alpha$ & & & & & & & 1 & 0.77 & -0.70 & 0.77 & -0.49 & 0.82 \\
\hline 11 & & & & & & & & 1. & 0.65 & 1 & 0.76 & 0.71 \\
\hline$h_{b}$ & & & & & & & & & 1 & -0.65 & 0.57 & -0.39 \\
\hline 1 & & & & & & & & & & 1 & 0.76 & 0,71 \\
\hline b & & & & & & & & & & & 1 & -0.38 \\
\hline 18 & & & & & & & & & & & & 1 \\
\hline
\end{tabular}

Table B-5. Correlation coefficients for Loam

\begin{tabular}{|c|c|c|c|c|c|c|c|c|c|c|c|c|}
\hline & $\theta_{s}$ & $\theta_{\mathbf{r}}$ & $\mathbf{p}_{\mathbf{e}}$ & $f_{c}$ & $\mathbf{w}_{\mathbf{p}}$ & awc & $\alpha$ & $\mathbf{n}$ & $\mathbf{h}_{\mathbf{b}}$ & $\lambda$ & b & $\mathbf{K}_{\mathbf{s}}$ \\
\hline$\theta_{s}$ & 1 & 0.00 & 0.99 & 0.55 & 0.18 & 0.63 & 0.03 & 0.00 & 0.04 & 0.00 & -0.46 & 0.03 \\
\hline 6. & & 1 & 0.13 & 0.29 & 0.79 & 0.03 & 0.04 & 0.70 & 0.07 & -0.70 & 0.67 & 0.14 \\
\hline $\mathbf{p}_{e}$ & & & 1 & 0.50 & 0.08 & 0.63 & 0.03 & 0.09 & 0.03 & 0.09 & -0.54 & 0.01 \\
\hline 48 & & & & 1 & 0.75 & 0.93 & 0.63 & 0.71 & 070 & 0.71 & 0.28 & 0.41 \\
\hline$w_{p}$ & & & & & 1 & 0.47 & -0.42 & -0.87 & 0.56 & -0.87 & 0.69 & -0.16 \\
\hline 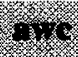 & & & & & & 1 & 0.62 & 0.49 & 0.63 & .0 .49 & 0.00 & -0.46 \\
\hline$\alpha$ & & & & & & & 1 & 0.60 & -0.73 & 0.60 & -0.37 & 0.82 \\
\hline 1, & & & & & & & & 1 & 0.55 & 1 & 0.79 & 0.41 \\
\hline$h_{b}$ & & & & & & & & & 1 & -0.55 & 0.39 & -0.42 \\
\hline 1 & & & & & & & & & & 1 & -0.79 & 0.41 \\
\hline b & & & & & & & & & & & 1 & -0.21 \\
\hline 18 & & & & & & & & & & & & 1 \\
\hline
\end{tabular}


Soil Parameter Correlation Coefficients

Table B-6. Correlation coefficients for Silt Loam

\begin{tabular}{|c|c|c|c|c|c|c|c|c|c|c|c|c|}
\hline & $\theta_{s}$ & $\theta_{\mathbf{r}}$ & $\mathbf{P}_{\mathbf{e}}$ & $\mathbf{f}_{c}$ & $\mathbf{w}_{\mathbf{p}}$ & awc & $\alpha$ & $\mathbf{n}$ & $\mathbf{h}_{\mathrm{b}}$ & $\lambda$ & b & $\mathbf{K}_{\mathbf{s}}$ \\
\hline$\theta_{s}$ & 1 & -0.01 & 0.98 & 0.48 & 0.20 & 0.70 & -0.02 & -0.01 & -0.02 & -0.01 & -0.20 & -0.02 \\
\hline$\theta$. & & 1 & -0.18 & 0.50 & 0.66 & 0.18 & -0.29 & 0.59 & 0.27 & 0.59 & 0.63 & 0.25 \\
\hline $\mathbf{P e}_{\mathbf{e}}$ & & & 1 & 0.39 & 0.08 & 0.66 & 0.03 & 0.10 & -0.06 & 0.10 & -0.31 & 0.03 \\
\hline$f_{c}$ & & & & 1 & 0.91 & 0.87 & 0.72 & -0.80 & 0.73 & 0.80 & 0.63 & 0.45 \\
\hline $\mathbf{w}_{\mathbf{p}}$ & & & & & 1 & 0.58 & -0.63 & -0.89 & 0.73 & -0.89 & 0.86 & -0.36 \\
\hline ave & & & & & & 1 & .0 .65 & -0.50 & 0.54 & .0 .50 & 0.20 & 0.44 \\
\hline$\alpha$ & & & & & & & 1 & 0.74 & -0.75 & 0.74 & -0.56 & 0.80 \\
\hline $\mathrm{n}$ & & & & & & & & 1 & 0.69 & 1 & 0.88 & 0.48 \\
\hline $\mathbf{h}_{\mathbf{b}}$ & & & & & & & & & 1 & -0.69 & 0.68 & -0.39 \\
\hline$\lambda$ & & & & & & & & & & 1 & -0.88 & 0.48 \\
\hline $\mathbf{b}$ & & & & & & & & & & & 1 & -0.31 \\
\hline$K_{s}$ & & & & & & & & & & & 2 & 1 \\
\hline
\end{tabular}

Table B-7. Correlation coefficients for Silt

\begin{tabular}{|c|c|c|c|c|c|c|c|c|c|c|c|c|}
\hline & $\theta_{s}$ & $\theta_{\mathbf{r}}$ & $\mathbf{p}_{\mathbf{e}}$ & $\mathbf{f}_{\mathrm{c}}$ & $\mathbf{w}_{\mathbf{p}}$ & awe & $\alpha$ & $\mathbf{n}$ & $h_{b}$ & $\lambda$ & b & $\mathbf{K}_{\mathbf{s}}$ \\
\hline$\theta_{s}$ & 1 & -0.02 & 1 & 0.90 & 0.52 & 0.97 & 0.00 & 0.00 & 0.03 & 0.00 & -0.39 & 0.02 \\
\hline$\theta_{t}$ & & 1 & 0.10 & 0.25 & 0.57 & 0.02 & 0.19 & 0.60 & 0.04 & 0.60 & 0.70 & 0.21 \\
\hline $\mathbf{p}_{\mathbf{e}}$ & & & 1 & 0.88 & 0.48 & 0.96 & 0.01 & 0.05 & 0.03 & 0.05 & -0.44 & 0.04 \\
\hline$f_{C}$ & & & & 1 & 0.81 & 0.92 & 0.35 & -0.37 & 0.16 & -0.37 & 0.03 & 0.30 \\
\hline $\mathbf{w}_{p}$ & & & & & 1 & 0.51 & -0.60 & -0.72 & 0.48 & -0.72 & 0.44 & -0.45 \\
\hline ance & & & & & & 1 & 0.10 & 0.06 & 0.09 & -0.06 & 0.35 & -0.94 \\
\hline$\alpha$ & & & & & & & 1 & 0.55 & -0.49 & 0.55 & -0.41 & 0.89 \\
\hline n & & & & & & & & 1 & -0.20 & 1 & -0.84 & 0.44 \\
\hline $\mathbf{h}_{\mathbf{b}}$ & & & & & & & & & 1 & -0.20 & 0.13 & -0.29 \\
\hline 2 & & & & & & & & & & 1 & 0.84 & 0.44 \\
\hline $\mathbf{b}$ & & & & & & & & & & & 1 & -0.34 \\
\hline r & & & & & & & & & & & & 4 \\
\hline
\end{tabular}


Table B-8. Correlation coefficients for Clay Loam

\begin{tabular}{|c|c|c|c|c|c|c|c|c|c|c|c|c|}
\hline & $\theta_{s}$ & $\theta_{\mathbf{r}}$ & $\mathbf{p}_{\mathbf{e}}$ & $\mathbf{f}_{\mathrm{c}}$ & $\mathbf{w}_{\mathbf{p}}$ & awc & $\alpha$ & $\mathbf{n}$ & $h_{b}$ & $\lambda$ & b & $\mathbf{K}_{\mathbf{s}}$ \\
\hline$\theta_{s}$ & 1 & 0.00 & 0.99 & 0.65 & 0.38 & 0.76 & -0.02 & 0.00 & -0.04 & 0.00 & -0.40 & 0.01 \\
\hline$\theta$ & & 1 & 0.11 & -0.50 & 0.46 & 0.43 & 0.73 & 0.58 & 0.74 & 0.58 & 0.35 & 0.51 \\
\hline $\mathbf{P e}_{\mathbf{e}}$ & & & 1 & 0.69 & 0.43 & 0.80 & -0.10 & -0.06 & 0.04 & -0.06 & -0.36 & -0.04 \\
\hline 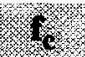 & & & & 1 & 0.89 & 090 & 0.60 & -0.71 & 0.55 & -0.71 & 0.23 & 10.42 \\
\hline $\mathbf{w}_{\mathbf{p}}$ & & & & & 1 & 0.60 & -0.55 & -0.84 & 0.75 & -0.84 & 0.57 & -0.33 \\
\hline aryc & & & & & & 1 & 0.52 & 0.45 & 0.26 & -0.45 & -0.13 & 0,42 \\
\hline$\alpha$ & & & & & & & 1 & 0.79 & -0.62 & 0.79 & -0.42 & 0.89 \\
\hline in & & & & & & & & 1 & 0.80 & 1 & 0.73 & 0.58 \\
\hline $\mathbf{h}_{\mathbf{b}}$ & & & & & & & & & 1 & -0.80 & 0.70 & -0.36 \\
\hline$\lambda$ & & & & & & & & & & 11 & $=0.73$ & 0.58 \\
\hline b & & & & & & & & & & & 1 & -0.26 \\
\hline $\mathrm{K}_{\mathrm{s}}$ & & & & & & & & & & & & 1 \\
\hline
\end{tabular}

Table B-9. Correlation coefficients for Silty Clay Loam

\begin{tabular}{|c|c|c|c|c|c|c|c|c|c|c|c|c|}
\hline & $\theta_{s}$ & $\theta_{\mathbf{r}}$ & $\mathbf{P e}_{\mathbf{e}}$ & $\mathbf{f}_{c}$ & $\mathbf{w}_{\mathbf{p}}$ & awc & $\alpha$ & $\mathrm{n}$ & $\mathbf{h}_{\mathbf{b}}$ & $\lambda$ & b & $\mathbf{K}_{\mathbf{s}}$ \\
\hline$\theta_{s}$ & 1 & 0.00 & 0.99 & 0.73 & 0.46 & 0.85 & -0.01 & 0.00 & 0.00 & 0.00 & -0.19 & -0.03 \\
\hline$\theta$ & & 1 & -0.13 & 0.42 & 0.46 & -0.21 & 0.72 & 0.53 & 0.71 & 0.55 & 0.37 & 0.47 \\
\hline $\mathbf{P}_{\mathbf{e}}$ & & & 1 & 0.77 & 0.51 & 0.87 & -0.10 & -0.07 & 0.10 & -0.07 & -0.15 & -0.09 \\
\hline f. & & & & 1 & 0.90 & 0.75 & 0.62 & -0.65 & 0.58 & -0.65 & 0.35 & -0.45 \\
\hline $\mathbf{w}_{\mathbf{p}}$ & & & & & 1 & 0.40 & -0.68 & -0.84 & 0.79 & -0.84 & 0.69 & -0.42 \\
\hline arc & & & & & & 1 . & -0.29 & 0.1 & 0.02 & -0.11 & -0.30 & 0.32 \\
\hline$\alpha$ & & & & & & & 1 & 0.86 & -0.75 & 0.86 & -0.57 & 0.83 \\
\hline in & & & & & 8 & & ; & 1 & -0.84 & 1 & -0.82 & 0.60 \\
\hline$h_{b}$ & & & & & & & & & 1 & -0.84 & 0.80 & -0.41 \\
\hline 1 & & & & & & & & & 政 & 1. & -0.82 & 0.60 \\
\hline b & & & & & & & & & & & 1 & -0.32 \\
\hline $\mathrm{K}_{8}$ & & & & & & & & & & & & 1 \\
\hline
\end{tabular}


Soil Parameter Correlation Coefficients

Table B-10. Correlation coeficients for Sandy Clay

\begin{tabular}{|c|c|c|c|c|c|c|c|c|c|c|c|c|}
\hline & $\theta_{s}$ & $\theta_{r}$ & $\mathbf{p}_{\mathbf{e}}$ & $\mathbf{f}_{\mathrm{c}}$ & $\mathbf{w}_{\mathbf{p}}$ & awc & $\alpha$ & $\mathbf{n}$ & $\mathbf{h}_{\mathbf{b}}$ & $\lambda$ & $\mathbf{b}$ & $\mathbf{K}_{\mathbf{s}}$ \\
\hline$\theta_{\mathrm{s}}$ & 1 & 0.00 & 0.97 & 0.58 & 0.35 & 0.68 & 0.02 & 0.00 & 0.01 & 0.00 & -0.23 & 0.05 \\
\hline 0 & & 1 & $=0.23$ & -0.70 & -0.82 & 0.42 & 0.75 & 0.88 & 0.92 & 0.88 & -0.78 & $0: 28$ \\
\hline $\mathbf{p e}_{\mathbf{e}}$ & & & 1 & 0.72 & 0.53 & 0.75 & -0.15 & -0.20 & 0.22 & -0.20 & -0.05 & -0.02 \\
\hline 18 & & & & 1 & 0.89 & 0.89 & -0.70 & 0.78 & 0.68 & -0.78 & 0.44 & -0.33 \\
\hline $\mathbf{w}_{\mathbf{p}}$ & & & & & 1 & 0.58 & -0.67 & -0.85 & 0.87 & -0.85 & 0.74 & -0.24 \\
\hline arce & & & & & & 1 & 0.58 & 0.55 & 0.35 & -0.55 & 0.05 & -0.35 \\
\hline$\alpha$ & & & & & & & 1 & 0.87 & -0.74 & 0.87 & -0.59 & 0.58 \\
\hline n & & & & & & & 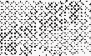 & 1 & -0.86 & 1 & -0.79 & 0.44 \\
\hline $\mathbf{h}_{\mathbf{b}}$ & & & & & & & & & 1 & -0.86 & 0.83 & -0.26 \\
\hline 12 & & & & & & & & & & 1 & 0.79 & 0.44 \\
\hline b & & & & & & & & & & & 1 & -0.23 \\
\hline $\mathrm{R}_{3}$ & & & & & & & & & & & & 1 \\
\hline
\end{tabular}

Table B-11. Correlation coefficients for Silty Clay

\begin{tabular}{|c|c|c|c|c|c|c|c|c|c|c|c|c|}
\hline & $\theta_{\mathbf{s}}$ & $\theta_{\mathbf{r}}$ & $\mathbf{P}_{\mathbf{e}}$ & $\mathbf{f}_{c}$ & $w_{p}$ & awc & $\alpha$ & n & $\mathbf{h}_{\mathbf{b}}$ & $\lambda$ & b & $\mathbf{K}_{\mathbf{s}}$ \\
\hline$\theta_{s}$ & 1 & 0.00 & 0.95 & 0.94 & 0.74 & 0.84 & -0.01 & -0.01 & -0.01 & -0.01 & -0.31 & 0.02 \\
\hline$\theta_{r}$ & & 1 & 0.31 & 0.29 & 0.49 & 0.19 & 0.89 & 0.79 & -0.88 & 0.79 & 0.46 & 0.64 \\
\hline $\mathbf{p}_{\mathbf{e}}$ & & & 1 & 0.98 & 0.86 & 0.74 & -0.28 & -0.25 & 0.26 & -0.25 & -0.15 & -0.18 \\
\hline$f_{c}$ & & & & 1 & 0.91 & 0.70 & -0.32 & -0.33 & 0.24 & -0.33 & 0.07 & -0.24 \\
\hline $\mathbf{w}_{\mathbf{p}}$ & & & & & 1 & 0.34 & -0.50 & -0.64 & 0.52 & -0.64 & 0.32 & -0.34 \\
\hline are & & & & & & 1 & 0.14 & 0.33 & 0.36 & 0.33 & -0.70 & 0.03 \\
\hline$\alpha$ & & & & & & & 1 & 0.84 & -0.72 & 0.84 & -0.47 & 0.86 \\
\hline n & & & & & & & & 1. & $=0.78$ & 1. & -0.77 & 0.64 \\
\hline $\mathbf{h}_{\mathbf{b}}$ & & & & & & & & & 1 & -0.78 & 0.63 & -0.44 \\
\hline 2 & & & & & & & & & & 1 & -0.77 & 0.64 \\
\hline b & & & & & & & & & & & 1 & -0.31 \\
\hline $\mathrm{K}_{\mathrm{s}}$ & & & & & & & & & & & & 1 \\
\hline
\end{tabular}




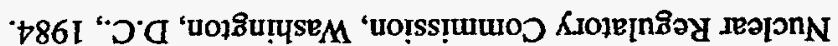

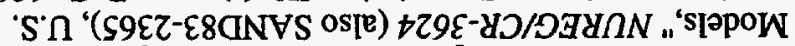

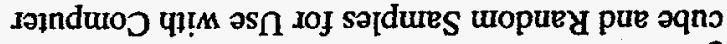

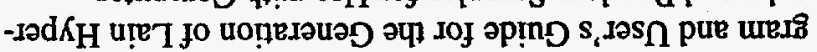

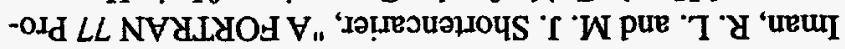

$286 \mathrm{I}$

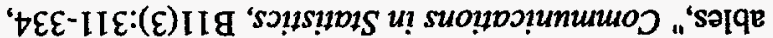
-!res indu! suoure toṇejpuos yuex su! onpu! of yorosdde

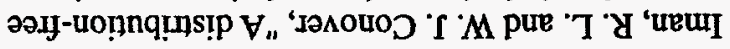

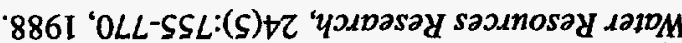

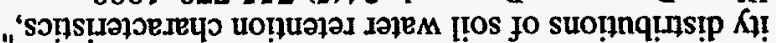

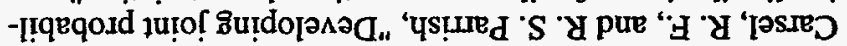

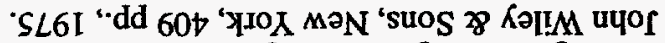

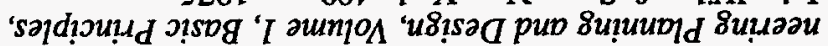

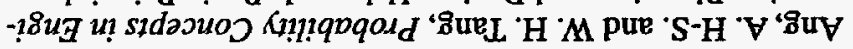

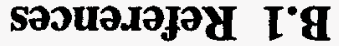

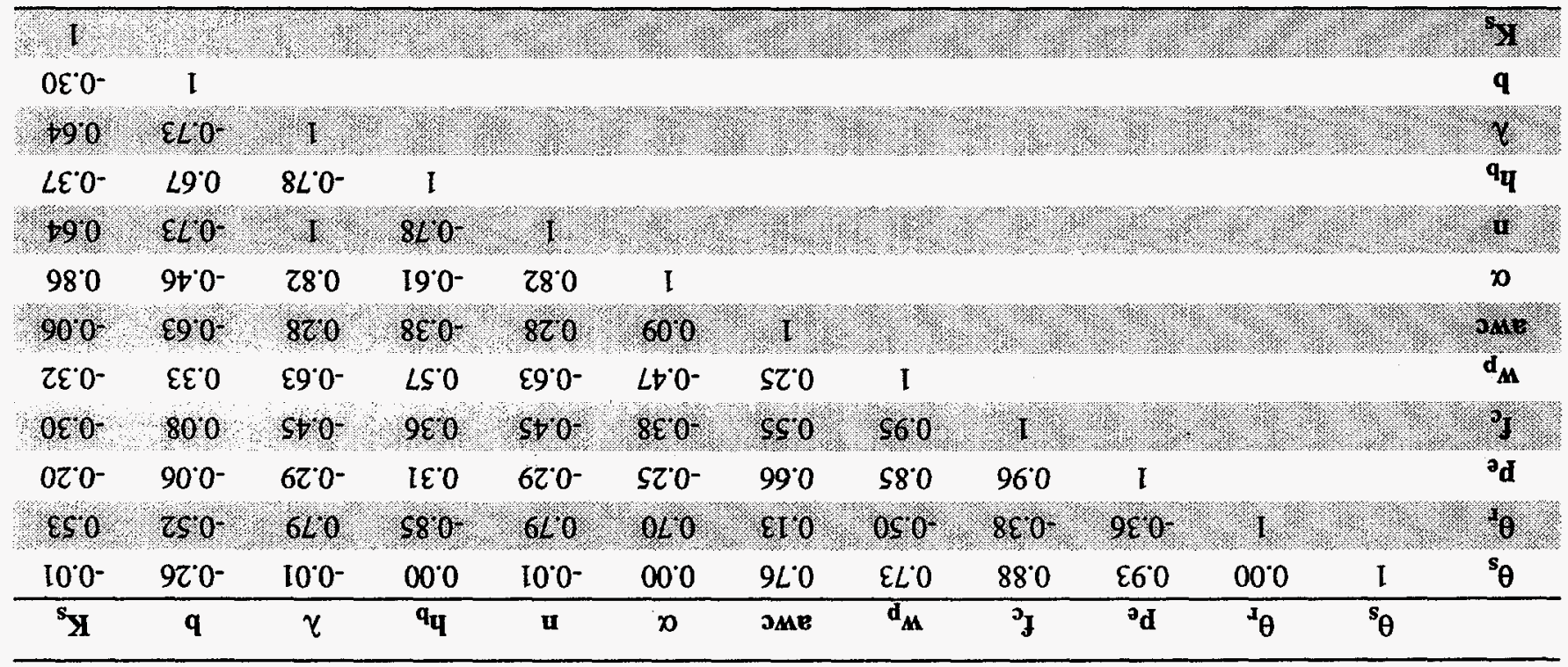

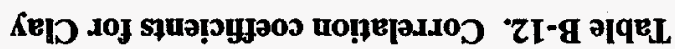




\section{Appendix C: Summary of Water Retention and Conductivity Models}

Richards equation (Richards, 1931) forms the basis for most process-based descriptions of water movement in the unsaturated zone. Richards equation can be expressed as

$$
\frac{\partial \theta}{\partial t}=\frac{\partial}{\partial z}\left[-K(h) \frac{\partial h}{\partial z}-K(h)\right]+u
$$

where

$$
\begin{aligned}
\theta= & \text { volumetric water content, or volume of water } \\
& \text { per unit bulk volume of soil, } \\
h= & \text { soil water tension, } h \geq 0 \\
z= & \text { depth, measured positive downward from the } \\
& \text { soil surface, } \\
t= & \text { time, } \\
K(h)= & \text { hydraulic conductivity, and } \\
u= & \text { a source or sink term used to account for } \\
& \text { water uptake by plant roots. }
\end{aligned}
$$

To solve Richards equation, constitutive functions relating the unsaturated hydraulic conductivity and the water content to the pressure head are needed. The most commonly used relationships are those of van Genuchten (1980), Brooks and Corey (1964), and Campbell (1974), although other expressions are available (Mualem, 1992; Rossi and Nimmo, 1994; Fayer and Simmons, 1995).

\section{C.1 Van Genuchten Model}

The van Genuchten water retention relationship is

$$
S_{e}(h)=\left[1+(\alpha h)^{n}\right]^{-m}
$$

where

$$
\begin{aligned}
S_{e}= & \text { effective saturation }=\frac{\theta-\theta_{r}}{\theta_{s}-\theta_{r}}, 0 \leq S_{e} \leq 1 \\
\alpha= & \begin{array}{c}
\text { curve fitting parameter related to air entry } \\
\text { pressure }
\end{array} \\
n, m= & \text { curve fitting parameters related to pore size } \\
& \begin{array}{l}
\text { distribution; the relationship, } m=1-1 / n, \text { is } \\
\text { often assumed }
\end{array} \\
\theta_{r}= & \text { residual water content } \\
\theta_{s}= & \text { saturated water content }
\end{aligned}
$$

The van Genuchten hydraulic conductivity relationship, based on the hydraulic conductivity model of Mualem (1976) is

$$
K\left(S_{e}\right)=K_{s} \sqrt{S_{e}}\left[1-\left(1-S_{e}^{1 / m}\right)^{m}\right]^{2} .
$$

$$
K(h)=K_{s} \frac{\left\{1-(\alpha h)^{n-1}\left[1+(\alpha h)^{n}\right]^{-m}\right\}^{2}}{\left[1+(\alpha h)^{n}\right]^{0.5 m}}
$$

where

$$
\mathrm{K}_{\mathrm{s}}=\text { saturated hydraulic conductivity }
$$

\section{C.2 Brooks-Corey Model}

The Brooks-Corey water retention relationship is

$$
\begin{gathered}
S_{e}(h)=\left(\frac{h_{b}}{h}\right)^{\lambda} \text { for } h \geq h_{b} \\
S_{e}(h)=1 \text { otherwise. }
\end{gathered}
$$

When combined with the relative permeability model of Burdine (1953), Brooks and Corey derived the following hydraulic conductivity relationship.

$$
K\left(S_{e}\right)=K_{s}\left(S_{e}\right)^{3+2 / \lambda}
$$

or

$$
\begin{gathered}
K(h)=K_{s}\left(\frac{h_{b}}{h}\right)^{2+3 \lambda} \text { for } h \geq h_{b} \\
\text { and } K(h)=K_{s} \text { otherwise. }
\end{gathered}
$$

where

$$
\begin{aligned}
h_{b}= & \text { curve fitting parameter related to air entry } \\
& \text { pressure } \\
\lambda= & \text { curve fitting parameter related to pore size } \\
& \text { distribution. }
\end{aligned}
$$

\section{C.3 Campbell Model}

Campbell (1974) adopted a water retention relationship similar to Brooks and Corey's, but with $\theta_{r}=0$.

$$
\begin{gathered}
\frac{\theta}{\theta_{s}}=\left(\frac{h_{b}}{h}\right)^{1 / b} \text { for } h \geq h_{b} \\
\frac{\theta}{\theta_{s}}=1 \text { otherwise. }
\end{gathered}
$$

Note that because $\theta_{r}=0, b \neq 1 / \lambda$. (See Section C.3.1 for the reltionship between $b$ and $\lambda$ used in this report.) Campbell (1974) derived a corresponding hydraulic conductivity relationship.

$$
K(\theta)=K_{s}\left(\frac{\theta}{\theta_{s}}\right)^{2 b+3}
$$




$$
\begin{gathered}
K(h)=K_{s}\left(\frac{h_{b}}{h}\right)^{2+3 / h} \text { for } h \geq h_{b} \\
\text { and } K(h)=K_{s} \text { otherwise. }
\end{gathered}
$$

where

$$
\begin{aligned}
& b=\text { curve fitting parameter related to pore size } \\
& \text { distribution. }
\end{aligned}
$$

Note that all of these single-valued relationships (Equations C-2 through C-14) assume that hysteresis is not important.

\section{C.3.1 Calculation of Campbell's b Parameter}

An expression for $b$ in terms of $\theta_{s}, \theta_{r}$ and $\lambda$ is derived by assuming that the Brooks-Corey model (Equation C-7) and the Campbell model (Equation C-12) predict the same hydraulic conductivity for a given value of water content. In this case, the water content used is that corresponding to an effective saturation of 0.5 . Assuming $S_{e}=0.5$ and using the definition of effective saturation given above, it follows that

$$
\frac{\theta}{\theta_{s}}=\frac{0.5\left(\theta_{s}-\theta_{r}\right)+\theta_{r}}{\theta_{s}}=0.5\left(1+\theta_{r} / \theta_{s}\right)
$$

Substituting this expression in Equation C-12 and equating this with Equation C-7 leads to

$$
\left(0.5\left(1+\theta_{r} / \theta_{s}\right)\right)^{3+2 b}=0.5^{3+2 / \lambda}
$$

Equation $C-16$ can be solved for $b$,

$$
b=0.5\left\{\frac{\ln (0.5)(3+2 / \lambda)}{\ln \left[0.5\left(1+\theta_{r} / \theta_{s}\right)\right]}-3\right\}
$$

\section{C.4 References}

Brooks, R. H., and A. T. Corey, "Hydraulic Properties of Porous Media," Hydrology Paper 3, Colorado State Univ., Ft. Collins, CO, 1964.

Burdine, N. T. "Relative permeability calculations from pore-size distribution data." Petr. Trans., Am. Inst. Mining Metall. Eng., 198:71-77, 1953.

Campbell, G. S., "A simple method for determining unsaturated conductivity from moisture retention data," Soil Sci. 117:311-314, 1974.

Fayer, M. J., and C. S. Simmons, "Modified soil water retention functions for all matric suctions," Water Resources Research, 31:1233-1238, 1995.

Mualem, Y., "A new model for predicting the hydraulic conductivity of unsaturated porous media," Water Resources Research, 12(3):513-522, 1976.

Mualem, Y., "Modeling the Hydraulic Conductivity of Unsaturated Porous Media," in Indirect Methods for Estimaing the Hydraulic Properties of Unsaturated Soils, M. Th. van Genucthen, F. J. Leij, and L. J. Lund (eds.), University of California, Riverside, CA, pp. 15-36, 1992.

Rossi, C. and J. R. Nimmo, "Modeling of soil water retention from saturation to oven dryness," Water Resources Research, 30(3):701-708, 1994.

van Genuchten, $M$. Th., "A closed-form equation for predicting the hydraulic conductivity of unsaturated soils," Soil Sci. Soc. Am. J., 44:892-898, 1980. 


\section{Appendix D: SCS Curve Number Estimation}

The appropriate SCS curve number depends on the hydrologic soil group, the vegetative cover or land use, the hydrologic condition (percent vegetative cover), and the antecedent moisture condition (AMC). The information in this appendix can be used to estimate the curve number at a given site. Most of the information presented here was taken from U.S. Soil Conservation Service (1985) and U.S. Soil Conservation Service (1986).

\section{D.1 Hydrologic Soil Group}

The hydrologic soil group represents the potential for runoff due to soil texture and structure. The following descriptions of the hydrologic soil groups are taken from U.S. Soil Conservation Service (1986).

Group A soils have low runoff potential and high infiltration rates even when thoroughly wetted. They consist chiefly of deep, well to excessively drained sands or gravels and have a high rate of water transmission [greater than $\left.2.1 \times 10^{-4} \mathrm{~cm} / \mathrm{s}(0.30 \mathrm{in} / \mathrm{hr})\right]$.
Group B soils have moderate infiltration rates when thoroughly wetted and consist chiefly of moderately deep to deep, moderately well to well drained soils with moderately fine to moderately coarse textures. These soils have a moderate rate of water transmission $\left[1.1 \times 10^{-4}-2.1 \times 10^{-4} \mathrm{~cm} / \mathrm{s}\right.$ $(0.15-0.30 \mathrm{in} / \mathrm{hr})]$.

Group C soils have low infiltration rates when thoroughly wetted and consist chiefly of soils with a layer that impedes downward movement of water and soils with moderately fine to fine texture. These soils have a low rate of water transmission $\left[3.5 \times 10^{-5}-1.1 \times 10^{-4} \mathrm{~cm} / \mathrm{s}(0.05-0.15 \mathrm{in} / \mathrm{hr})\right]$.

Group D soils have high runoff potential. They have very low infiltration rates when thoroughly wetted and consist chiefly of clay soils with a high swelling potential, soils with a permanent high water table, soils with a claypan or clay layer at or near the surface, and shallow soils over nearly impervious material. These soils have a very low rate of water transmission [less than $3.5 \times 10^{-5} \mathrm{~cm} / \mathrm{s}(0.05 \mathrm{in} / \mathrm{hr})$ ].

U.S. Soil Conservation Service (1986) also recommends that if the soil has been disturbed but no significant compac-

Table D-1. SCS runoff curve numbers for average antecedent moisture condition (AMC II)

\begin{tabular}{|c|c|c|c|c|c|}
\hline \multirow[b]{2}{*}{ Land Use or Cover } & \multirow{2}{*}{$\begin{array}{c}\text { Hydrologic } \\
\text { Condition }\end{array}$} & \multicolumn{4}{|c|}{ Hydrologic Soil Group } \\
\hline & & $\mathbf{A}$ & $\mathbf{B}$ & $\mathbf{C}$ & $\mathbf{D}$ \\
\hline Fallow & & 77 & 86 & 91 & 94 \\
\hline \multirow[t]{3}{*}{ Pasture or Range } & Poor & 68 & 79 & 86 & 89 \\
\hline & Fair & 49 & 69 & 79 & 84 \\
\hline & Good & 39 & 61 & 74 & 80 \\
\hline \multirow[t]{3}{*}{ Contoured Pasture or Range } & Poor & 47 & 67 & 81 & 88 \\
\hline & Fair & 25 & 59 & 75 & 83 \\
\hline & Good & 6 & 35 & 70 & 79 \\
\hline Meadow & & 30 & 58 & 71 & 78 \\
\hline \multirow[t]{3}{*}{ Woods } & Poor & 45 & 66 & 77 & 83 \\
\hline & Fair & 36 & 60 & 73 & 79 \\
\hline & Good & 25 & 55 & 70 & 77 \\
\hline \multirow[t]{3}{*}{ Brush-brushwood grass mixture with brush the major element } & Poor & 48 & 67 & 77 & 88 \\
\hline & Fair & 35 & 56 & 70 & 77 \\
\hline & Good & 30 & 48 & 65 & 73 \\
\hline \multirow[t]{3}{*}{ Woods-grass combination (orchard or tree farm) } & Poor & 57 & 70 & 82 & 86 \\
\hline & Fair & 48 & 65 & 76 & 82 \\
\hline & Good & 32 & 58 & 72 & 79 \\
\hline Roads (dirt) & & 72 & 82 & 87 & 89 \\
\hline Roads (hard surface) & & 74 & 84 & 90 & 92 \\
\hline
\end{tabular}


tion has occurred, the hydrologic soil group can be assigned based on soil texture

Group A: Sand, loamy sand, or sandy loam

Group B: Silt loam or loam

Group C: Silt, Sandy clay loam

Group D: Clay loam, silty clay loam, sandy clay, silty clay, or clay

\section{D.2 Antecedent Moisture Condition}

The antecedent moisture condition represents the degree of saturation of the soil prior to a rainfall event. AMC II is the average condition, AMC I is dryer than average, and AMC III is wetter than average. If the curve number will be held constant for a water budget analysis, AMC II should be used. If the curve number will vary over the time period of the analysis according to the changing soil moisture, AMC I and AMC III curve numbers can be used.

\section{D.3 Hydrologic Condition}

The hydrologic condition depends on a number of factors including the density of the canopy, the amount of cover, and the surface roughness. Fair condition represents the average amount of infiltration and runoff. Good represents conditions that result in increased infiltration and decreased runoff relative to average conditions. Poor conditions result in decreased infiltration and increased runoff.

In general, the hydrologic condition can be related to the amount of ground cover as follows.

Poor: less than $50 \%$ ground cover

Fair: $50-75 \%$ ground cover

Good: greater than $75 \%$ ground cover

\section{D.4 Curve Number Tables}

The SCS runoff curve number for average antecedent moisture conditions (AMC II) can be estimated from Table D-1. If appropriate, this number can be adjusted for dryer or wetter conditions using Table D-2.

Schroeder et al. (1994) suggest that the AMC II curve number can be adjusted for the site slope conditions according to the following equation.

$$
C N=100-\left(100-C N_{0}\right) \cdot\left(\frac{L / 500}{S / 0.04}\right)^{C N_{0}^{-0.81}}
$$

where $C N_{0}$ is the AMC II curve number from Table D-1, $L$ is the slope length in feet, and $S$ is the slope. This adjusted curve number could be used with Table D-2 to further adjust for antecedent moisture conditions.
Table D-2. Adjusted curve numbers for dry (AMC I) and wet (AMC III) antecedent moisture condition

\begin{tabular}{|c|c|c|}
\hline \multirow{2}{*}{$\begin{array}{l}\text { Curve Number } \\
\text { for AMC II }\end{array}$} & \multicolumn{2}{|c|}{ Adjusted Curve Number } \\
\hline & AMCI & AMC III \\
\hline 100 & 100 & 100 \\
\hline 95 & 87 & 98 \\
\hline 90 & 78 & 96 \\
\hline 85 & 70 & 94 \\
\hline 80 & 63 & 91 \\
\hline 75 & 57 & 88 \\
\hline 70 & 51 & 85 \\
\hline 65 & 45 & 82 \\
\hline 60 & 40 & 78 \\
\hline 55 & 35 & 74 \\
\hline 50 & 31 & 70 \\
\hline 45 & 26 & 65 \\
\hline 40 & 22 & 60 \\
\hline 35 & 18 & 55 \\
\hline 30 & 15 & 50 \\
\hline 25 & 12 & 43 \\
\hline 20 & 9 & 37 \\
\hline 15 & 6 & 30 \\
\hline 10 & 4 & 22 \\
\hline 5 & 2 & 13 \\
\hline
\end{tabular}

\section{D.5 References}

Schroeder, P. R., T. S. Dozier, P. A. Zappi, B. M. McEnroe, J. W. Sjostrom, and R. L. Peyton, "The Hydrologic Evaluation of Landfill Performance (HELP) Model, Engineering Documentation for Version 3," EPA/600/R-94/168b, U.S. Environmental Protection Agency, Cincinnati, OH, 1994.

U.S. Soil Conservation Service, National Engineering Handbook, Section 4, Hydrology, U.S. Department of Agriculture, Washington, DC, 1985.

U.S. Soil Conservation Service, Urban Hydrology for Small Watersheds, Technical Release 55, U.S. Department of Agriculture, Washington, DC, 1986. 


\section{Appendix E: Plant-Related Parameters}

The plants growing on a site will have a strong influence on evapotranspiration. Models that calculate the water budget typically take this into account using a small number of parameters: the root zone depth, the fraction of soil area covered by plants, and the distribution of roots with soil depth. Models that assume a constant water content within the root zone do not require the distribution of roots with soil depth. More sophisticated models may have a timedependent distribution of roots with depth. This appendix provides a brief summary of several review papers whose results can be used to estimate plant-related parameters for water budget analyses.

\section{E.1 Root Distribution with Depth}

Jackson et al. (1996) compiled a global database of root studies, subdividing the results according to biomes and plant functional groups. In total, the database included 250 studies. Fifty studies in the database sampled roots to a depth of $1 \mathrm{~m}$ or more and were included in an analysis of root distribution. A single parameter model was fit to the data. The form of the model was

$$
Y=1-\beta^{d}
$$

where

$Y \quad=$ cumulative root fraction

$d \quad=$ depth from the soil surface $(\mathrm{cm})$

$\beta \quad=$ fitting parameter, larger $\beta$ values correspond to a larger fraction of roots at depth.
Jackson et al. (1996) determined the least squares fit of $\beta$ to all of the data for each biome and each plant group. The resulting models for biomes are shown in Figure E-1. (Jackson et al. (1996) also considered tundra, boreal forest, and several tropical biomes, which are not shown.) Models for the plant groups considered are shown in Figure E-2. Values of $\beta$ are listed in the figures.

The root distributions displayed in Figures E-1 and E-2 represent average distributions based on data for a number of different plant species. Depending on the species present at an actual site, the models shown may not represent the distribution of roots. In addition, site-specific factors such as soil texture and permeability will influence the root distribution. Nevertheless, the models shown are an appropriate starting point in the absence of site-specific information.

\section{E.2 Root Zone Depth}

Canadell et al. (1996) assembled a global database of maximum rooting depth containing 290 observations of 253 species. The data were subdivided according to biome and plant functional groups. A portion of their results are summarized in Figure E-3. The observed maximum rooting depth for various biomes is shown. The number of observations, the mean maximum rooting depth, and the standard deviation are shown for each biome. The inset table gives the number of observations, mean, and standard deviation for the four plant groups considered.

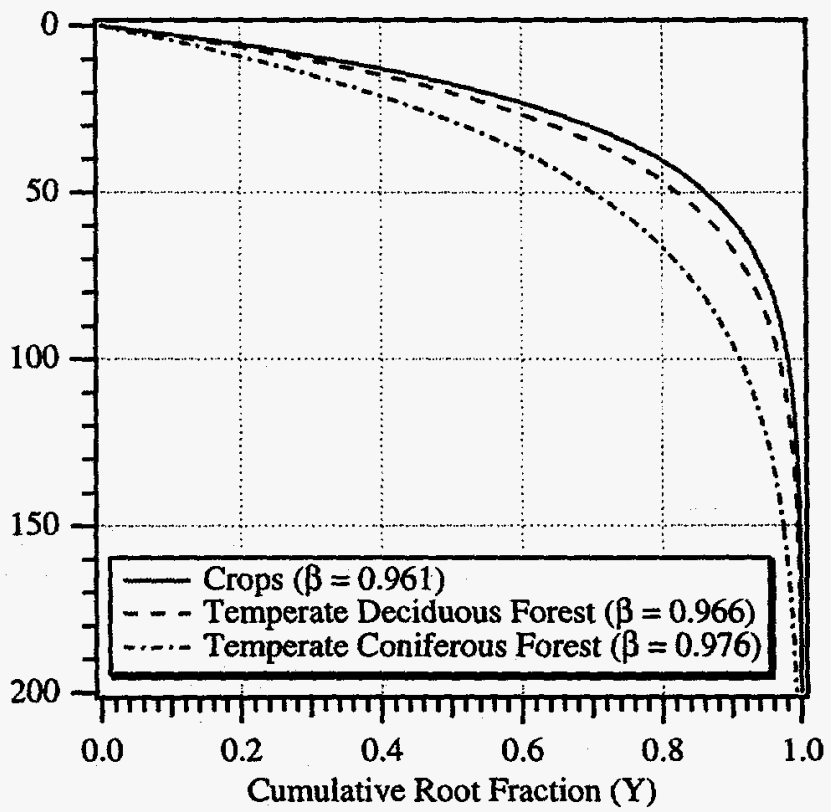

Figure E-1. Cumulative root fraction as a function of soil depth with the model parameter $\beta$ listed for each of the biomes considered. Results taken from Jackson et al. (1996). 


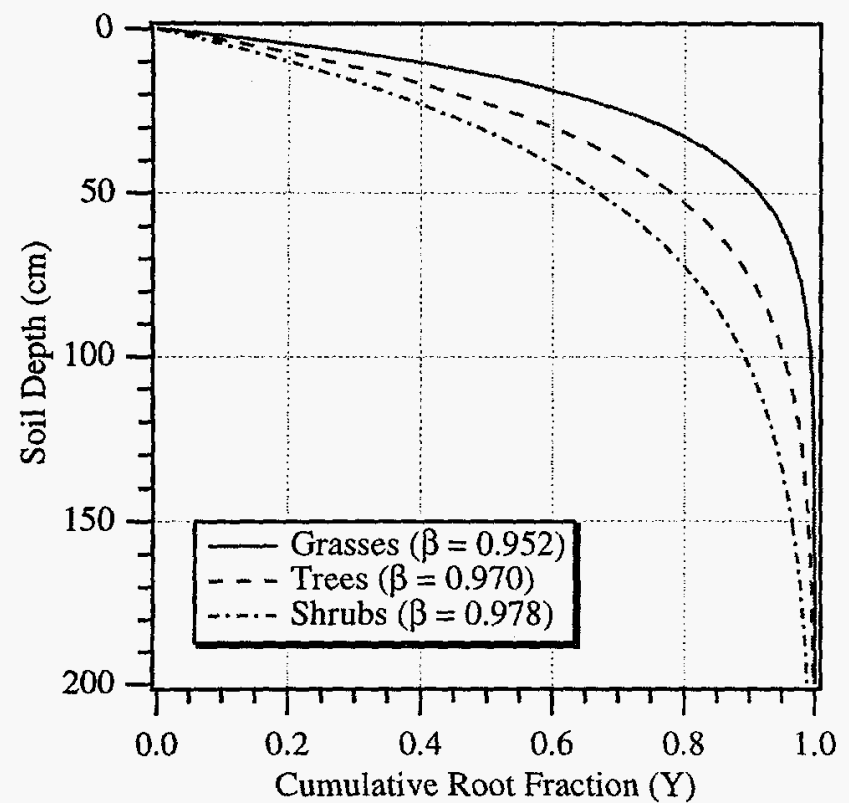

Figure E-2. Cumulative root fraction as a function of plant group. Results taken from Jackson et al. (1996).

The data presented in Canadell et al. (1996) represent those individual plants within a community that have the greatest rooting depth. As they note, these depths may be reached by only a small number of individuals within a community and may be significantly larger than the average maximum rooting depth of the community as a whole.

In contrast, the models in Figures E-1 and E-2 represent an average of observations over a number of plant species. As such, they may be more representative of the average maximum rooting depth of a plant community. In the absence of information on the particular plant species present at a site, Figures E-1 and E-2 can be used to estimate the root zone depth. This depth varies from approximately $1 \mathrm{~m}$ for grassland to approximately $2 \mathrm{~m}$ for desert (see Figure E-1).

It can be observed that the maximum rooting depths in Figure E-3 are significantly larger than the maximum depths in Figures E-1 and E-2. Canadell et al. (1996) note a number of studies that demonstrate the function of deep roots in maintaining transpiration during dry periods. Neglecting the contribution of deep roots may lead to an underestimate of evapotranspiration. An appropriate value for the root zone depth may thus lie somewhere between the values in Figures E-1 and E-2 and the values in Figure E-3. Site-specific knowledge of plant species, soil texture, and climatic conditions can be used to modify this value.

Foxx et al. (1984) assembled a database of rooting depth from 1034 studies of plants in the U.S., primarily west of the Mississippi river. They subdivided their data according to plant groups; results are summarized in Table E-1. A comparison of these results with those discussed previously shows that they lie somewhere between the models of Figure E-2 and the maximum rooting depths of Figure E-3. Table E-1 thus provides an additional basis for selecting a root zone depth when site-specific data is limited.

\section{E.3 Vegetative Cover}

For the purpose of calculating evapotranspiration, it should generally be assumed that plants cover 100 percent of the soil surface since roots will generally occupy all of the available area even if the plant canopy does not. If the sitespecific conditions warrant it, however, the vegetative cover fraction can be reduced.

Table E-1. Average Root Depth by Plant Group from Foxx et al. (1984) (N: number of observations, $\mu$ : mean, $\sigma:$ standard deviation. All units in meters.)

\begin{tabular}{ccccc}
\hline & N & $\mu$ & $\sigma$ & Range \\
\hline Evergreen Trees & 40 & 3.4 & 9.5 & $0.1-61.0$ \\
Deciduous Trees & 107 & 3.3 & 4.5 & $0.7-30.0$ \\
Shrubs & 87 & 3.5 & 3.5 & $0.2-17.4$ \\
Subshrubs $^{1}$ & 36 & 1.4 & 1.0 & $0.5-6.4$ \\
Perennial Forbs $^{2}$ & 370 & 1.7 & 2.5 & $0.02-39.3$ \\
Biennial Forbs & 9 & 1.1 & 0.4 & $0.5-1.5$ \\
Annual Forbs & 81 & 0.8 & 0.8 & $0.04-3.0$ \\
Perennial Grasses & 305 & 1.4 & 0.9 & $0.05-8.2$ \\
Annual Grasses & 50 & 0.5 & 0.4 & $0.05-1.1$ \\
$\quad$ Vines & 4 & 1.7 & 0.8 & $1.0-2.8$ \\
\hline
\end{tabular}

1. Subshrubs are woody species less than $30 \mathrm{~cm}$ tall.

2. Forbs are non-grass herbaceous species.

\section{E.4 References}

Canadell, J., R. B. Jackson, J. R. Ehleringer, H. A. Mooney, O. E. Sala, and E.-D. Schulze, "Maximum rooting depth of vegetation types at the global scale," Oecologia, 108:583$595,1996$.

Foxx, T. S., G. D. Tierney, and J. M. Williams, "Rooting Depths of Plants Relative to Biological and Environmental Factors," LA-10254-MS, Los Alamos National Laboratory, Los Alamos, NM, 1984.

Jackson, R. B., J. Canadell , J. R. Ehleringer, H. A. Mooney, O. E. Sala, and E.-D. Schulze, "A global analysis of root distributions for terrestrial biomes," Oecologia, 108:389411, 1996. 


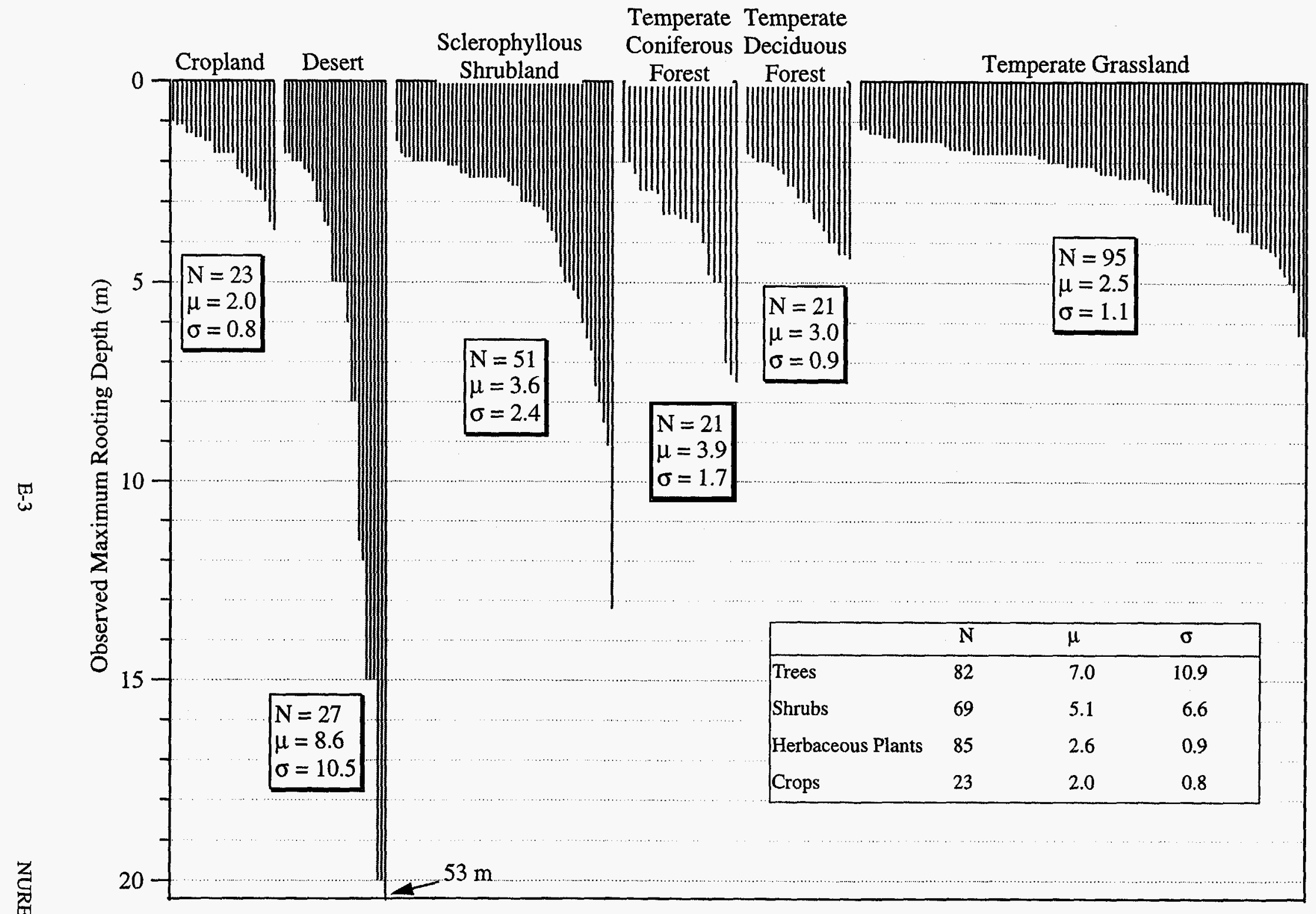

Figure E-3. Maximum rooting depth as a function of biome and plant group (inset). Results are from Canadell et al. (1996). N: number of observations, $\mu$ : mean (m), $\sigma$ : standard deviation (m). 


\section{Appendix F: An Improved Method for Vadose Zone Transport Analyses}

The MEPAS and RESRAD computer codes currently assume that water flow through the vadose zone is at steady state under a unit hydraulic gradient. The unit gradient approximation implies a uniform value of water content within any given soil layer. Pressure head and water content changes associated with a capillary fringe above a water table and across interfaces between different soil types are neglected. This approximation may be adequate in some cases (i.e., a shallow water table and high net infiltration rates), but does not honor all of the physics (namely capillarity) associated with water flow through layered, unsaturated soils. Vadose zone transport calculations based on water content distributions determined using the unit gradient approximation can thus be inaccurate.

An analytical solution technique for one-dimensional steady vertical water flow in layered soils was recently described by Rockhold et al. (1997). This accurate and computationally efficient solution technique is based on an exact integral solution to Darcy's law and is applicable to unsaturated and saturated conditions with arbitrary hydraulic properties. The following example demonstrates the differences in water content distributions and travel times that can result from using a unit gradient approximation versus this analytical solution technique.

Steady flow through a 6-m-deep soil profile was simulated using the analytical solution technique. The soil profile consisted of $2 \mathrm{~m}$ of fine sand, overlying $2 \mathrm{~m}$ of silty clay loam, overlying another $2 \mathrm{~m}$ of fine sand. Fluxes of $1.6 \times 10^{-4}$ $\mathrm{cm} / \mathrm{s}$ and $7.9 \times 10^{-7} \mathrm{~cm} / \mathrm{s}$ were specified for the upper boundary condition and a pressure head of zero (representing a water table) was specified for the lower boundary. The van Genuchten (1980) model hydraulic parameters used in this example are listed in Table F-1.

Water content distributions generated using the analytical solution technique are compared to the unit gradient approximation in Figure F-1. Note that the larger of the two applied fluxes for this example is greater than $\mathrm{K}_{\mathrm{s}}$ of the silty clay loam resulting in a perched water table (Figure F-1, left side). Unrealistic, uniform values of water content result in each layer from the unit gradient approximation. The analytical solution technique accurately captures the variation of water content within the profile.

For a flux of $1.6 \times 10^{-4} \mathrm{~cm} / \mathrm{s}$, the calculated water travel times through the 6-m-deep profile are approximately 13.6 and 12.7 days for the analytical solution and unit gradient approximation, respectively. This difference represents an error of approximately $6.6 \%$ in the travel time calculated on the basis of the unit gradient assumption. For a flux of $7.9 \times 10^{-7} \mathrm{~cm} / \mathrm{s}$, the calculated water travel times are approximately 1753 and 1494 days for the analytical solution and unit gradient approximation, respectively. This difference represents an error of approximately $14.8 \%$ in the travel time time calculated on the basis of the unit gradient approximation.

This type of calculation can be easily modified to account for specific chemicals or radionuclides by factoring in the appropriate retardation factors and decay rates. The relative magnitude of error that results from using the unit gradient approximation is problem specific but is likely to be greater for thicker vadose zones and lower net infiltration rates. The errors resulting from using a unit gradient approximation may or may not be conservative, depending on the sorption characteristics and half lives of the solutes and their decay products.

This simple example demonstrates the potential errors that can result in vadose zone transport calculations made using the current methods employed in the RESRAD and MEPAS codes. These errors are directly propagated into the contaminant flux and dose calculations made by these codes. The analytical solution technique described in Rockhold et al. (1997) provides an accurate and computationally efficient alternative.

\section{F.1 References}

Hills, R. G., D. B. Hudson, I. Porro, and P. J. Wierenga. "Modeling one-dimensional infiltration into very dry soils. 2. Estimation of soil water parameters and model predictions," Water Resources Research, 25(6):1271-1282, 1989.

Rockhold, M. L., C. S. Simmons, and M. J. Fayer, "An analytical solution technique for one-dimensional steady vertical water flow in layered soils," Water Resources Research, 33(4):897-902, 1997.

van Genuchten, M. Th., "A closed-form equation for predicting the hydraulic conductivity of unsaturated soils," Soil Sci. Soc. Am. J., 44:892-898, 1980.

Table F-1. Hydraulic Parameters used for Analytical Solution Technique Example ${ }^{1}$

\begin{tabular}{cccccc}
\hline Material & $\mathbf{K s}(\mathbf{c m} / \mathbf{s})$ & $\alpha_{\mathbf{v}}\left(\mathbf{c m}^{-1}\right)$ & $\mathbf{n}$ & $\theta_{\mathbf{s}}$ & $\theta_{\mathbf{r}}$ \\
\hline Berino Loamy Fine Sand & $6.26 \times 10^{-3}$ & 0.0208 & 2.2390 & 0.3658 & 0.0286 \\
Glendale Silty Clay Loam & $1.52 \times 10^{-4}$ & 0.0104 & 1.3954 & 0.4686 & 0.1060 \\
\hline
\end{tabular}

1. from Hills et al. 1989; Method 1. 
An Improved Method for Vadose Zone Transport Analyses
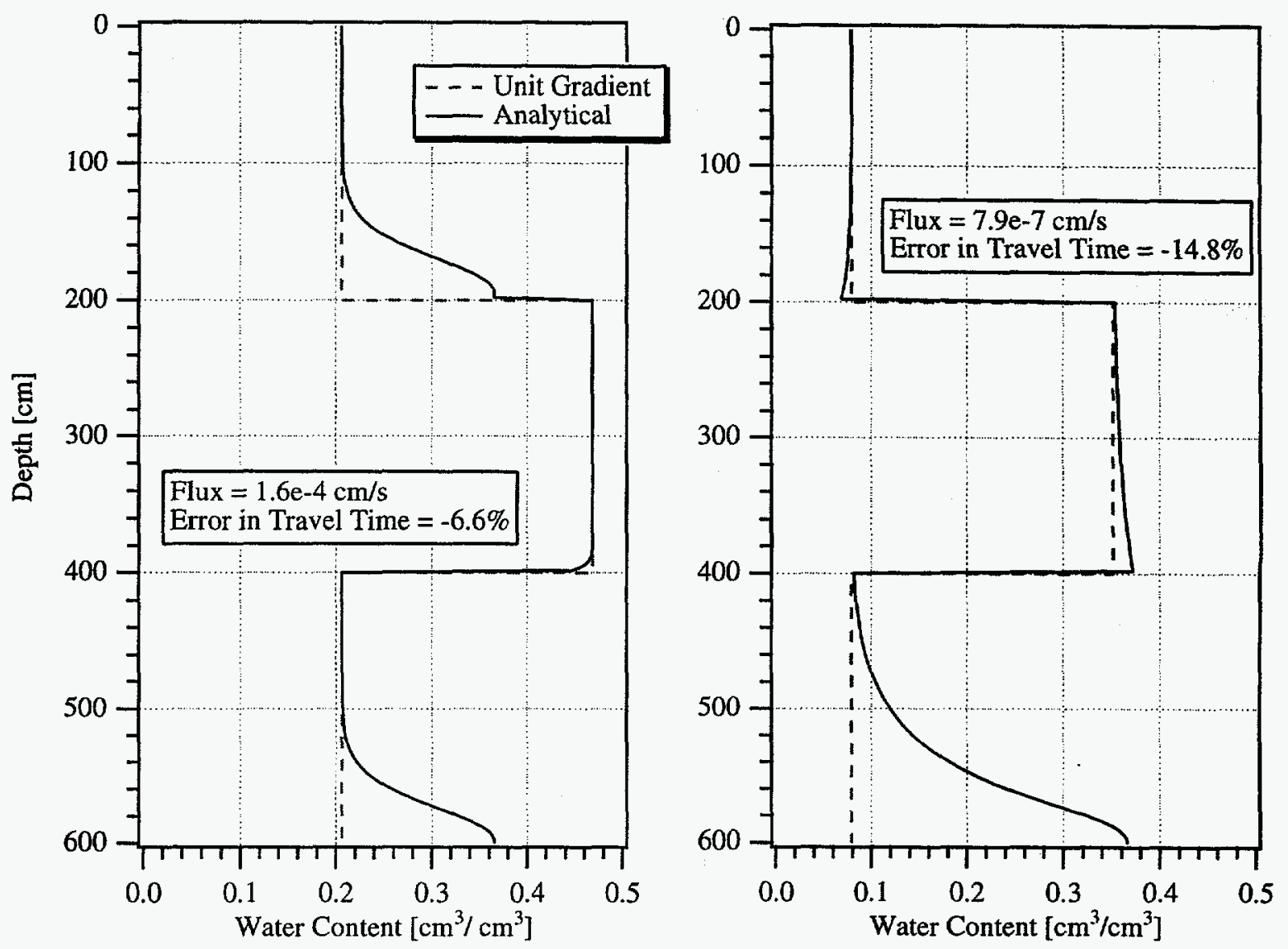

Figure F-1. Volumetric water content as a function of depth for the analytical solution and the unit gradient approximation 


\section{Appendix G: Empirical and Recommended Distributions for Soil Hydraulic Parameters by Soil Texture}

This appendix contains empirical pdf's and cdf's for the 500 Latin hypercube realizations of each soil hydraulic parameter generated using the statistical distributions of Carsel and Parrish (1988). The recommended distributions were determined using the Kolmogorov-Smirnov D-statistic, which represents the maximum absolute difference between the cdf's of the empirical and recommended distributions. The recommended distributions are overlain on the empirical distributions to allow a visual appraisal of the goodness of fit. The functional form of the recommended distribution is indicated in each pdf figure. Normal, lognormal, and beta distributions were considered. The box in each cdf figure contains summary statistics of the empirical distributions.
Recall that the mean and standard deviation of each recommended distribution equal the mean and standard deviation of its corresponding empirical distribution.The mean and standard deviation are indicated in each cdf plot with the circle symbol and error bars.

For a complete discussion of the derivation of the recommended distributions, see Chapter 2.

The soil hydraulic parameters are presented by soil texture, with the coarser textures presented first. There are two parameters per page and six pages per soil texture. 

Empirical and Recommended Distributions for Soil Hydraulic Parameters by Soil Texture
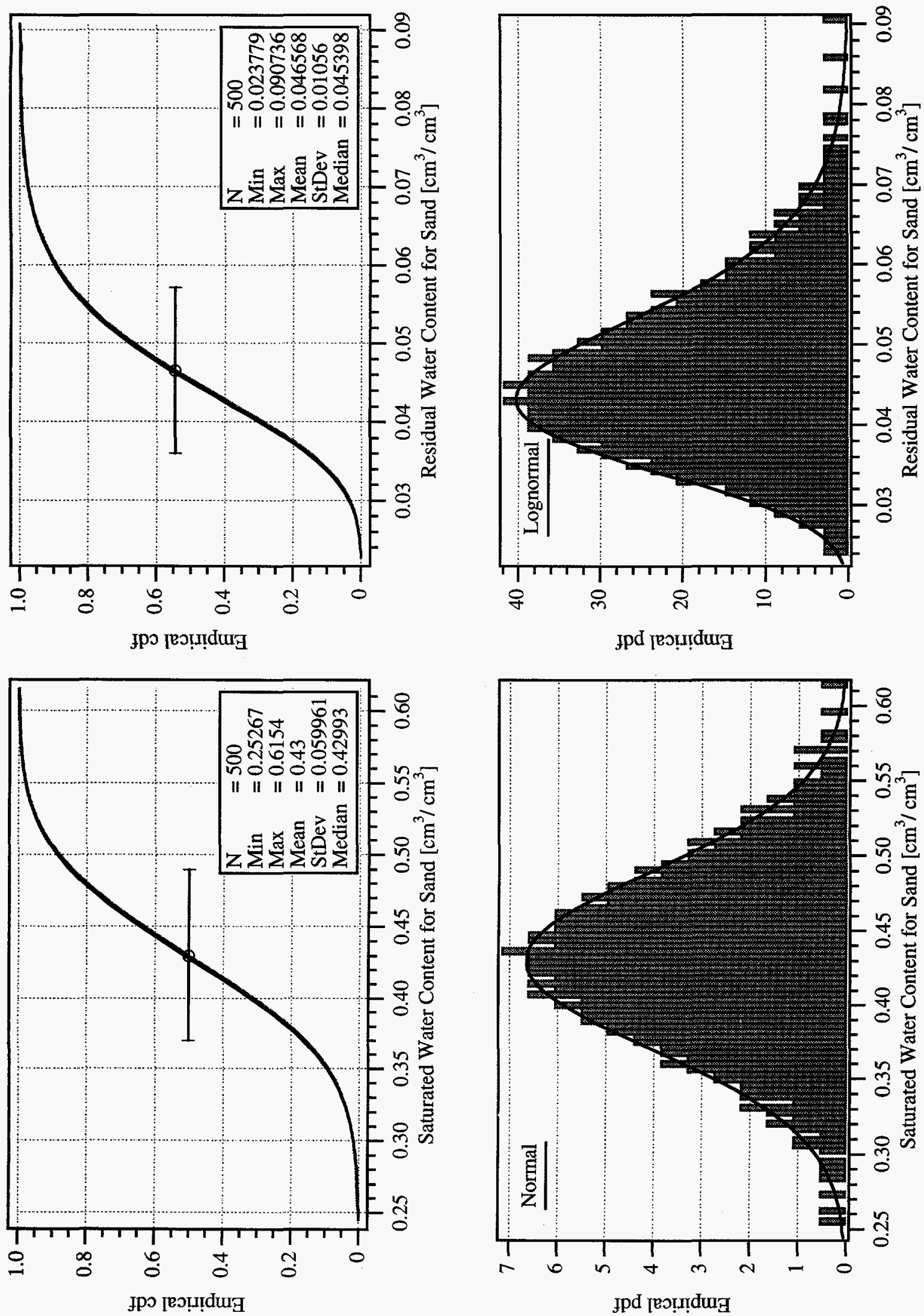
Empirical and Recommended Distributions for Soil Hydraulic Parameters by Soil Texture
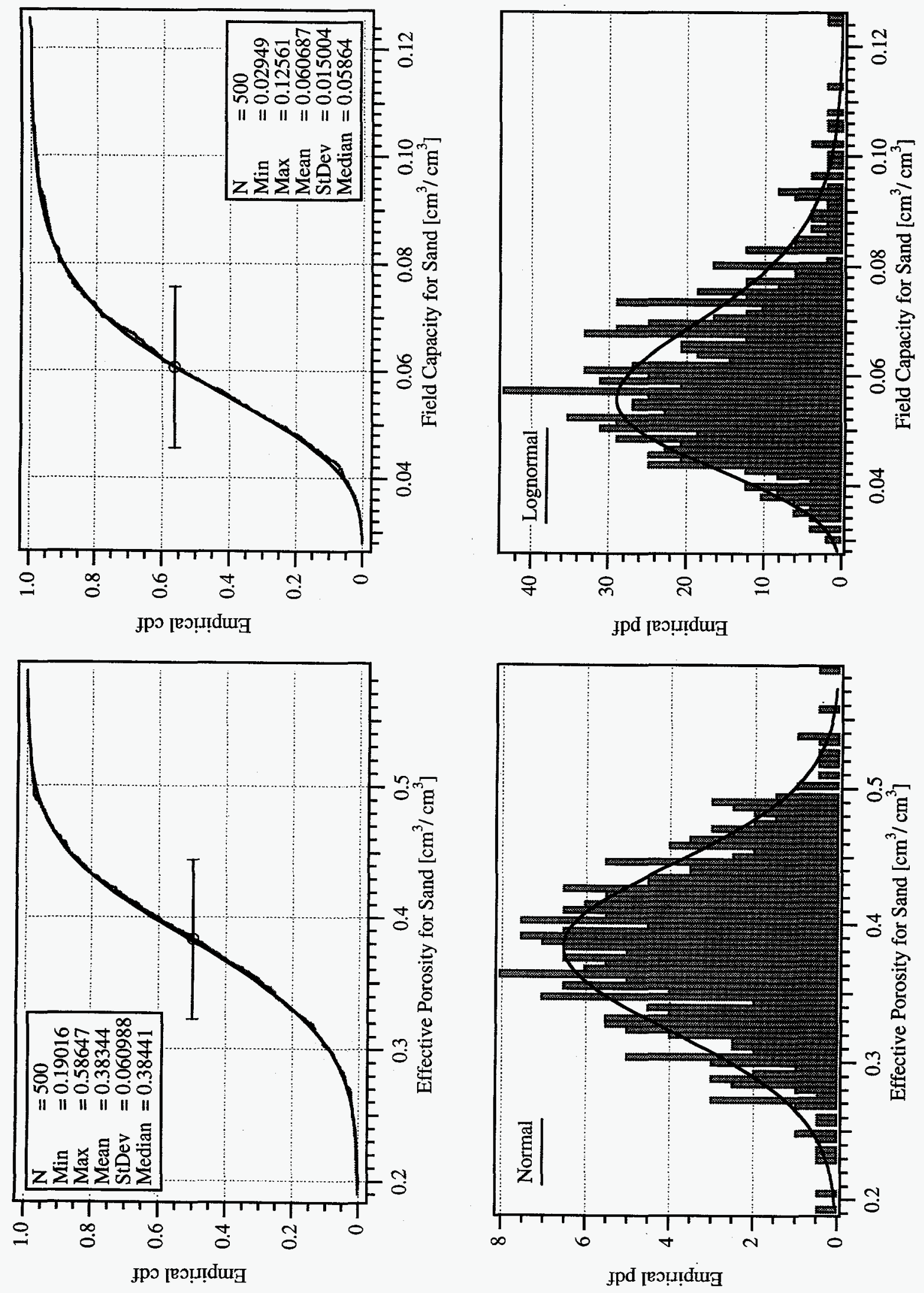

NUREG/CR-6565

G-4 
Empirical pdf

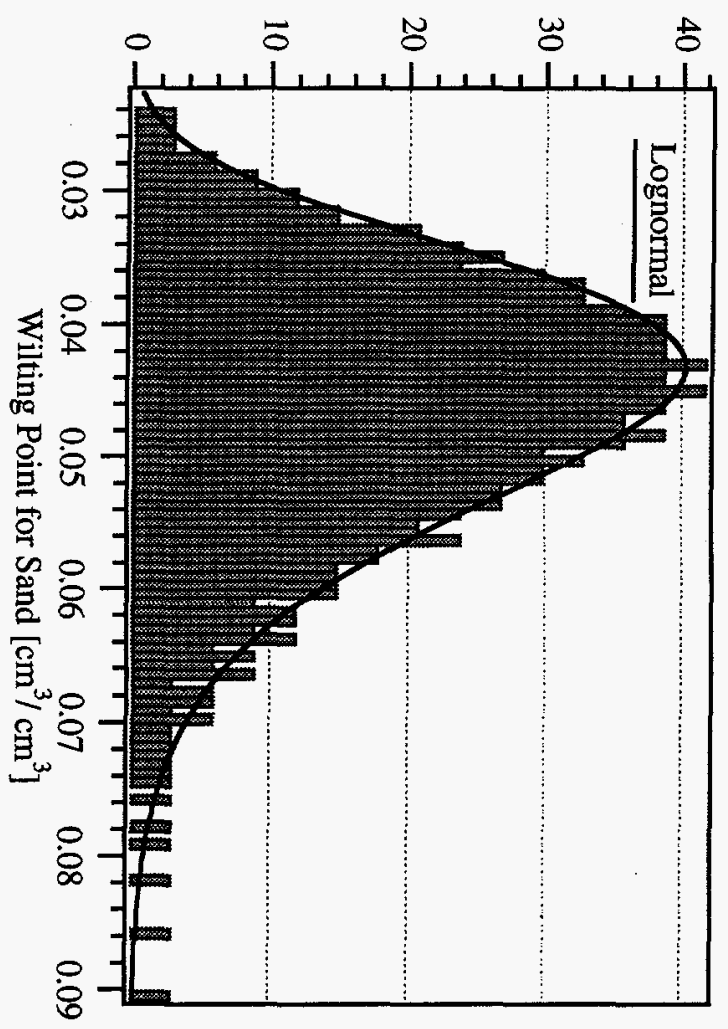

Empirical pdf

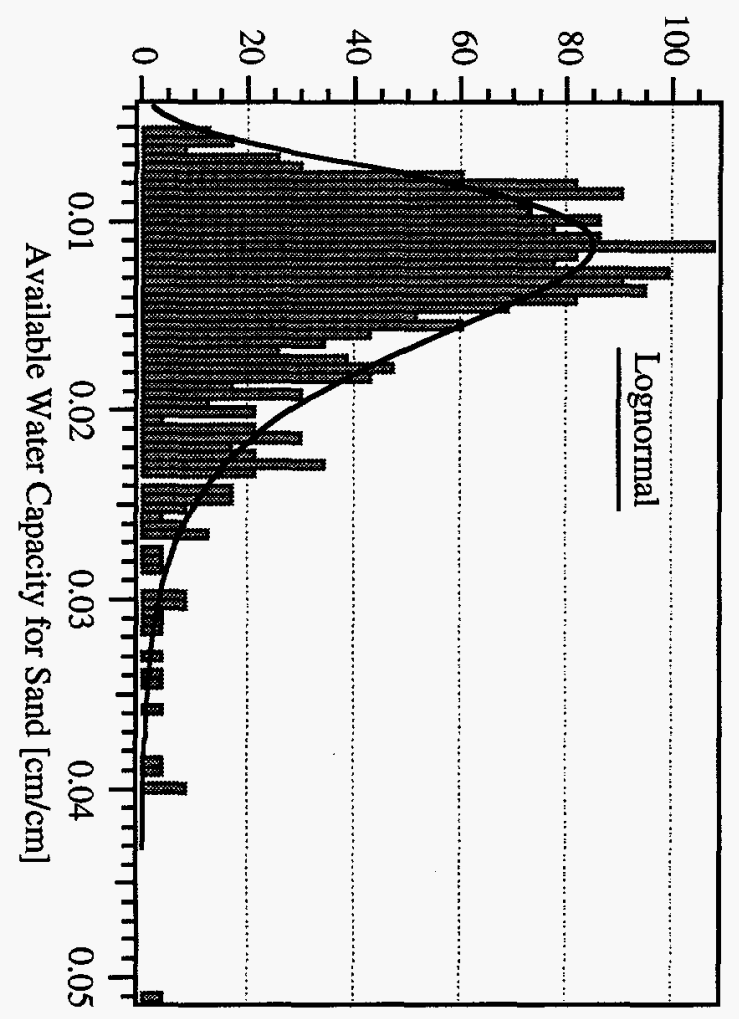

Empirical cdf

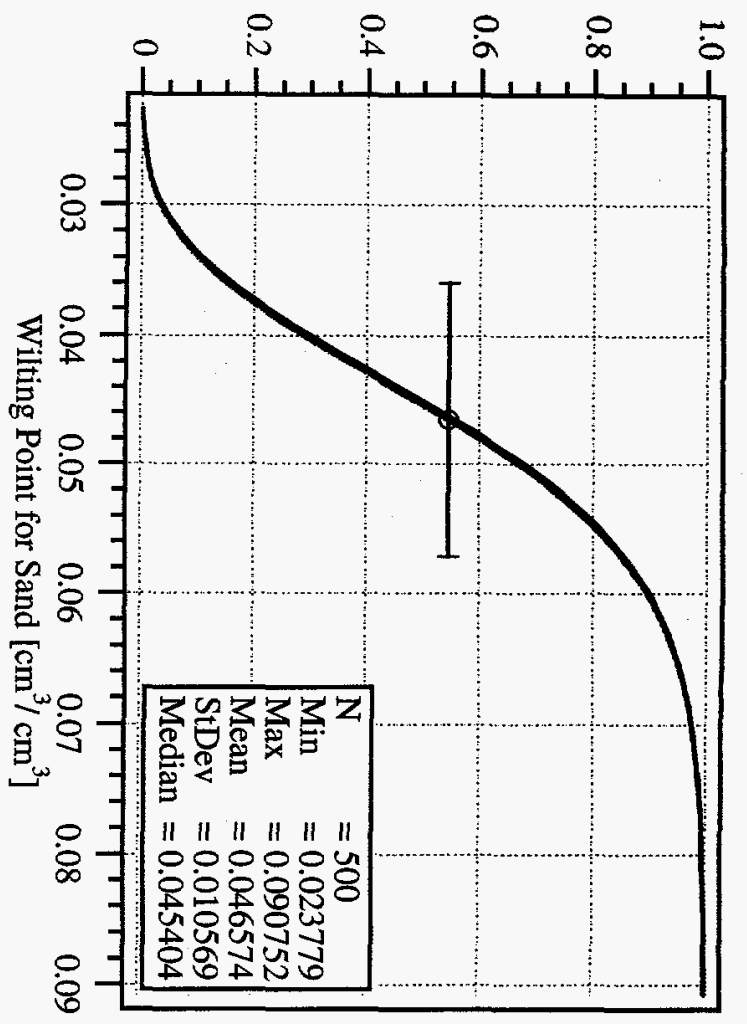

Empirical cdf

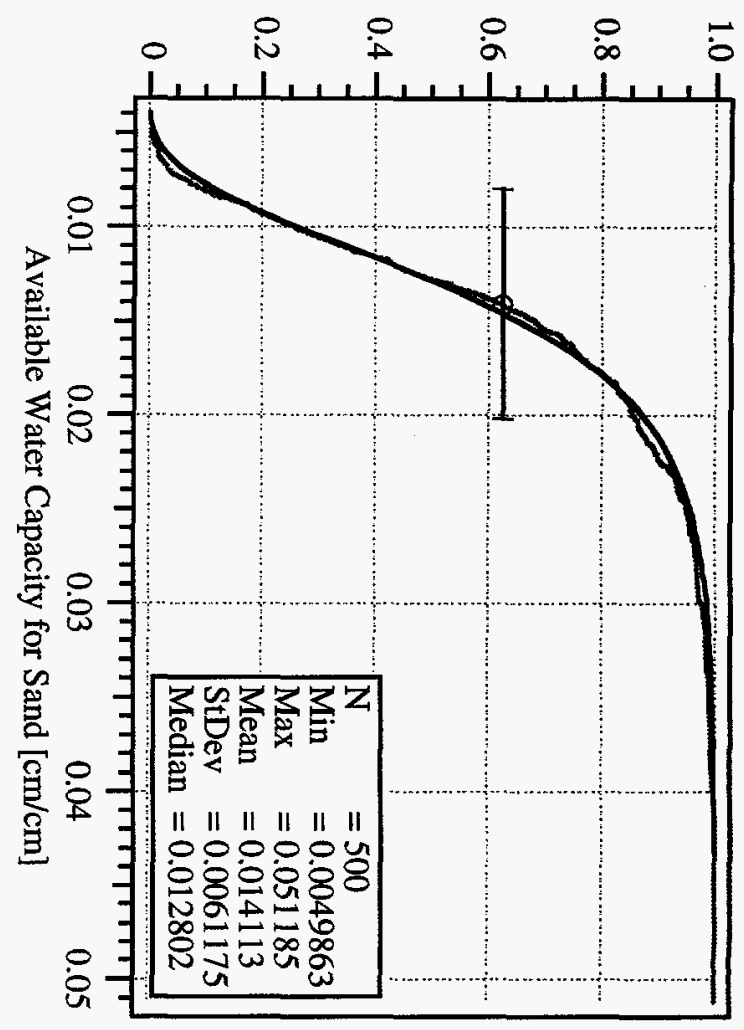



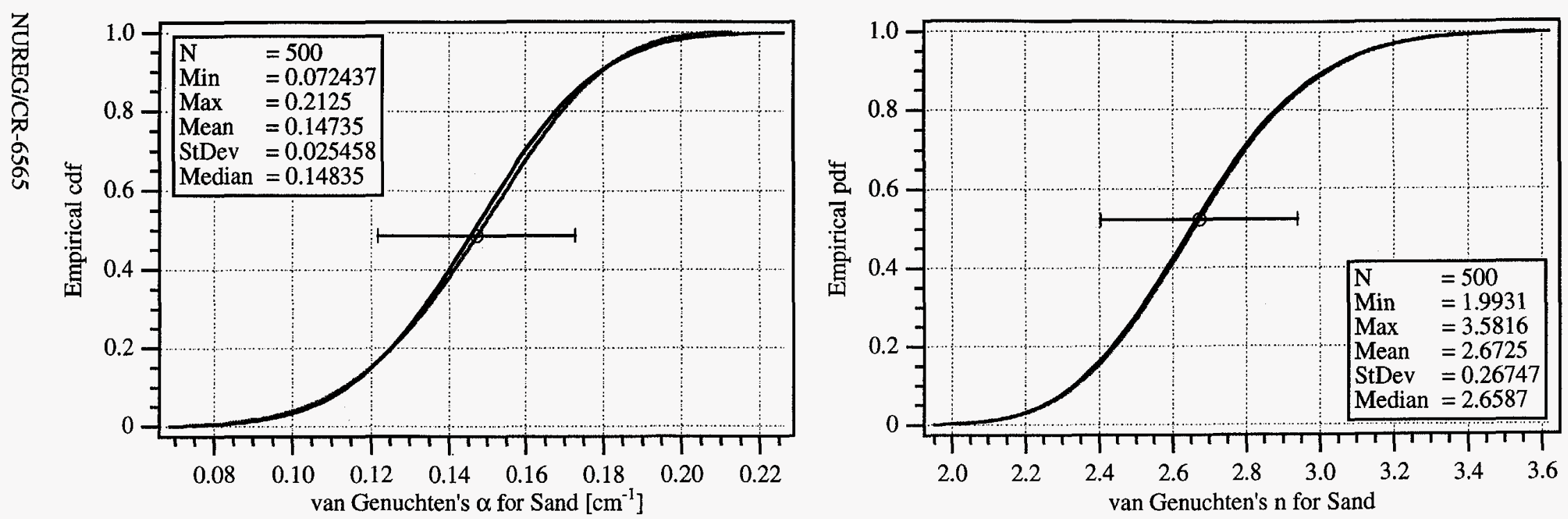

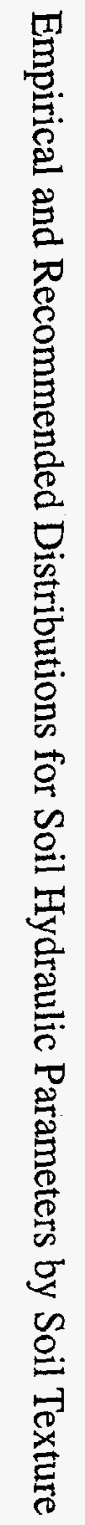
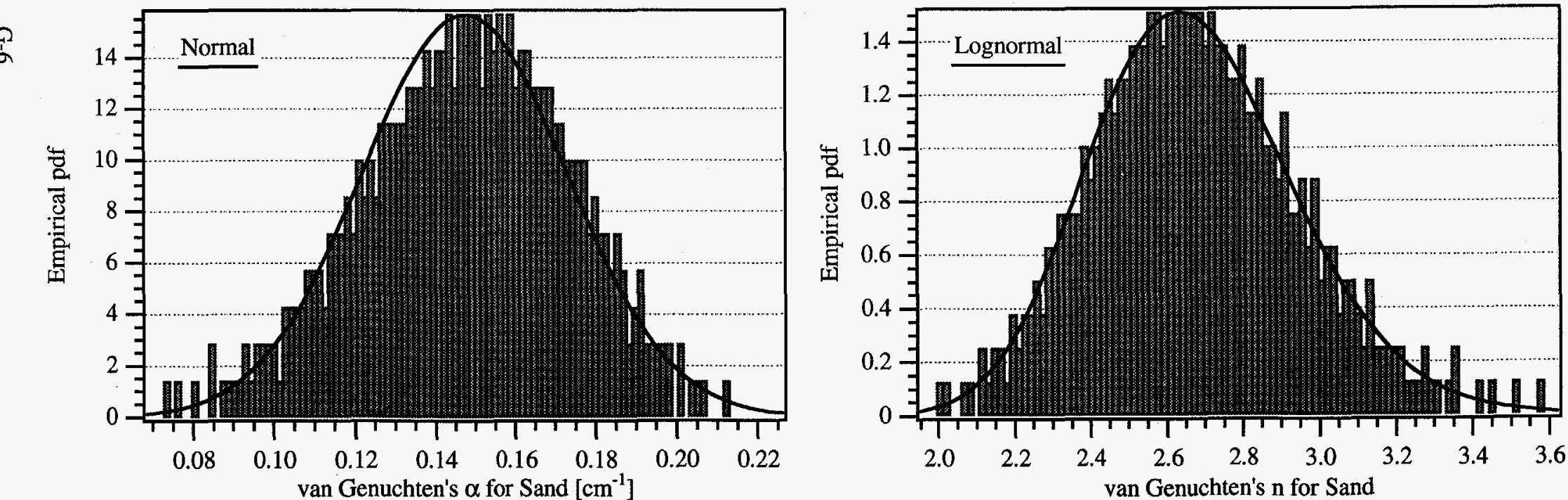


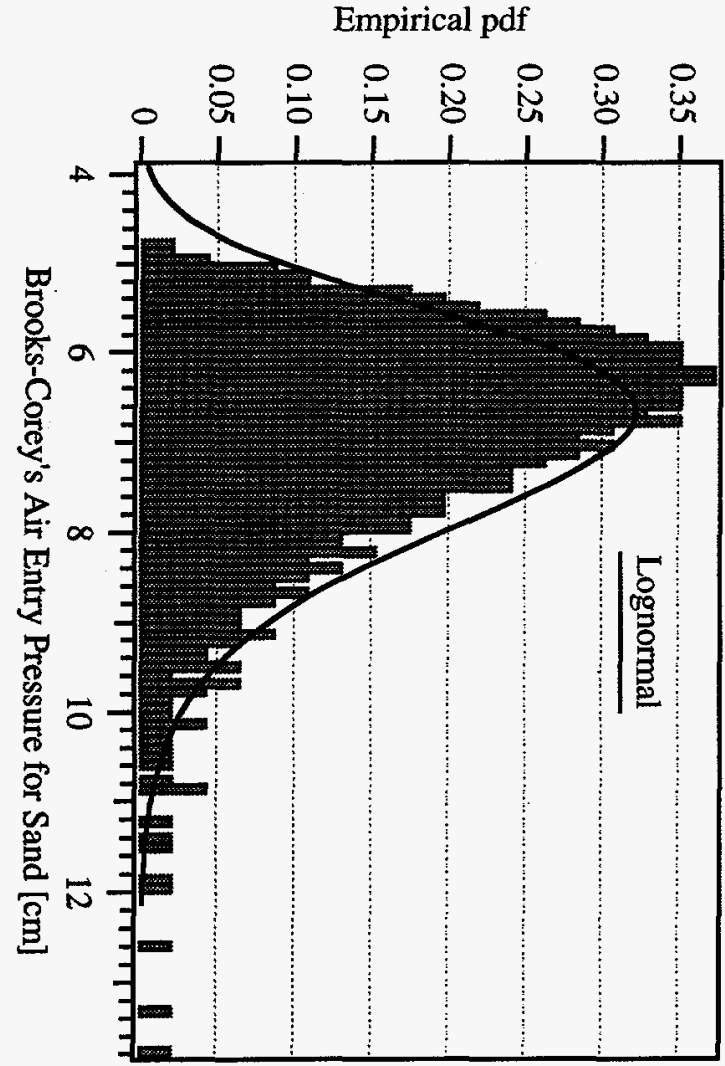

Empirical pdf

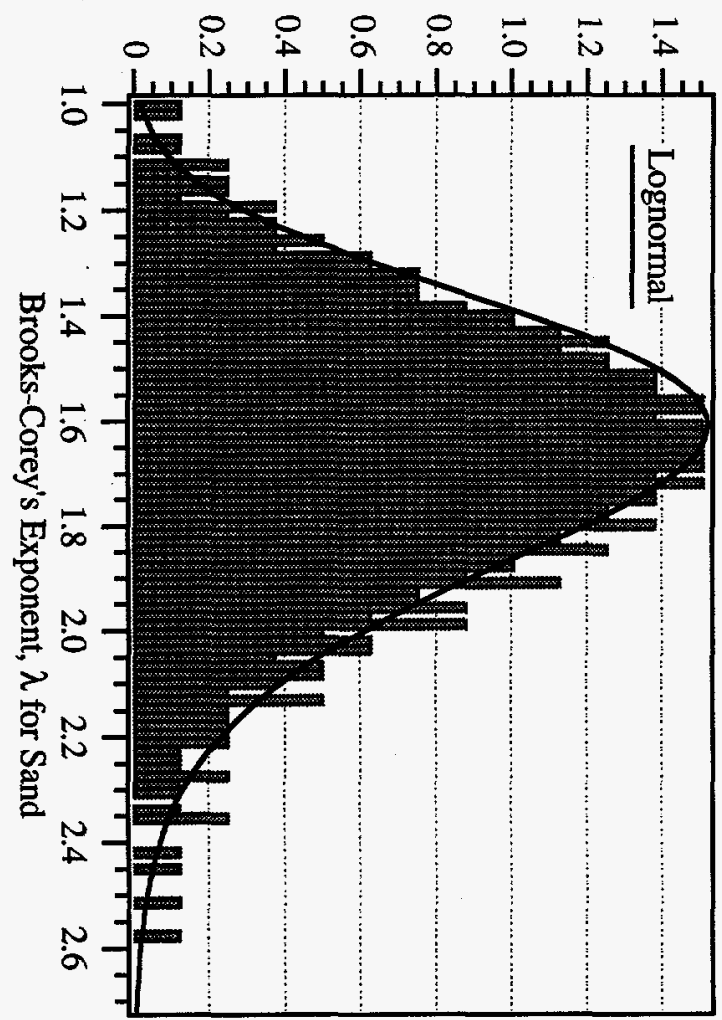

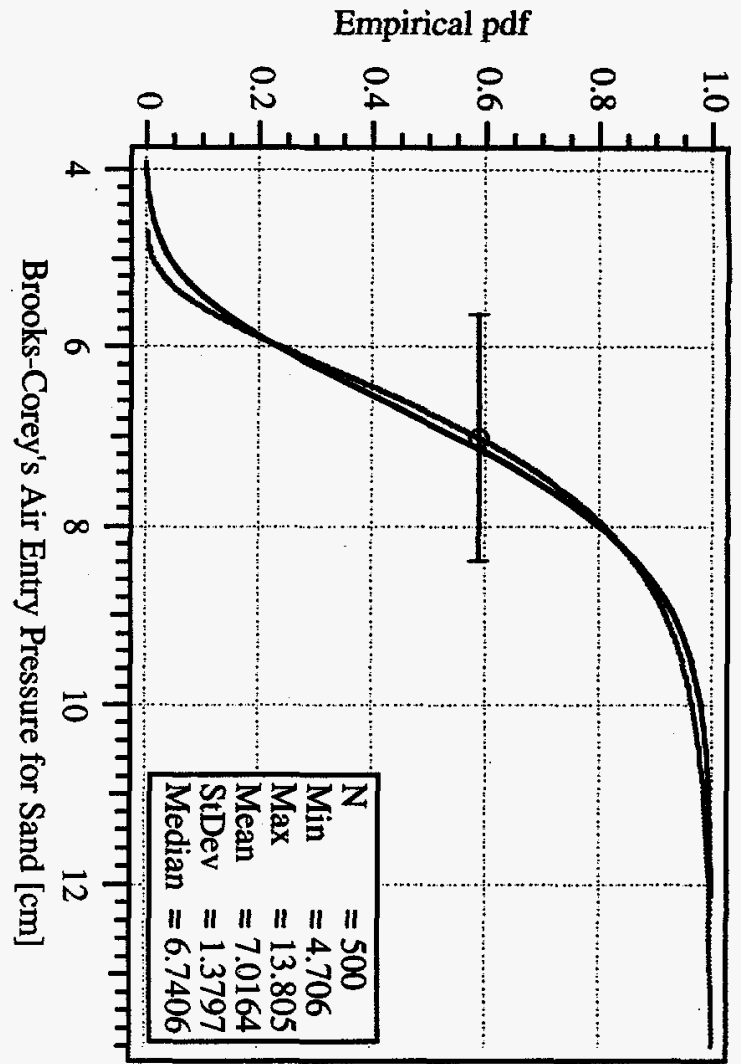

Empirical cdf

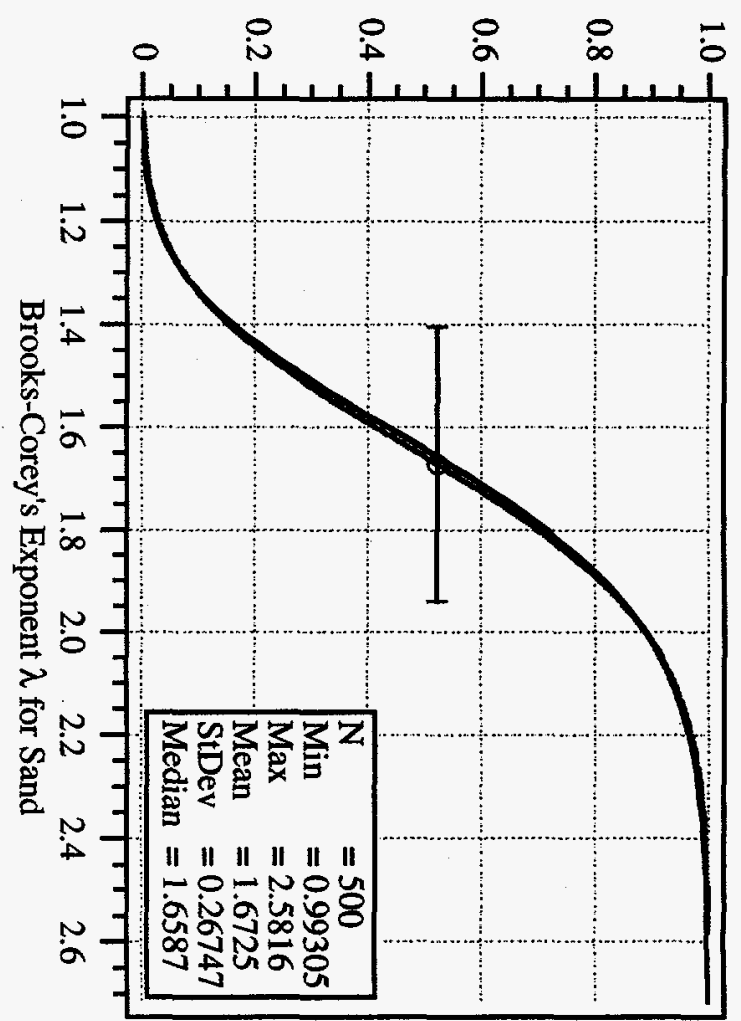


Empirical and Recommended Distributions for Soil Hydraulic Parameters by Soil Texture
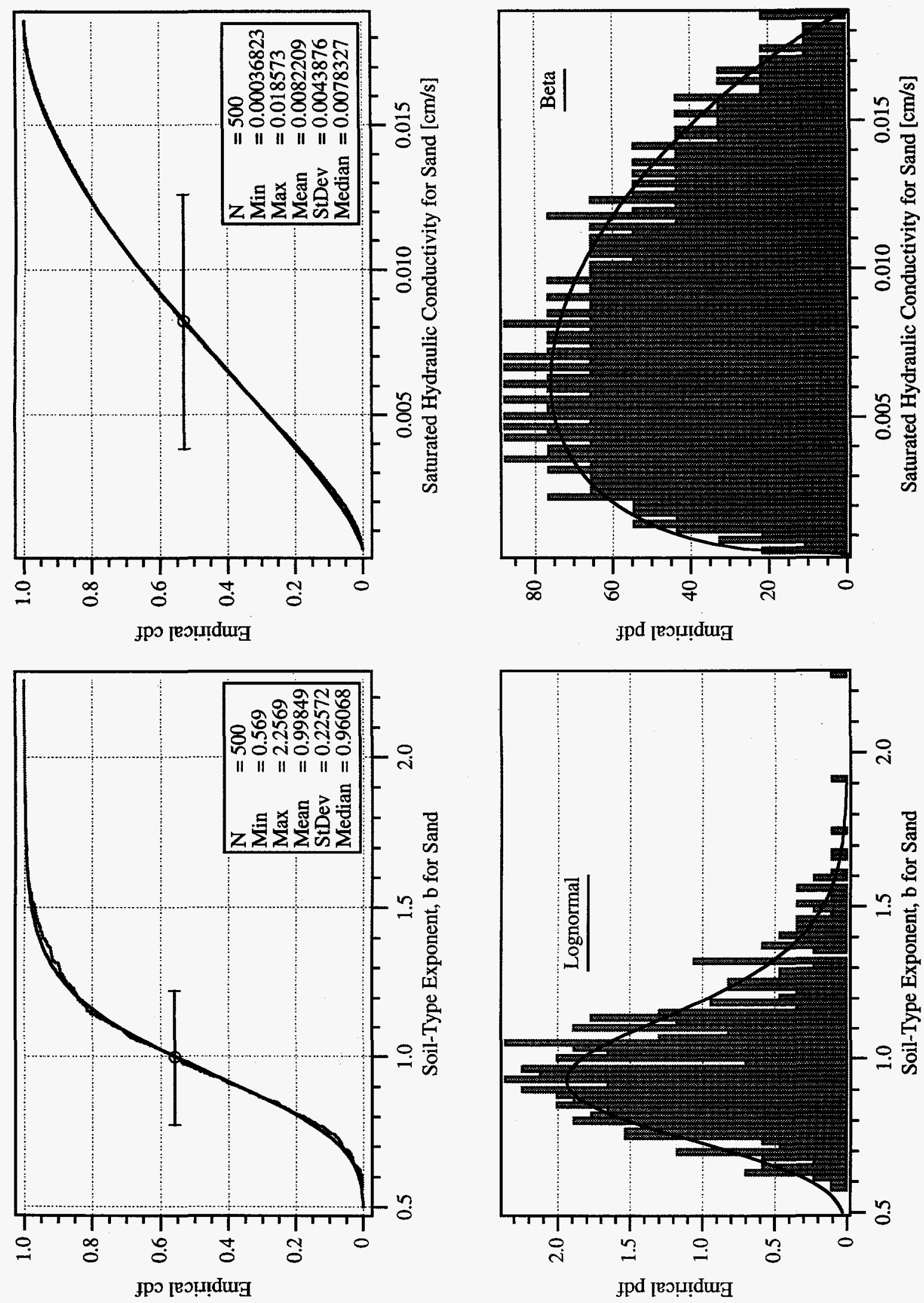

NUREG/CR-6565

G-8 

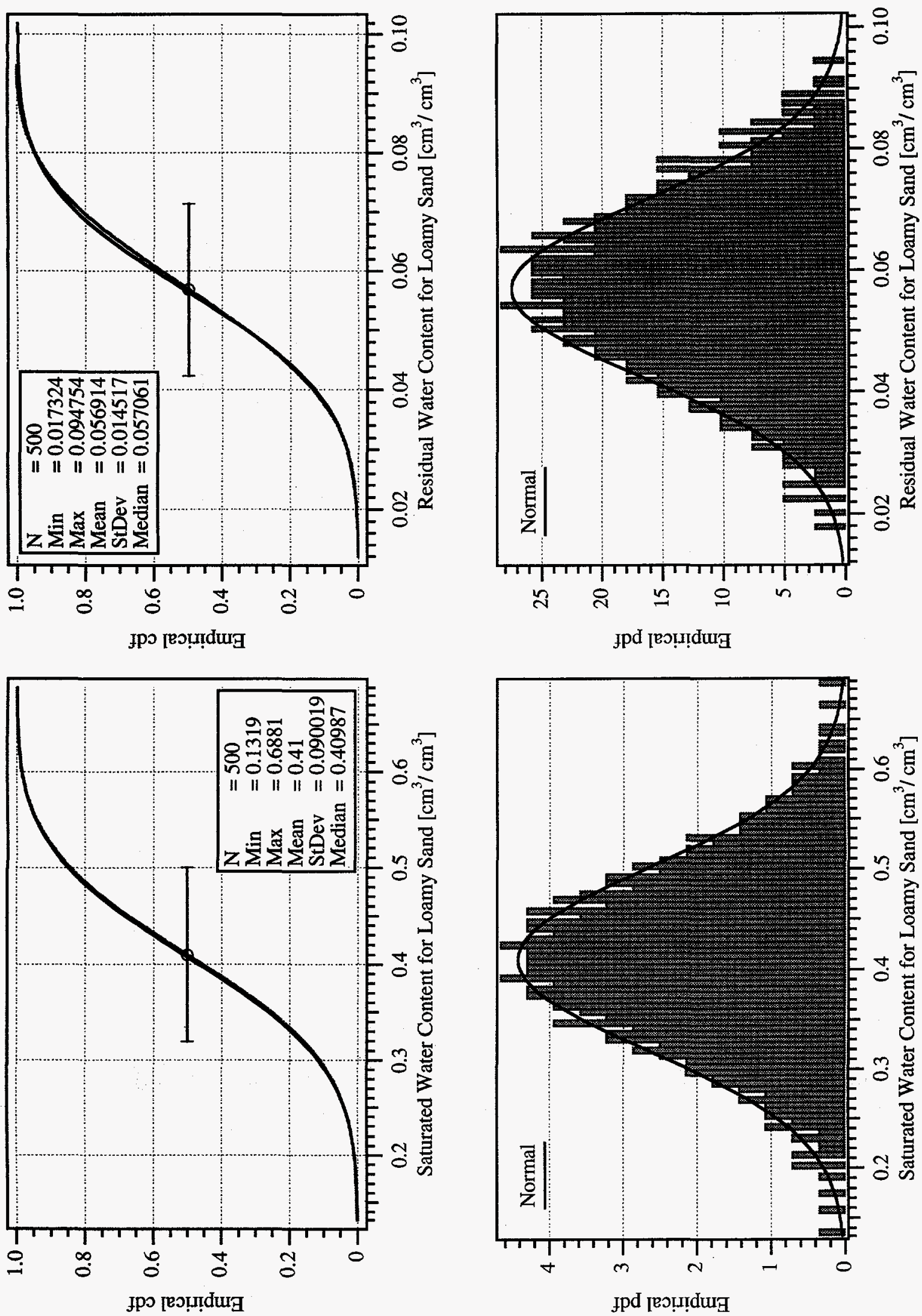

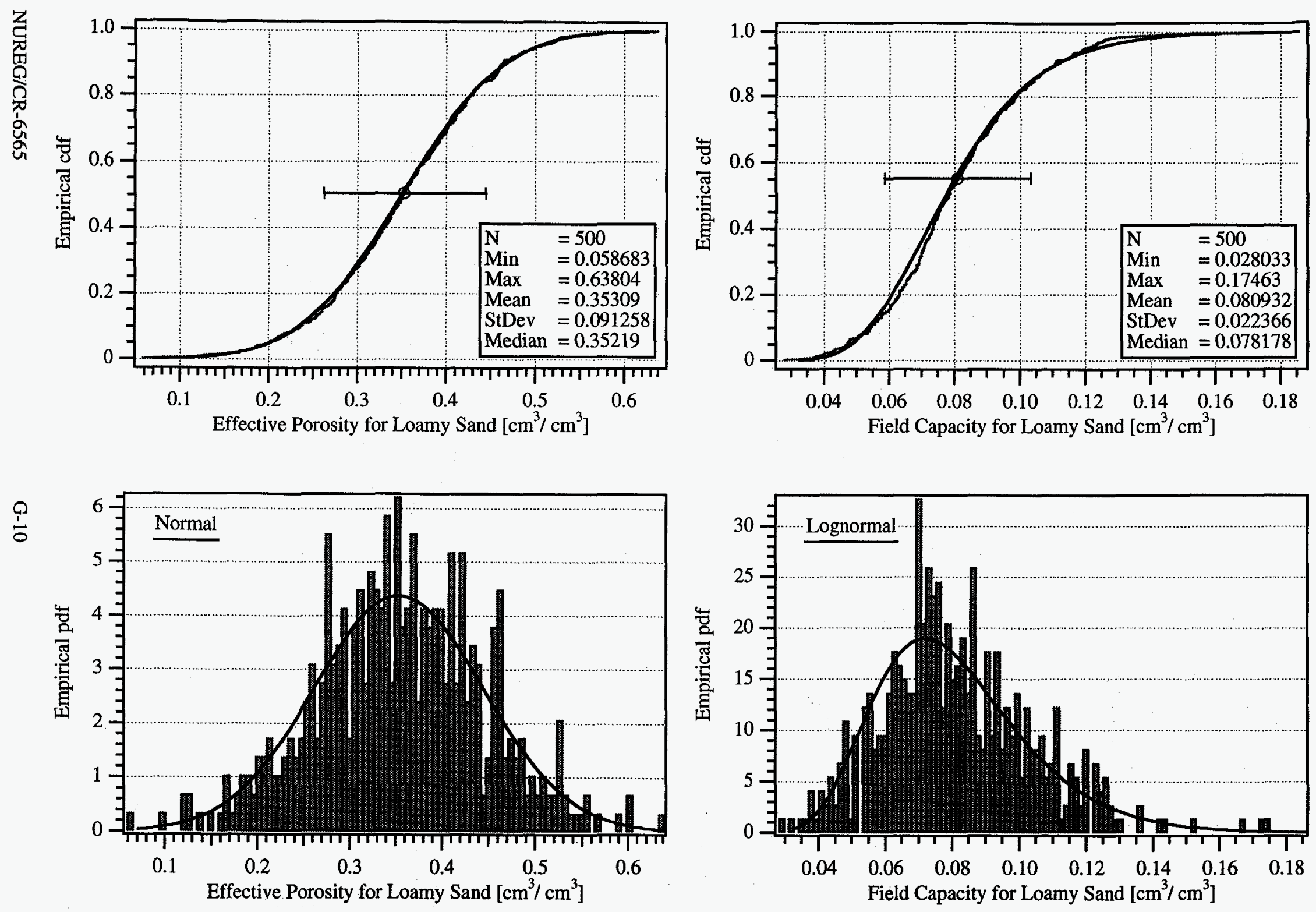

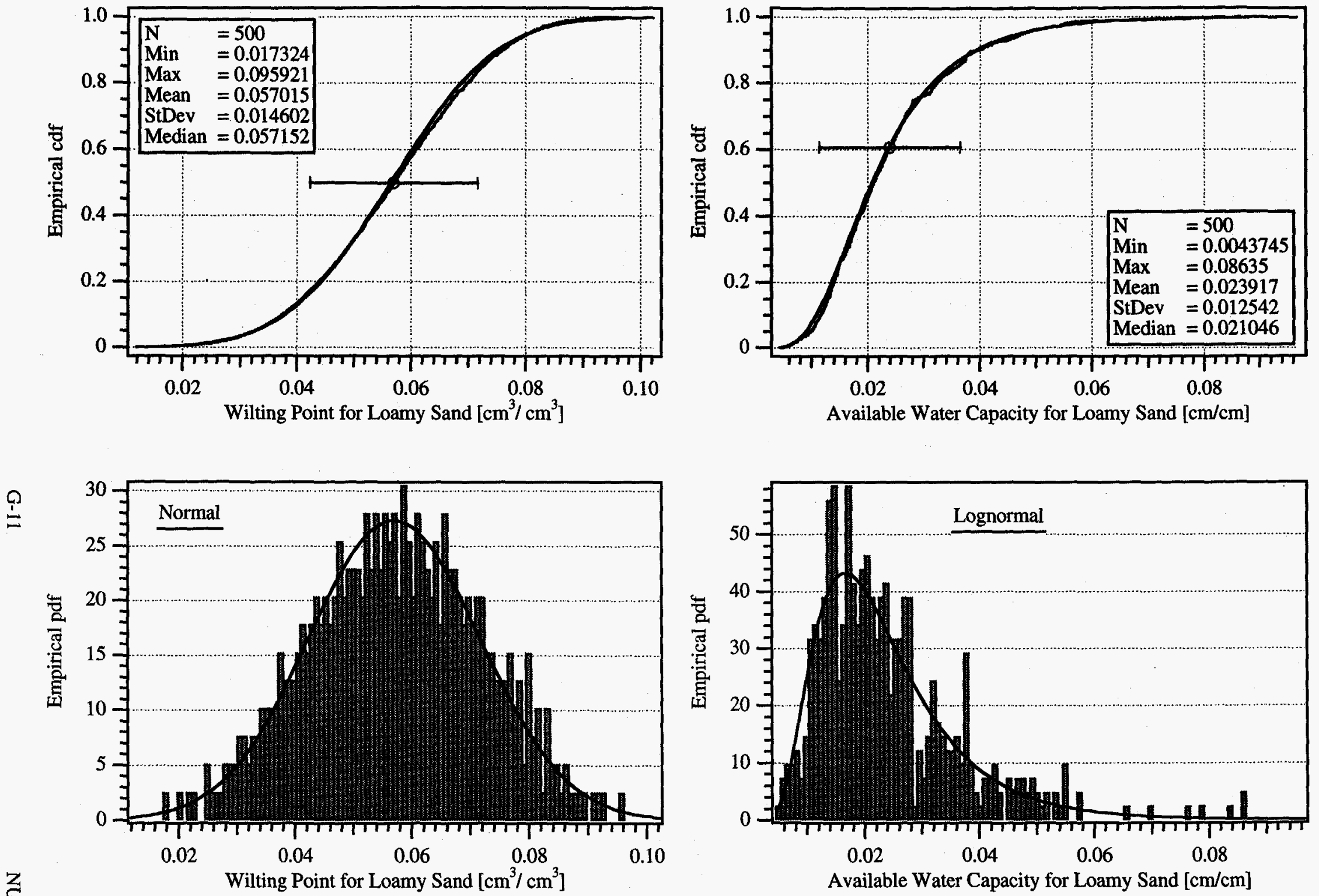
Empirical and Recommended Distributions for Soil Hydraulic Parameters by Soil Texture
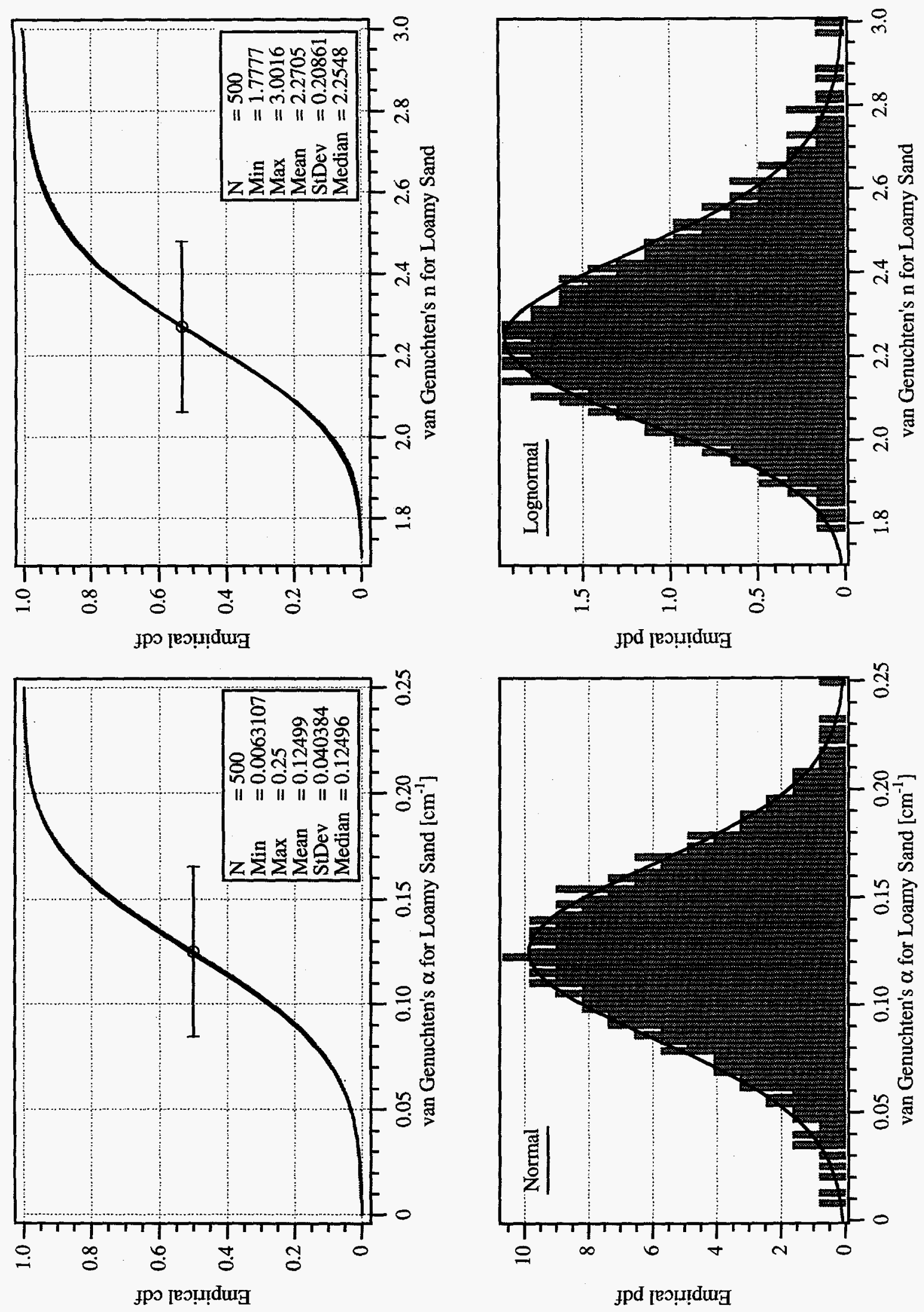

NUREG/CR-6565

G-12 

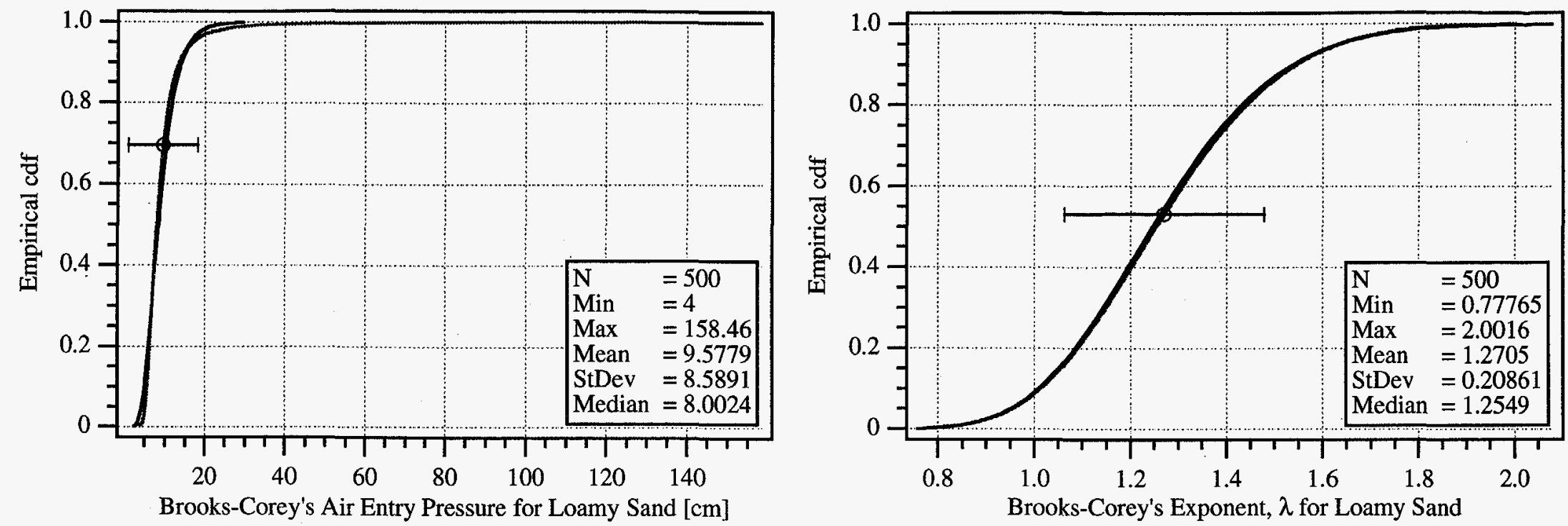

$\frac{i}{\omega}$
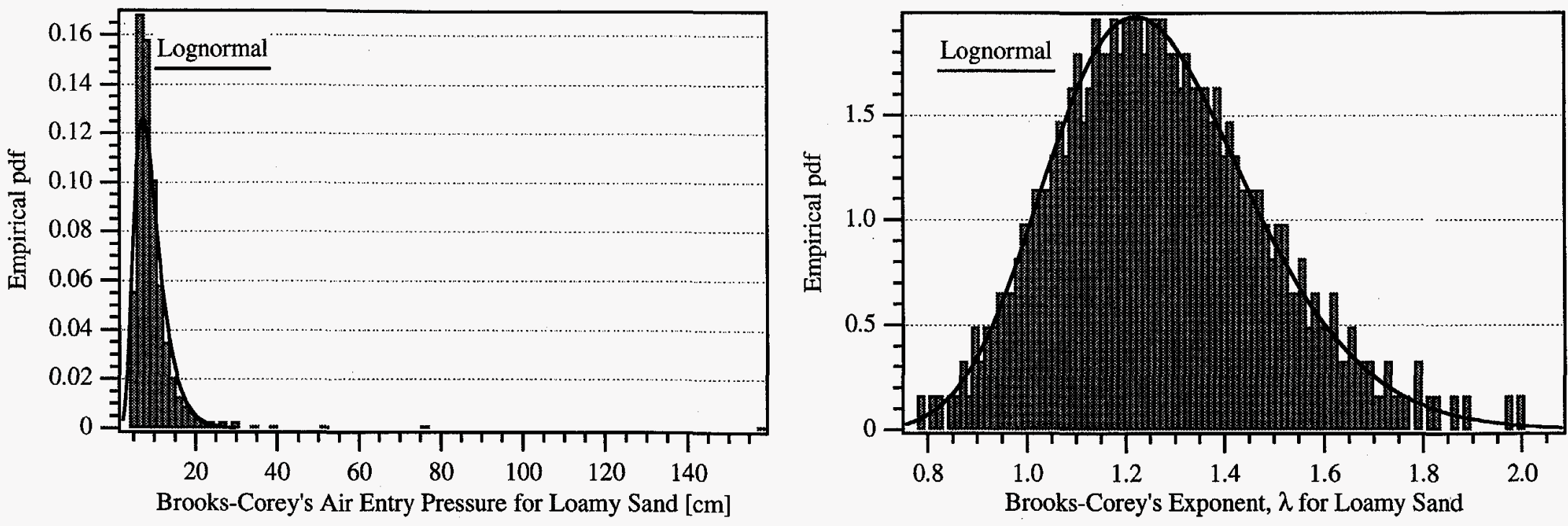

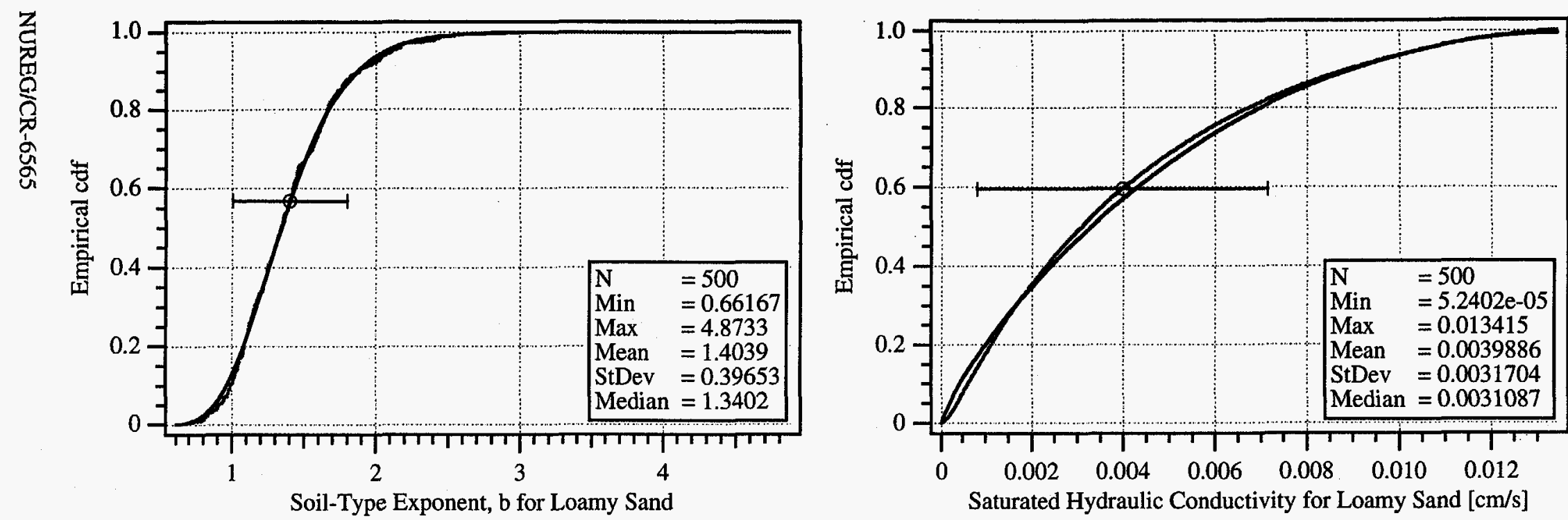

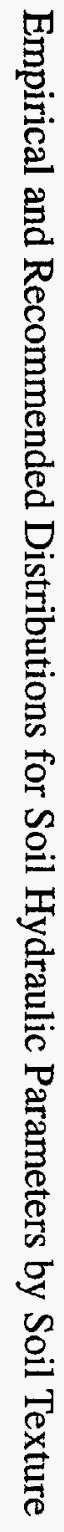
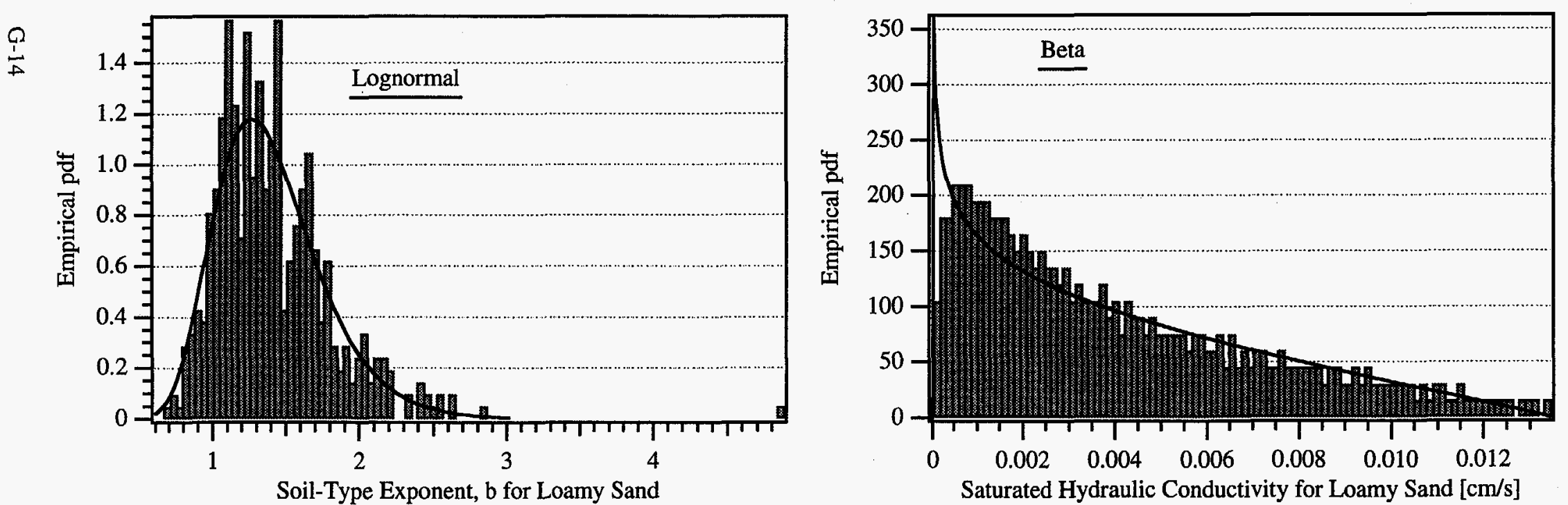

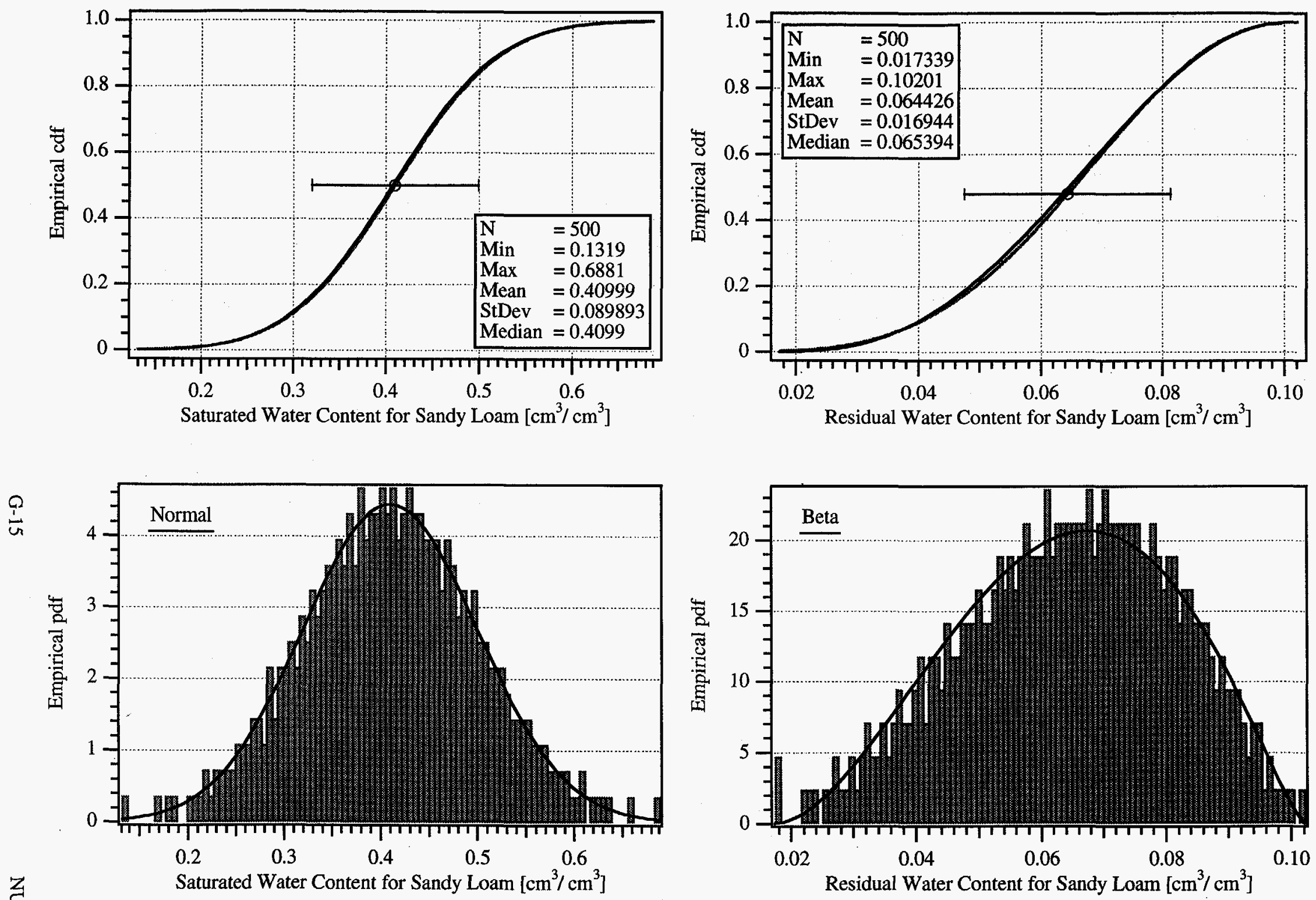

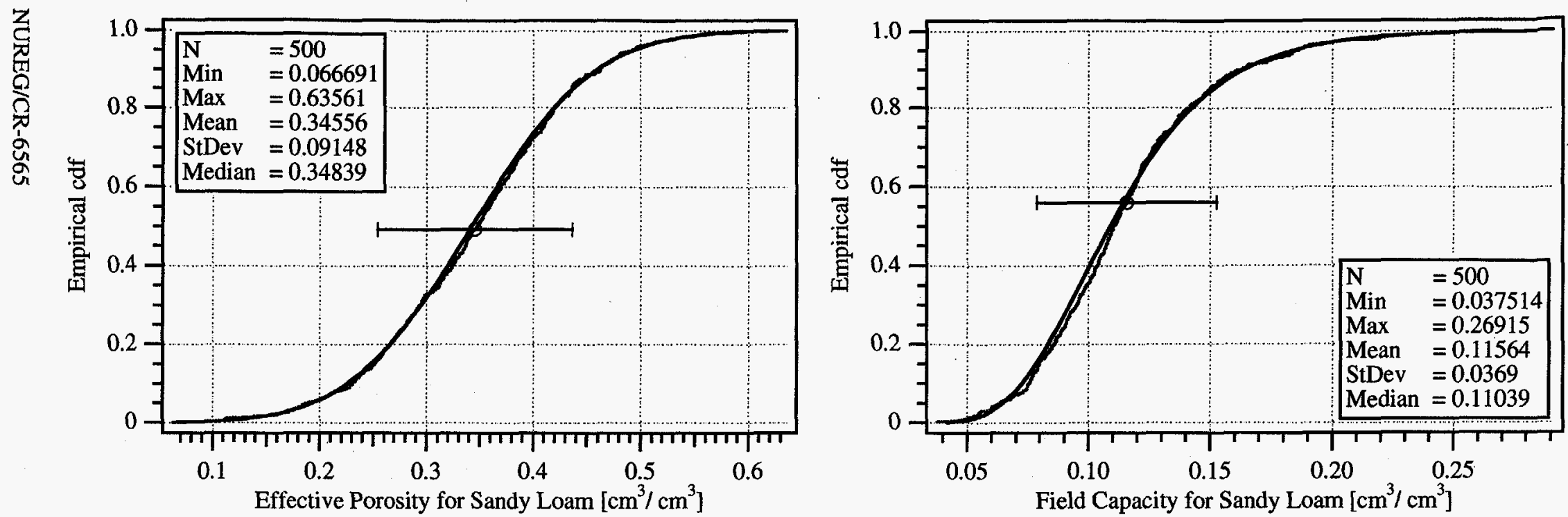

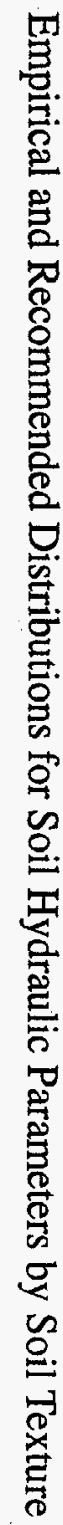
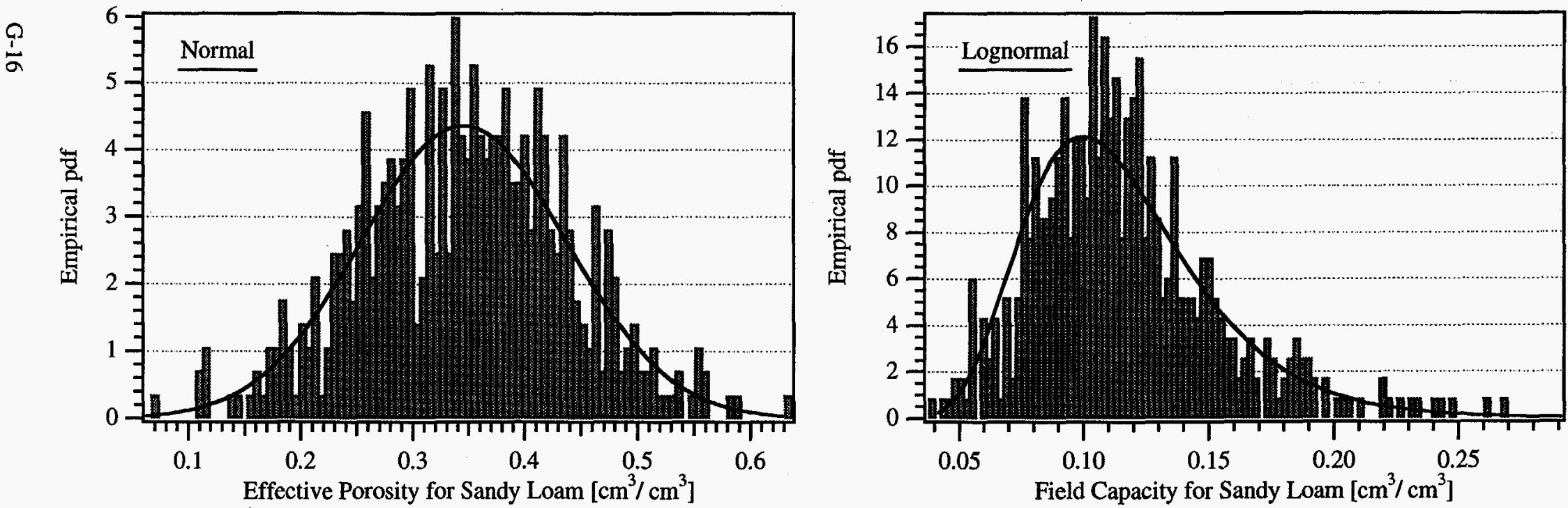

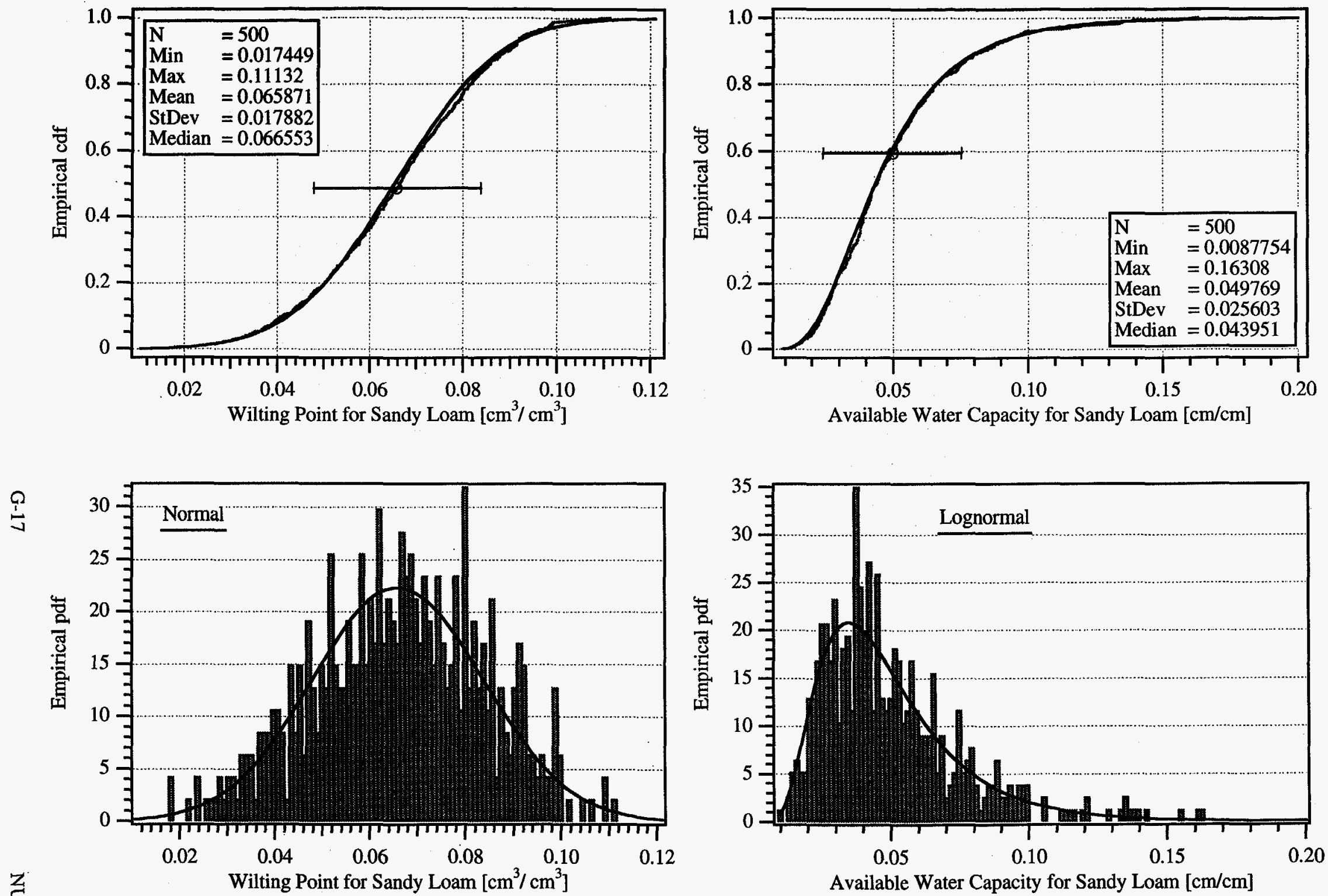

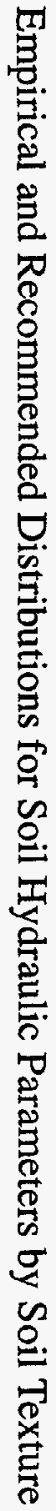



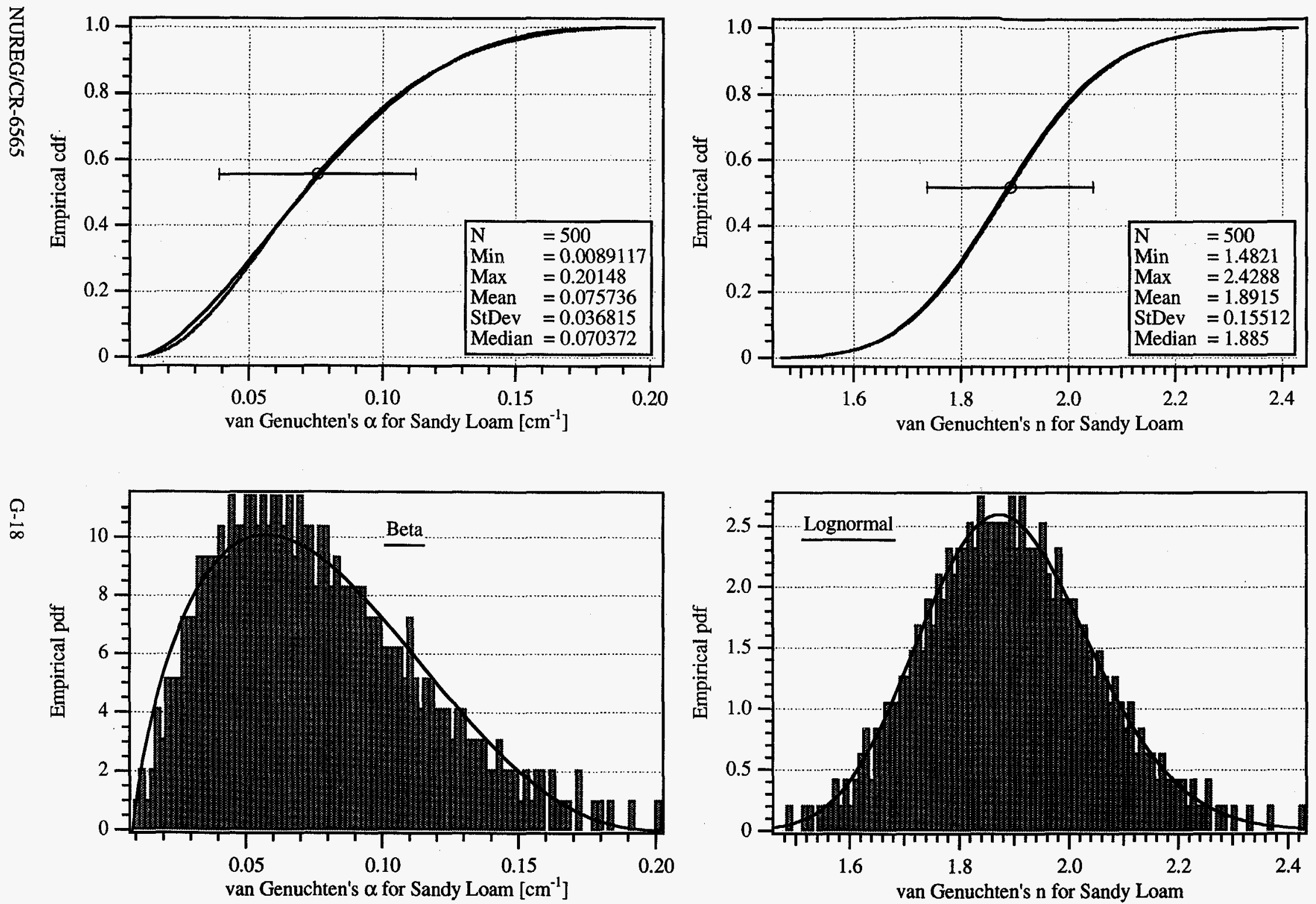

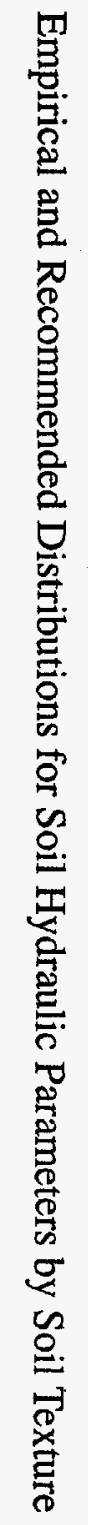


Empirical and Recommended Distributions for Soil Hydraulic Parameters by Soil Texture
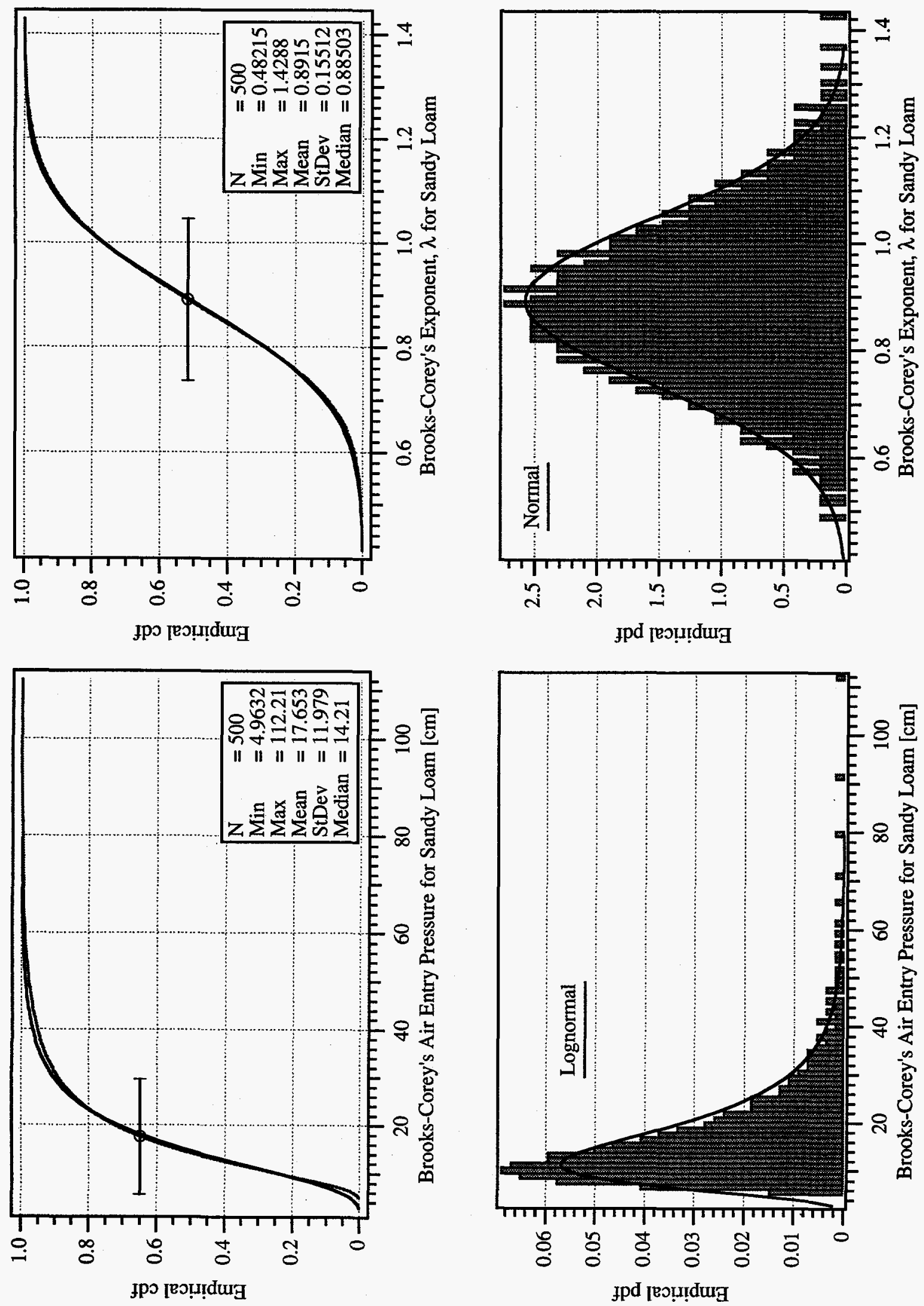

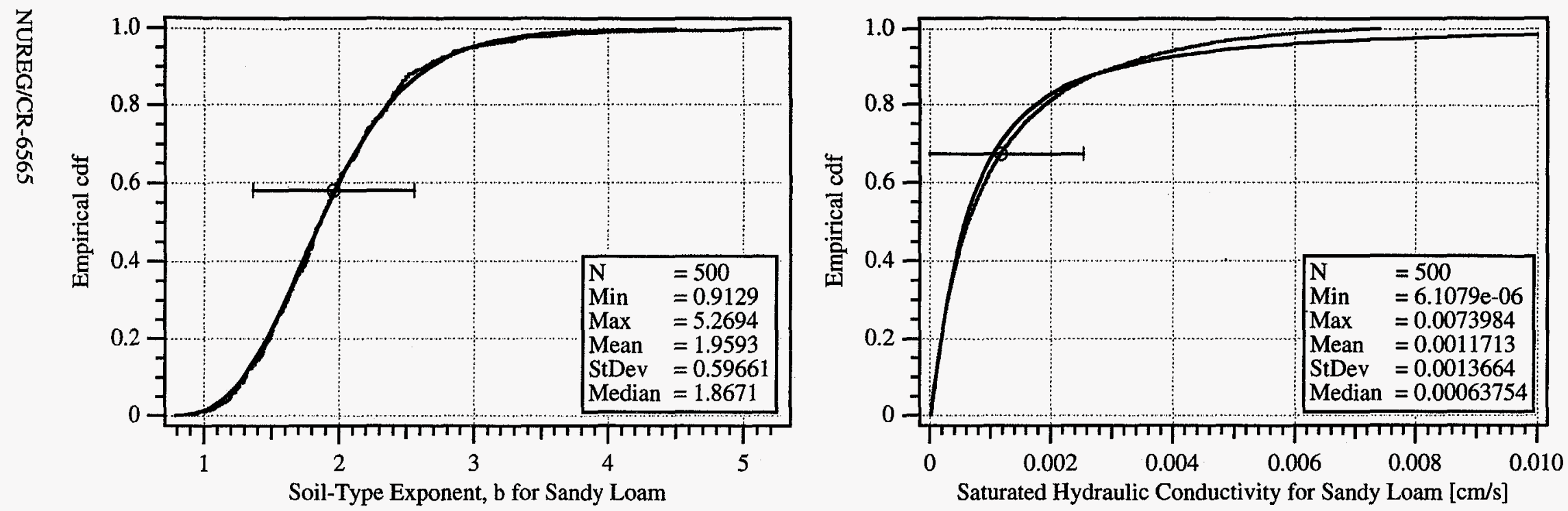

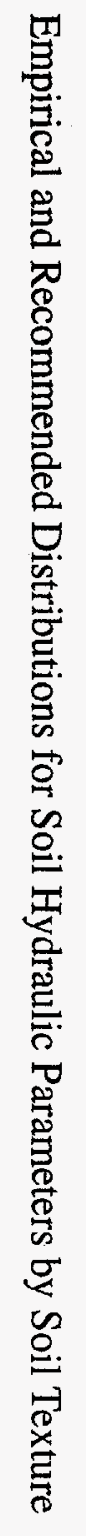
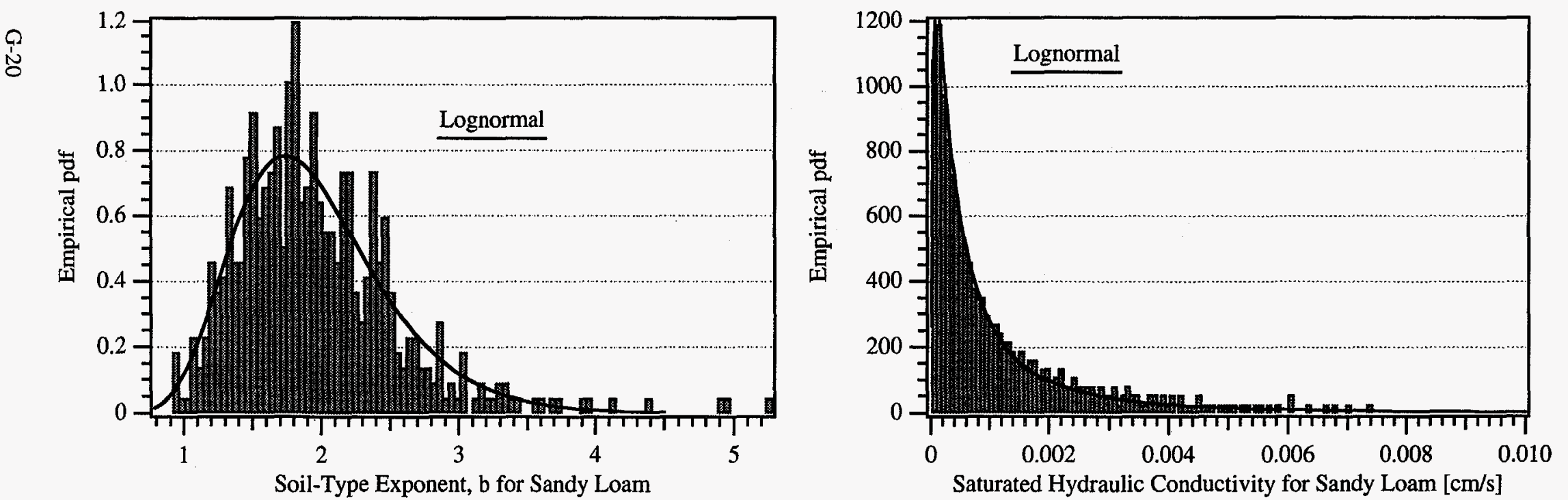

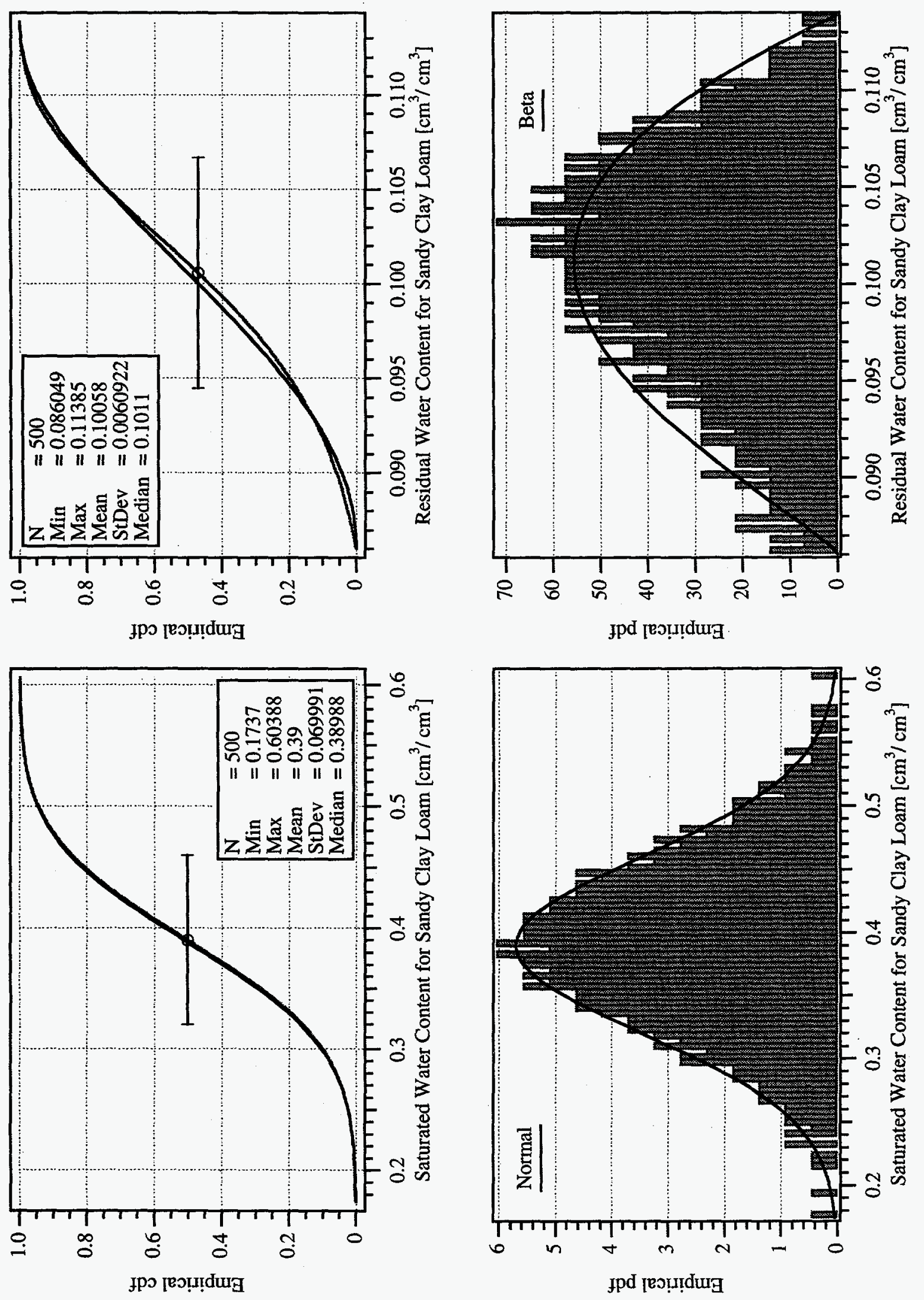

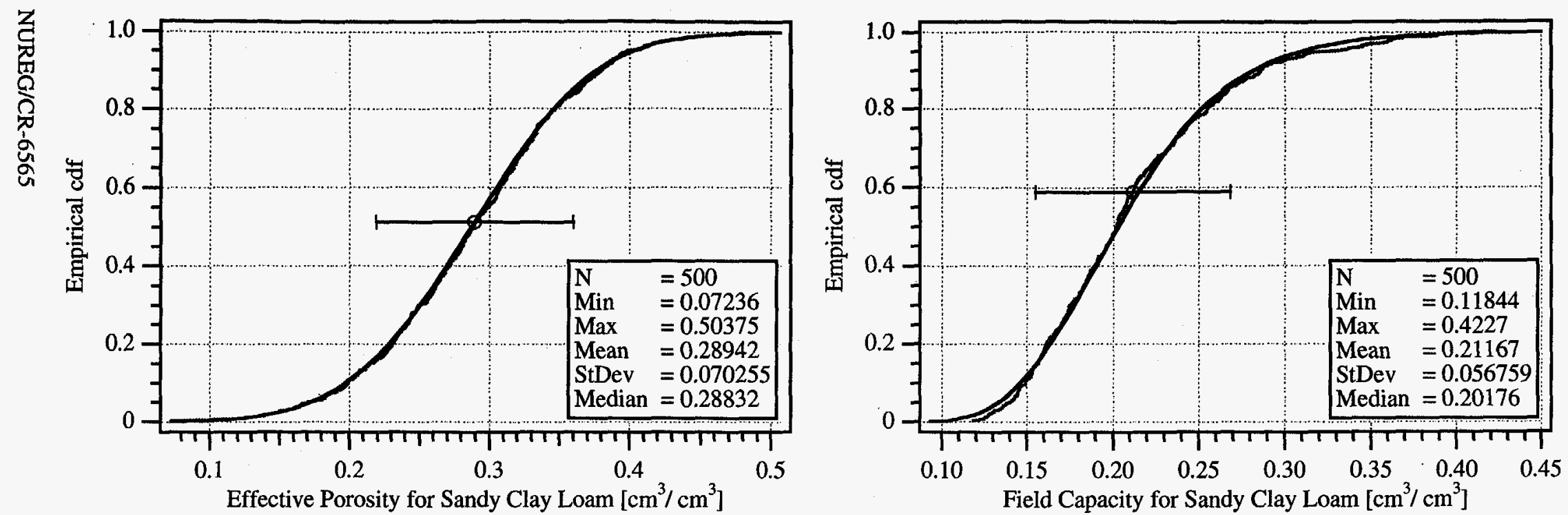

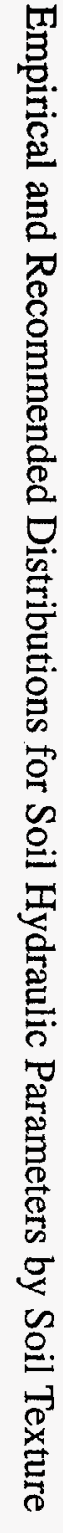
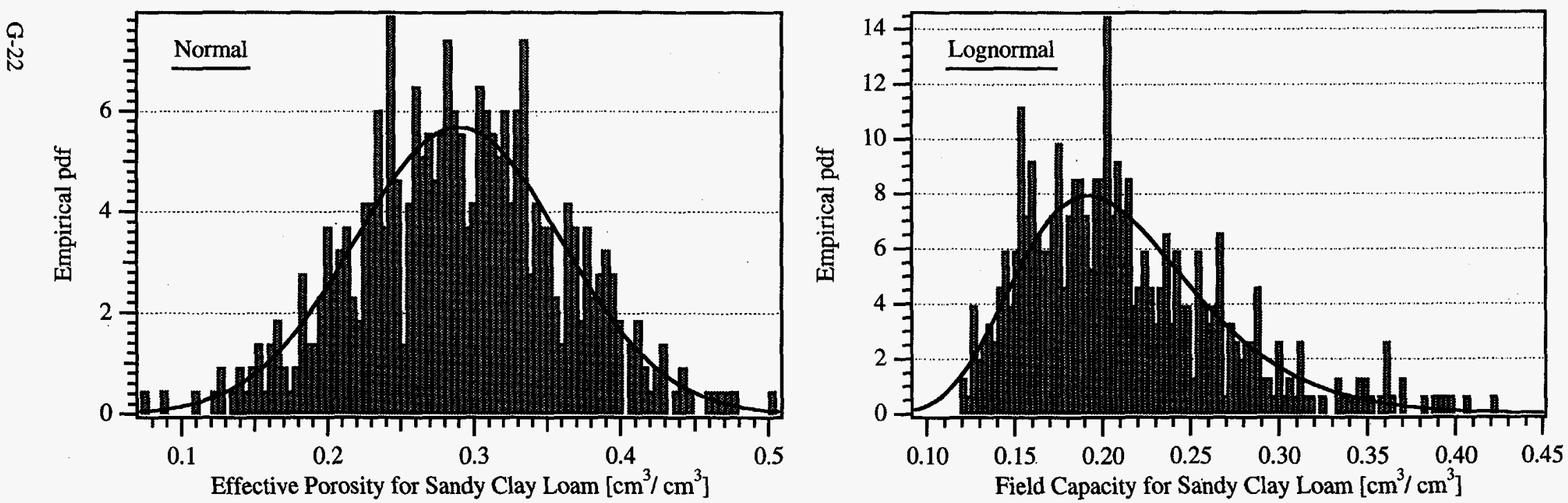
Empirical and Recommended Distributions for Soil Hydraulic Parameters by Soil Texture
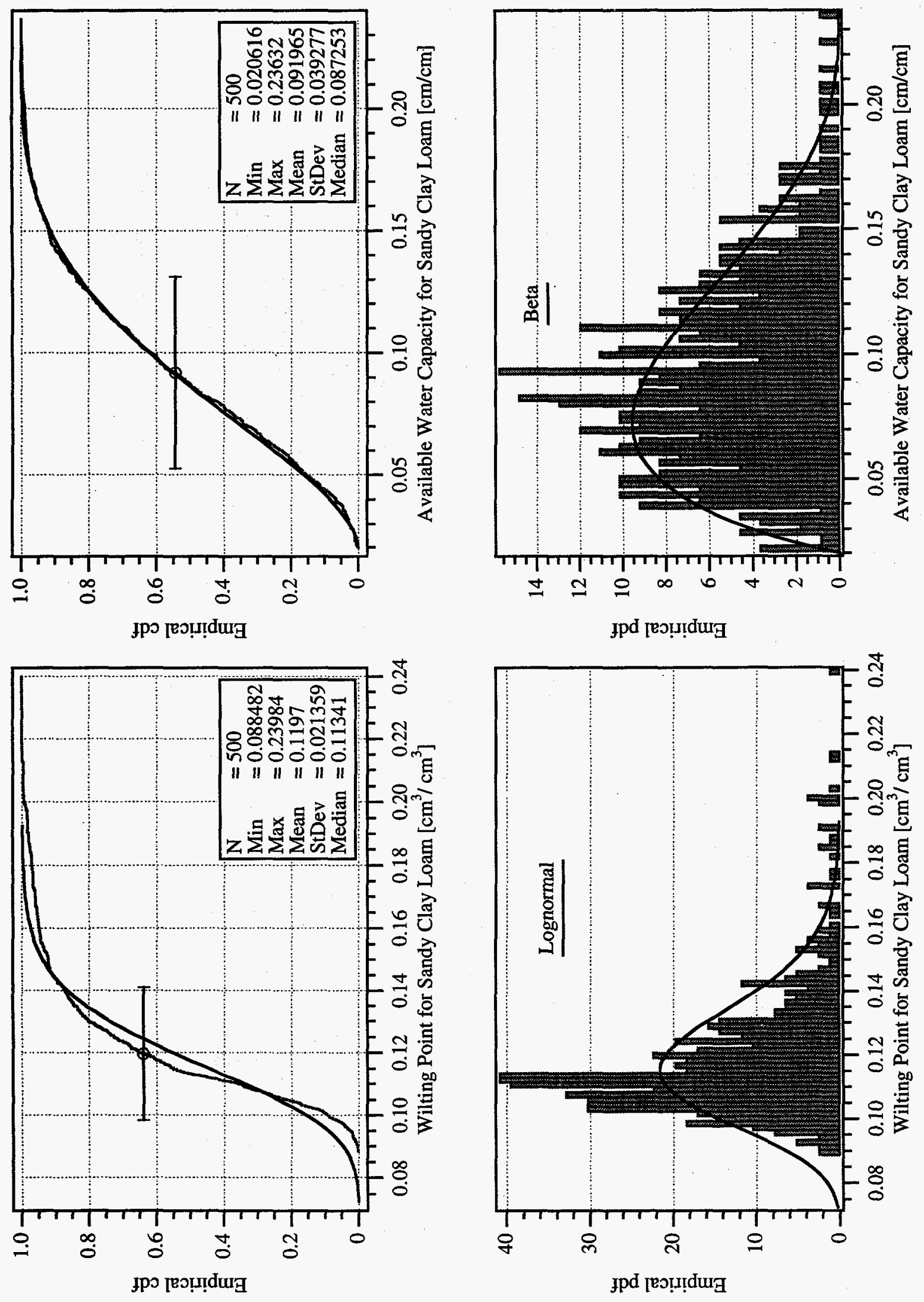

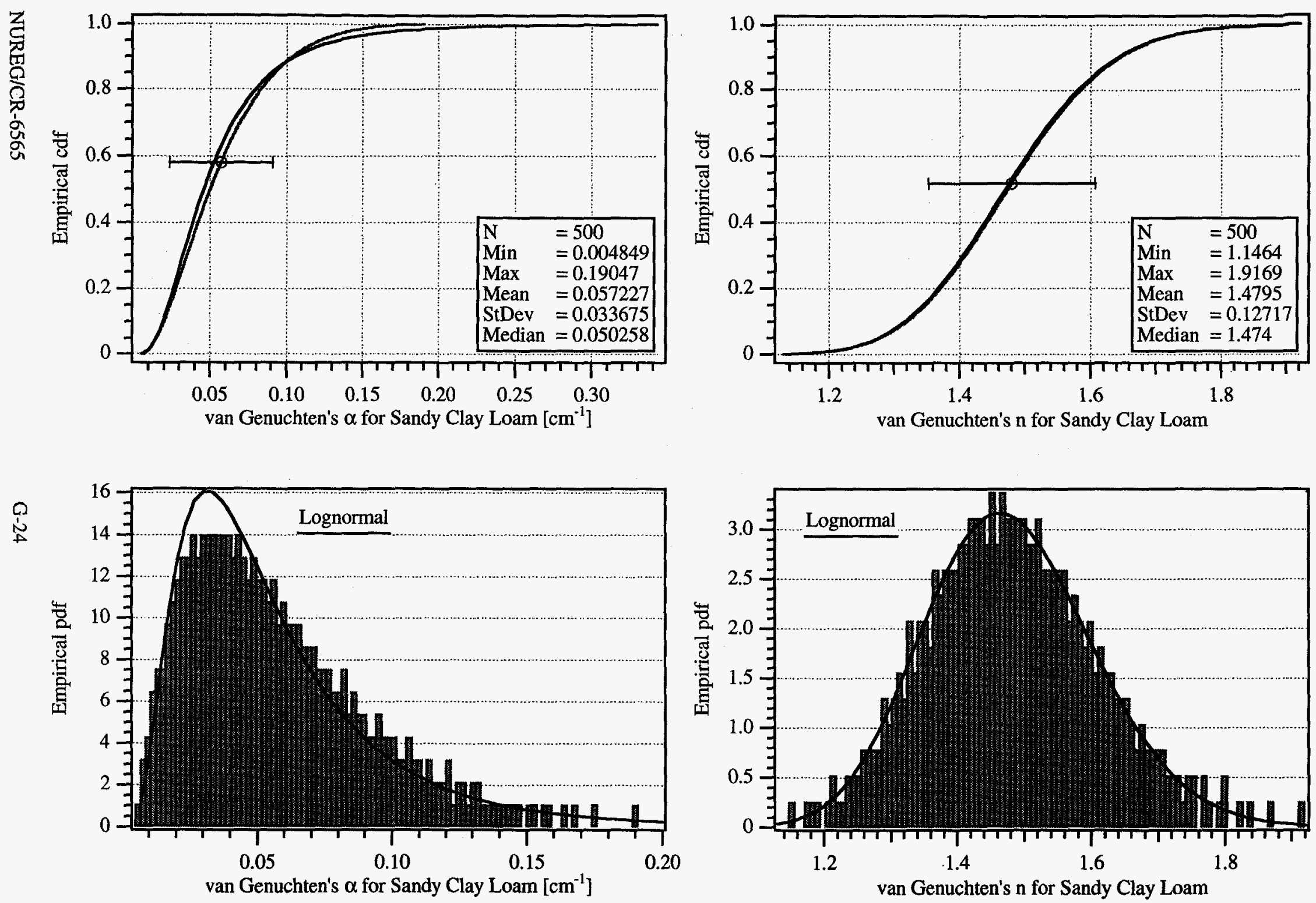

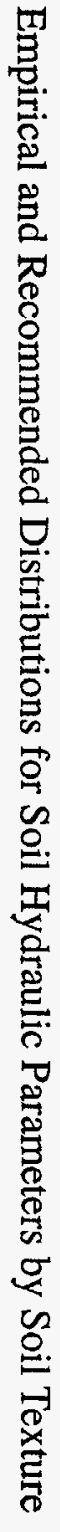



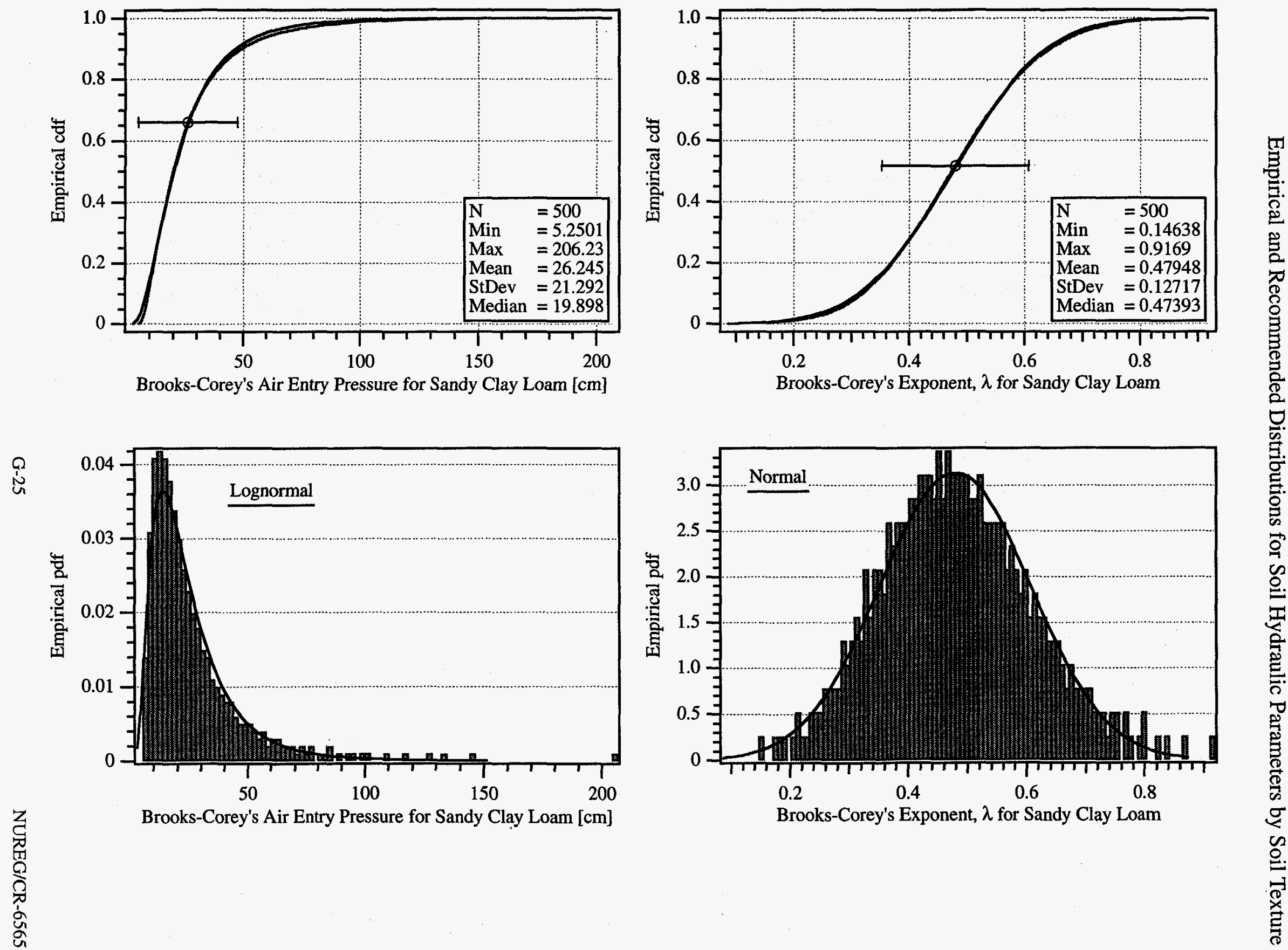

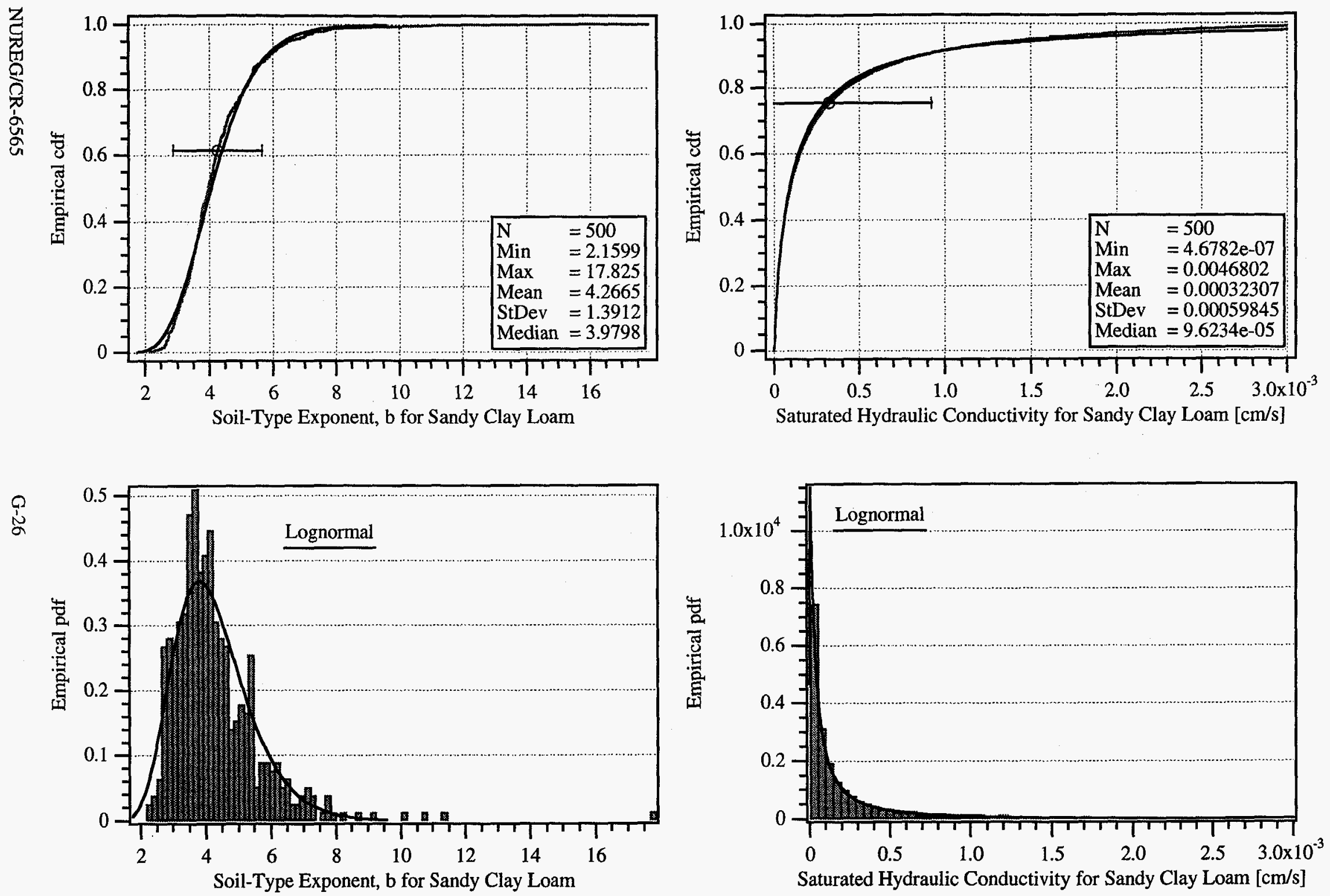

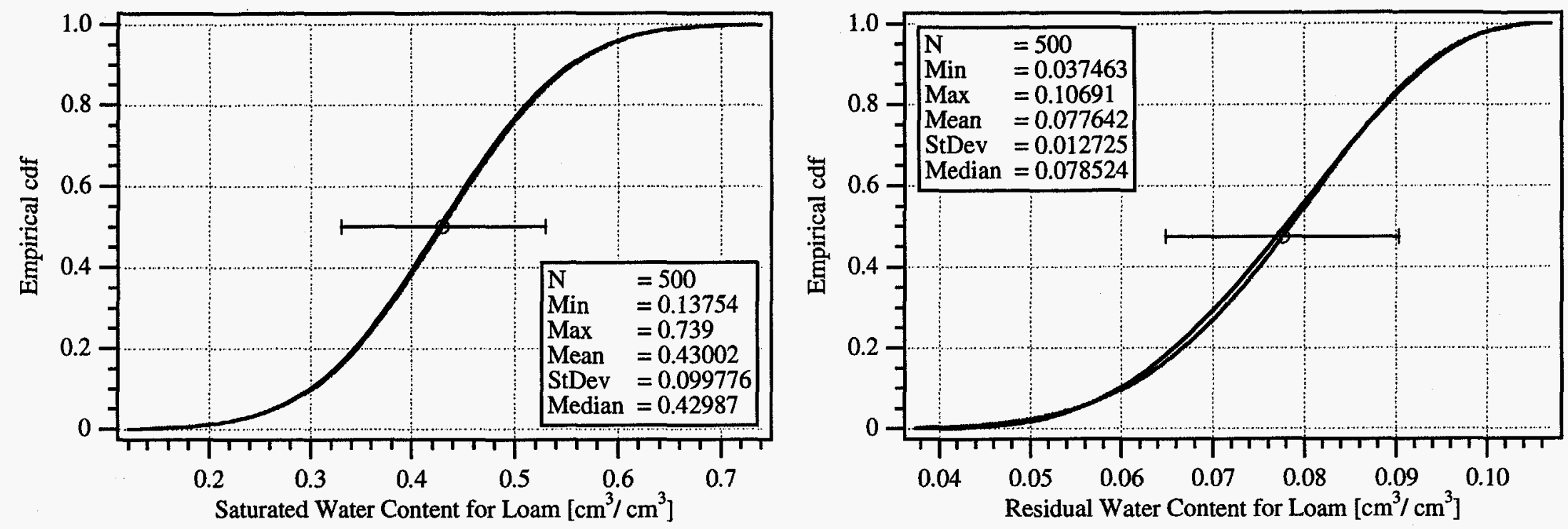

N
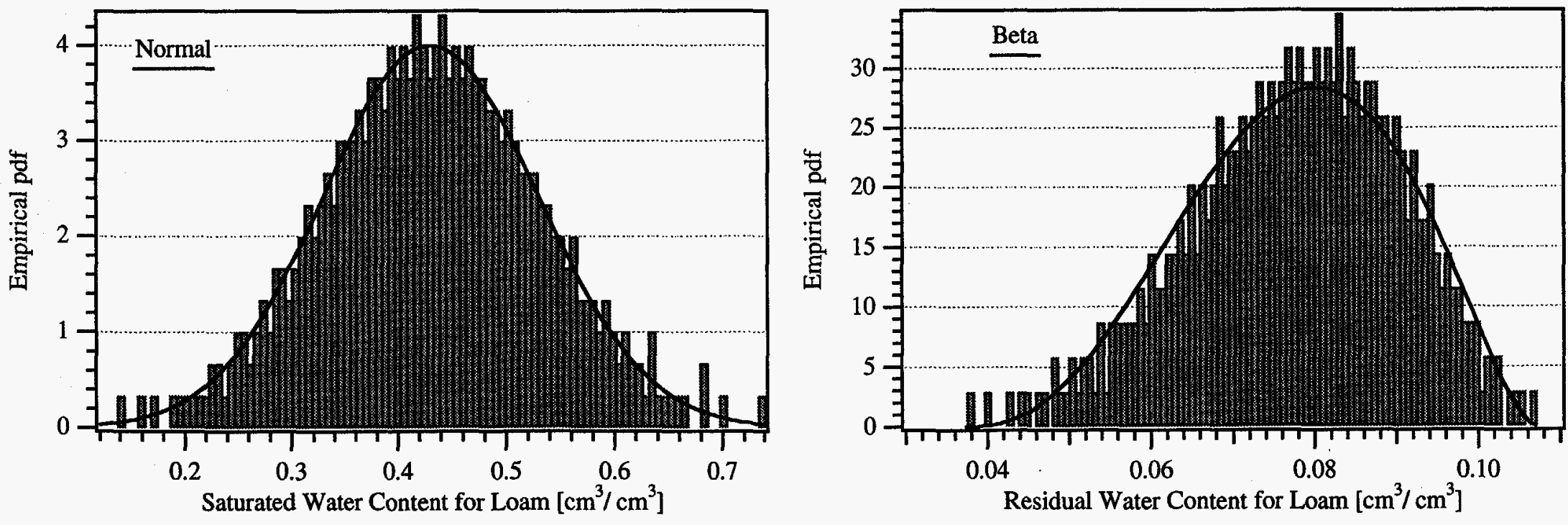

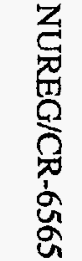


Empirical and Recommended Distributions for Soil Hydraulic Parameters by Soil Texture
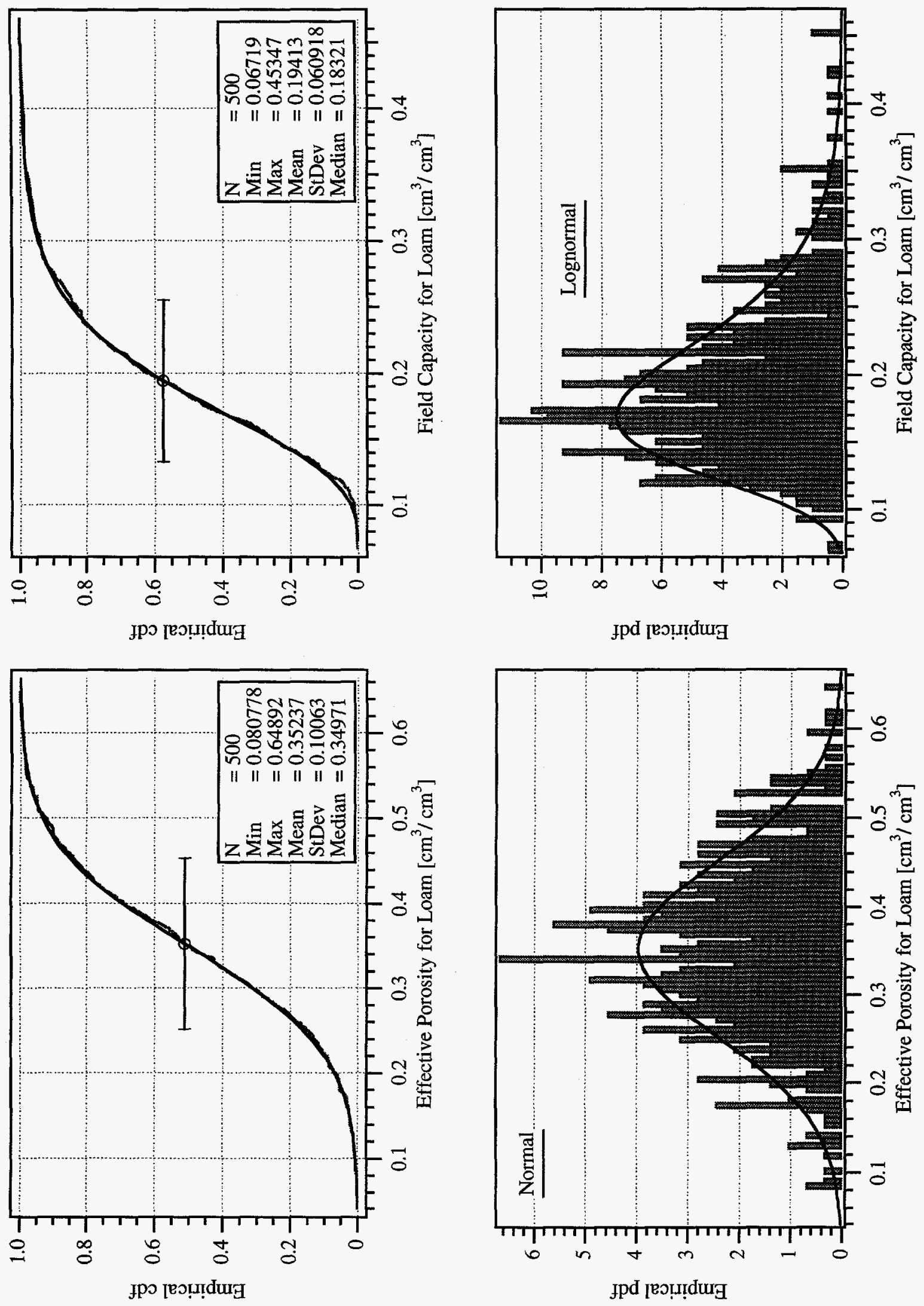

NUREG/CR-6565

G-28 

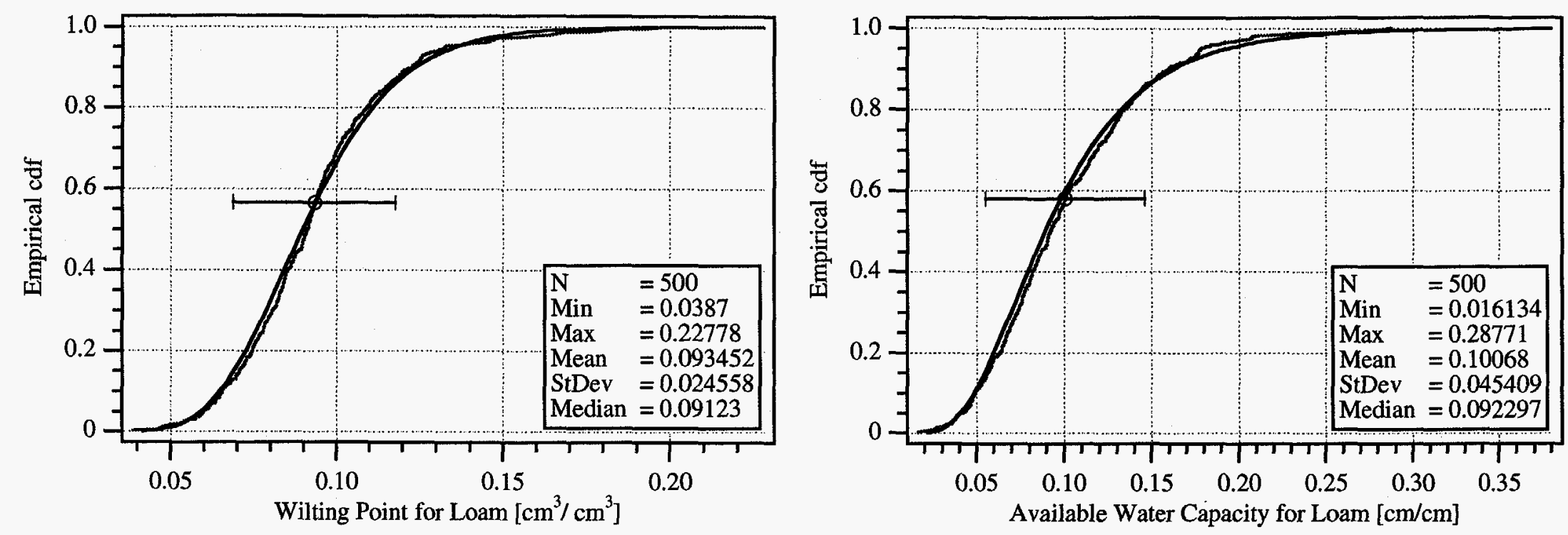

怘
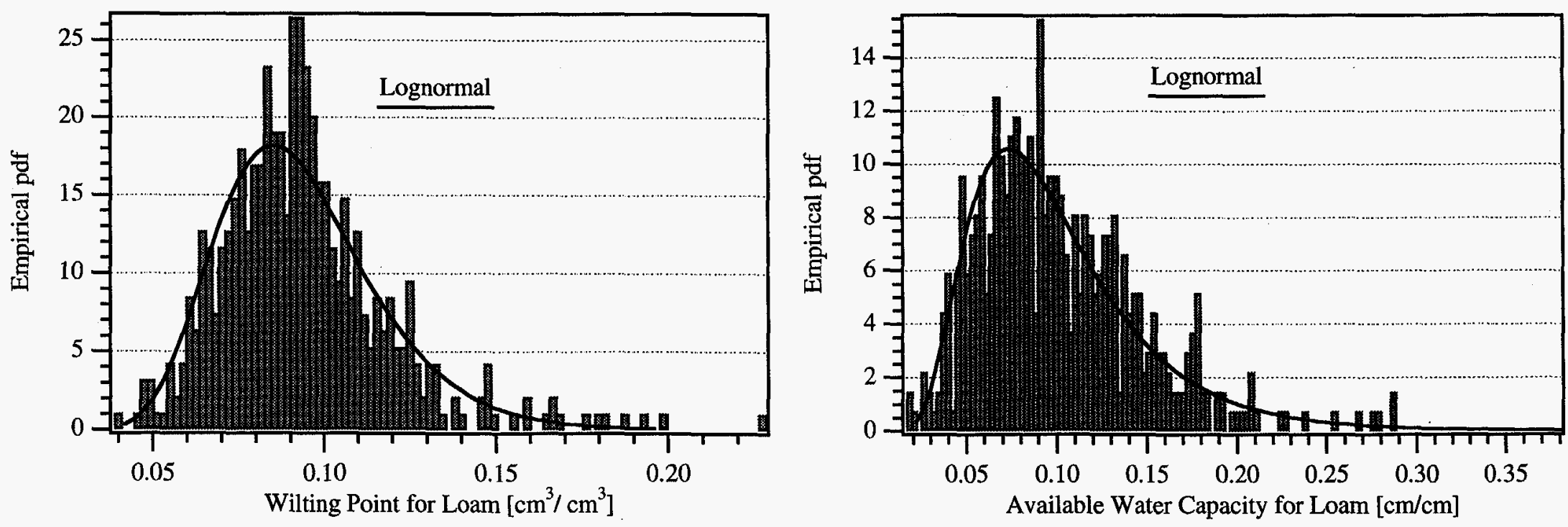

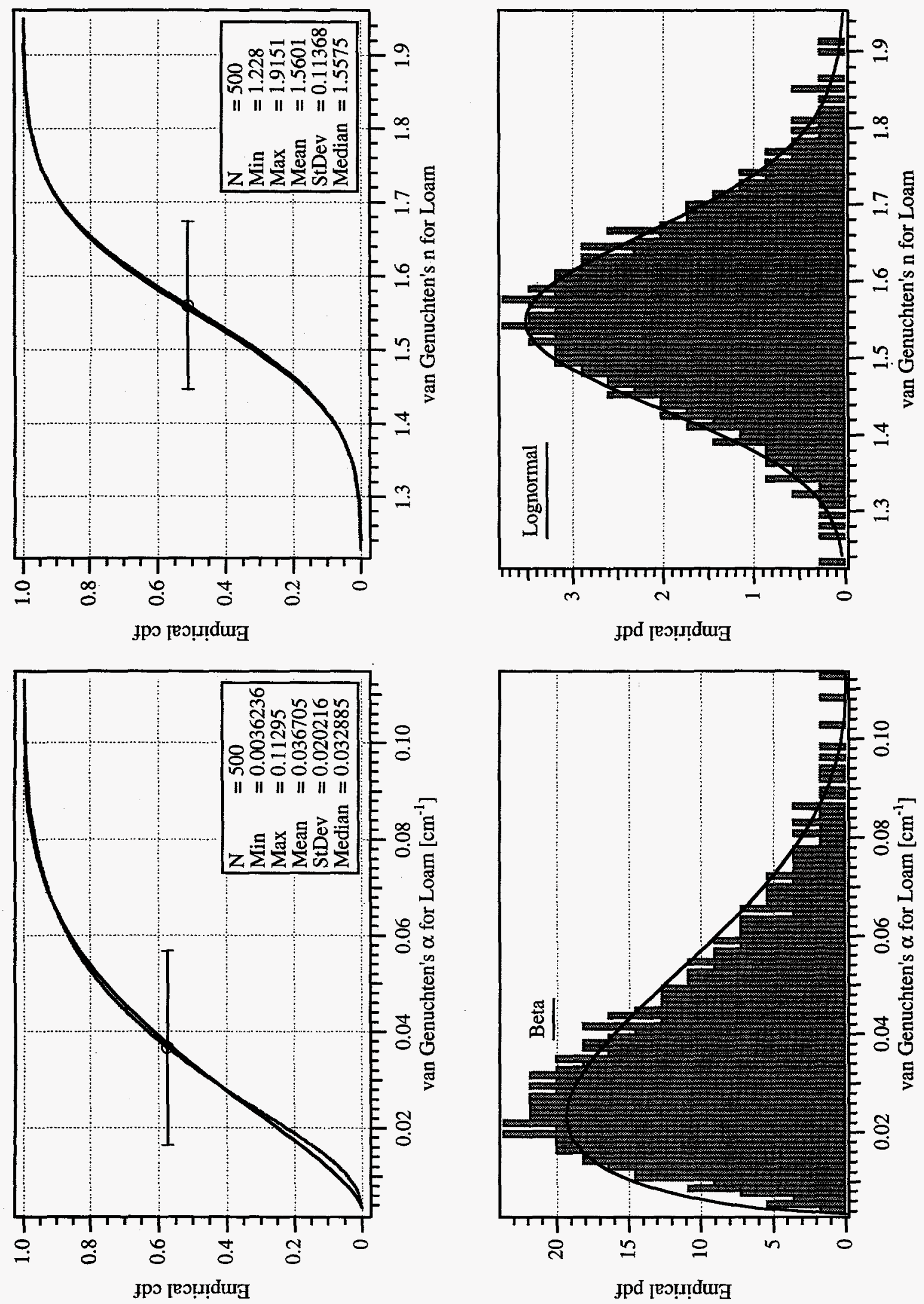

NUREG/CR-6565 

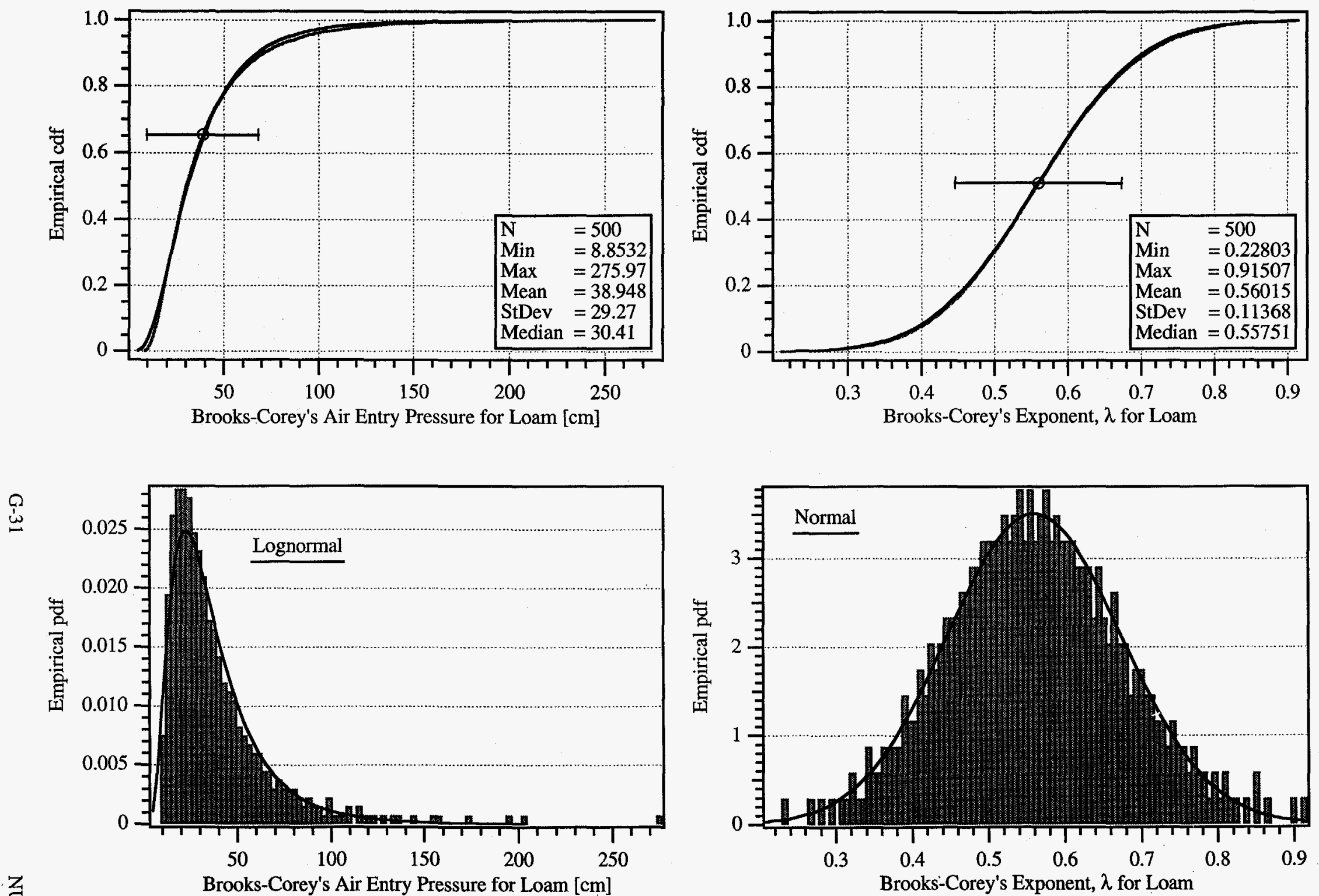

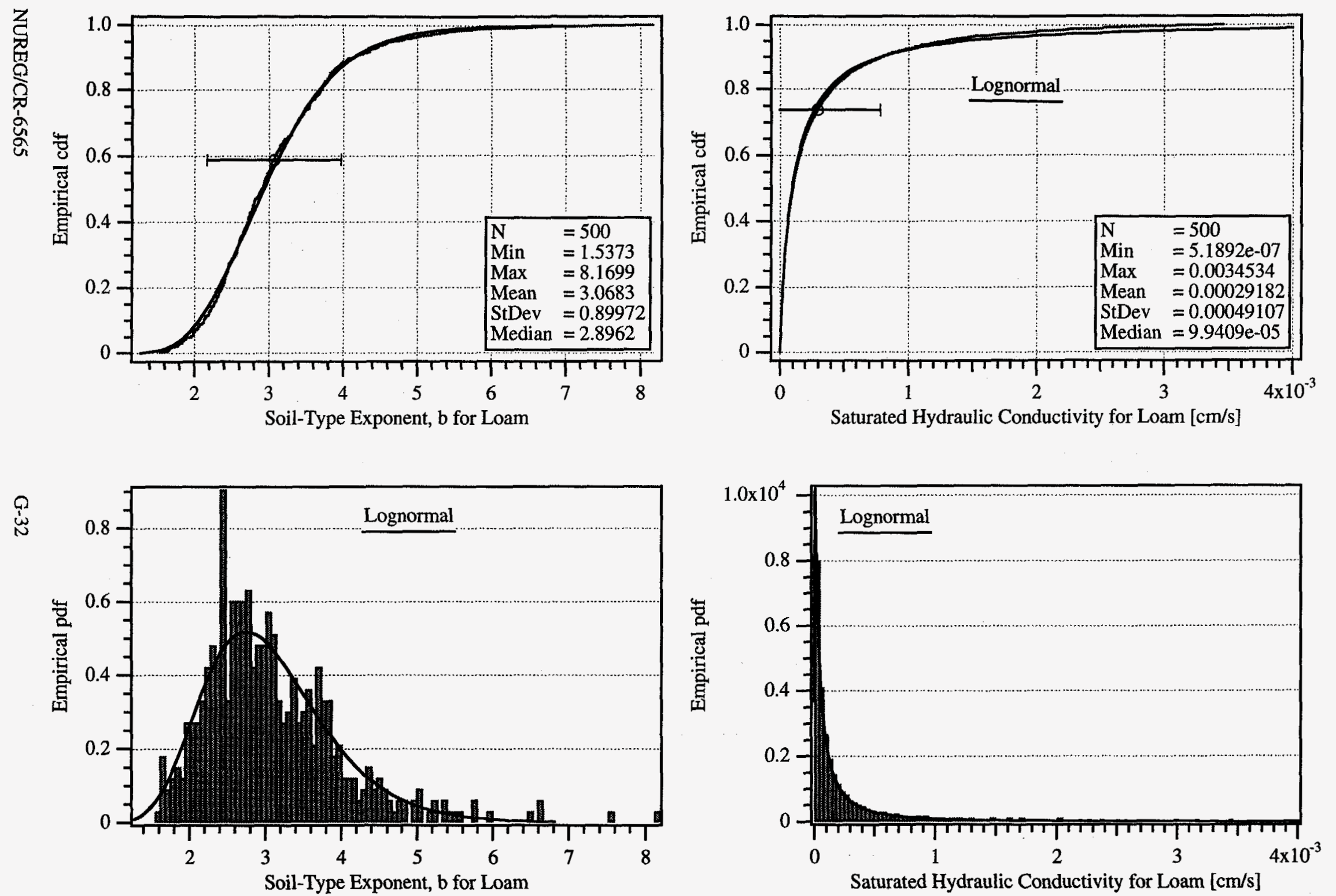
Empirical and Recommended Distributions for Soil Hydraulic Parameters by Soil Texture
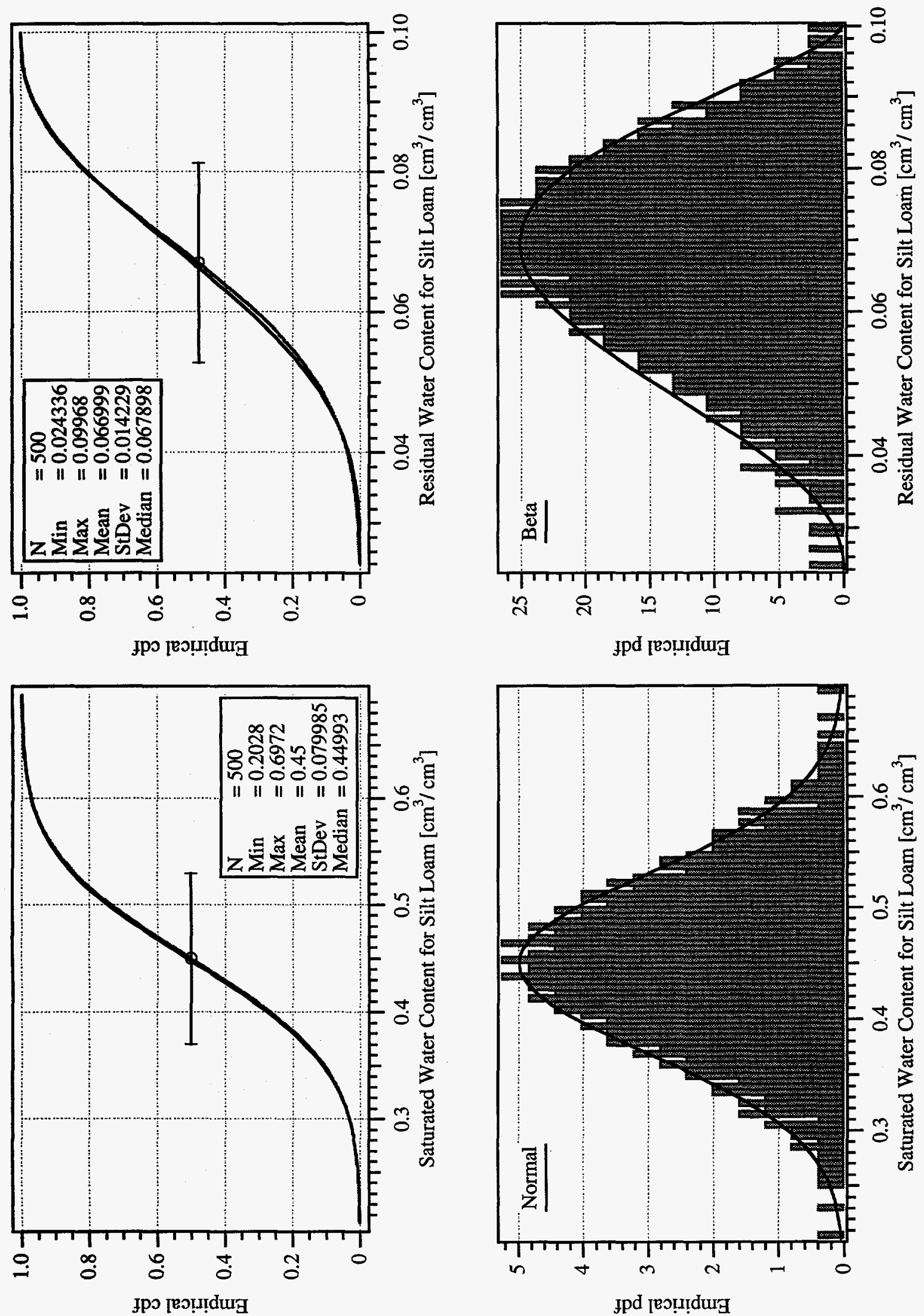

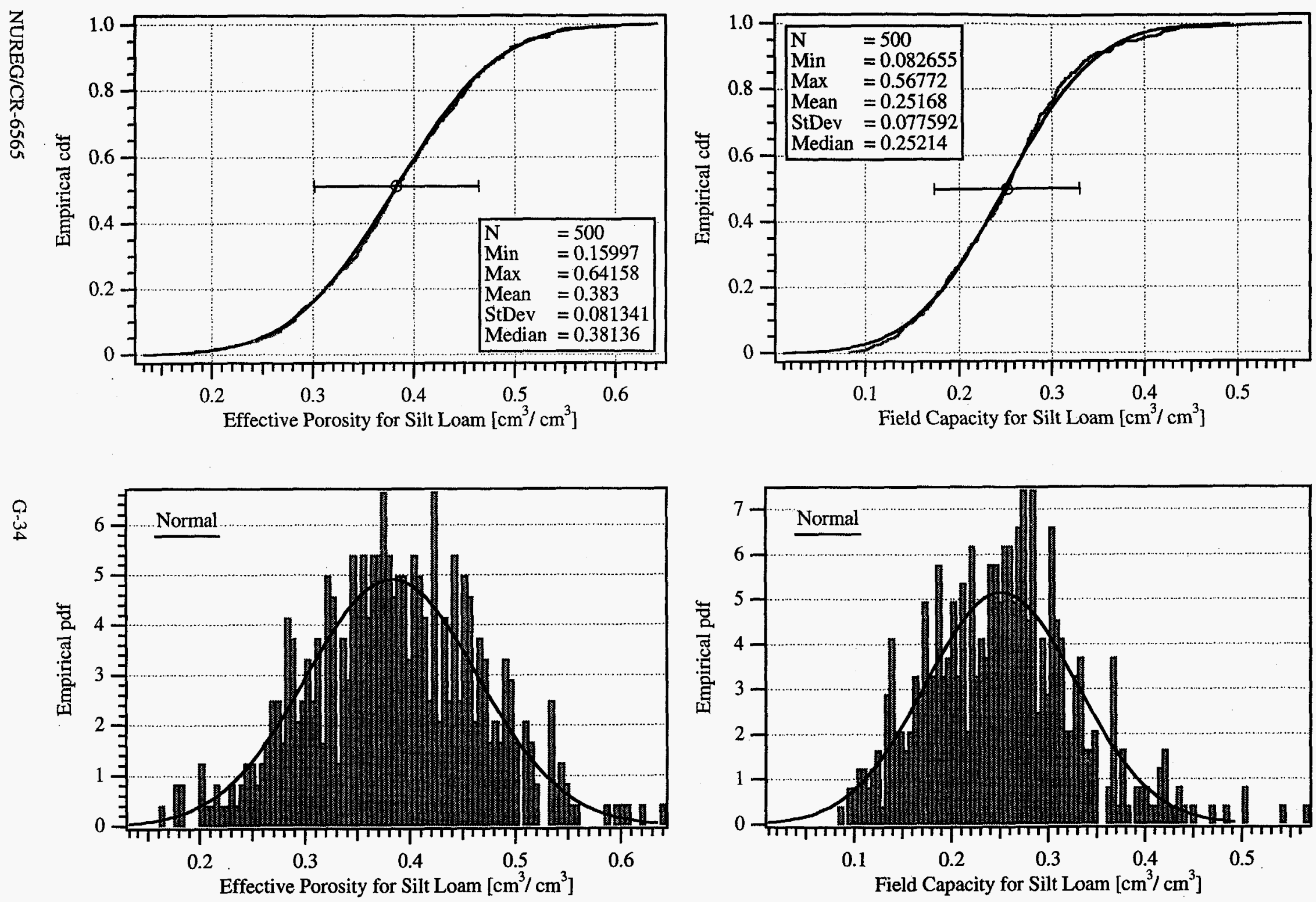

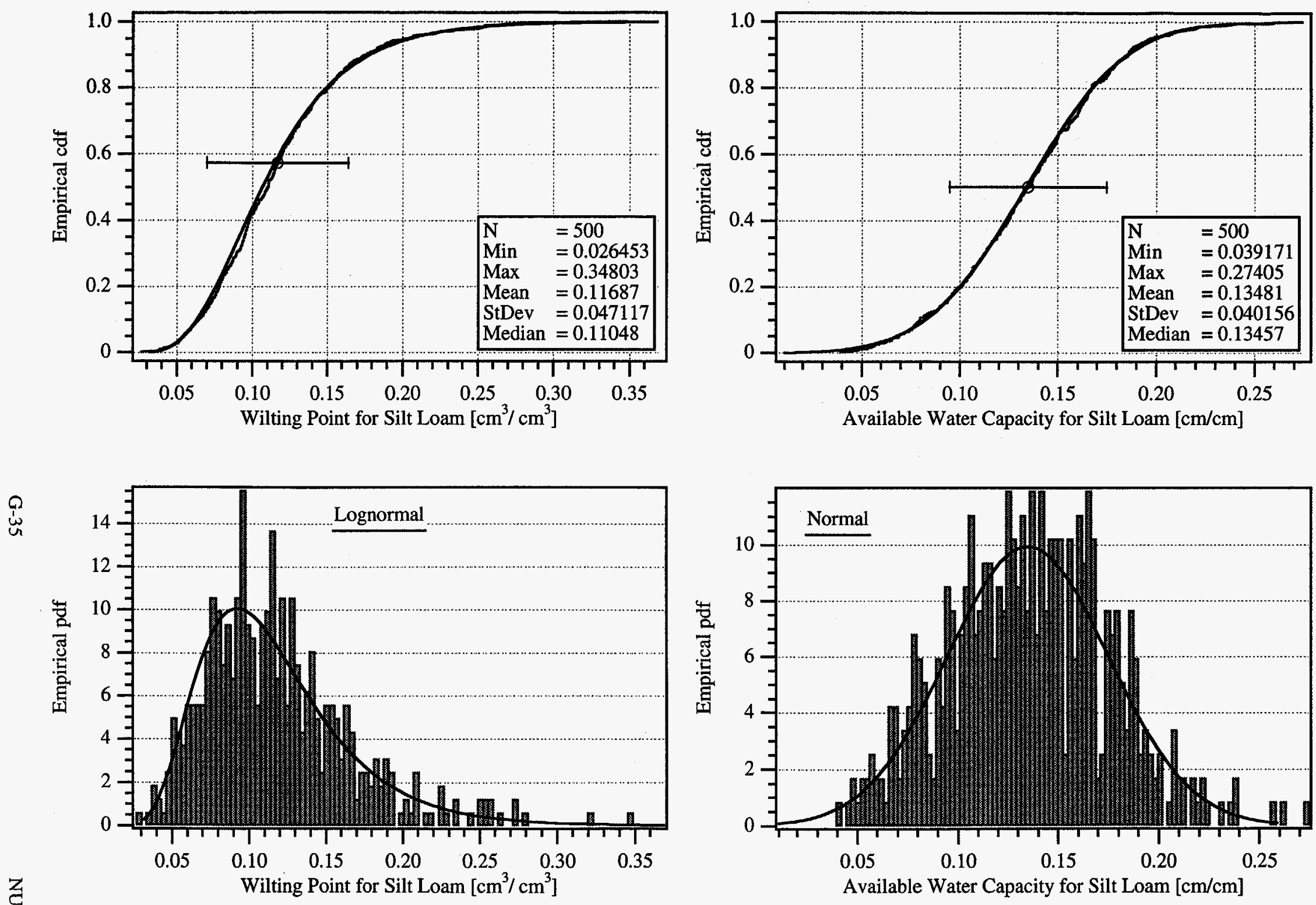

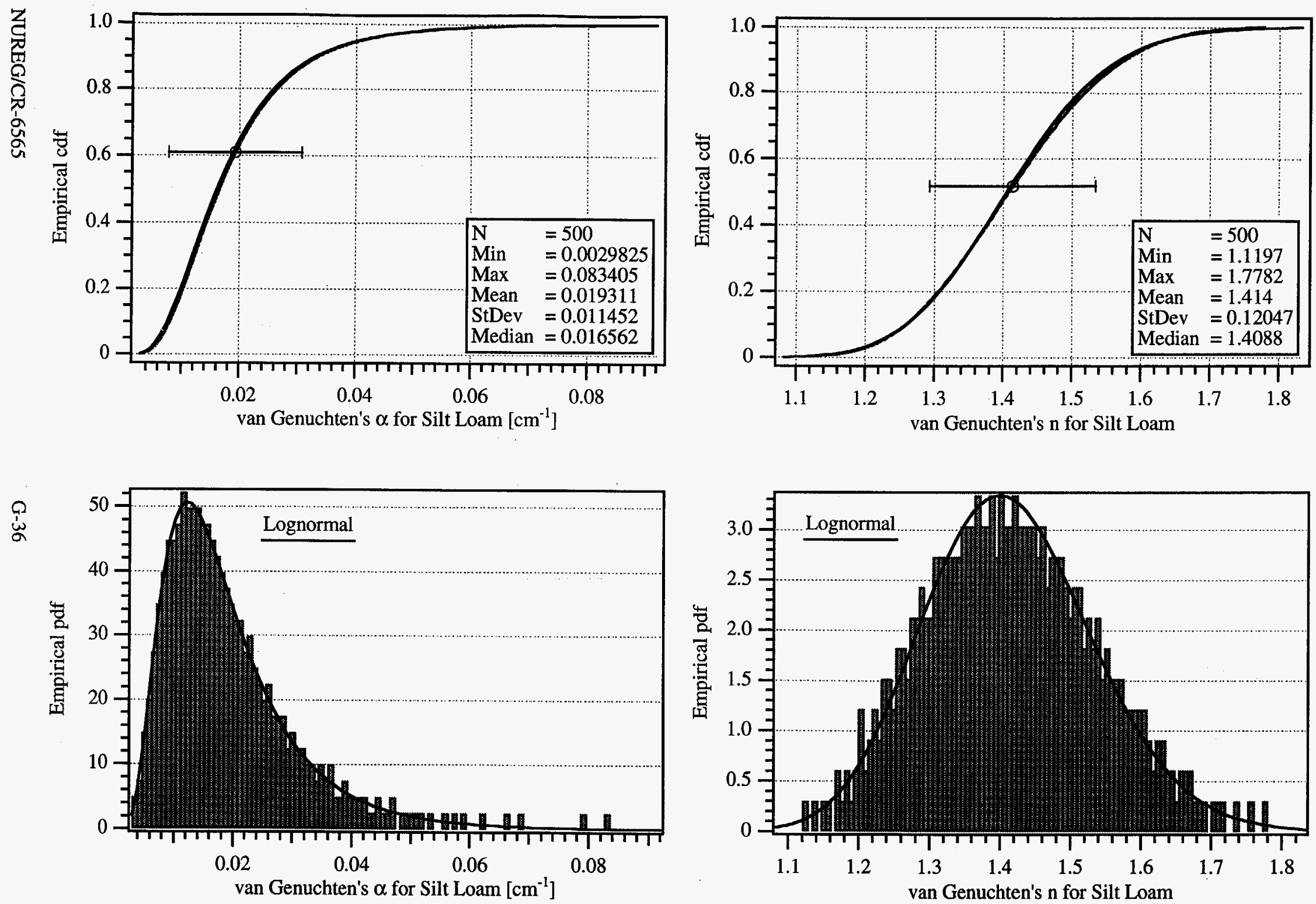

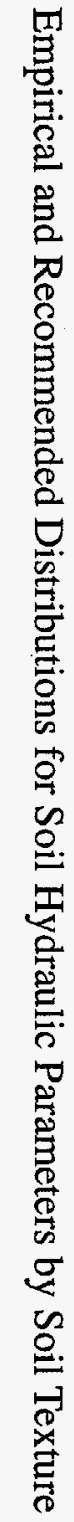



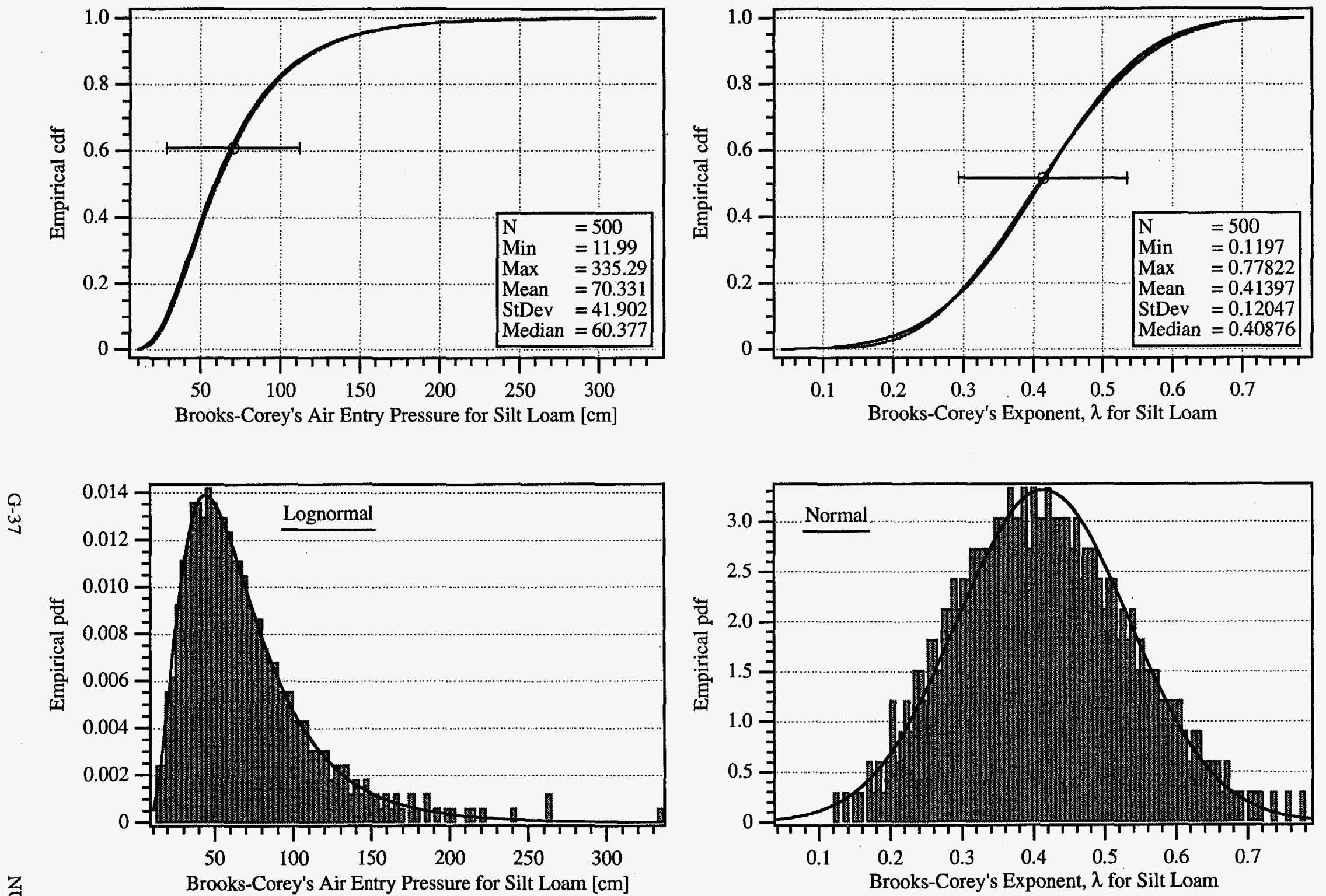

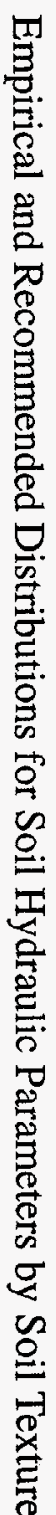



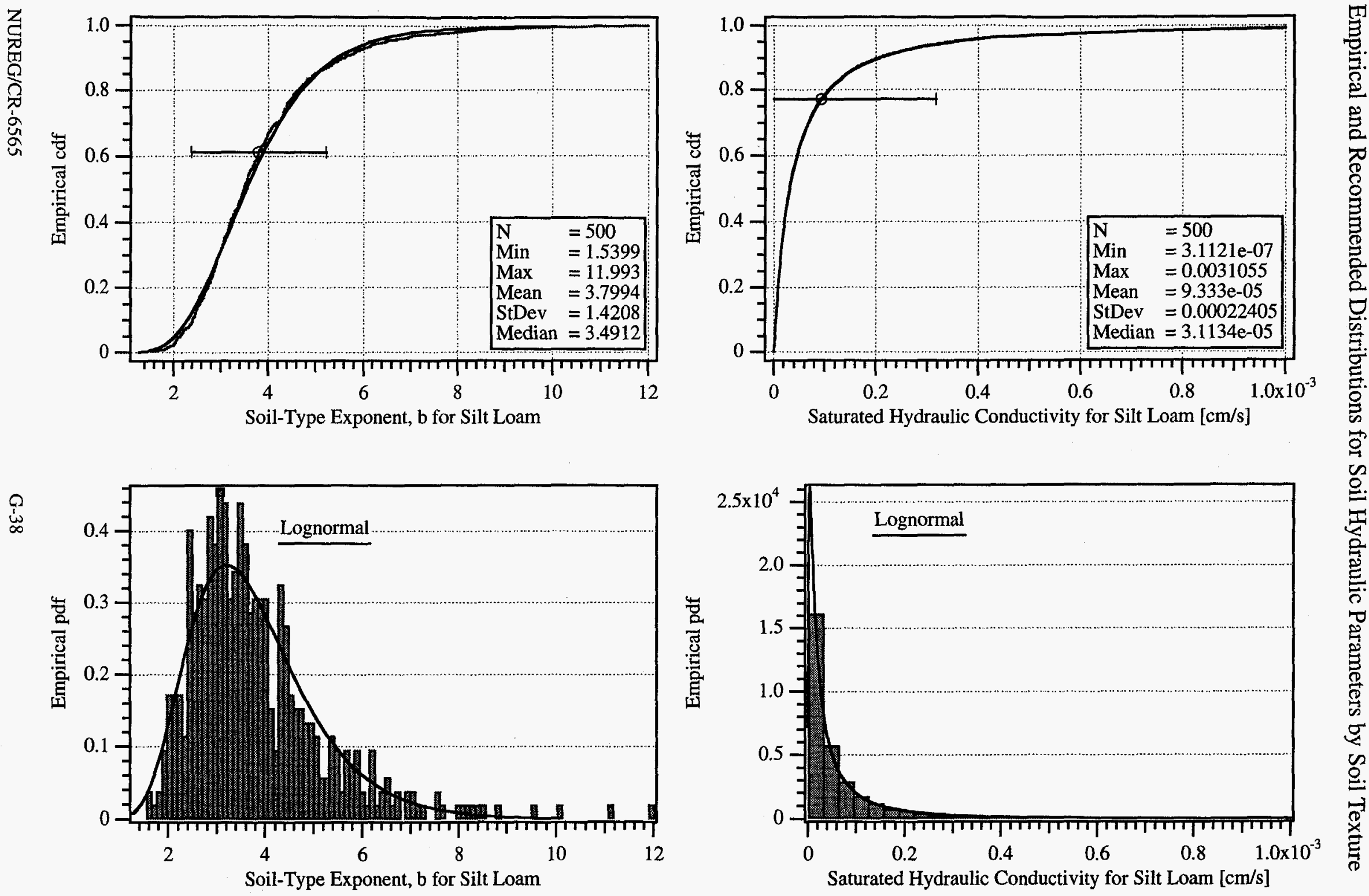
Empirical and Recommended Distributions for Soil Hydraulic Parameters by Soil Texture
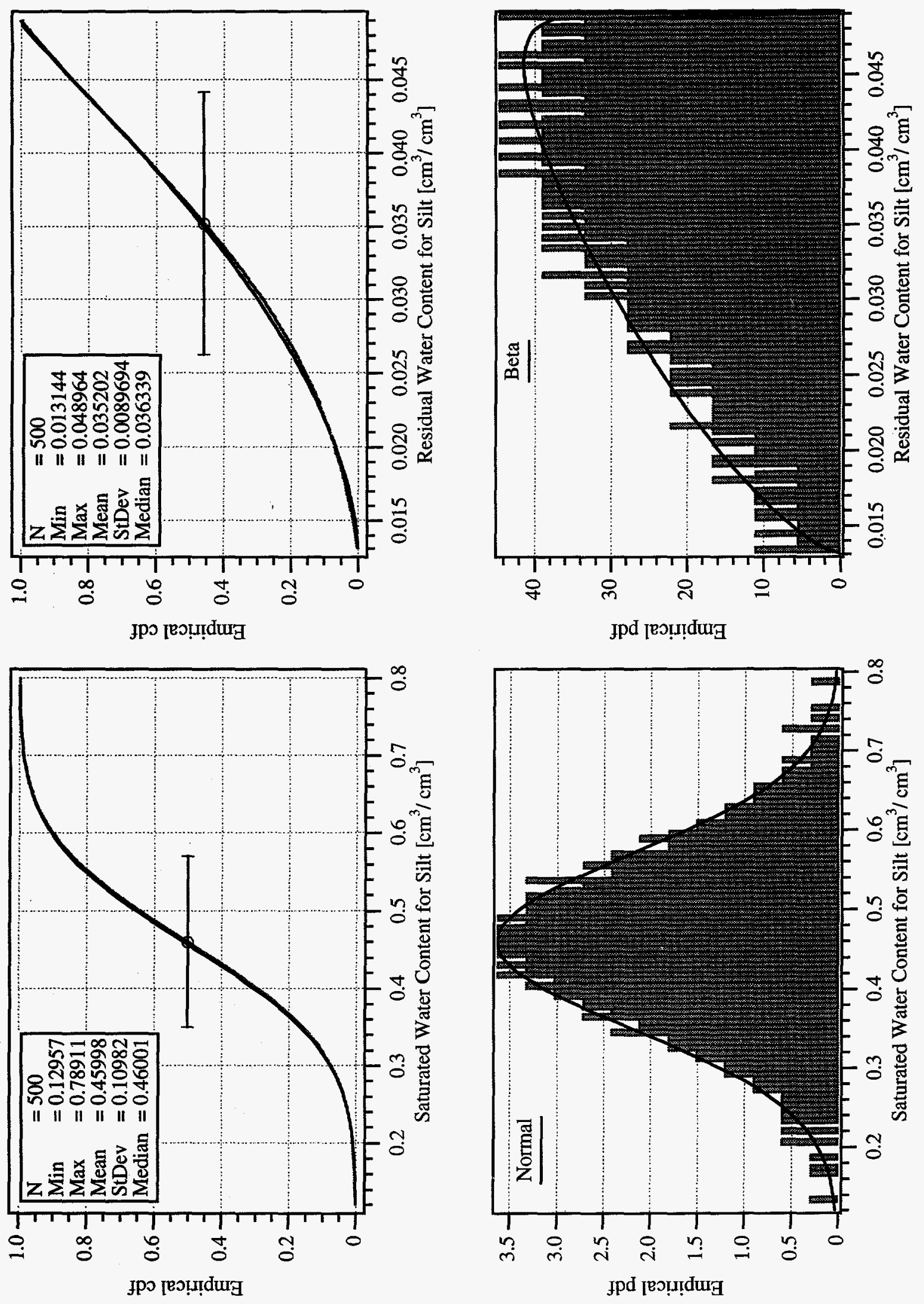

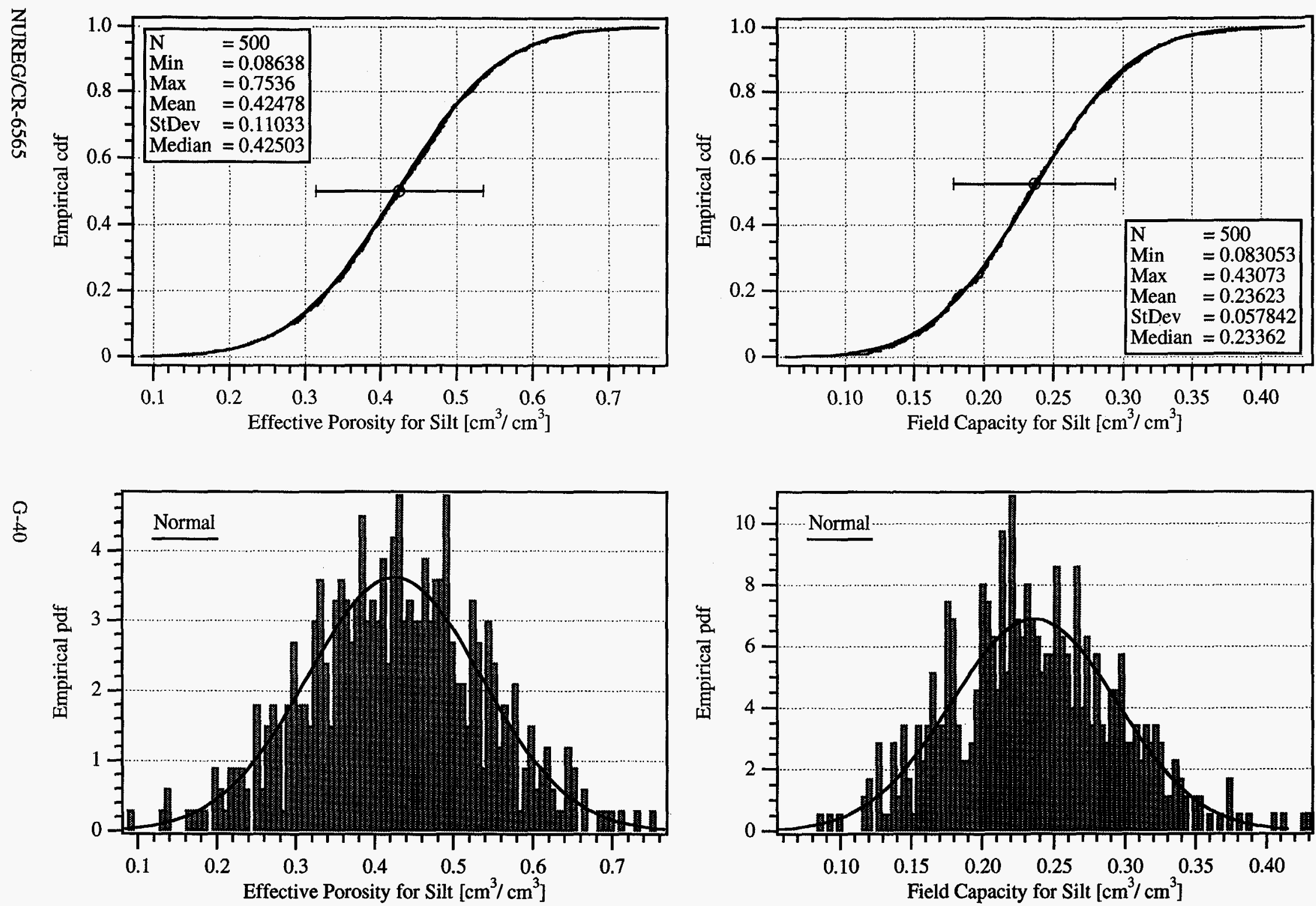
Empirical and Recommended Distributions for Soil Hydraulic Parameters by Soil Texture
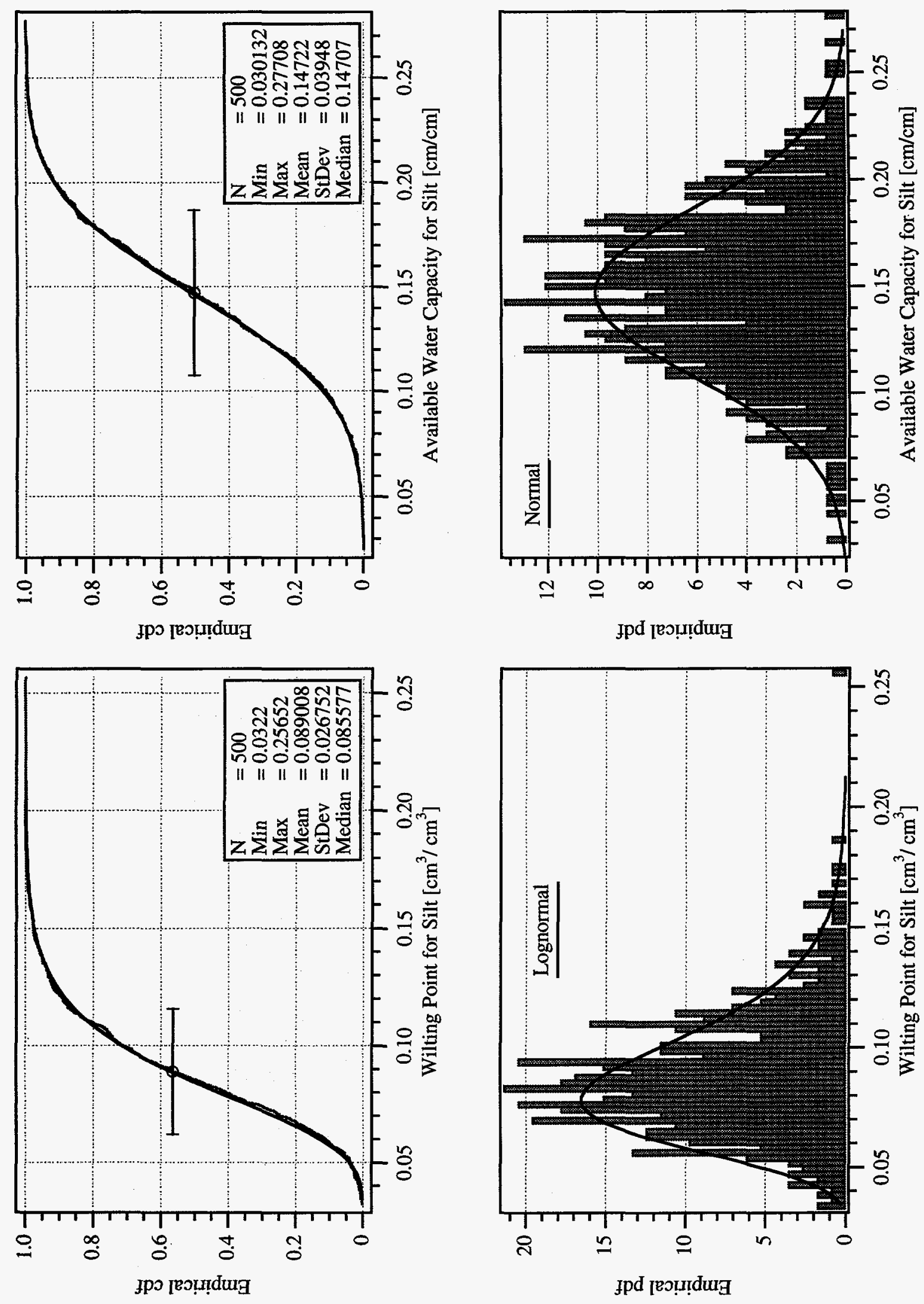

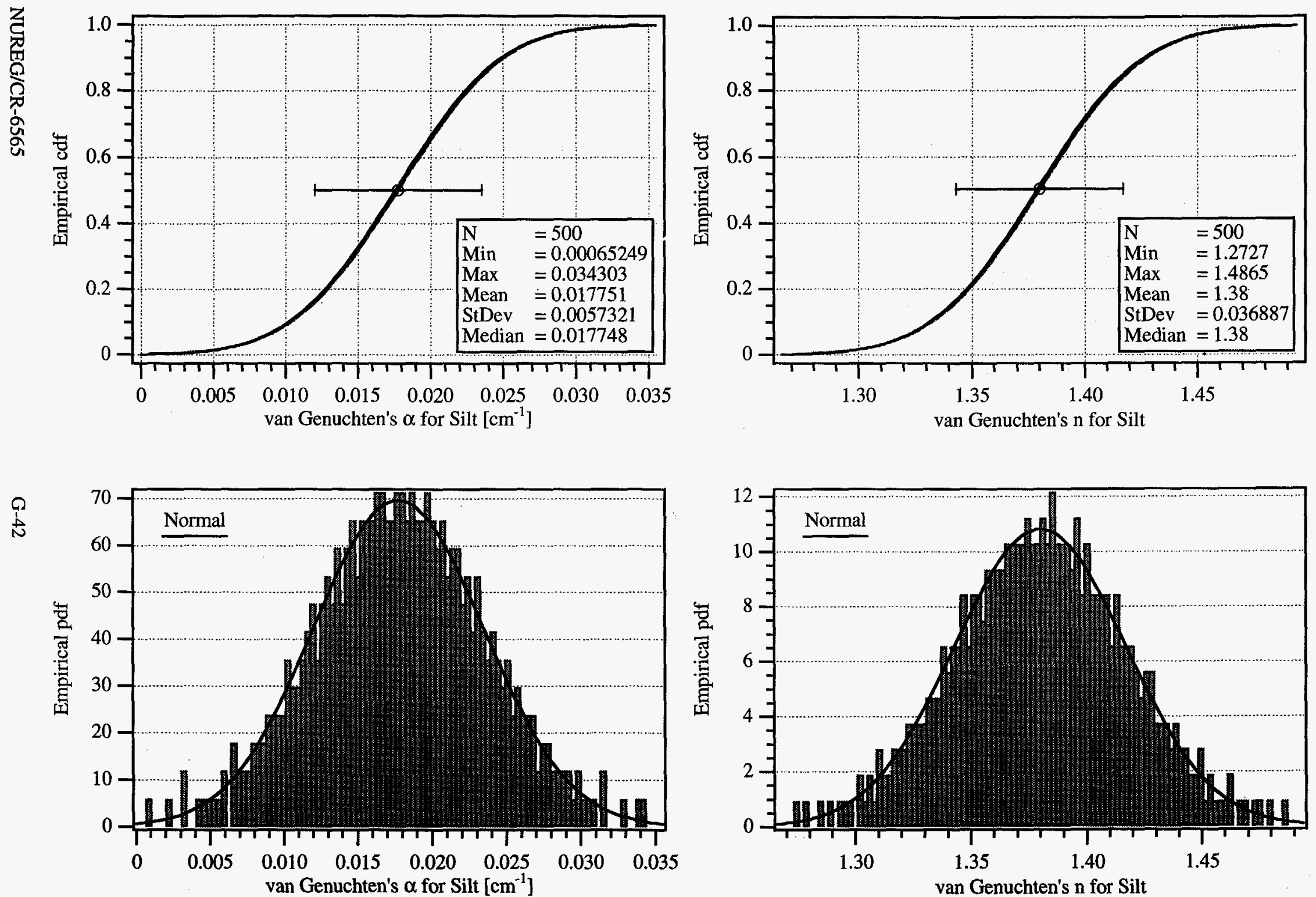

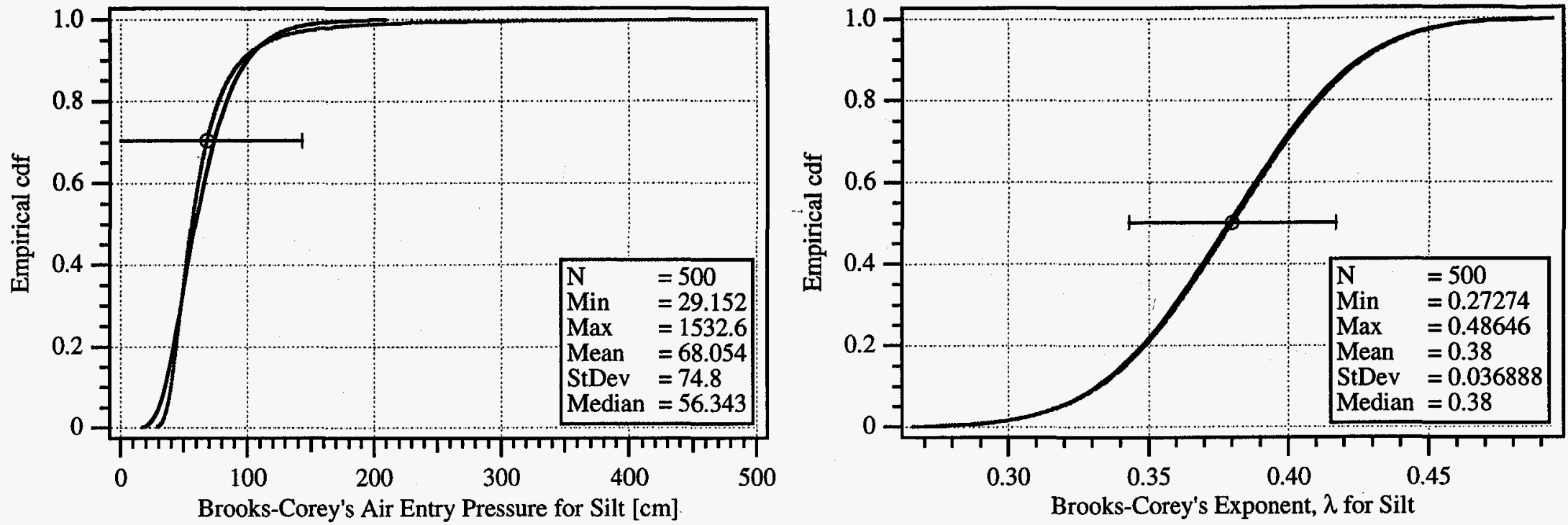

$\stackrel{a}{b}$
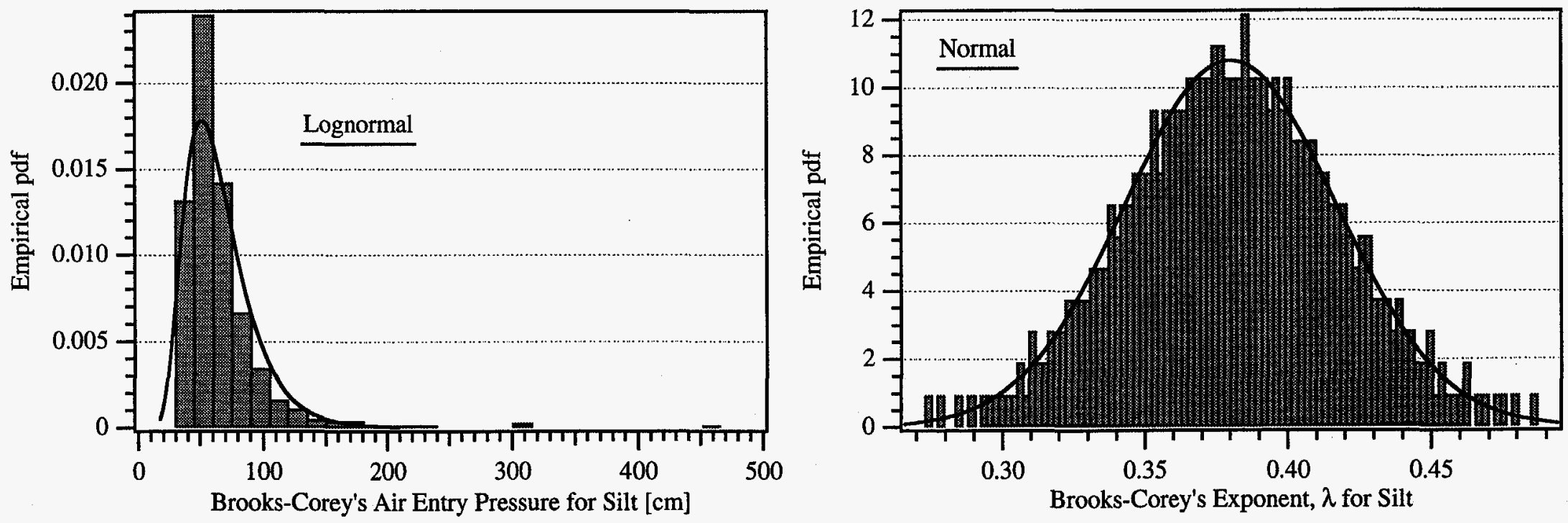

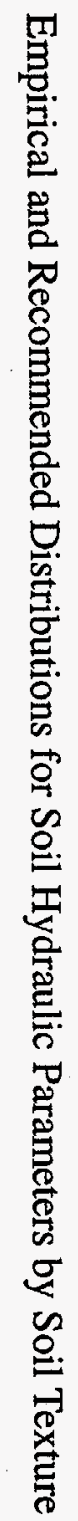



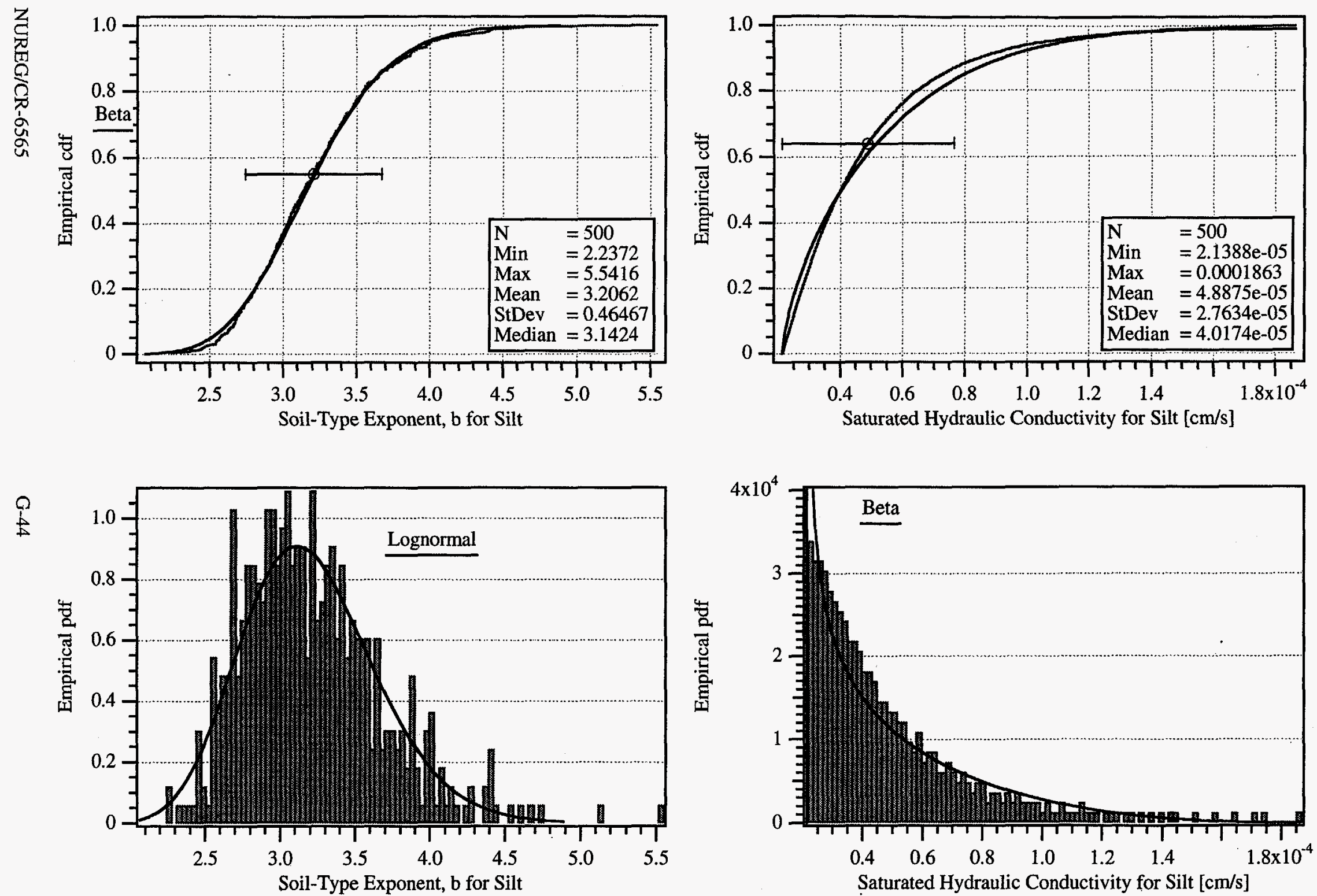

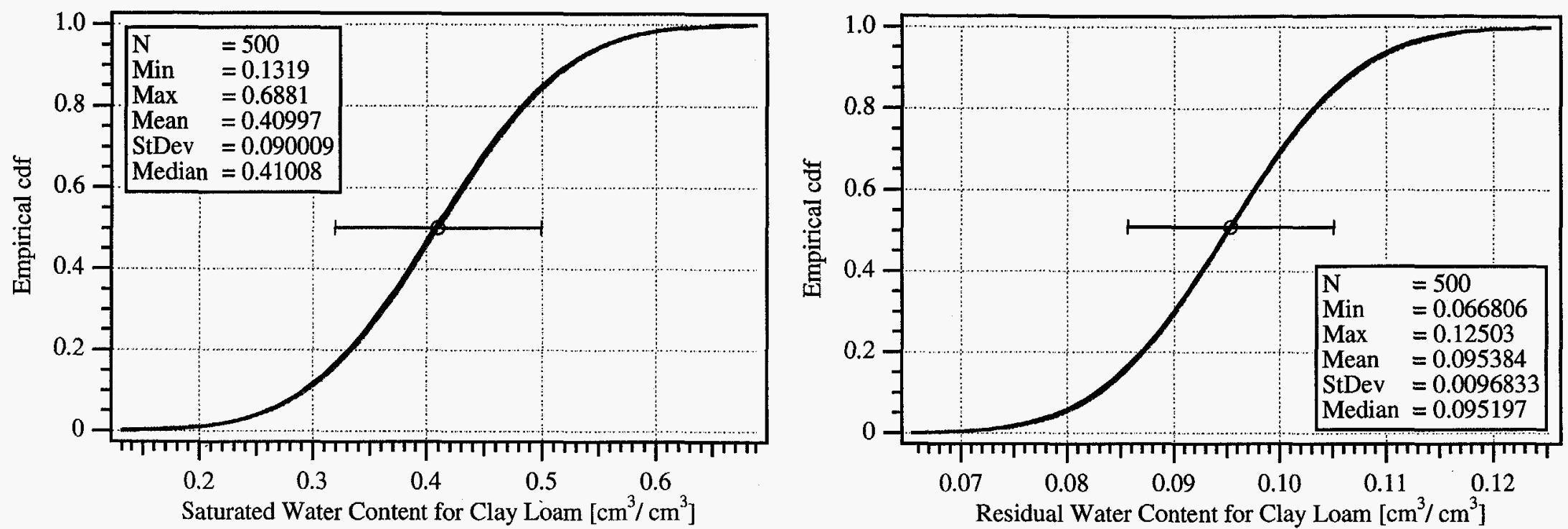

古
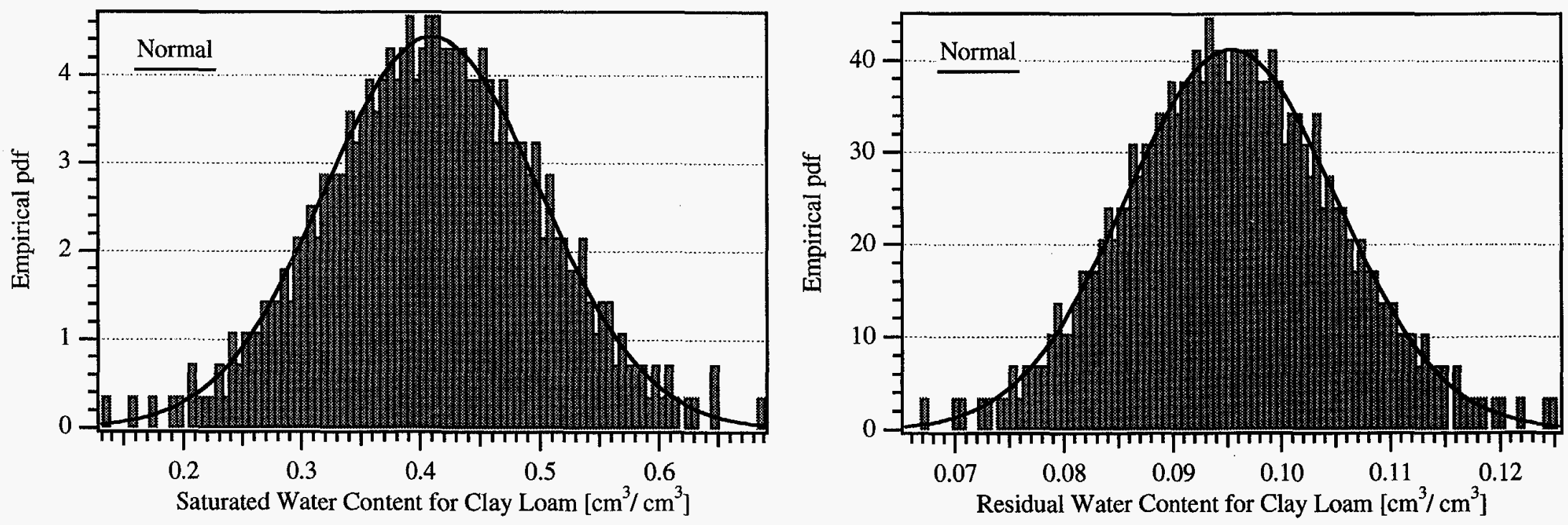

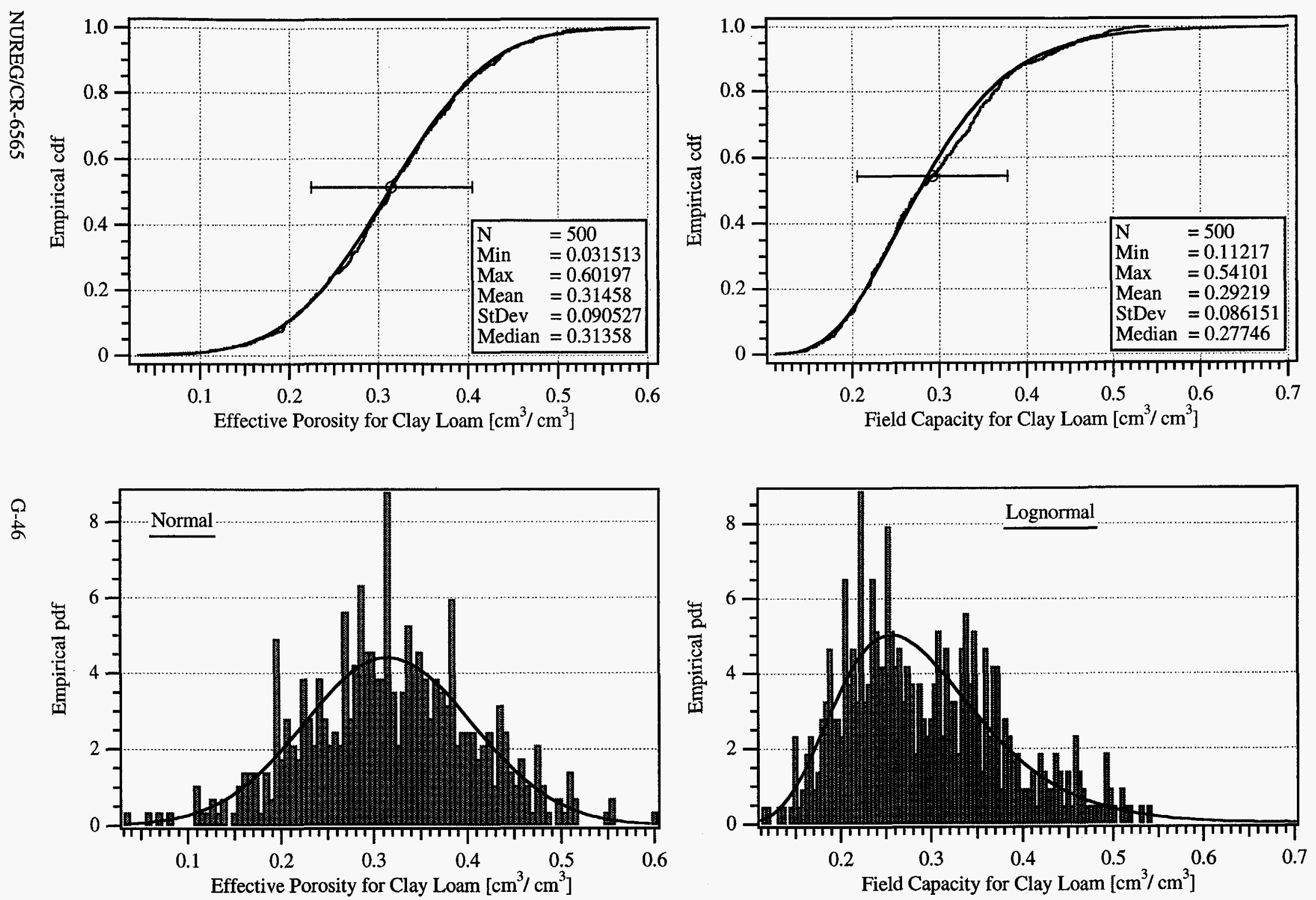
Empirical pdf

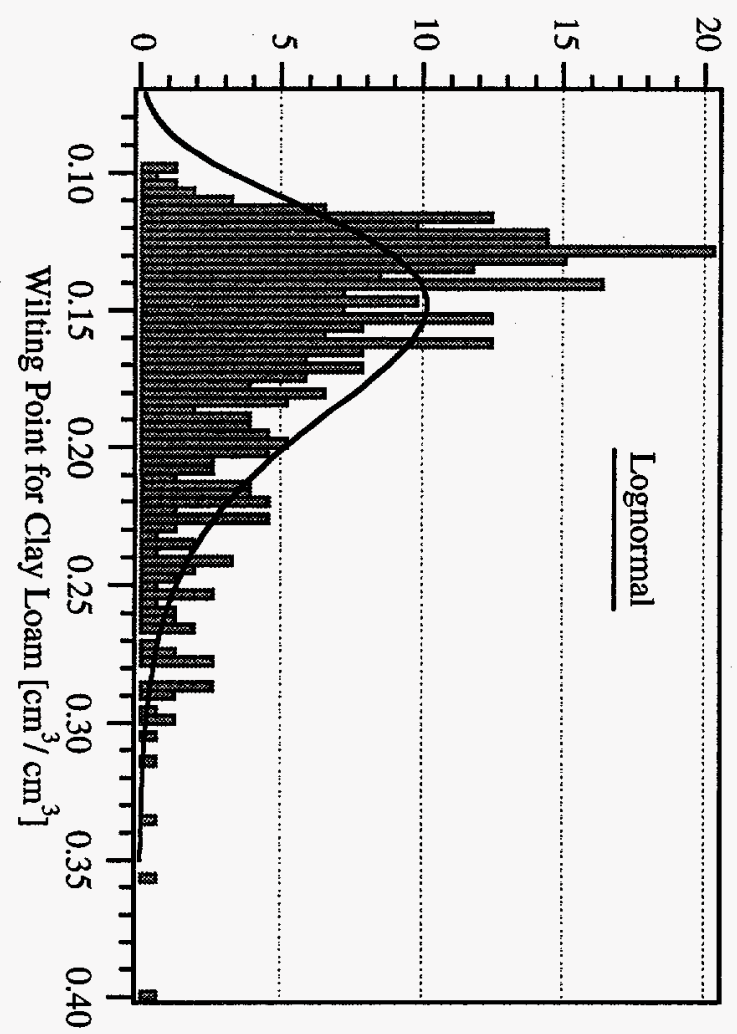

Empirical pdf

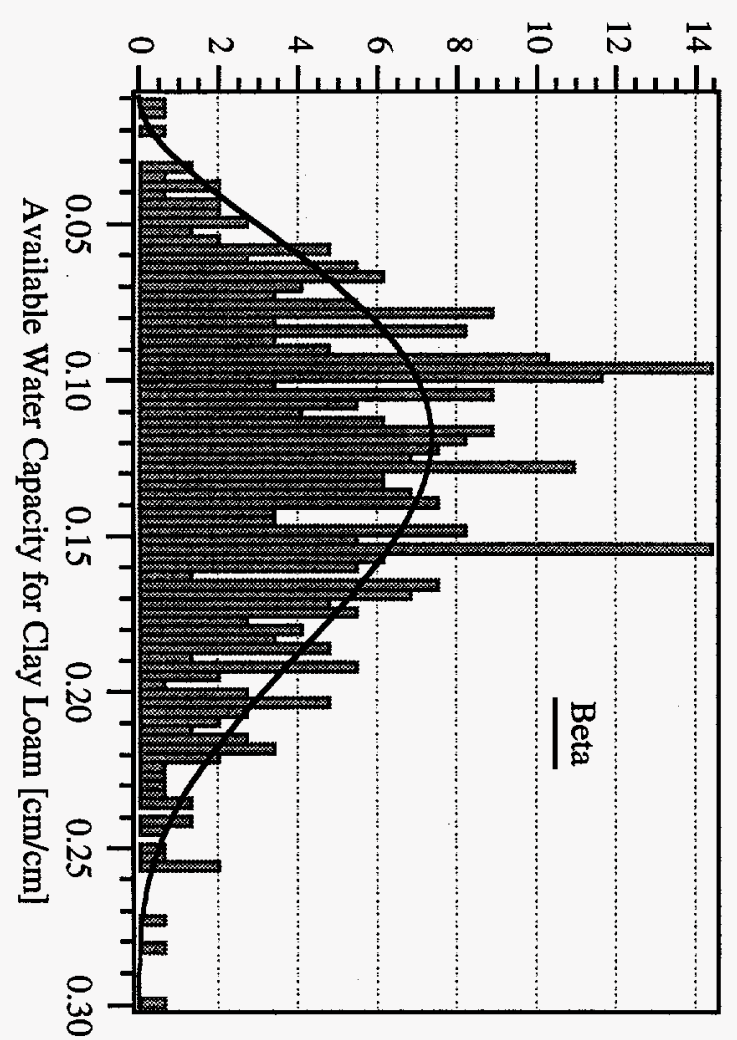

Empirical cdf

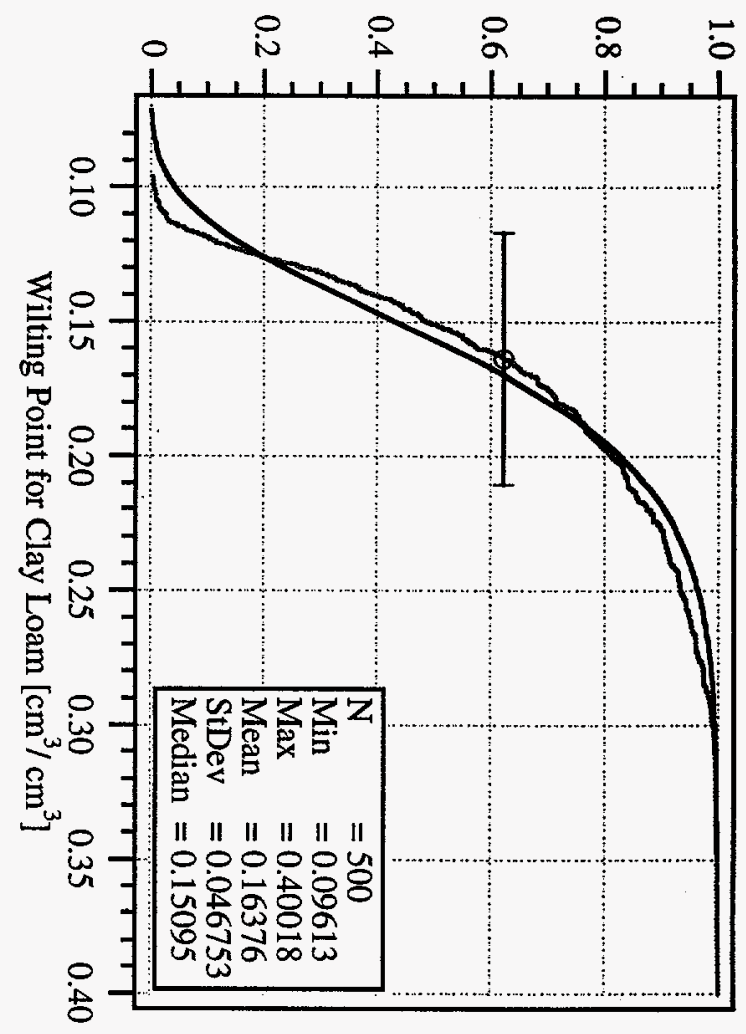

Empirical cdf

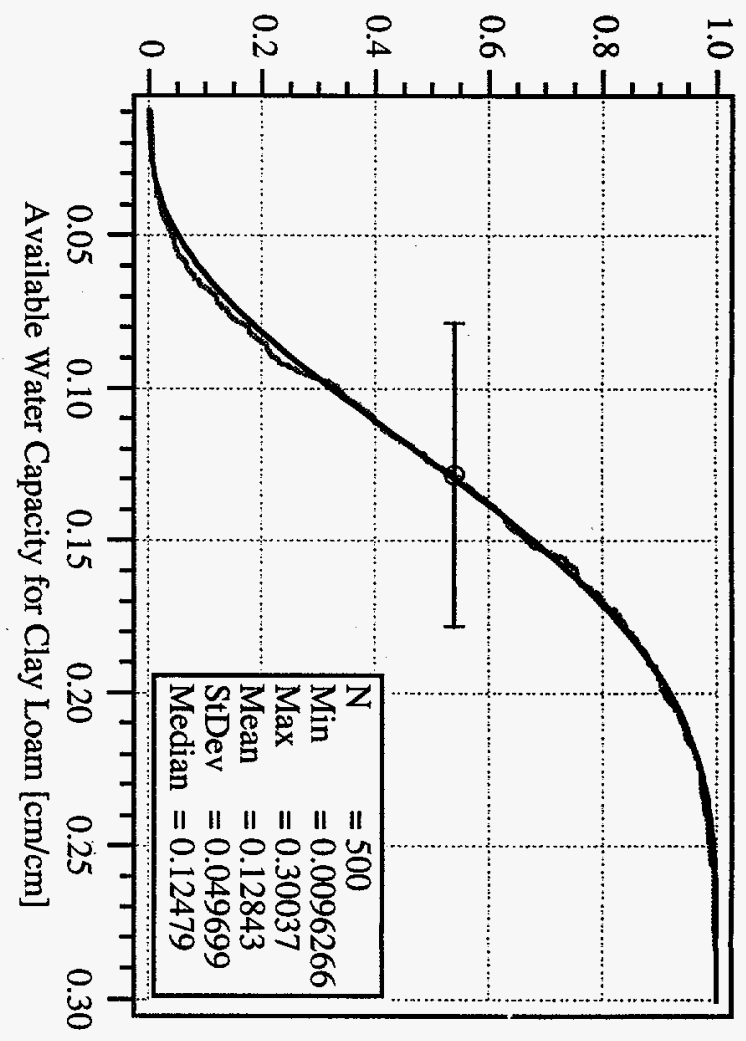


Empirical and Recommended Distributions for Soil Hydraulic Parameters by Soil Texture
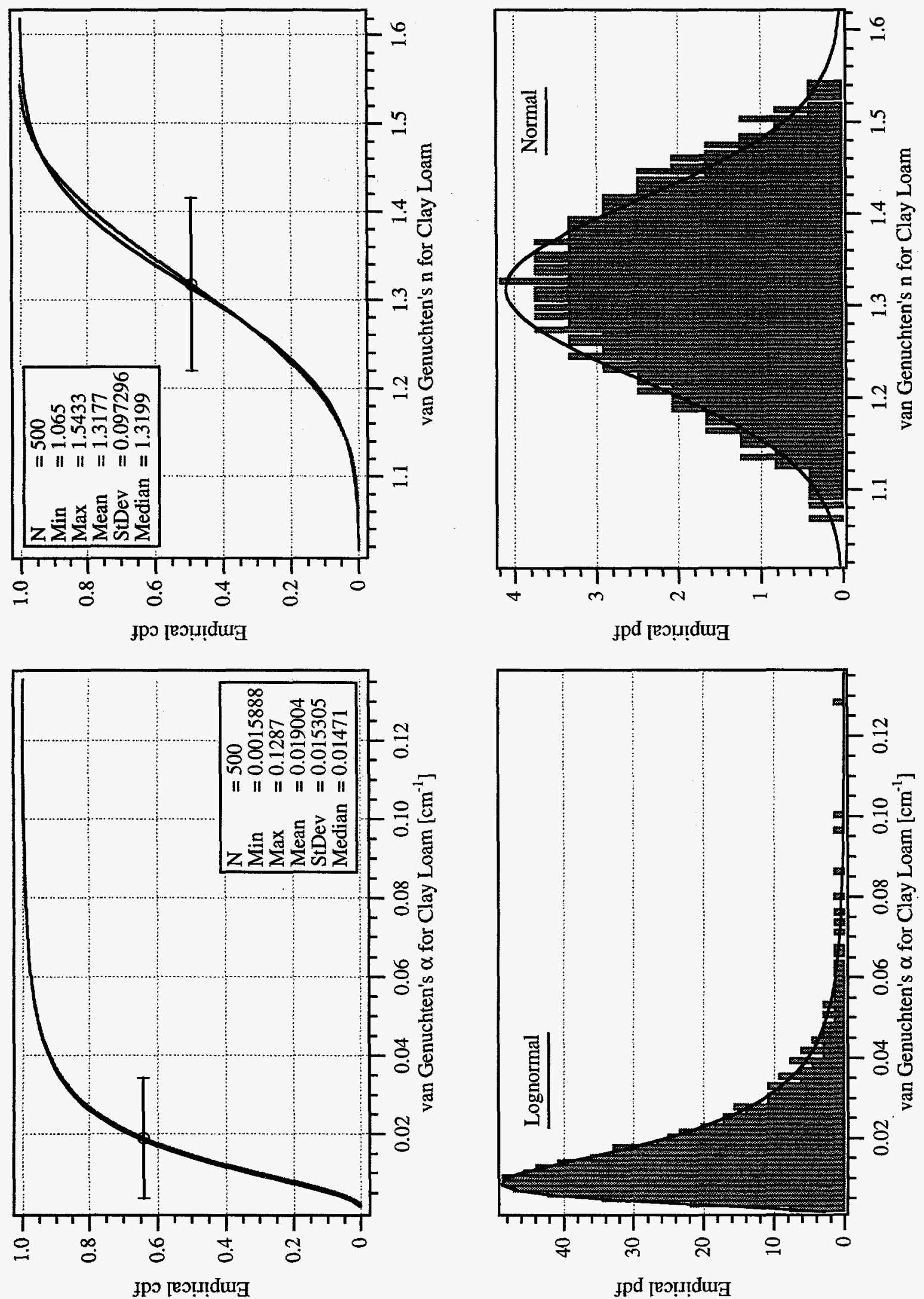

NUREG/CR-6565 

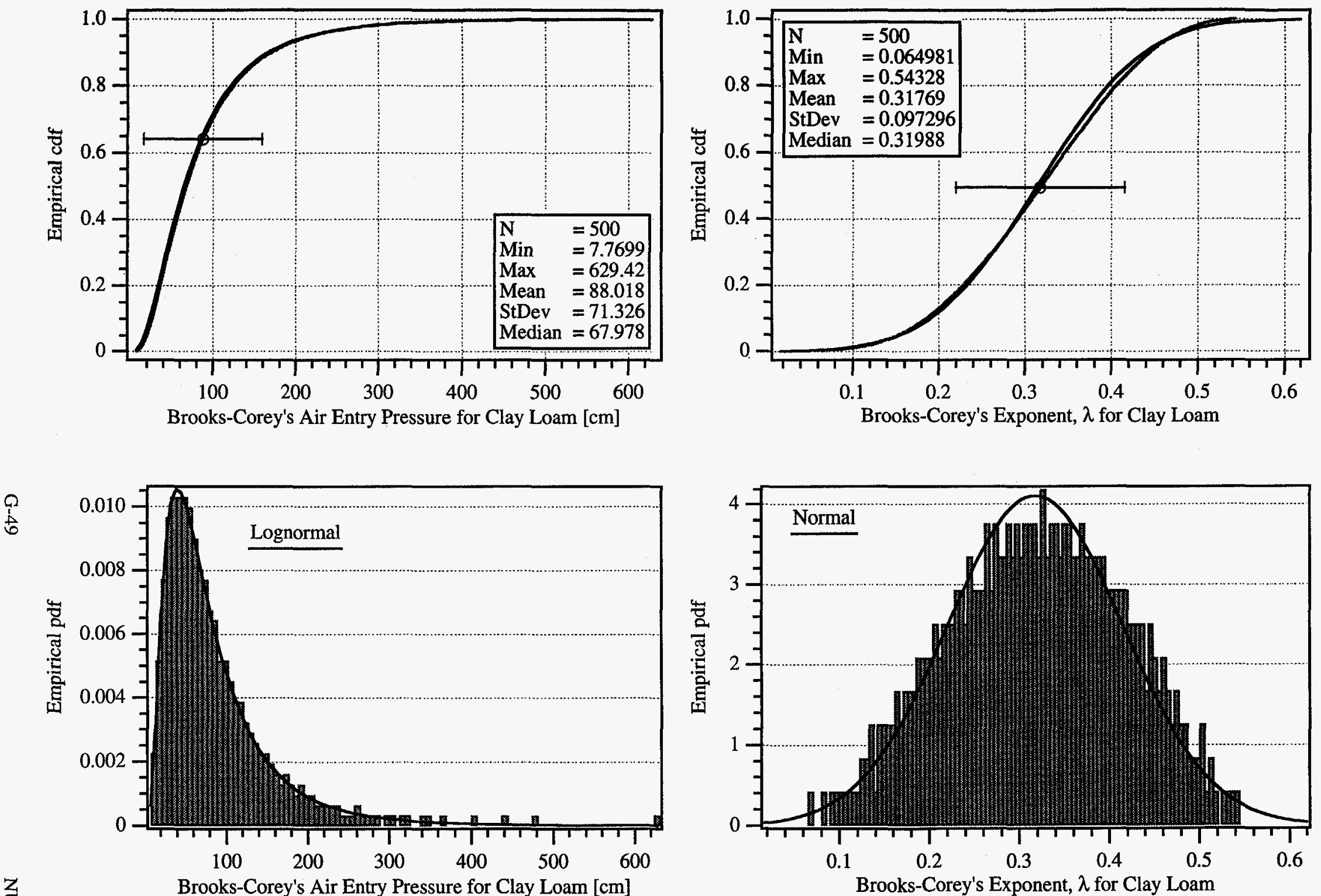

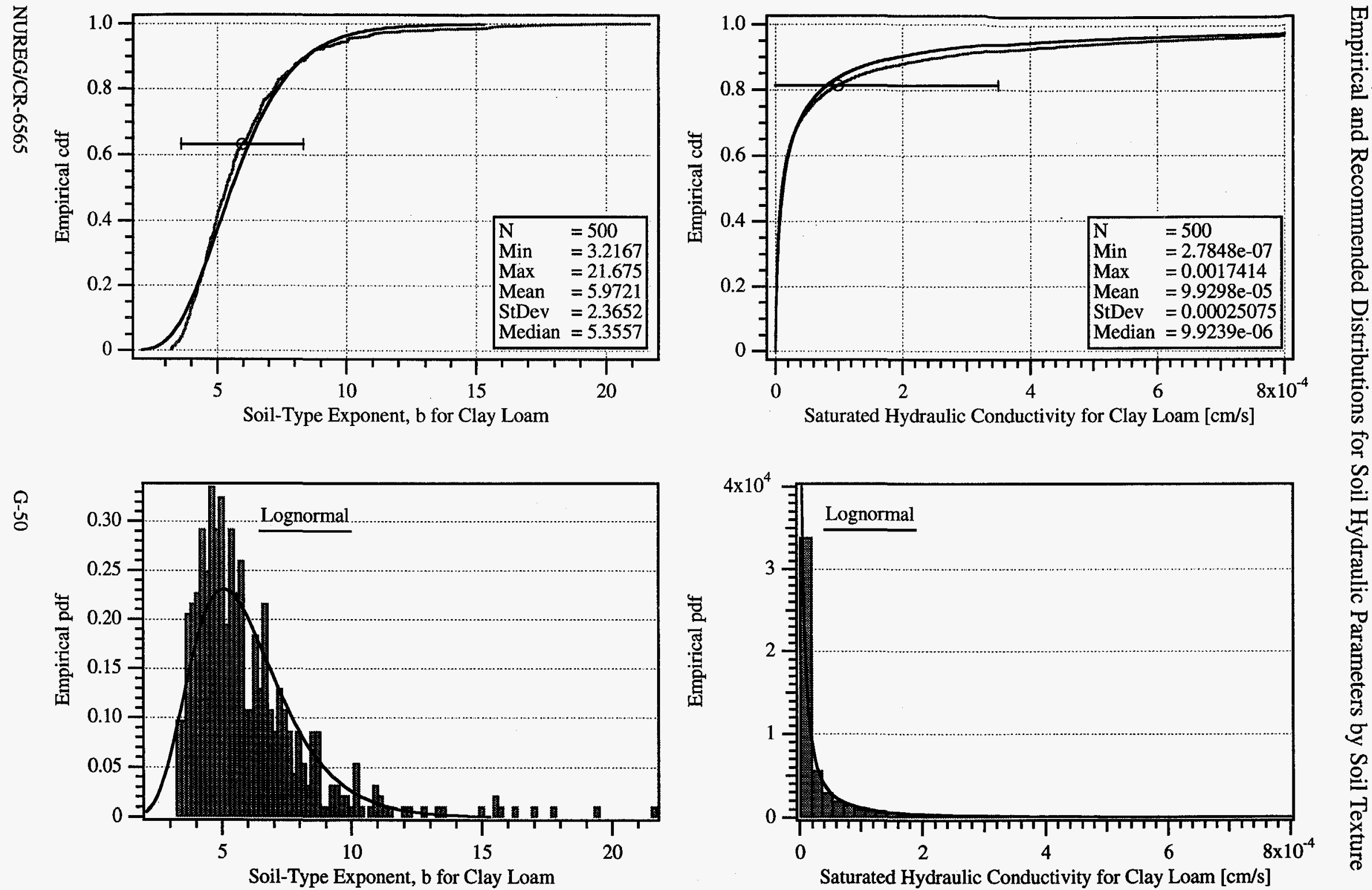

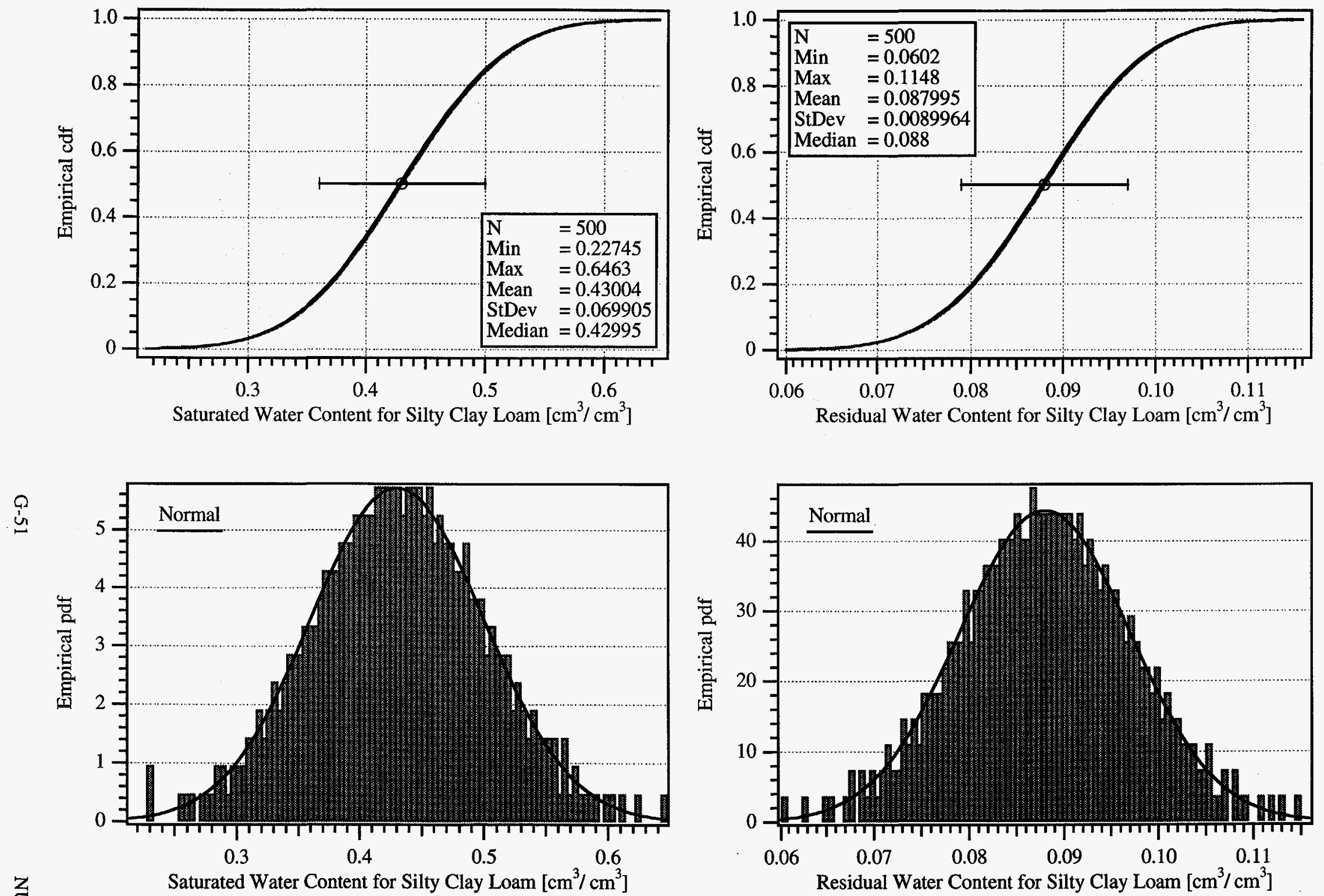

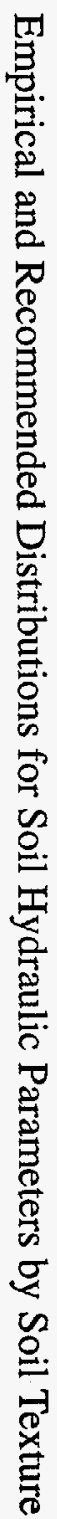


Empirical and Recommended Distributions for Soil Hydraulic Parameters by Soil Texture
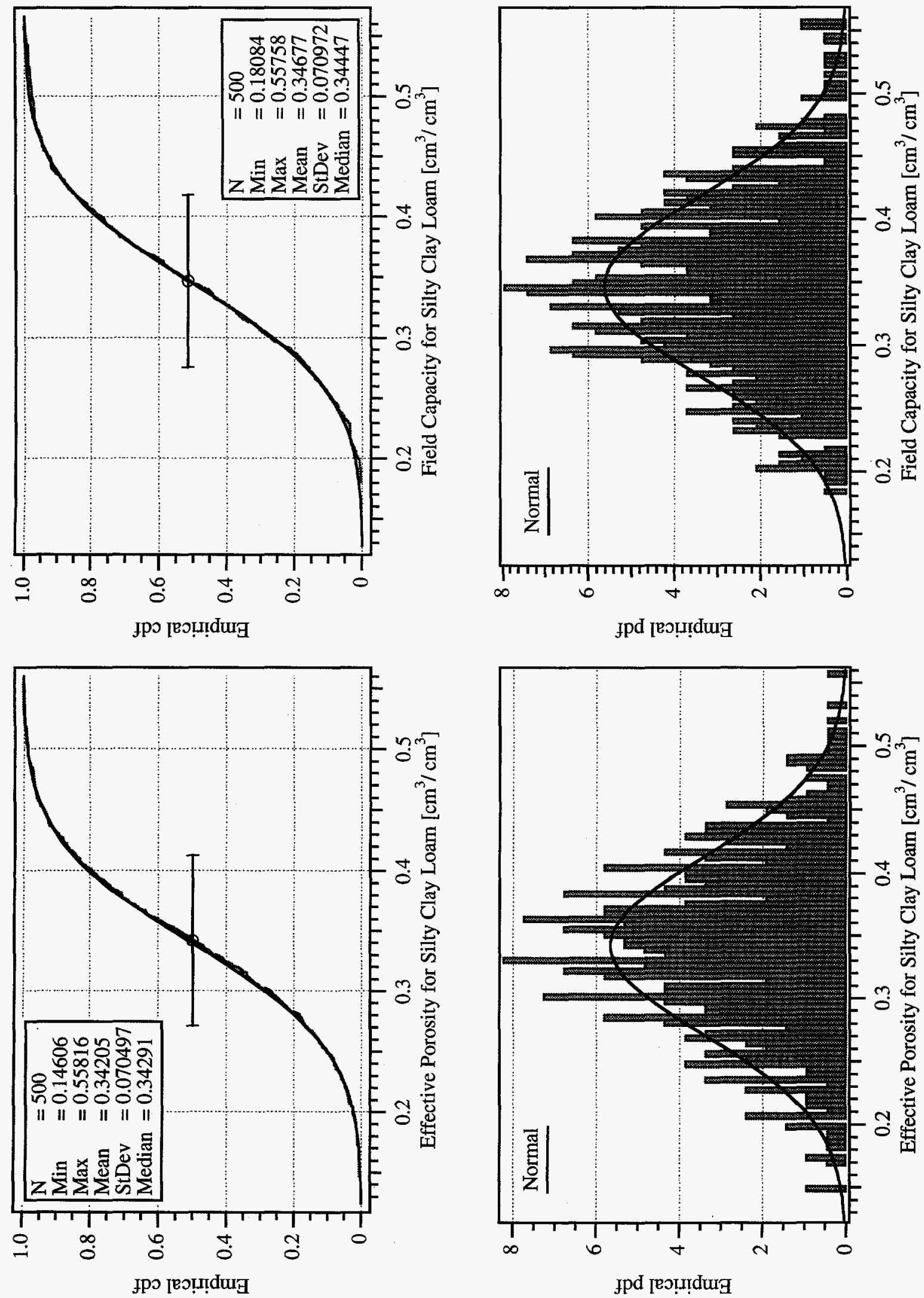
Empirical and Recommended Distributions for Soil Hydraulic Parameters by Soil Texture
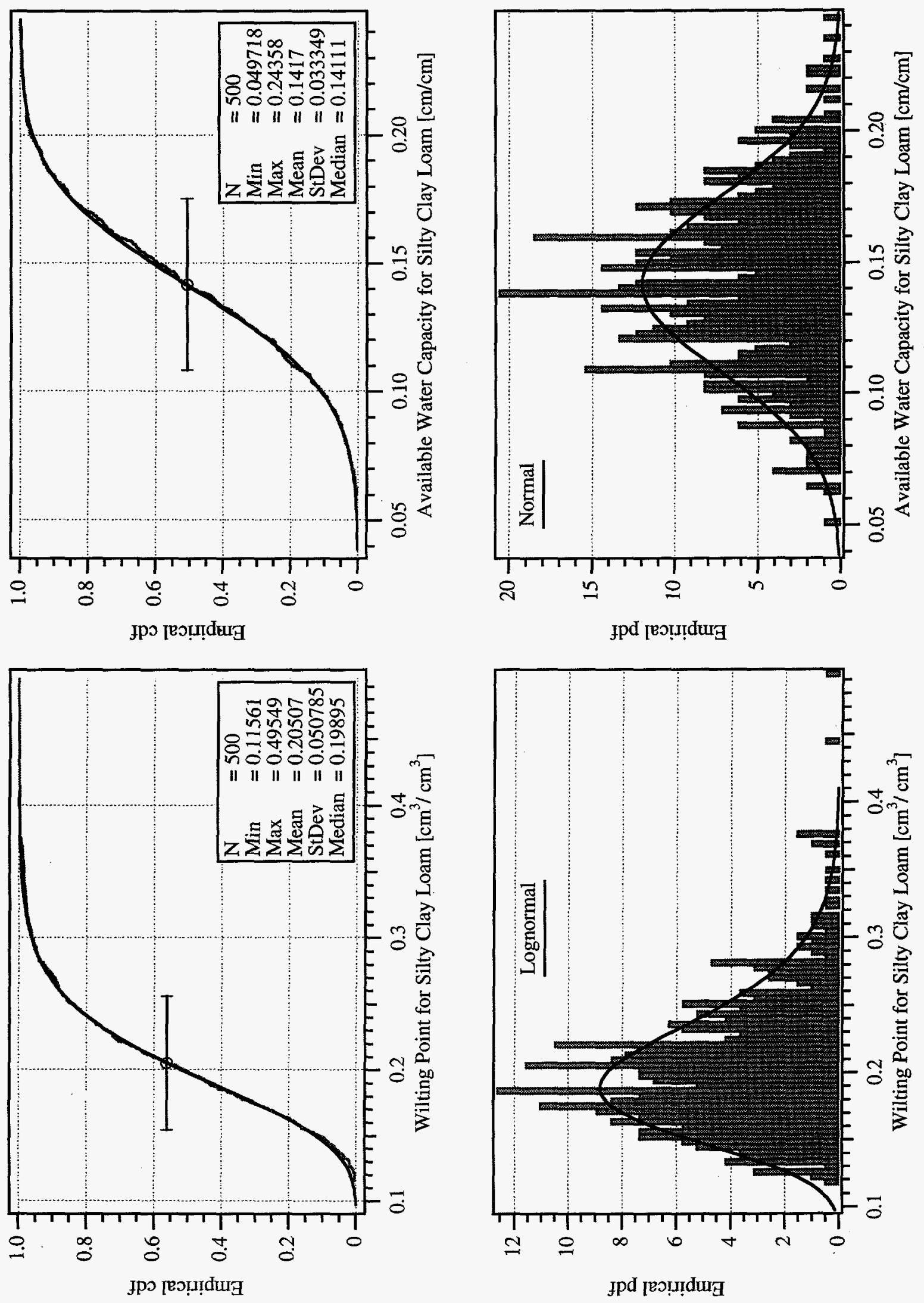
Empirical and Recommended Distributions for Soil Hydraulic Parameters by Soil Texture
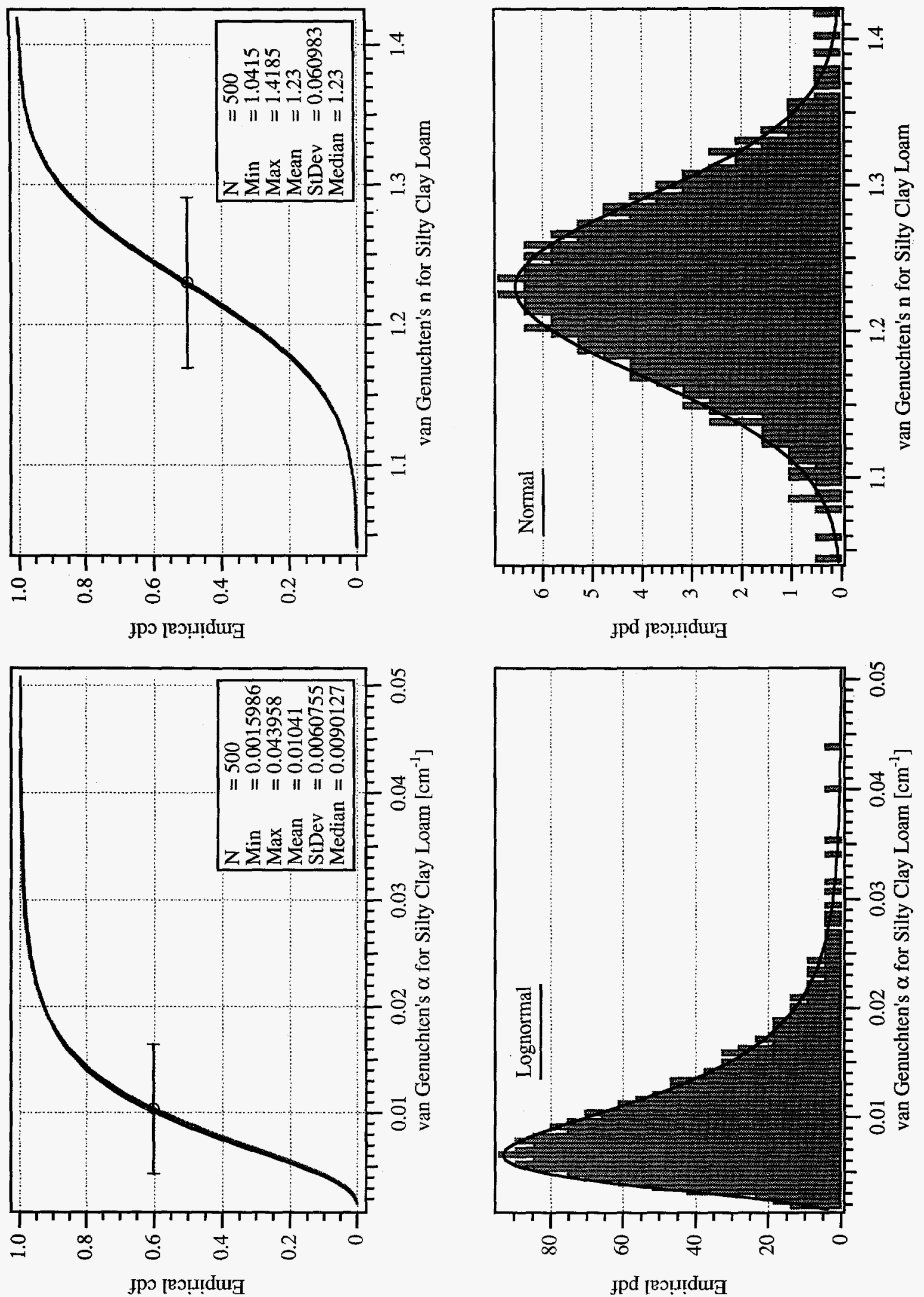

NUREG/CR-6565 

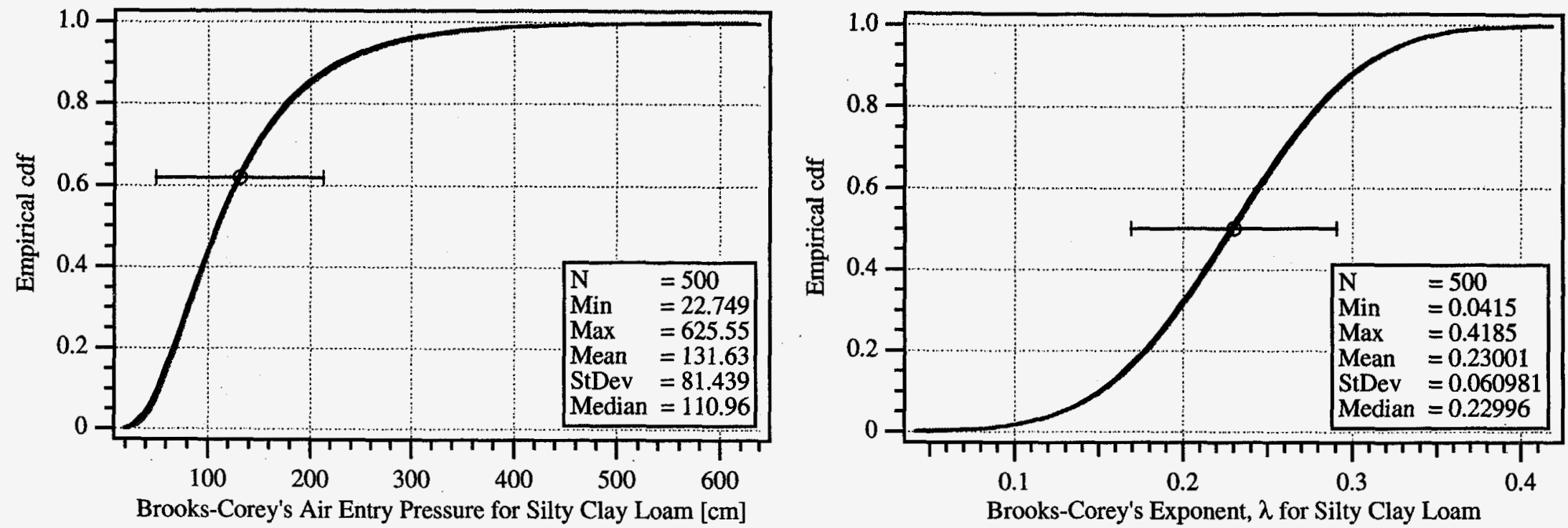

虽
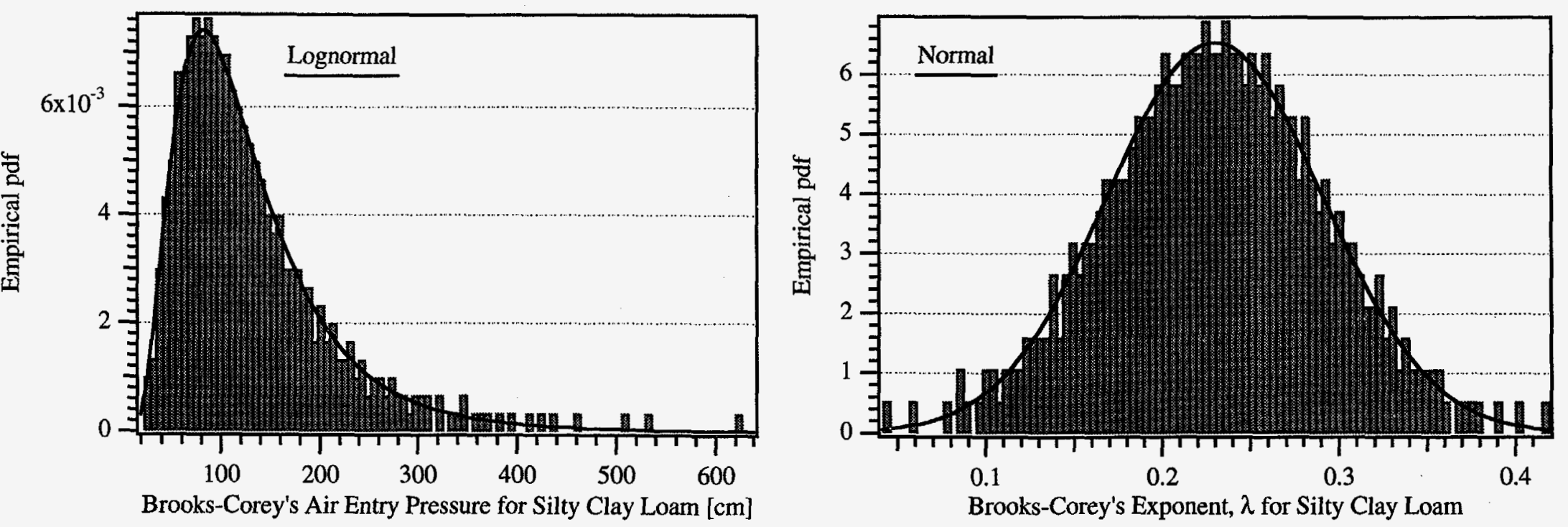

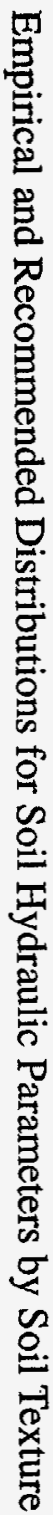



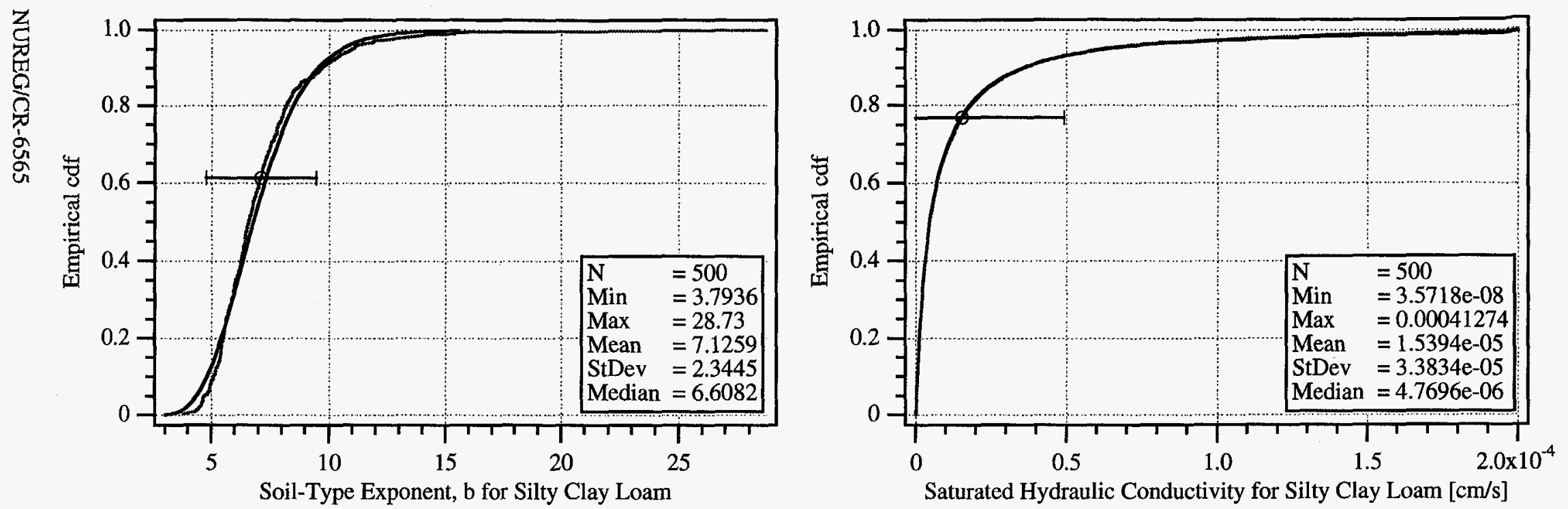

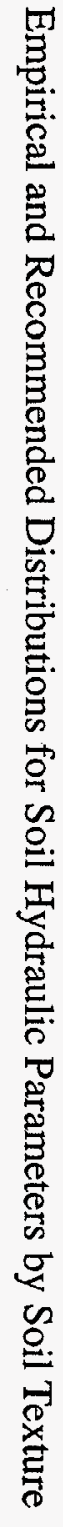
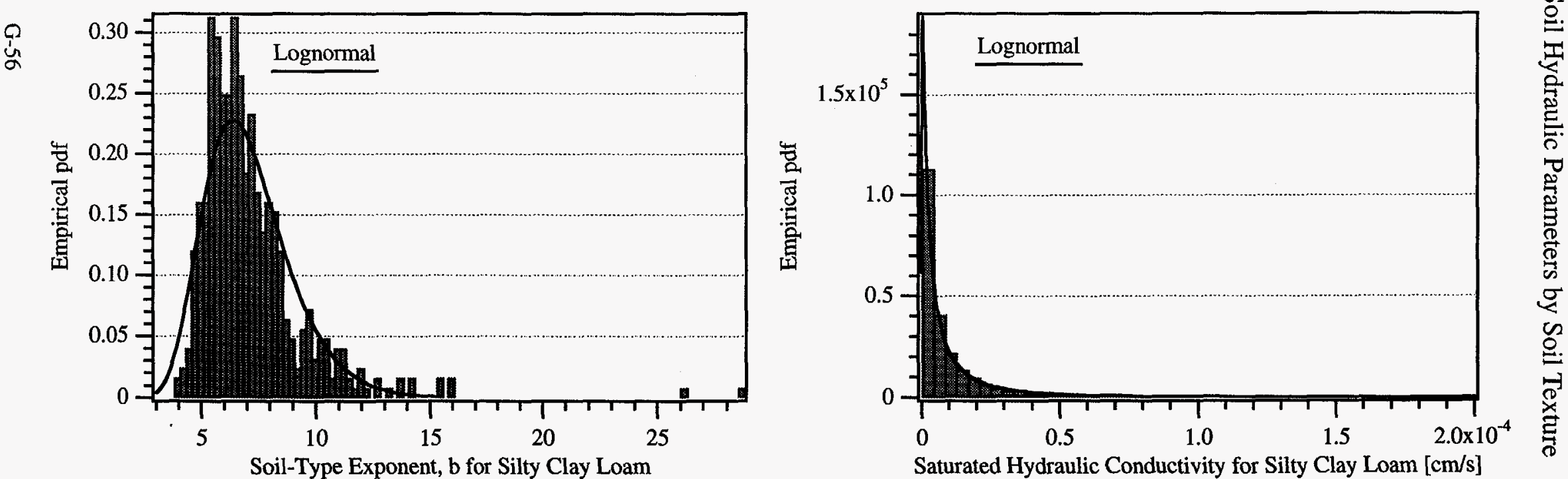

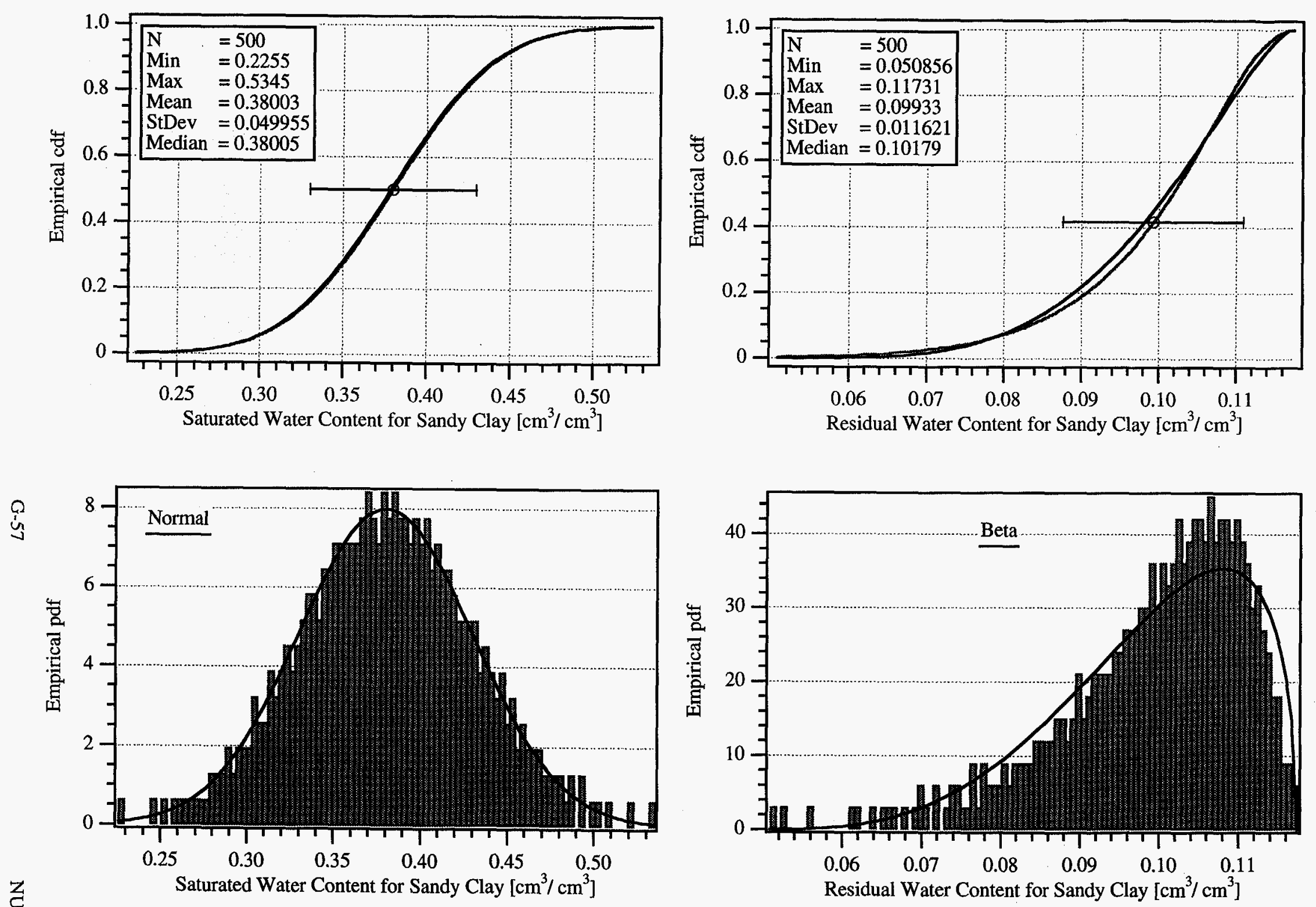

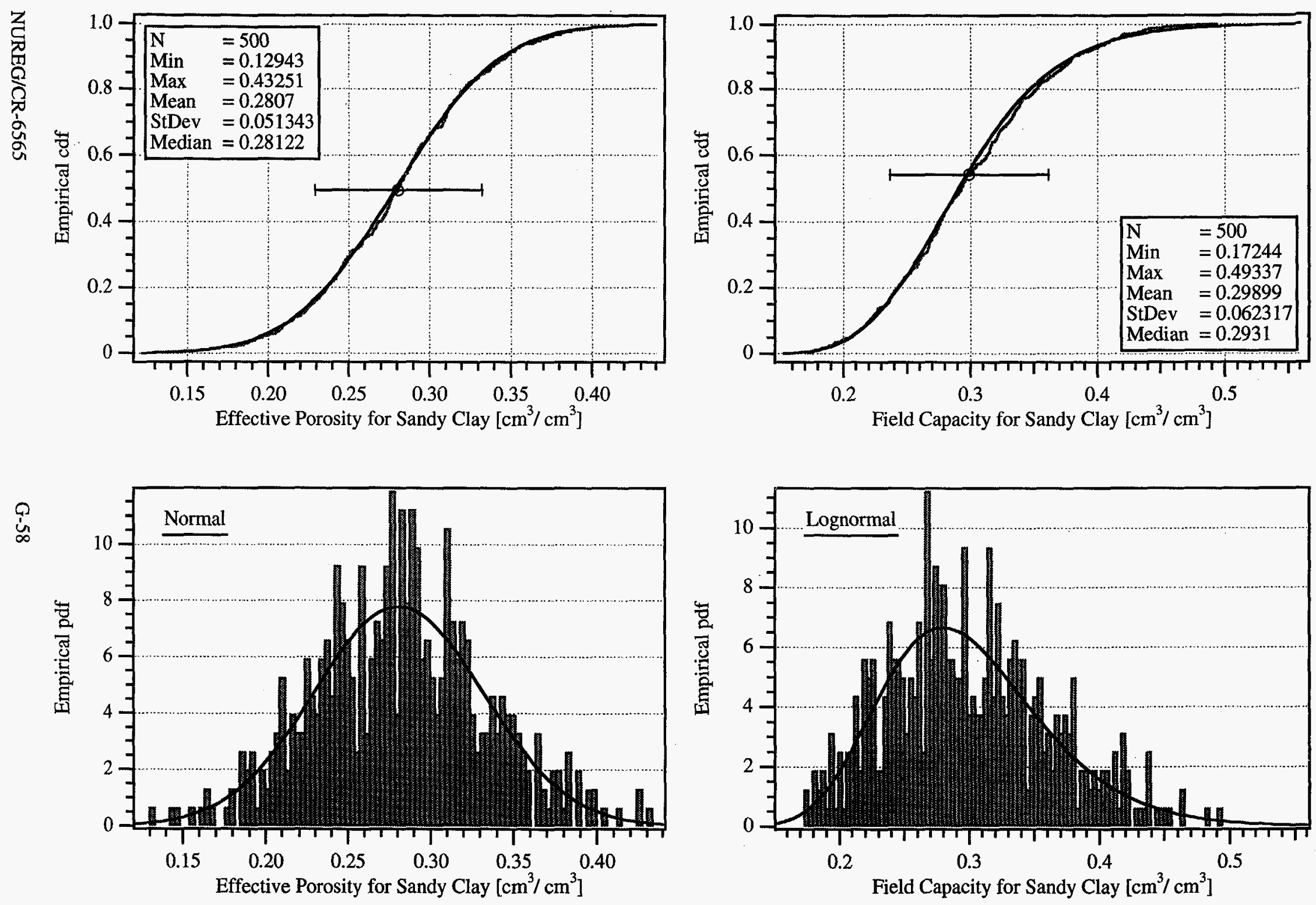

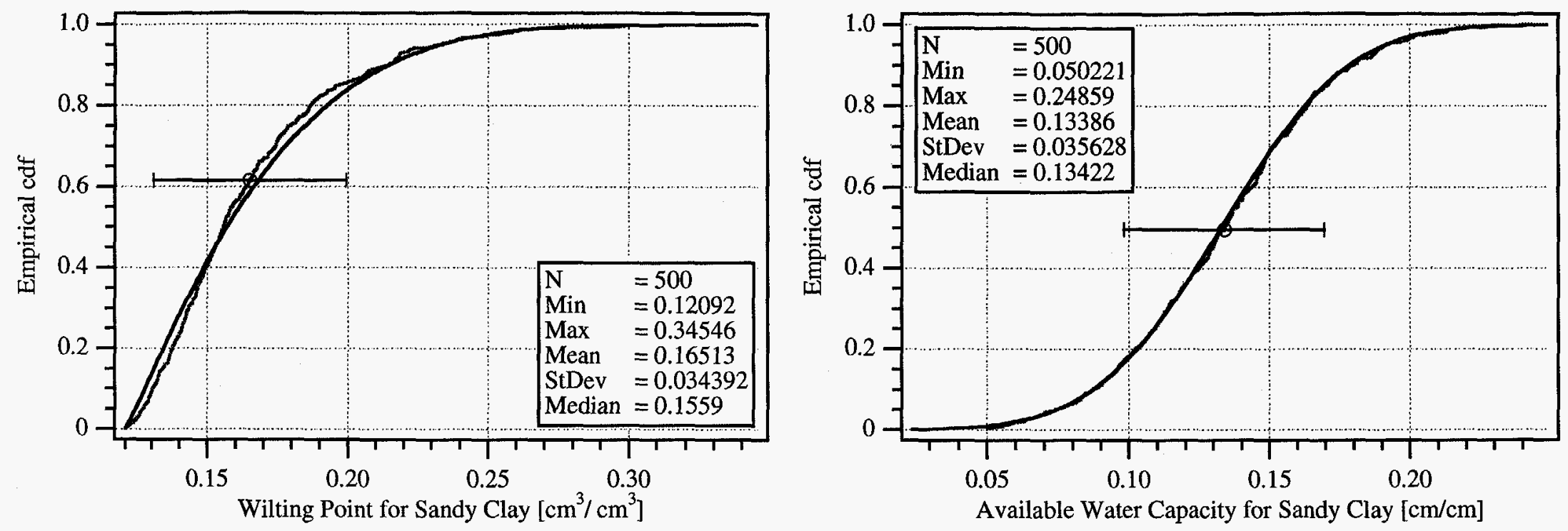

ù
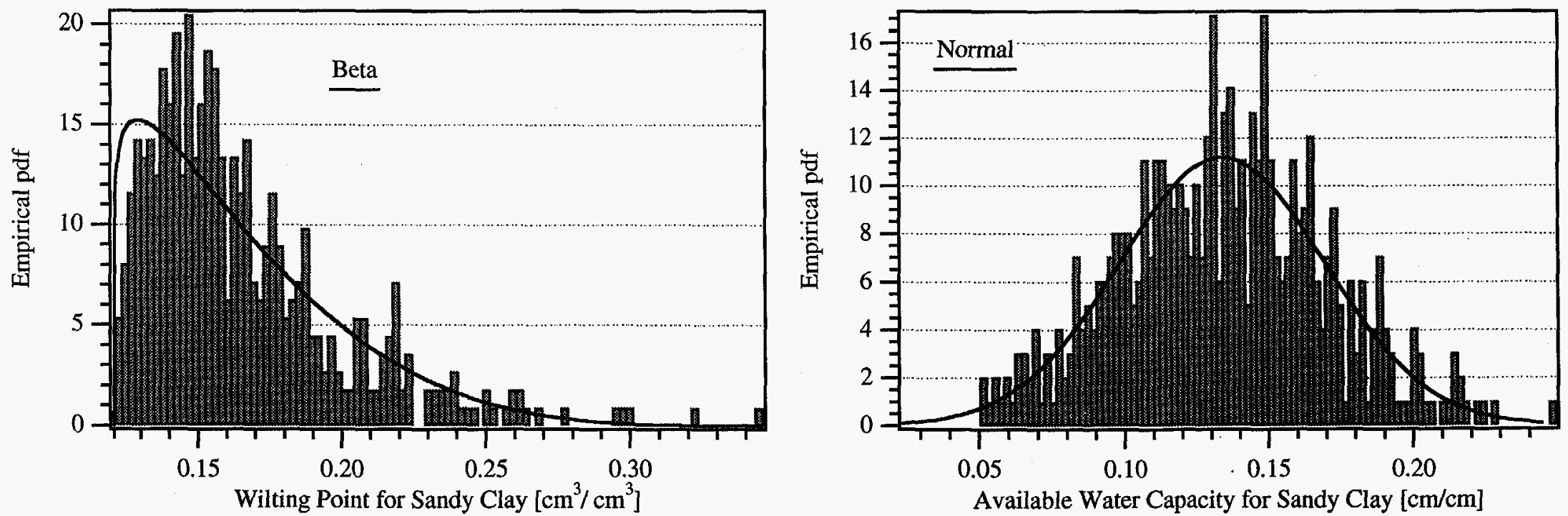
Empirical and Recommended Distributions for Soil Hydraulic Parameters by Soil Texture

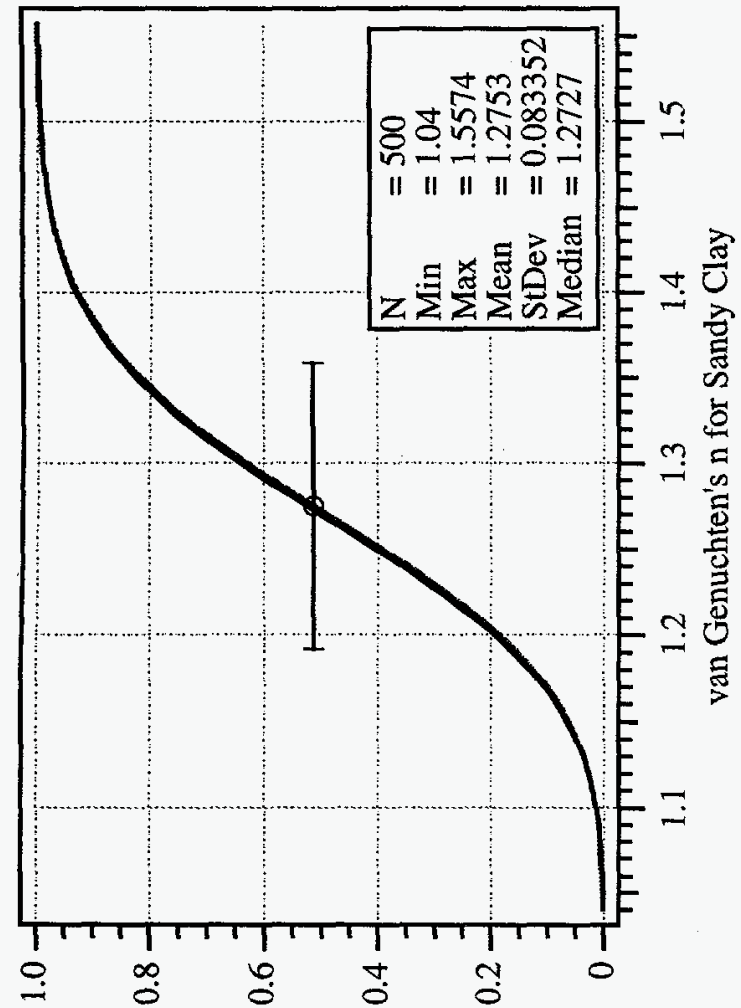

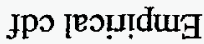

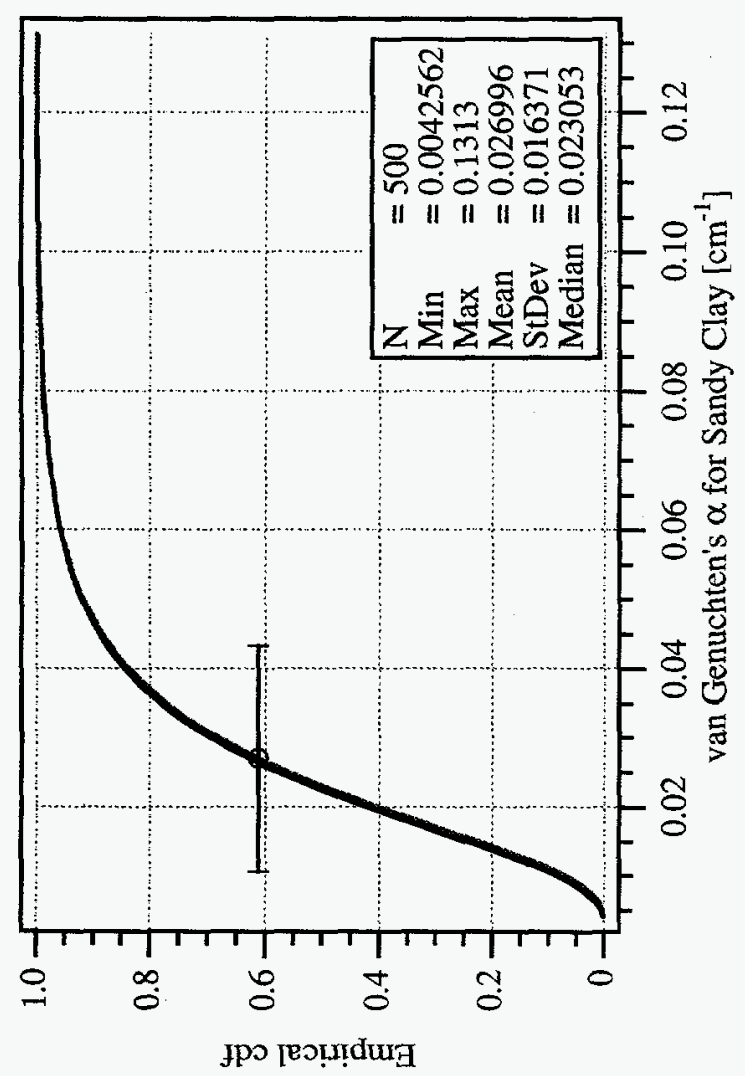

NUREG/CR-6565

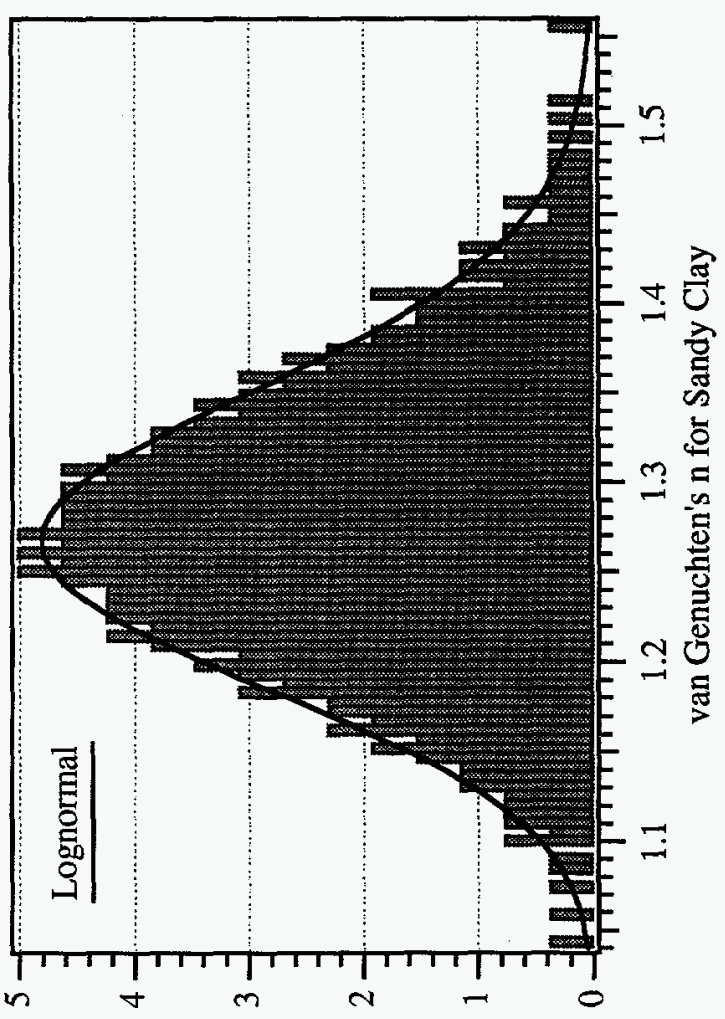

ıpd [eэ!ฺ!dü

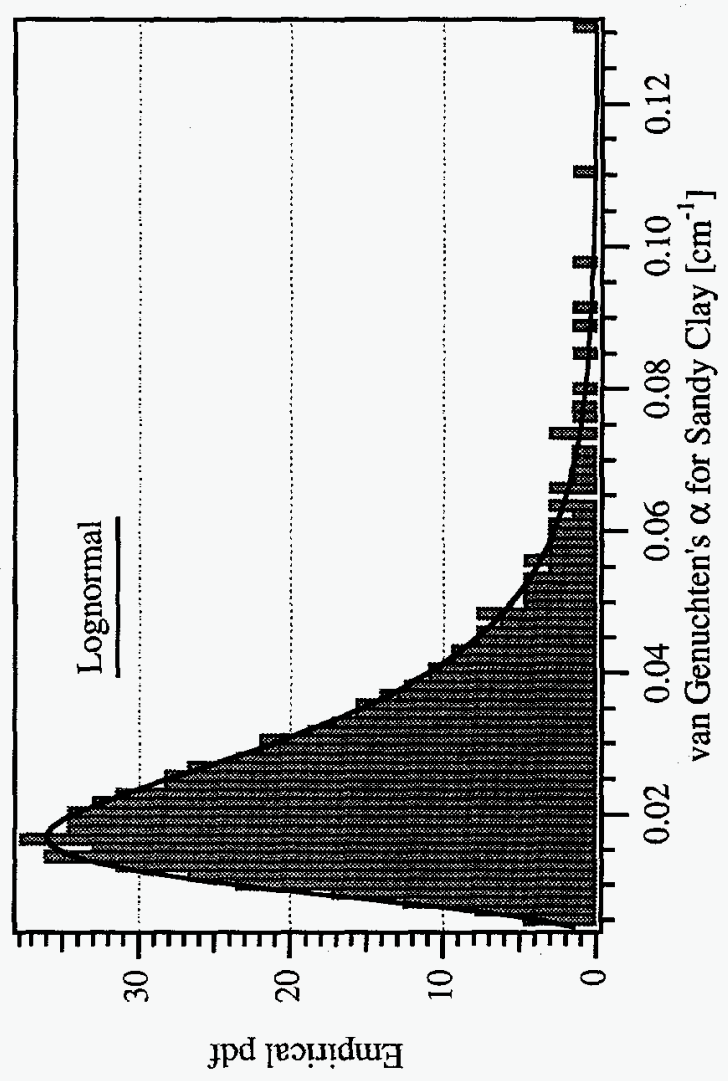

G-60 

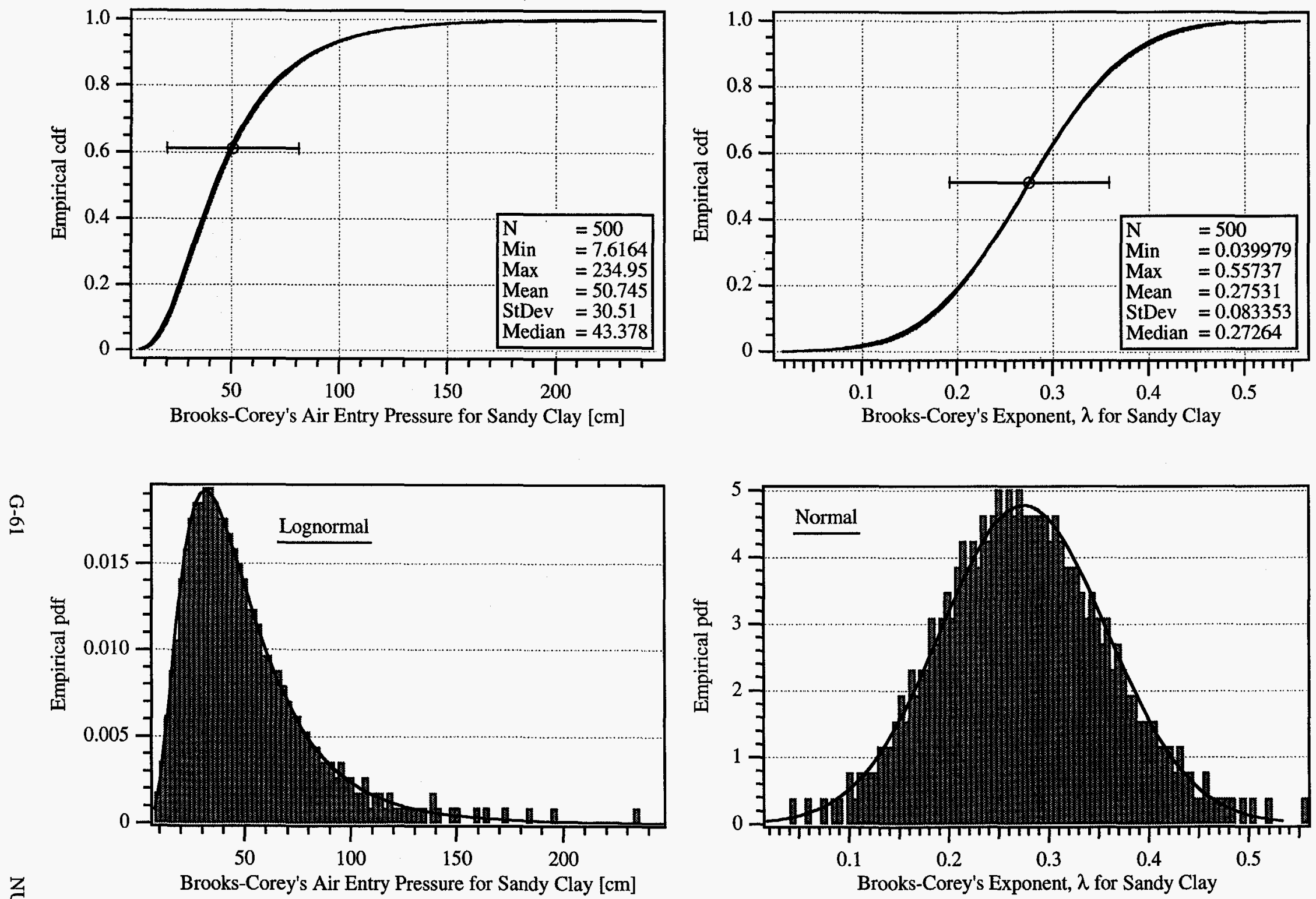

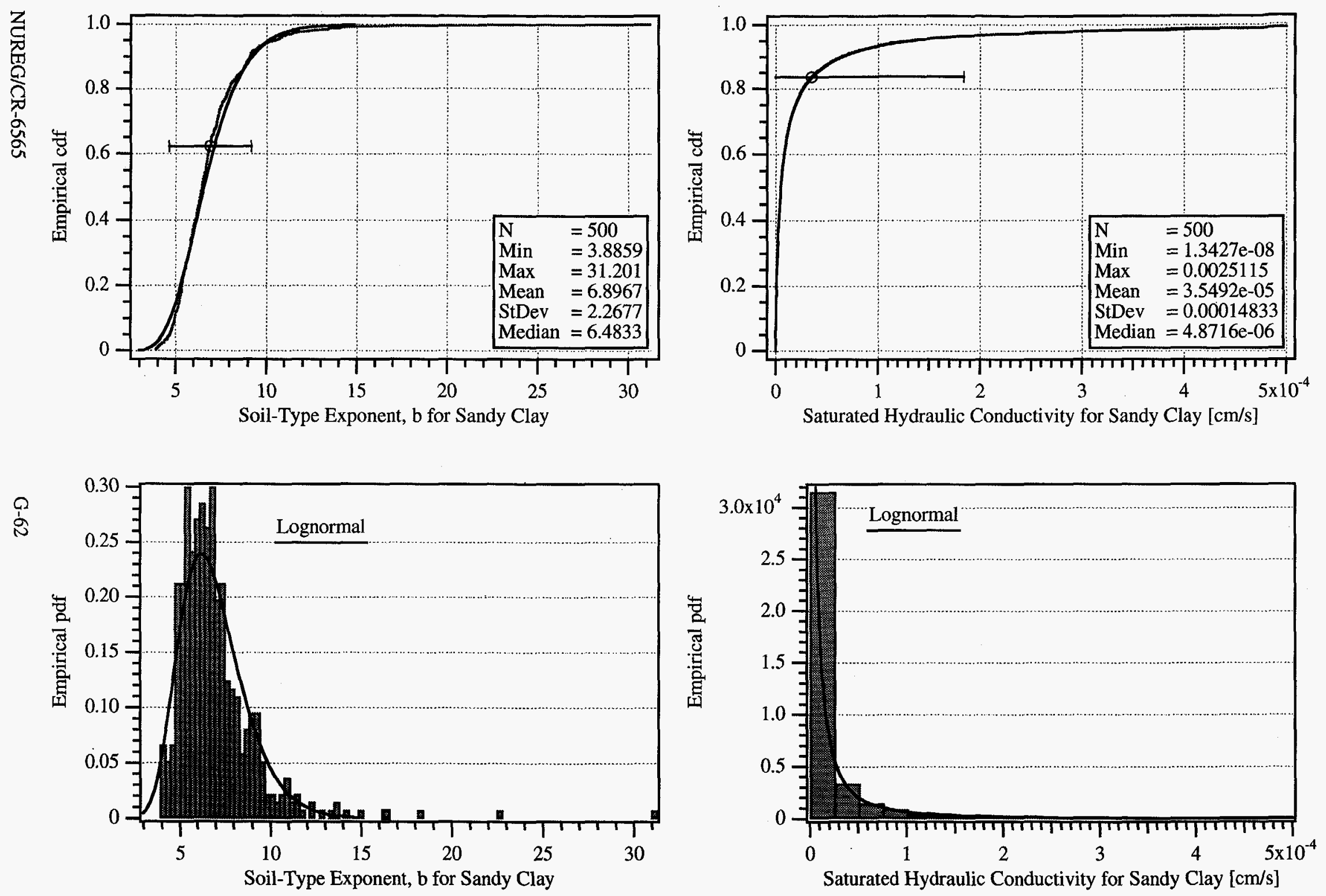
Empirical and Recommended Distributions for Soil Hydraulic Parameters by Soil Texture
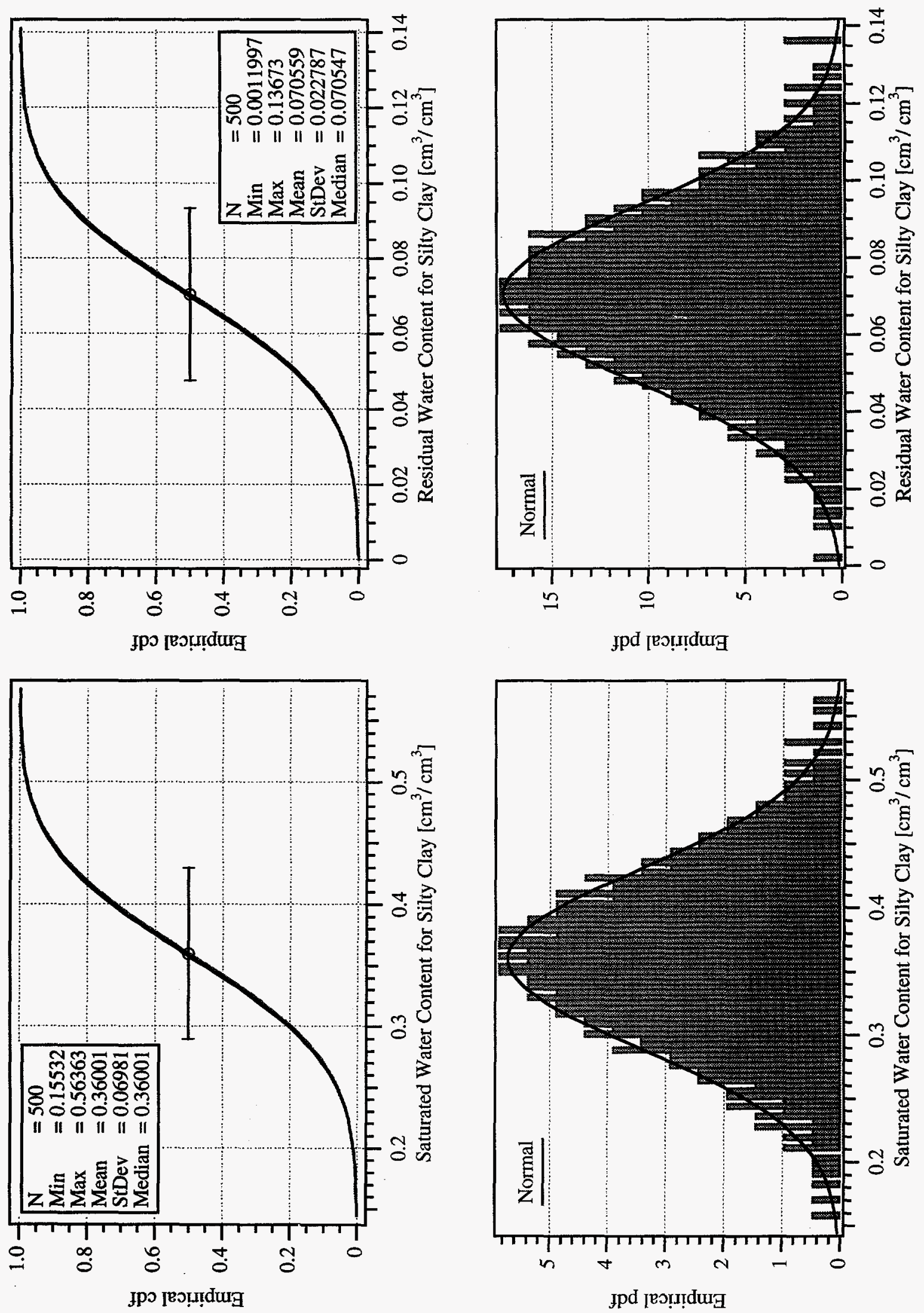

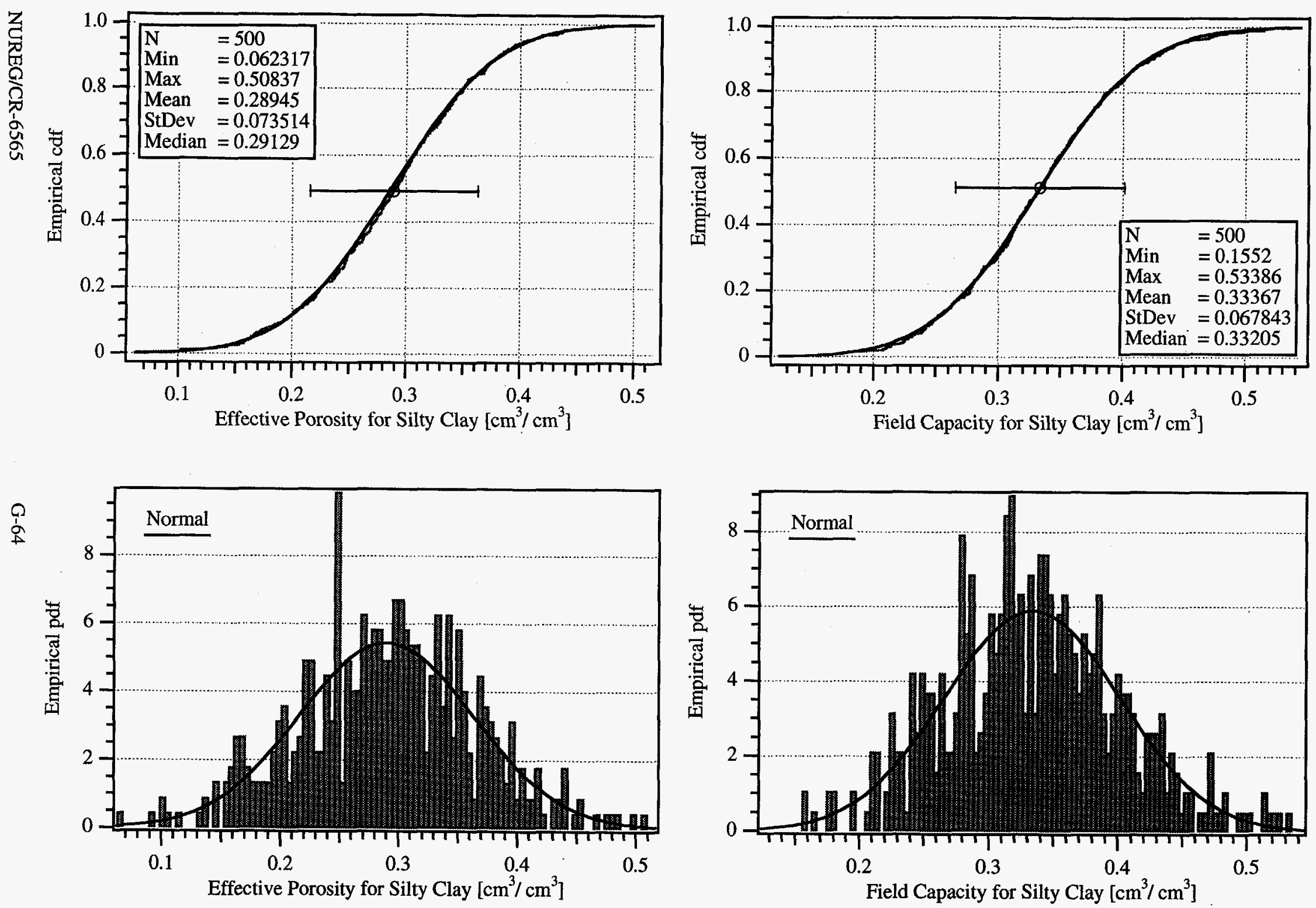

T. 

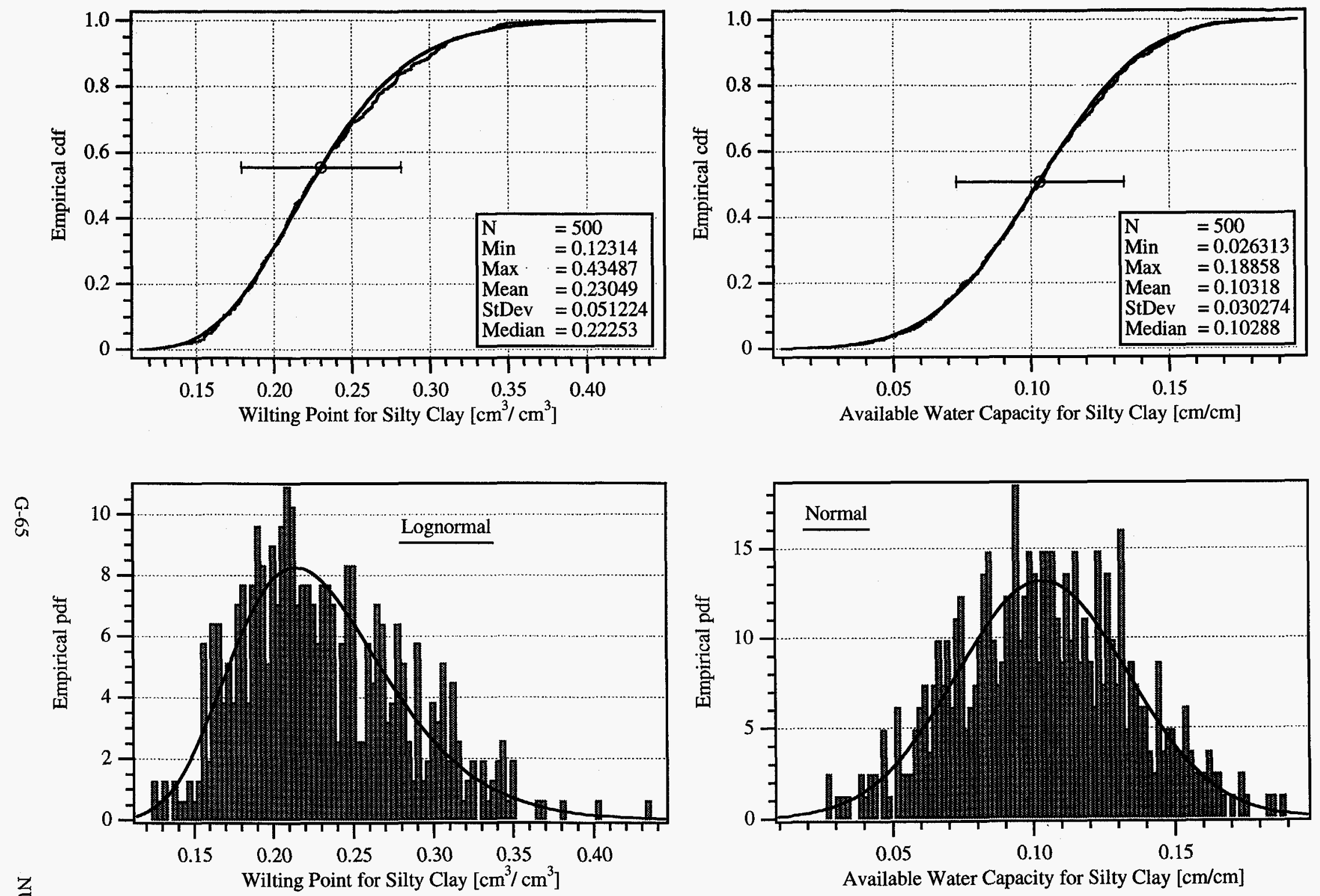
Empirical and Recommended Distributions for Soil Hydraulic Parameters by Soil Texture
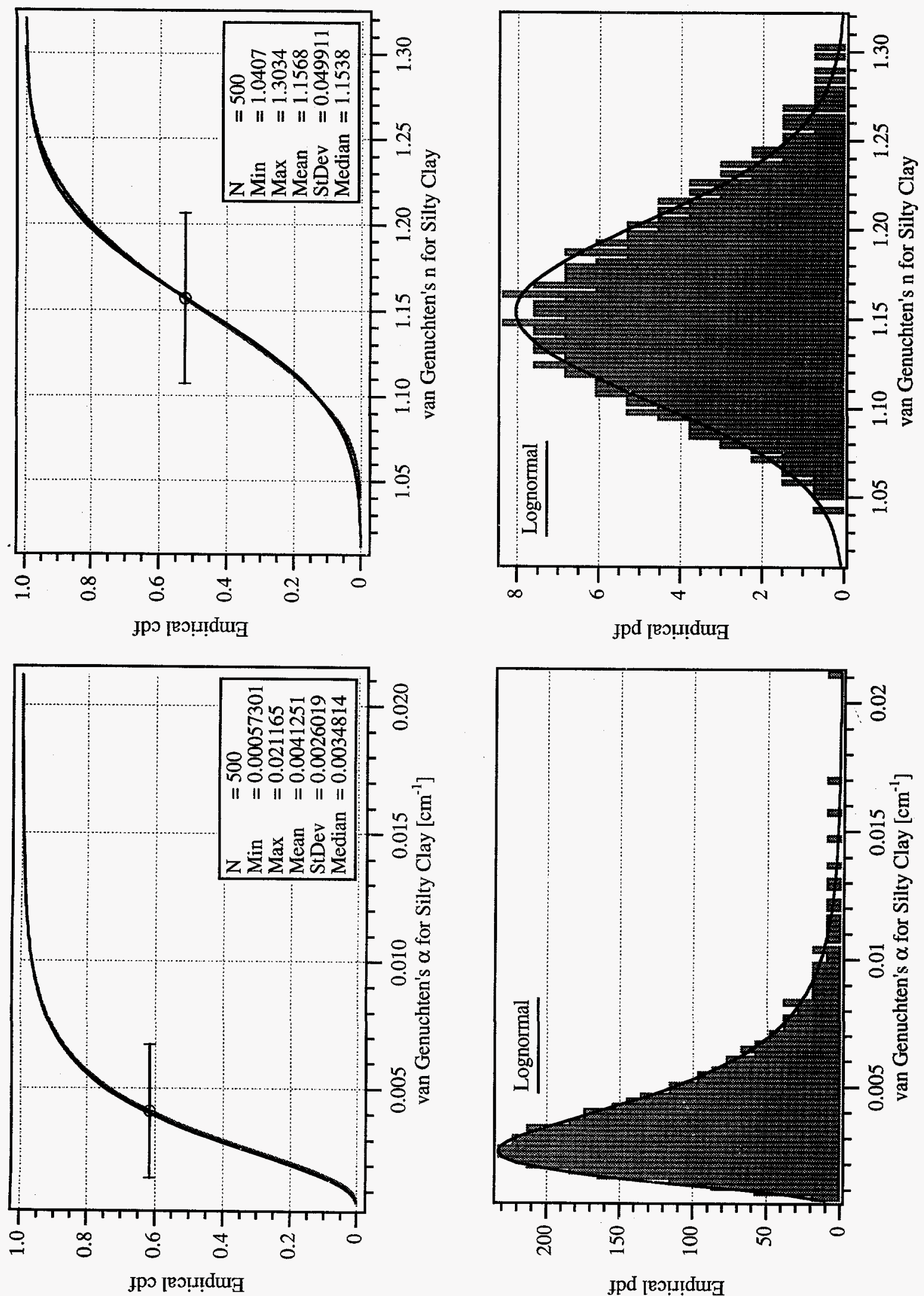

NUREG/CR-6565

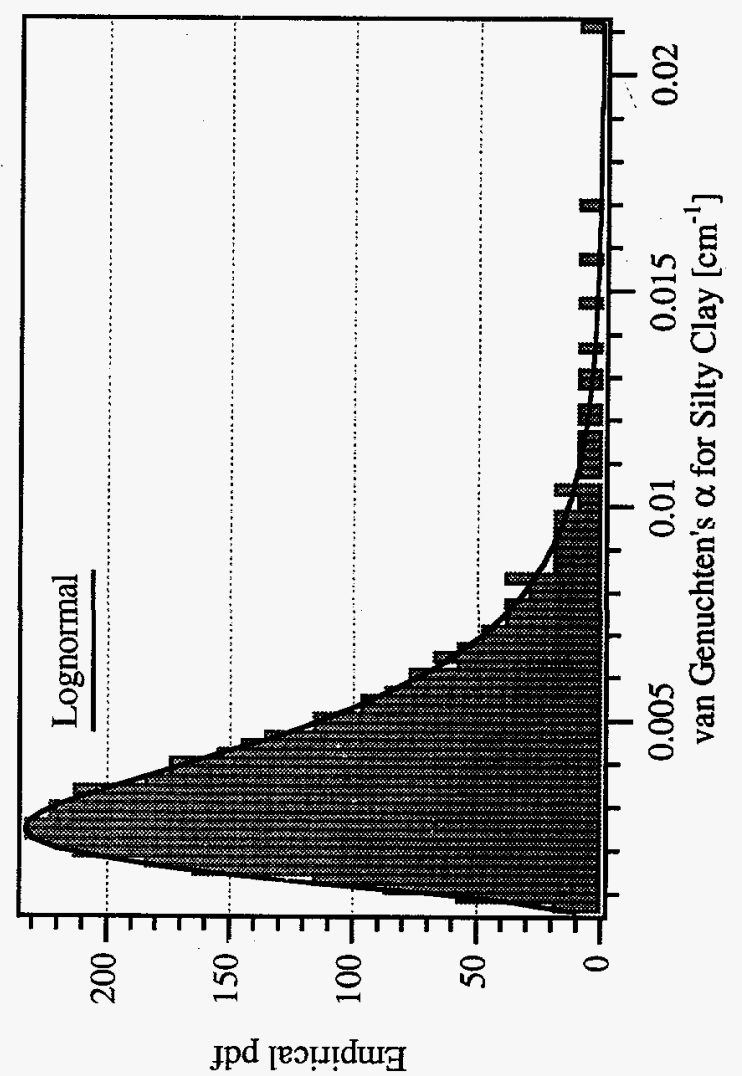

G-66 

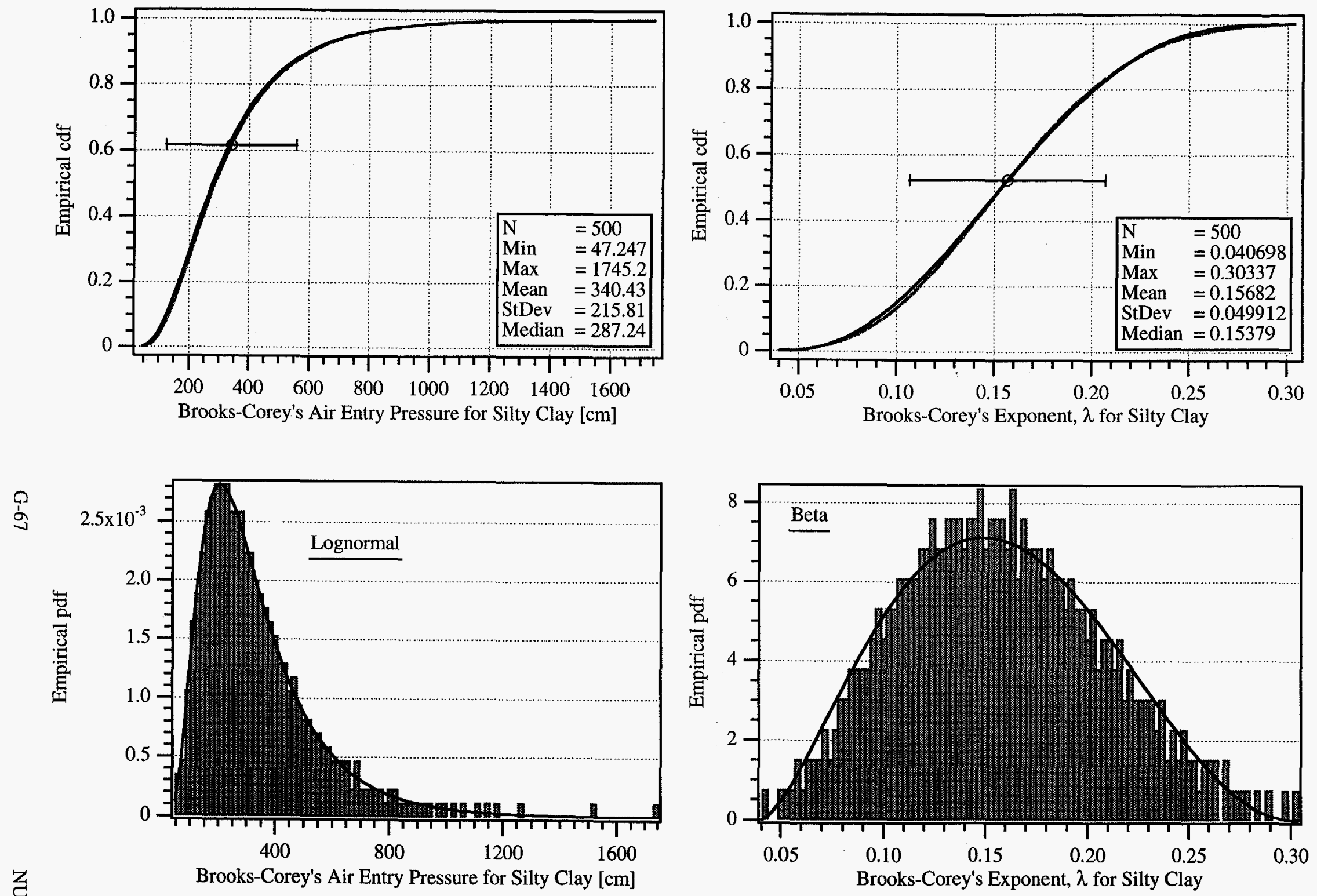

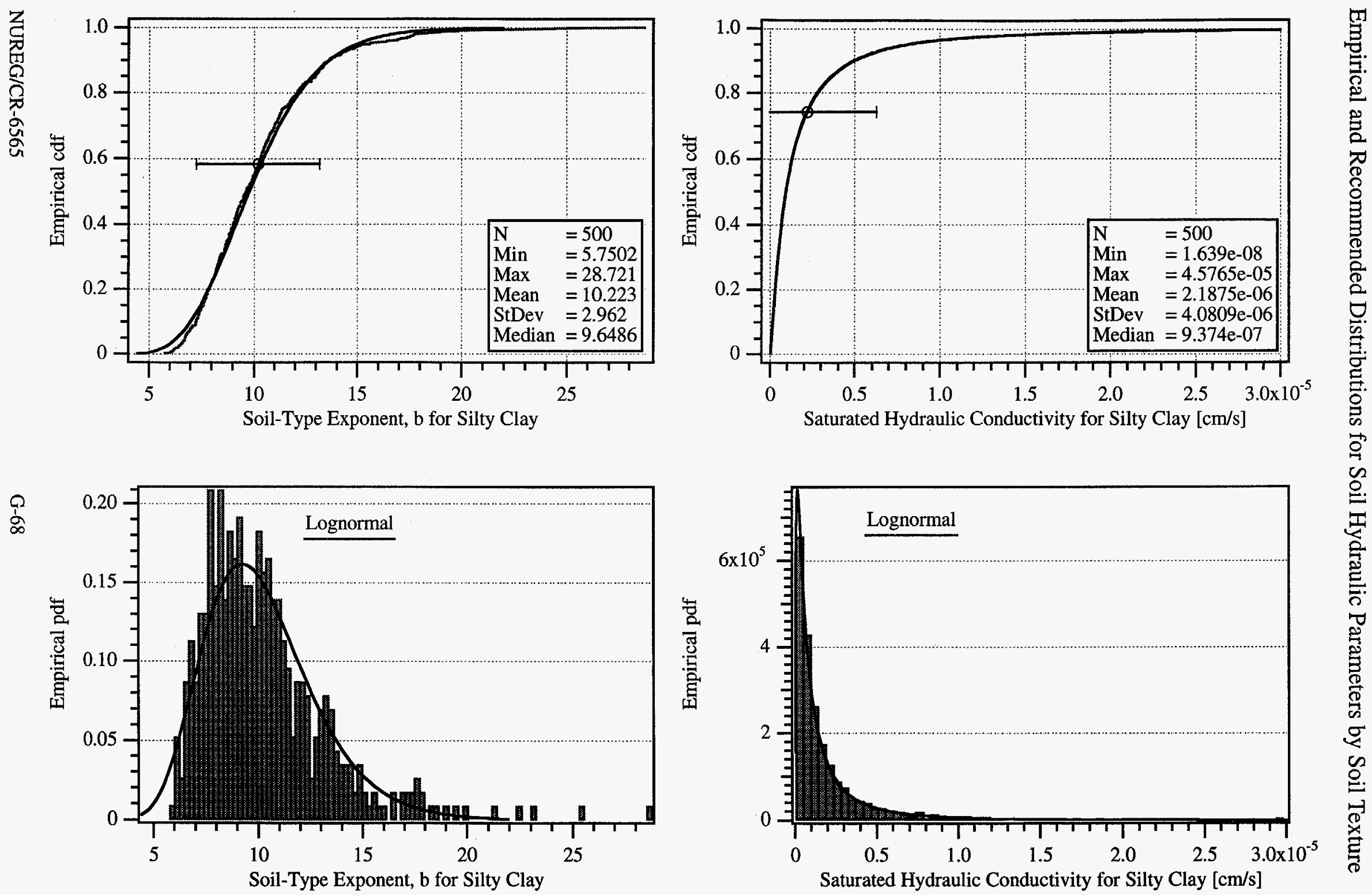
Empirical and Recommended Distributions for Soil Hydraulic Parameters by Soil Texture
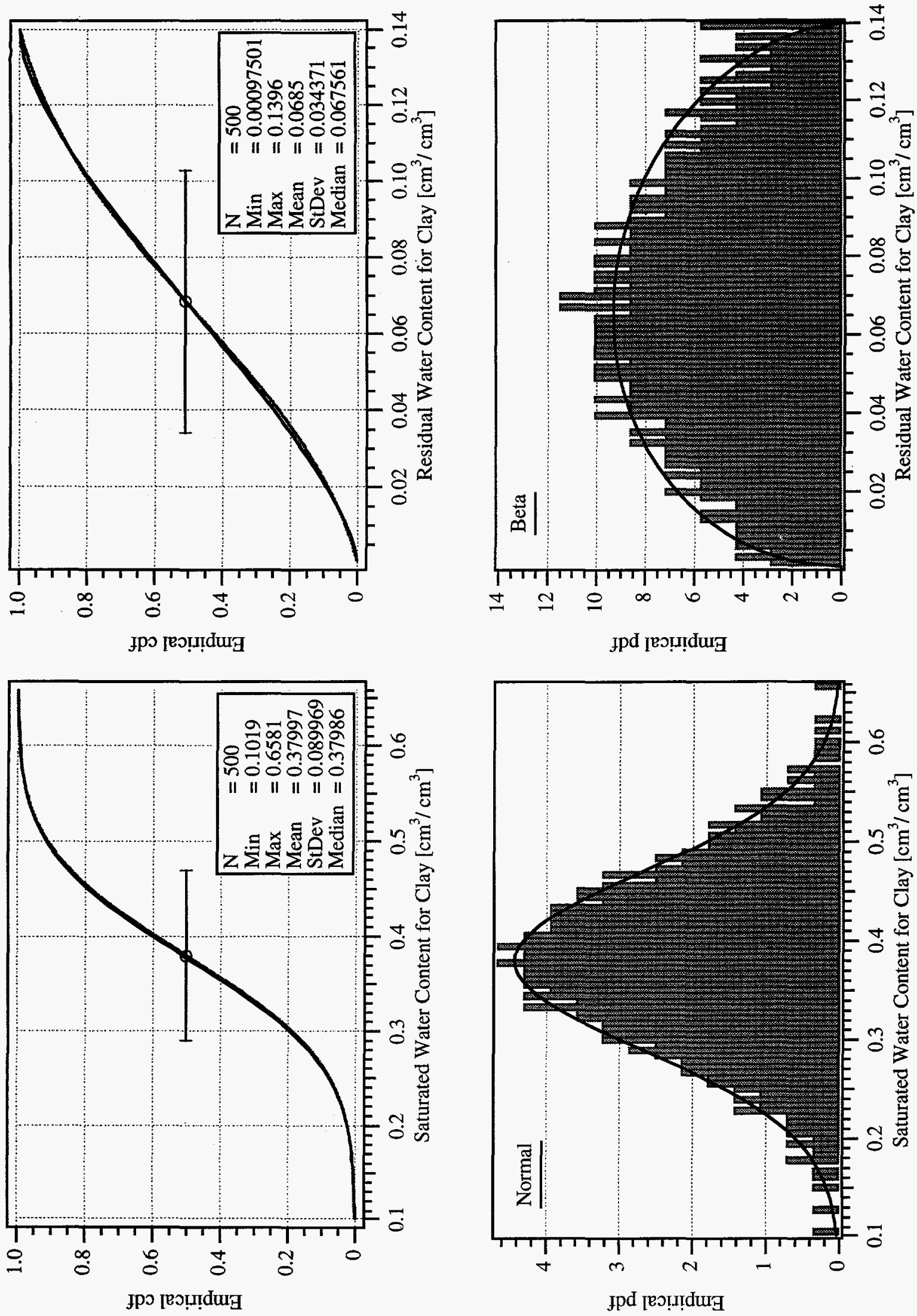
Empirical and Recommended Distributions for Soil Hydraulic Parameters by Soil Texture
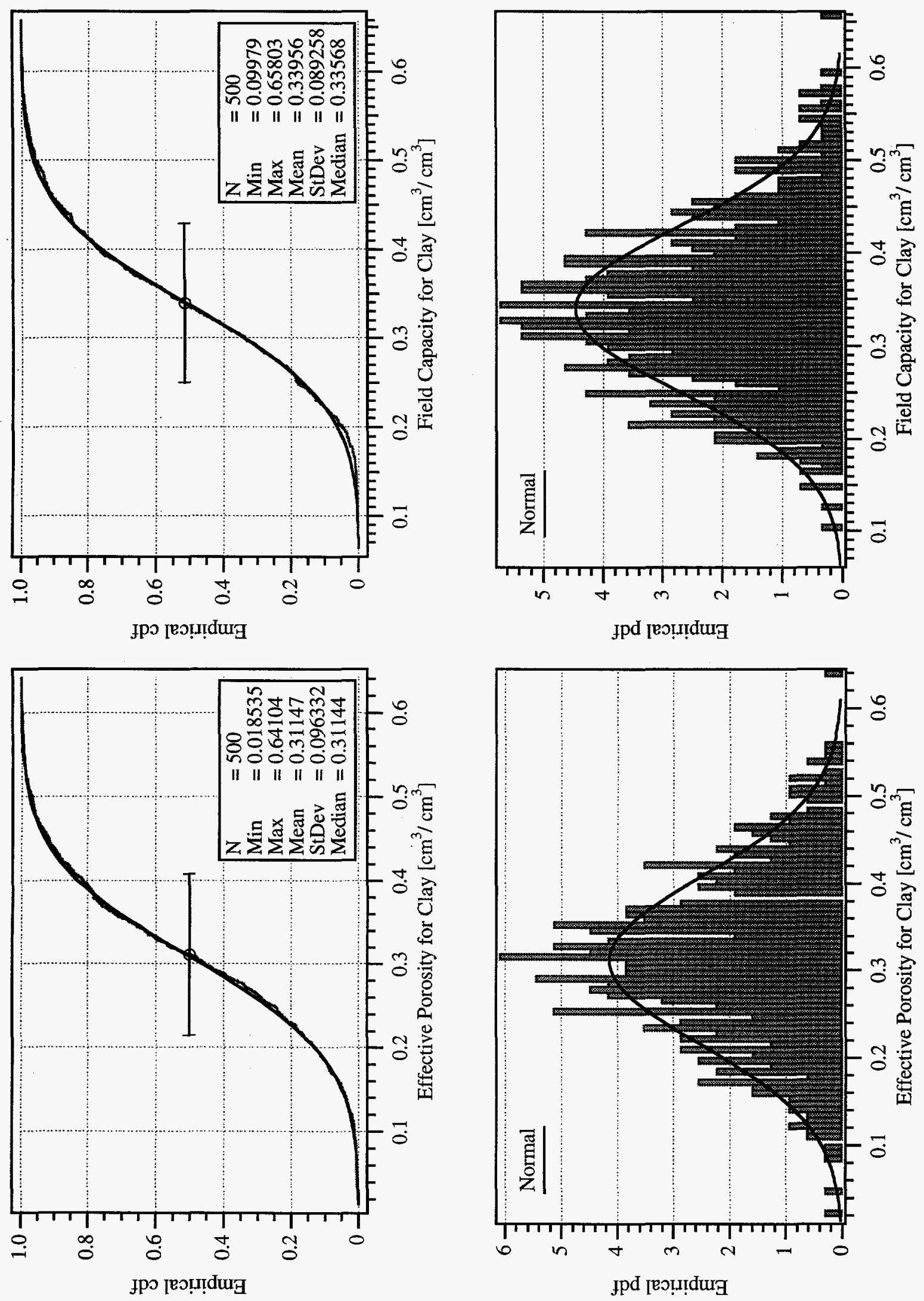

NUREG/CR-6565

G-70 

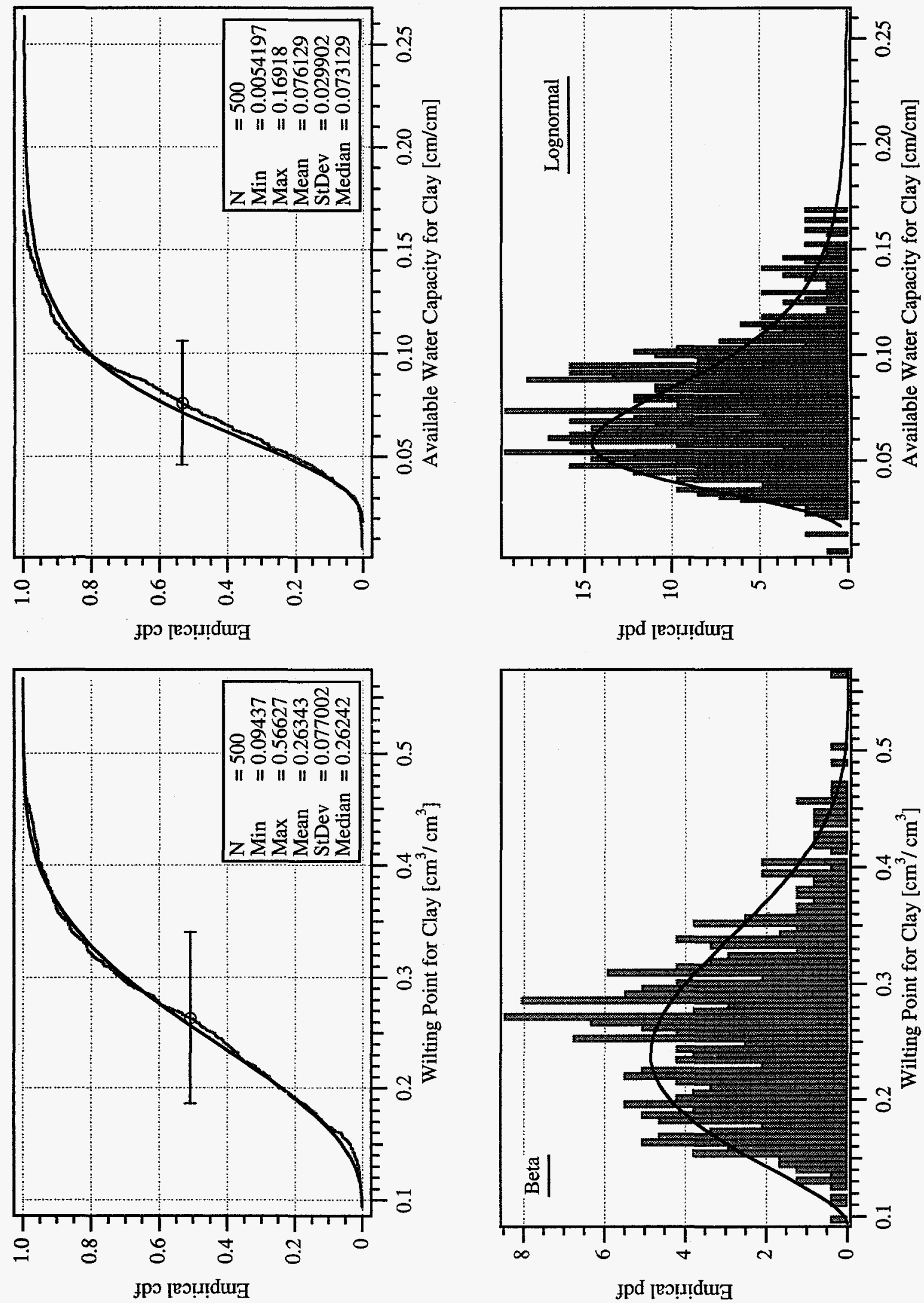

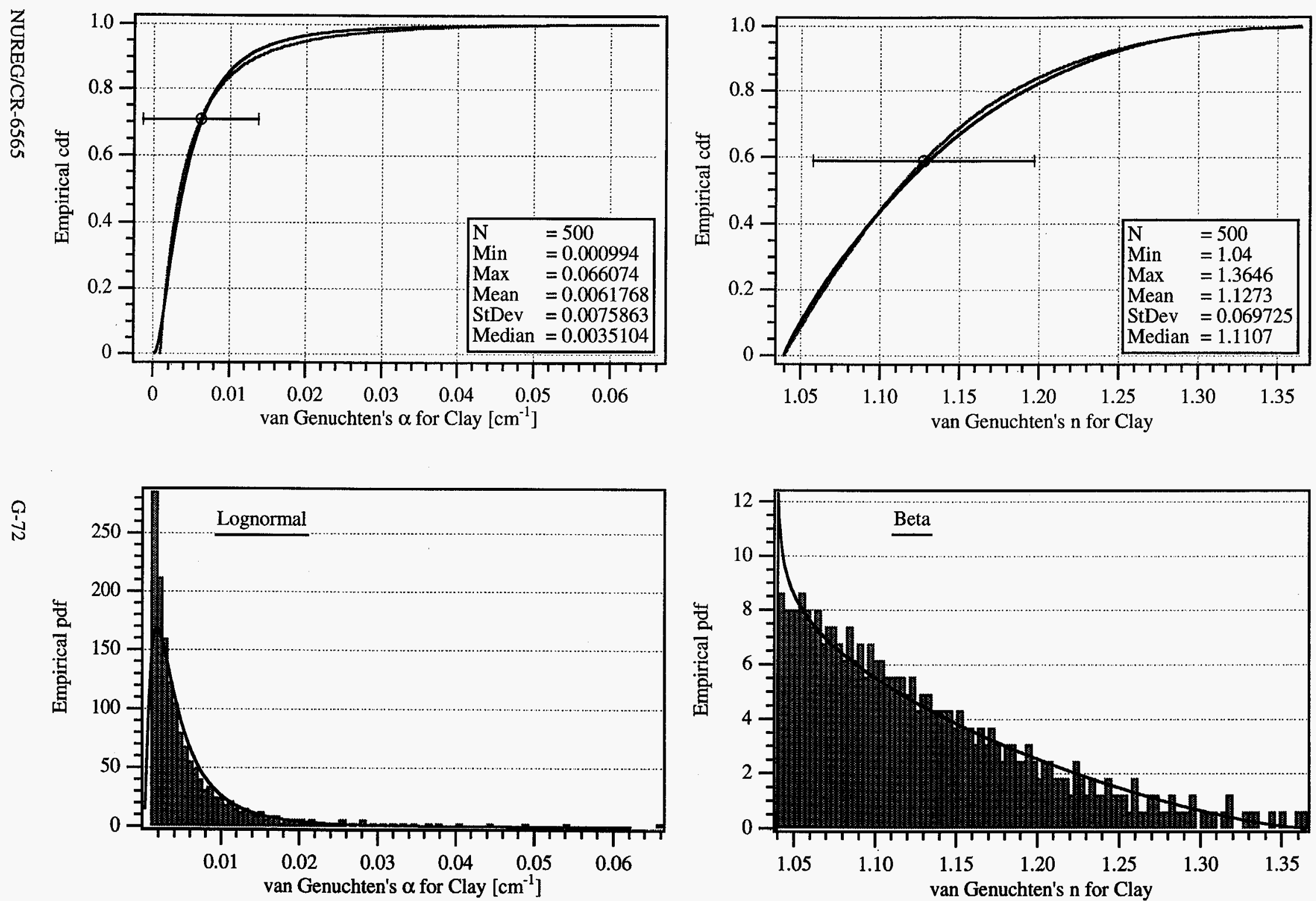

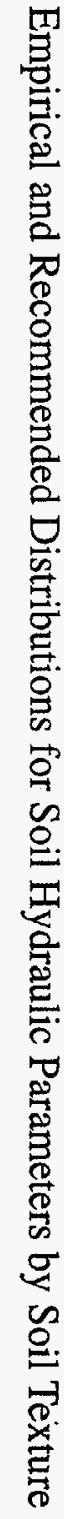


Empirical and Recommended Distributions for Soil Hydraulic Parameters by Soil Texture
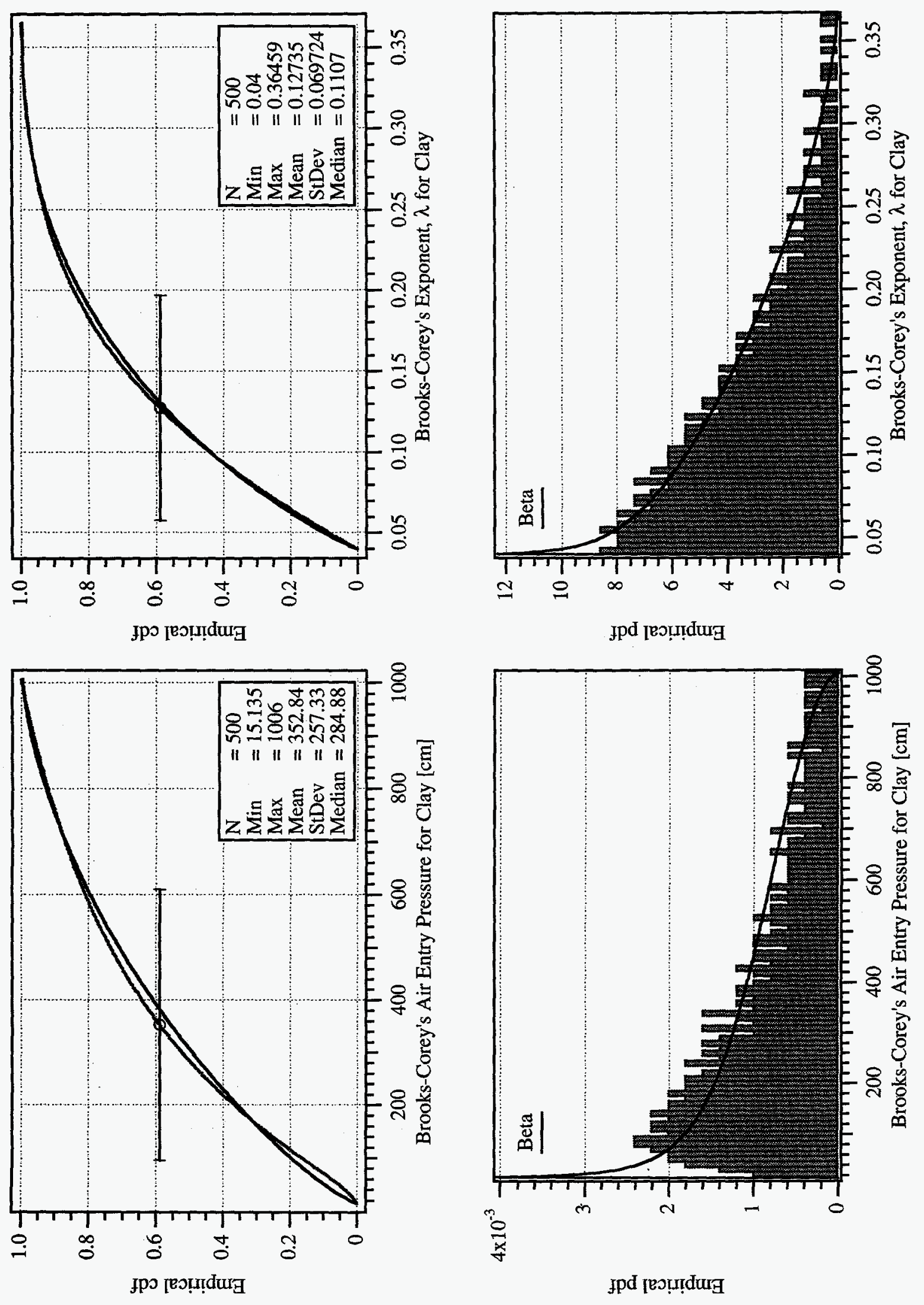

G-73

NUREG/CR-6565 

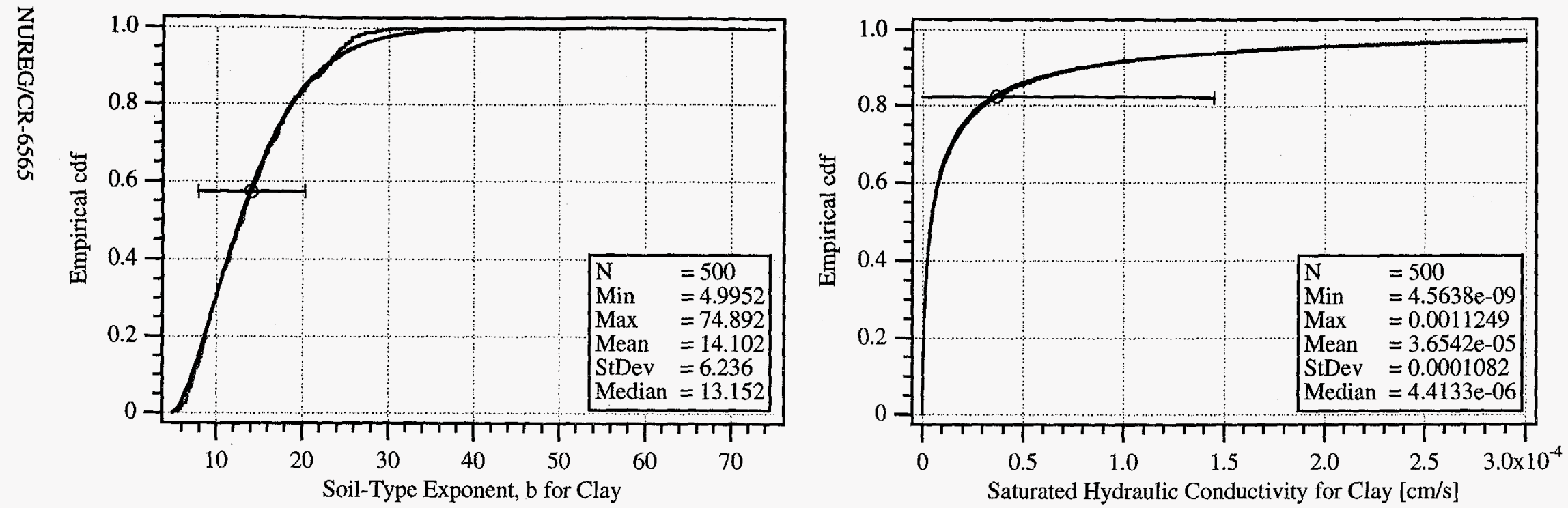

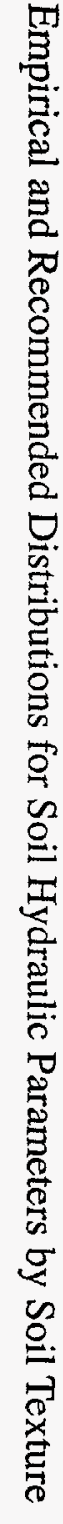
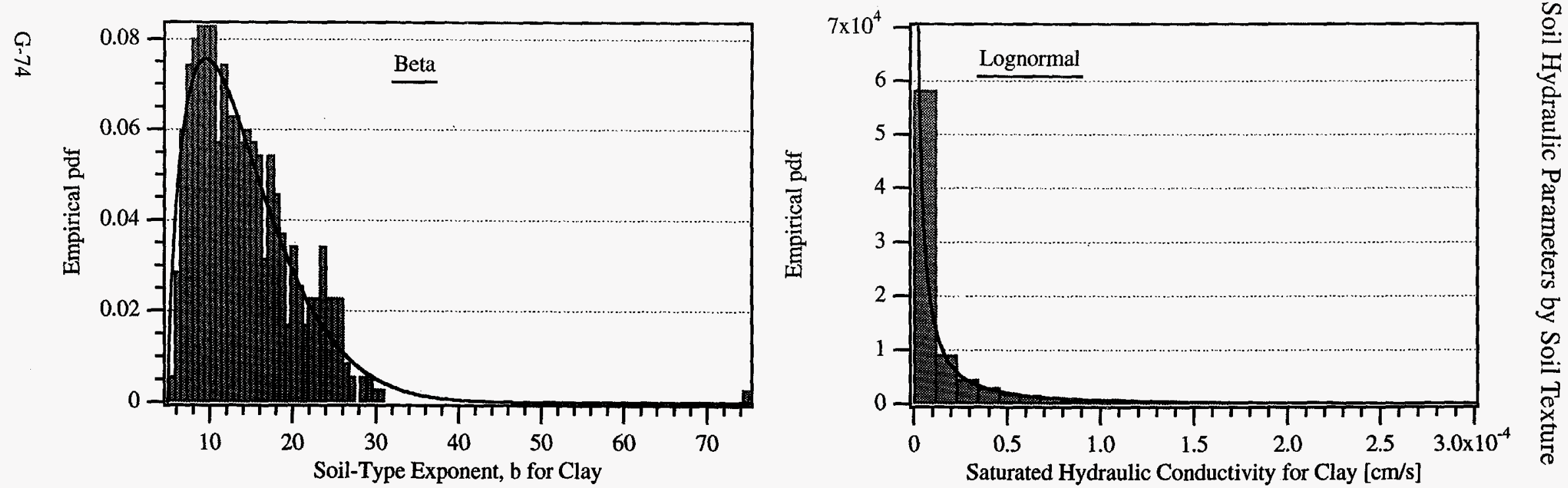


\section{TITLE AND SUBTITLE}

Uncertainty Analyses of Infiltration and Subsurface Flow and

Transport for SDMP Sites

(See instructions on the reverse)

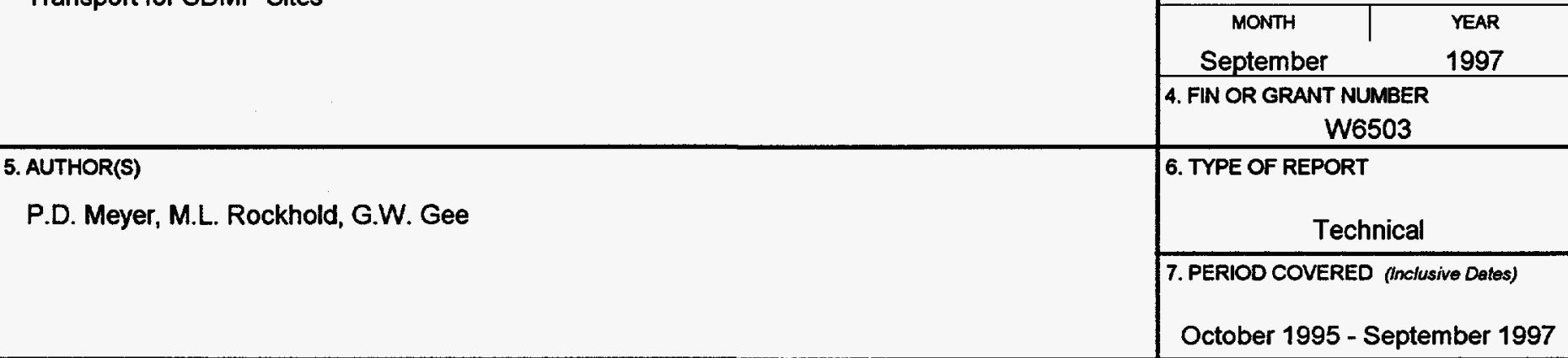

8. PERFORMING ORGANIZATION - NAME AND ADDRESS (If NRC, provide Division, Office or Region, U.S. Nuclear Regulatory Commission, and mailing address; if contractor, provide name and mailing address.)

Pacific Northwest National Laboratory

Richland, WA 99352

9. SPONSORING ORGANIZATION - NAME AND ADDRESS (If NRC, type "Same as above"; if contractor, provide NRC Division, Office or Region, U.S. Nucleer Regulatory Commission, and mailing address.)

Division of Regulatory Applications

Office of Nuclear Regulatory Research

U.S. Nuclear Regulatory Commisssion

Washington, DC 20555-0001

\section{SUPPLEMENTARY NOTES}

T. J. Nicholson, NRC Project Manager

11. ABSTRACT (200 words or less)

Traits common to many SDMP sites include limited data characterizing the subsurface, the presence of long-lived radionuclides necessitating a long-term analysis (1000 years or more), and potential exposure through multiple pathways. As a consequence of these traits, the uncertainty in predicted exposures can be significant. Several tools for improving uncertainty analyses of exposure estimates through the groundwater pathway are discussed in this report. Generic probability distributions for unsaturated and saturated zone soil hydraulic parameters are presented. These distributions can be used with available dose assessment codes to estimate exposure uncertainty in screening-level and preliminary analyses where site-specific data is limited. The use of the generic distributions is illustrated in a method for the estimation of net infiltration uncertainty. The method uses a relatively simple water budget calculation contained in an existing multiple pathway dose assessment code. A comparison between the distribution of predicted annual net infiltration and the observed lysimeter drainage (mean and standard error) showed an agreeable match. At many SDMP sites there may be some site-specific soil hydraulic property data available. A method is presented to combine the generic distributions with site-specific water retention data using a Bayesian analysis. The resulting updated soil hydraulic parameter distributions can be used to obtain an updated estimate of the probability distribution of dose. The method is illustrated using an hypothetical example decommissioning site.

12. KEY WORDS/DESCRIPTORS (List words or phrases that will assist researchers in loceting the report.)

Bayesian analysis decommissioning dose assessment ground-water analysis hydrology infiltration

SDMP

soil properties

subsurface flow uncertainty analysis

unsaturated zone water balance

\begin{tabular}{|}
$\begin{array}{c}\text { 13. AVALABILITY STATEMENT } \\
\text { Unlimited }\end{array}$ \\
\hline $\begin{array}{c}\text { 14. SECURTY CLASSIFICATION } \\
\text { (This Page) } \\
\text { unclassified }\end{array}$ \\
\hline $\begin{array}{c}\text { (This Report) } \\
\text { unclassified }\end{array}$ \\
\hline $\begin{array}{c}\text { 15. NUMBER OF PAGES } \\
\text { 16. PRICE }\end{array}$ \\
\hline
\end{tabular}

